\title{
Competitor recruitment : theory and practice-based explorations
}

Citation for published version (APA):

Horn, S. S. (2012). Competitor recruitment : theory and practice-based explorations. [Doctoral Thesis, Maastricht University]. Universiteit Maastricht. https://doi.org/10.26481/dis.20120209sh

Document status and date:

Published: 01/01/2012

DOI:

10.26481/dis.20120209sh

Document Version:

Publisher's PDF, also known as Version of record

\section{Please check the document version of this publication:}

- A submitted manuscript is the version of the article upon submission and before peer-review. There can be important differences between the submitted version and the official published version of record.

People interested in the research are advised to contact the author for the final version of the publication, or visit the DOI to the publisher's website.

- The final author version and the galley proof are versions of the publication after peer review.

- The final published version features the final layout of the paper including the volume, issue and page numbers.

Link to publication

\footnotetext{
General rights rights.

- You may freely distribute the URL identifying the publication in the public portal. please follow below link for the End User Agreement:

www.umlib.nl/taverne-license

Take down policy

If you believe that this document breaches copyright please contact us at:

repository@maastrichtuniversity.nl

providing details and we will investigate your claim.
}

Copyright and moral rights for the publications made accessible in the public portal are retained by the authors and/or other copyright owners and it is a condition of accessing publications that users recognise and abide by the legal requirements associated with these

- Users may download and print one copy of any publication from the public portal for the purpose of private study or research.

- You may not further distribute the material or use it for any profit-making activity or commercial gain

If the publication is distributed under the terms of Article $25 \mathrm{fa}$ of the Dutch Copyright Act, indicated by the "Taverne" license above, 




\section{COMPETITOR RECRUITMENT:}

Theory and Practice-Based Explorations

Sarah S. Horn 
ISBN: 978-90-9026529-2

(C) S.S. Horn, Maastricht 2011

All rights reserved. No part of this publication may be reproduced in any form or by any means without prior written consent by the author. Cover vector graphic from

VectorVaco.com who retain ownership and copyright.

Layout \& Cover Concept // S.S. Horn

Cover Design // Schwann Verlag KG - J. Seemann, 2011

Printed by: aprinta druck GmbH \& Co. KG 


\title{
COMPETITOR RECRUITMENT: Theory and Practice-Based Explorations
}

\author{
Dissertation | Proefschrift
}

to obtain the degree of Doctor at Maastricht University, on the authority of the Rector Magnificus, Prof. Mr. G.P.M.F. Mols, in accordance with the decision of the Board of Deans, to be defended in public on Thursday, February 9, 2012, at 12:00 hours

by

Sarah Susanne Horn 


\section{Promotor:}

Prof.dr. Mariëlle G. Heijltjes

\section{Co-Promotor:}

Dr. Woody van Olffen (Rotterdam School of Management, Erasmus University, Netherlands)

\section{Assessment Committee:}

Prof.dr. Martin A. Carree (chair)

Prof.dr. David G. Allen (University of Memphis, United States of America)

Prof.dr. Andries de Grip

Dr. Ad van Iterson 
Eigentlich wollte ich diese Arbeit Robo und all den Anderen widmen. Doch dann hat sich die Welt verändert.

Für Paddi. 



\section{Acknowledgements | Danksagung}

It is my pleasure to thank the many people who made this thesis possible. First, I would like to thank Prof.dr. Mariëlle Heijltjes and Dr. Woody van Olffen: Mariëlle for granting me to create this PhD trajectory according to my professional needs and desires, to take on additional responsibilities next to writing this dissertation that allowed me to gain practical insights, and for always helping me to structure my thoughts and writing, to be pragmatic and focused; Woody for all the personal talks we had often through Skype that helped me to assimilate to the research world, develop as a person and fight the Gremlin, and for all the feedback provided that was always tremendously helpful. You both made this journey enjoyable, insightful, an excellent preparation for my future career and a great learning experience - personally and professionally.

Special thanks also to Prof.dr. Wil Foppen, Maurice Olivers and Martin Lammers who tremendously contributed to my professional development. Due to Wil I received among others the opportunity to serve as a programme manager for an in-company executive programme, which was one of the most valuable experiences of the past years. Maurice impressed and inspired me by his always positive approach towards clients and his PGE team regardless of how busy he was, which created a highly enjoyable, motivating and supportive atmosphere to work in. Martin took every chance to challenge me along the way. Wil's, Maurice's and Martin's confidence in me really brought out the best in me.

I am also greatly thankful for Marion Hameleers and Désirée Schumacher having been part of my final PhD year, which was exciting but also one of the most difficult years in my life. They have always been there for me, and made me laugh and think positively. Marion, I will miss your enthusiasm and passion for your work, customers and family that you told me about during car rides, dinners and drinks; Désirée, I enjoyed sharing the office with you, the many talks we had and thoughts we shared as well as your cupcakes. Thank you both for your trust, openness and care.

Many thanks also to all members of my assessment committee who took the time, energy and interest to read my work and provide me with feedback: Prof.dr. Martin Carree, Prof.dr. David Allen, Prof.dr. Andries de Grip and Dr. Ad van Iterson. I have appreciated every single, highly thought-through comment received. Ad and David deserve special thanks at this stage. Ad already supervised my Bachelor thesis and also recommended to accept this PhD position. David has provided me with sharp and elaborate food for thought already at the SMA over a lovely lunch that has helped me to develop this work further.

Many other people contributed to this dissertation too along the way - by sharing valuable feedback and support, or by simply being great companions. Among those are Dr. Stuart Dixon, Dr. Boris Lokshin, Prof.dr. Gerard Pfann, Dr. Marc van Wegberg, Dr. Boris Blumberg, Dr. Hannes Günter, Bas van Diepen, Dr. Peter Bollen and Prof.dr. Hetty van Emmerik as well as Dr. Maarten Cuijpers and Dr. Sjir Uitdewilligen, Dr. Anneloes Raes, Dr. Omar Solinger and Dr. Li Jia, Kristin Kronenberg, Anant Joshi, Antonio Della Malva, Irem Bozbay and Denes Palvöglyi, Bart Dormans and Nico Classen, Tom Kuypers, Ingrid van Wesselingh and Ingrid Voncken, and Bas Giesbers (in chronological order). All other members especially of the Department of Organization and Strategy and of Postgraduate Education I thank too for an enjoyable and supportive work environment!

I am also indebted to some externals that I have spent exciting conferences or PhD courses with, or who have otherwise contributed to my research project. Among those are Markus Burger, Jörg Musiolik, Hanko Zeitzmann and Dr. Marko Horn (my conference spouse); Christine Nickels, Jennifer Czaplik, Georg Zysk and Katharina Daube; participants and lecturers of the Vodafone Business Strategy Course; executive search consultants, 
students of the many courses I have taught, as well as friends and acquaintances who filled in my survey.

I am not less thankful for the organizational support received and the many efforts made to accommodate my personal needs during the past three years, thereby allowing me to combine work and private obligations. Thanks in this regard to Prof.dr. Martin Carree, Mieke van Zutphen, Adela Buttolo, Dr. Wilko Letterie and Anita Weijzen-Spek.

A big thank you also to Magdalena Schlömer and Jürgen Seemann. Ein besonderes Dankeschön geht an Sie für zuvorkommende, geduldige und inspirierende Stunden im Schwann Verlag und Ihre wertvolle Unterstützung hinsichtlich der professionellen Gestaltung und Umsetzung meiner Layout-Ideen. Der Kaffeeklatsch mit Ihnen, Herr Seemann, hat mir immer sehr viel Freude bereitet.

I would also like to thank the people who have indirectly been involved in this dissertation and without whose understanding, support and friendship I would have never been able to complete this dissertation. Besonderer Dank gilt hierbei meinen jahrelangen, warmherzigen und treuen Freunden Denise Beek, Philippe Frey, Markus Adler, Bethany Lewis sowie Gisela, Günter und Jonas Berndt. Ohne euer Verständnis, eure Toleranz und eure positiven Worte hätte ich dieses Projekt nicht so zielstrebig und fokussiert abschließen können. Noch mehr danke ich Sandra Horn und Johanna und Christian Raser. Danke für eure Aufopferung, euer stetiges Lachen und eure so wertvolle familiäre Unterstützung. Ihr habt mir gezeigt, was es heißt, für Andere uneingeschränkt und aufrichtig, ohne jede Erwartung von Gegenleistung, da zu sein. Und dass Karriere nicht alles ist. Ich wünsche euch und uns ganz viel Kraft und Zukunft.

Vor allem aber meiner Familie habe ich zu danken. Liebe Eltern, danke für eure Unterstützung, die ihr mir trotz des schwierigen Weges, den ihr währenddessen gehen musstet, habt zukommen lassen; für die Sicherheit, Ruhe und Zuversicht, die von euch ausging; für euren festen Glauben an mich. Ich bin froh und dankbar, dass wir diesen Weg gemeinsam gegangen sind. Brüderchen, ohne dich wäre ich jetzt nicht die, die ich heute bin. Danke für die vielen schönen und unbezahlbaren Stunden mit Pünktchen, Milky, Agami und Lia; in Mettmann, Mesenich und Kalenborn; auf Mauritius, den Malediven, in Flachau, auf Røm $\varnothing$ oder in Otterndorfs Neuseeland; beim Schwimmen, Tennis, Badminton oder Joggen; zu Hause mit Matchbox Autos, Power Rangers, den Schlümpfen oder DSDS; beim Lachen, Weinen oder Streiten. Ich bin dankbar für jeden einzelnen Tag mit dir: von dir habe ich gelernt, das Leben so zu nehmen wie es kommt, mit all seinen brutalen und unvorhersehbaren Hürden; im Hier und Jetzt zu leben, Prioritäten zu setzen und an seine Träume von einer besseren Welt zu glauben; zu kämpfen, die Hoffnung nie aufzugeben. Durch dich habe ich erkannt, wie bereichernd es ist, zu lieben; und was es bedeutet, Konsequenzen zu tragen; und, dass man nicht am Leben, Freunden, einem Beruf oder der Familienplanung, wohl aber an der eigenen Zufriedenheit und dem positiven Denken festhalten kann - um so in jeder Lebenslage Glück und Dankbarkeit zu empfinden. Deine Schwester werde ich immer bleiben.

And finally Marius: there are no words for how valuable your understanding, patience, commitment and loyalty, your friendship and care - simply your unconditional love and optimism has been - particularly during the past three years. Deine Unterstützung, deine Zuversicht und deine Wärme waren und sind unendlich wertvoll und unvergleichlich. Danke.

Sara(h) | Maastricht/Mettmann, 2011 


\section{Contents}

Introduction $\quad \mathbf{1}$

Some Illustrative Cases $\quad 4$

Elements of the CR Phenomenon $\quad 8$

Practical Elements $\quad 8$

Theoretical Elements 9

Scope and Contingencies of the CR Phenomenon 11

$\begin{array}{ll}\text { Dissertation Outline } & 13\end{array}$

$\begin{array}{llr}\text { Chapter } 1 \text { Putting CR into Perspective } & 17\end{array}$

The Societal Context of CR 18

Hypotheses $\quad 20$

Method $\quad 24$

Data Collection $\quad 24$

Data Analysis $\quad 29$

Results $\quad 31$

Test of Hypotheses $\quad 33$

Post-Hoc Analysis $\quad 39$

Discussion $\quad 41$

Limitations and Future Research $\quad 41$

$\begin{array}{ll}\text { Conclusion } & 43\end{array}$

Chapter 2 The Theoretical Case for CR 45

Competitor Recruitment: A Review $\quad 46$

Theoretical Perspectives on Competitor Recruitment $\quad 54$

Estimating Competitor Recruit Value $\quad 57$

Estimating Competitor Recruitment Costs 60

Realizing the Expected Competitor Recruit Value 62

$\begin{array}{ll}\text { Discussion } & 63\end{array}$

$\begin{array}{ll}\text { Further Research } & 64\end{array}$

Chapter 3 Characteristics and Drivers of CR in Practice 67

$\begin{array}{ll}\text { Method } & 68\end{array}$

$\begin{array}{ll}\text { Data Collection } & 68\end{array}$

Data Analysis $\quad 71$

$\begin{array}{ll}\text { Results } & 73\end{array}$

$\begin{array}{ll}\text { The CR Concept } & 73\end{array}$

CR Motives $\quad 75$

CR Impediments $\quad 76$

Discussion $\quad 80$

Limitations and Future Research $\quad 83$

Chapter 4 How to Practically Make CR a Success $\quad 85$

Reviewing the Value of Competitor Recruit Mobility $\quad 87$

Human Capital Benefit of Competitor Recruits 87

Costs of Competitor Recruitment $\quad 89$

Institutional Barriers Moderating CR Value Appropriation $\quad 90$ 
Method 94

Data Collection $\quad 94$

Data Analysis $\quad 96$

Results $\quad 96$

Human Capital Benefits of Competitor Recruits 99

Costs of Competitor Recruitment 99

(Institutional) Barriers to Competitor Recruitment 100

$\begin{array}{ll}\text { Discussion } & 107\end{array}$

Theoretical and Managerial Implications $\quad 107$

Limitations and Further Research 109

Conclusion 110

Chapter 5 CR Recruits at Work and How They Differ from Other Recruits 111

Literature Review and Hypotheses 113

Recruit Work Context Origin and Type of Human Capital Carried 113

Dominant Human Capital and Commitment Focus 114

Dominant Commitment Focus and Willingness to Switch 118

$\begin{array}{ll}\text { Method } & 119\end{array}$

Data Collection $\quad 119$

Data Analysis 123

Results 123

Test of Hypotheses 126

Discussion 129

Limitations and Further Research 129

Conclusion 132

Conclusion $\quad 133$

Bringing It All Together $\quad 138$

Limitations and Future Research Areas $\quad 140$

$\begin{array}{ll}\text { Concluding Implications } & 145\end{array}$

Implications for Theory $\quad 145$

$\begin{array}{ll}\text { Implications for Practice } & 145\end{array}$

$\begin{array}{ll}\text { Closing Words } & 147\end{array}$

$\begin{array}{ll}\text { References } & 149\end{array}$

$\begin{array}{ll}\text { Appendices } & 165\end{array}$

Summary $\quad 175$

Samenvatting $\quad 179$

$\begin{array}{ll}\text { Zusammenfassung } & 183\end{array}$

$\begin{array}{ll}\text { About the Author } & 186\end{array}$ 
Introduction $^{1,2}$

\footnotetext{
${ }^{1}$ When using 'we' in this dissertation, I designate myself as the author and my two promotors, and any assistants with whom the various studies have been performed and who are mentioned at the beginning of each chapter in the respective footnote.

${ }^{2}$ For sake of simplicity, we use any gender-related expressions like he or she, or him or herself interchangeably.
} 
"The world is changing at a bewildering pace.

Everywhere new markets are opening up, new workforces are emerging, and new ways of working are

challenging our thinking. We are in a new stage of globalization where

talent and brainpower are becoming the predominant currency."

- Cheese, Thomas and Craig, 2007 -

A Google search of October 2011 resulted in more than 10,800,000 hits when looking up the term 'Talent Management' and about 2,910,000 hits when searching for 'Headhunting'. In contrast, a Google search for the established management tool 'Balanced Scorecard', for instance, only led to about 1,670,000 hits, although the concept was established already almost 20 years ago (Kaplan \& Norton, 1992). This example seems to underline the general claim that talent management is among the top strategic priorities managers are confronted with in the $21^{\text {st }}$ century (Boudreau \& Ramstad, 2005; Capgemini Consulting, 2009; Cheese, Thomas \& Craig, 2007; Collings \& Mellahi, 2009; Mellahi \& Collings, 2009). Nevertheless, nearly all of forty surveyed companies of a study conducted by Ready and Conger (2007) miss the opportunity to fill strategic positions in the organization through their current talent pipeline not only because attracting and managing talent has never been as difficult and challenging as it is today (Cheese et al., 2007).

Globalization, an aging workforce, increases in task environment complexity and competition, or the deteriorating norm that employees should spend their whole careers with one firm - all fuel the so-called 'war for talent' (e.g. Beechler \& Woodward, 2009; McDonnell, 2011; Michaels, Handfield-Jones \& Axelrod, 2001) and prompt the re-evaluation of current recruitment policies and the role of human resources in building a competitive advantage (Barner, 2000; Castrogiovanni, 2002; Gardner, 2002; Rappaport, Bancroft \& Okum, 2003; Somaya, Williamson \& Lorinkova, 2008; Streb, Voelpel \& Leibold, 2007). One product of this re-assessment is the emergence of more aggressive HR practices (Rynes \& Barber, 1990) such as Competitor Recruitment (CR), whereby companies recruit valuable employees from rivals in an effort to gain a competitive (human capital) advantage (Cappelli, 2004; Gardner, 2005). This practice is gaining ground since the 1990s, despite existing legal restrictions such as non-compete clauses and lawsuits filed against firms recruiting from rivals (Cappelli, 2004; 2008; Lee, Gerhart, Weller \& Trevor, 2008; Preston, 2008; Sturman, Walsh \& Cheramie, 2008). CR can thus be considered an epi-phenomenon of a trend toward intensified competition for human resources among business organizations especially in tight labor markets (Cappelli, 2008; Gardner, 2002; 2005; Groysberg, Lee \& Nanda, 2008; Lepak \& Snell, 1999; Sturman et al., 2008; Rao \& Drazin, 2002; Somaya et al., 2008; Wezel, Cattani \& Pennings, 2006).

The rise of competitor recruitment is suggested by three major developments. First, there is a visible increase in the occurrence of attracting employed managers, as in the examples at Apple or Opel (see next sub-section) (Herz \& Schneider, 2010; McLean, 2008). Second, a steady increase can also be witnessed in unsolicited job offers - also beyond the management level (Lee et al., 2008) -, which contributed to a dramatic rise of the number of 
personnel search firms and the personnel search industry's financial turnover in the past 15 years ${ }^{3}$ (Alsleben, 2005; Cappelli, 2004; BDU ${ }^{4}$, 2008; 2009; Fernandez-Mateo, 2007; Fuchs, Söhnlein \& Weber, 2008; Gardner, 2002; Gardner, Stansbury \& Hart, 2010; Gehring \& Stenbacka, 2007; Hamori, 2010; Mehrmann, 2004; Murmann, 1999; 2009). In addition to broadening their hunting ground and enlarging the potential pool of candidates through this indirect approach, firms have been more likely to address otherwise risky-to-address specialists and higher managers such as those currently employed at a company that competes in the same industry or product market (Gardner, 2005). By cooperating with an executive search firm, companies can stay anonymous during the search process and so prevent retaliatory or defensive actions until they eventually hire an employee from a specific firm. Third, firms seem to assume that recruiting employees from direct competitors compared to hiring from non-competing firms can have clear advantages since they are willing to pay a premium to candidates transferring from a rival (Cappelli, 2000; Sturman et al., 2008). The continuing economic crisis - which generally lowers the demand for employees - does not change this dynamic. Firms continue to seek valuable and rare human resources such as strong leaders or specialists to beat the competition. In practice, this means that they extend the search area to employees currently bound to rivaling companies.

We thus decided to dedicate this dissertation to theory and practice-based explorations of this phenomenon and begin by defining Competitor Recruitment (CR) as the strategic human resource practice of identifying, transferring and deploying one or more employees bound to a rival firm ${ }^{5}$ to obtain or retain a human capital advantage ${ }^{6}$. As such, we present $\mathrm{CR}$ as a special case of lateral hiring, sometimes pejoratively called poaching, that more generically refers to the recruitment of one or more employees bound to any organization (Gardner et al., 2010).

\footnotetext{
${ }^{3}$ Growth of the personnel search industry dipped between 2001 and 2003 in the aftermath of September 11 and the financial crisis (Brück, 2002). From 2004 onwards, the executive search industry regained growth reaching new heights in 2007. Specifically, between 2003 and 2008, the search industry denoted an increase in business volume of 72 percent. This increase might be due to global economic trends but also due to changes in the legal environment. In 1999, for example, a legal ruling by the higher regional court Oberlandesgericht (OLG) Stuttgart stated that recruiters are not allowed to phone potential candidates at their working place (direct search). Only 6 month later, the regional court Landesgericht (LG) Mannheim revised this decision and allowed poaching employees through calling them at their working place in principle. As a result, around 1,975 HR and search consultancies have offered their services in Germany in 2008, for instance. They employed about 5,425 consultants, 2,525 researchers and 3,275 support staff members. There was an increase in financial turnover in 2008 of about 8.5 percent to $€ 1.49$ billion, and private and public firms assigned more than 71,000 search and selection orders in that year (cf. 2006: 58,000) (BDU, 2009).

${ }^{4}$ Bundesverband Deutscher Unternehmensberater (BDU). The Federal Association of German Management Consultants publishes studies on the development of the executive search industry's total annual turnover since 1990.

${ }^{5}$ We consider competitors as companies that compete in the same industry for the same product markets (Porter, 1985). Further on, the terms "rival firm", "rival", "competitor", "competing firm" or "rival company" are used interchangeably.

${ }^{6}$ Here, human capital advantage is defined as an advantage gained from one or more employees carrying human capital, which includes e.g. knowledge, skills, abilities, experience, judgment or intelligence relative to product-market competitors (Barney, 1991).
} 


\section{Some Illustrative Cases}

The habit of recruiting and hiring from competitors is probably as old as business itself. What is new however - and a hot topic among employers nowadays - is how to strategically attract qualified candidates in a highly competitive labor market (Cappelli, 2009). The increasing recognition of human capital as a performance driver is clearly reflected not only in the initial quote we started this dissertation with but by the thousands of discussions on the topic to be found on the Internet, whether in blogs, forums or online newspapers ${ }^{7}$.

Judging from these practitioner debates, competitor recruitment seems to be developing into a core strategy to deal with the talent crunch. Or in other words: not including rivals in one's hunting ground in times of limited labor supply and increased market consolidation could severely limit the group of potential candidates to attract. Firms who incorporate competitor recruitment as a recruitment practice in a strategic but sensible manner run a better chance of winning the race for talent after all (Cappelli, 2009). As evidence shows, competitor recruitment can be effective, especially when costly court cases or reputational damages are avoided, or even despite of the latter (see Elmer-DeWitt, 2008).

The following paragraphs will provide one elaborate and three shorter examples of competitor recruitment cases that occurred in the past two decades and caught major media attention.

Apple vs. IBM (2008-2009). Apple Inc. (Apple) recruited Mark Papermaster, a top chip designer from International Business Machines Corp. (IBM) in 2009, which resulted in a lawsuit that sought to prevent the executive from taking his knowledge as "IBM's top expert in power architecture and technology" to the Mac maker. The whole tide of events was triggered by Robert Mansfield, the vice president of Apple's computer hardware development department, in January 2008. Steve Jobs $^{8}$ asked him to compose a list of possible hires and Mark Papermaster, a former classmate and colleague of his, became part of it. At this point, Papermaster held the position at IBM as a top executive in the blade server unit with microprocessor expertise (Dignan, 2008). Papermaster was then invited to meet Jobs with the intention to talk about a vacant senior executive position in a different field. He, however, declined the job initially (Elmer-DeWitt, 2008).

In September of the same year, Steve Jobs approached Papermaster again, which resulted in an offer to replace Tony Fadell who was the responsible executive of the 'iPhone and iPod division' at Apple at that time. Papermaster was interested and informed IBM of this (Elmer-DeWitt, 2008). IBM in turn reacted with a considerable boost of his salary suspecting a strategic move behind Apple's poaching effort: Apple acquired P.A.Semi in April 2008 that was active in the field of power-efficient processors, which are based on the power architecture developed by IBM (Elmer-DeWitt, 2008). Besides the salary increase, IBM pointed at the non-compete agreement Papermaster had signed at his appointment in June

\footnotetext{
${ }^{7}$ See e.g. Johnson, 2011; Norton, 2010; Preston, 2008; Stafford, 2010.

${ }^{8}$ Steven Paul Jobs $(* 1955-+2011)$, next to being co-founder and chairman, was chief executive officer of Apple Inc. at that time.
} 
2006 (Elmer-DeWitt, 2008; United States District Court/Southern District of New York, 2008a) and emphasized that:

"during [his] employment with IBM and for one (1) year following the determination of [his] employment... [he] will not directly or indirectly within the 'Restricted Area' (i) 'Engage in or Associate with' (a) any 'Business Enterprise' or (b) any significant competitor or major competitor of the Company." ( $\$ 1$ (b) of Noncompetition Agreement, United States District Court/Southern District of New York, 2008a)

They further referred to non-solicitation covenants that Papermaster had agreed to stating that:

"during [his] employment with IBM and for one (1) year following the termination of [his] employment...[he] will not directly or indirectly within the 'Restricted Area'...solicit, for competitive business purposes, any customer of the Company with which [he was] involved as part of [his] job responsibilities during the last twelve (12) months of [his] employment with the Company.";

and:

"for the two (2) year period following the termination of [his] employment... [he] will not directly or indirectly within the 'Restricted Area', hire, solicit or make an offer to any employee of the Company to be employed or perform services outside of the Company." (United States District Court/Southern District of New York, 2008b)

IBM offered Papermaster an extra compensation of a one-year salary if he obeyed to the contractual clauses. Papermaster still rejected the counter-offer intending to begin to work for Apple in November 2008 (Elmer-DeWitt, 2008).

As a result, IBM filed a court action at the end of October 2008 attempting to stop the hiring process by handing in a 10-page long complaint (Elmer-DeWitt, 2008; Reuters, 2008). In this complaint, it is stated that:

"IBM brings this action to prevent Mark D. Papermaster, one of IBM's top executives who is in the possession of significant and highly-confidential IBM trade secrets and know-how, as well as highly sensitive information regarding business strategy and long-term opportunities, from breaching his Noncompetition Agreement with, and confidentiality obligations to, IBM by accepting an executive position at Apple Inc. ("Apple"), a competitor of IBM." (United States District Court/Southern District of New York, 2008b)

IBM concluded that:

"[i]f Mr. Papermaster is not enjoined from working for Apple, thereby violating his Nonconcompetition Agreement [...] and nonsolicitation covenants, IBM will be irreparably harmed. (United States District Court/Southern District of New York, 2008b) 
IBM was convinced that Papermaster moving to Apple was "an attempt to expand Apple's presence in the markets for servers and chips for handheld devices" thereby becoming one of IBM's major rivals" (Elmer-DeWitt, 2008).

About two weeks later, on Tuesday, November 4, Apple announced in a press release that Papermaster had become the senior vice president of their "devices hardware engineering" with the intention to "lead the iPod and iPhone division" and would therefore have nothing to do with chips or servers in the first place (Elmer-DeWitt, 2008). At the same time, Papermaster submitted a response to the Southern District Court of New York (ElmerDeWitt, 2008) disconfirming that IBM and Apple are competitors by saying that:

“...IBM does not design, manufacture or market consumer electronic products - IBM sold its personal computer business to Lenovo in 2005. Instead, IBM focuses on high-performance business systems such as information technology infrastructure, servers and information storage products, and operating systems software. [...] Apple, on the other hand, is in the business of designing, manufacturing and marketing consumer oriented hardware and related products. Apple's business model centers on selling its product line of personal computers, portable digital music players and mobile communication devices, along with compatible software, accessories and services, directly to the customer." (United States District Court/Southern District of New York, 2008c)

This statement implied that the filed action by IBM would not be applicable. Since opinions hence diverged in terms of whether IBM can be considered a current or future competitor of Apple, as part of the eventual settlement, Mark Papermaster had to sign and submit court-governed declarations twice in the first year of employment stating that he had not divulged any of the company's trade secrets while performing his new duties at Apple. The obligation expired in October 2009 and Papermaster each time credibly testified not to have passed on any IBM trade secrets (Spear, 2009).

Following Apple's legal affair with IBM, Steve Jobs approached the head of his competitor Palm, Ed Colligan, in 2009 suggesting a gentlemen's agreement not to poach each other's top talent partly to secure knowledge but also to suppress salary levels. Colligan refused, however, arguing that an agreement about not hiring each other's employees regardless of the individual employee's needs is not only wrong but likely illegal. An agreement between the two executives on this issue was already expected in August 2007, shortly after the debut of the iPhone and Palm's poaching of Jon Rubinstein, a former Apple executive. Jobs at that time was concerned that Rubinstein would try to lure away his former colleagues; but apparently an agreement was never reached.

As a note to conclude this case: on August 7, 2010, the New York Times reported that Papermaster was leaving Apple in the wake of the iPhone 4 antenna troubles to work for Cisco (Elmer-De Witt, 2010a; 2010b; Helft, 2010). The Wall Street Journal later reported that Papermaster's exit from Apple was due to "broader cultural incompability", and a loss of confidence from Apple CEO Steve Jobs (Kane \& Sherr, 2010). In any case, it is difficult to judge whether the poaching of Mark Papermaster paid off in the end considering the hassle 
and critical press coverage involved and the short period of Papermaster's employment. This example nevertheless shows the relevance of competitor recruitment initiatives and suggests that major benefits can potentially be reaped - considering the legal struggles that Apple was willing to incur.

Volkswagen vs. General Motors (1993-1996). A more dated case, which also generated a lot of business press coverage, heated debate and even long-lasting legal battles, involved General Motors Company (GM) and Volkswagen AG (Volkswagen) about 15 years ago. After earning a tough cost-cutter reputation as head of global purchasing at GM, José I. López de Arriortúa was lured to Volkswagen in March 1993. Several European GM executives subsequently quit to follow Lopez. But not only that: shortly after, he was accused of stealing trade secrets by taking with him a stack of documents that detailed purchasing strategies that he had helped develop for GM. The result was a GM lawsuit charging Volkswagen with industrial espionage. Consequently, in November 1996, Lopez resigned as part of the German automaker's apparent effort to head off a lengthy court battle that could cost it billions of dollars in damages. His departure from Volkswagen, however, did not compensate GM for the substantial damages incurred from the loss of business secrets and highly qualified employees (Hirsh, 1996).

Motorola vs. RIM and Apple (2008). Motorola Inc. (Motorola) may have taken the issue even to another level in 2008. Rather than trying to stop employees from leaving Motorola to go to a competitor they tried to stop employees already laid off from going to work for Research in Motion Ltd. (RIM). Motorola had initially sued RIM in 2008 for actively enticing employees to leave Motorola and work for RIM. The lawsuit accused RIM of luring away some 40 of Motorola employees since the beginning of that year. Motorola was concerned that former employees would not be able to work for RIM without disclosing confidential industrial secrets. "Motorola is threatened with losing customers, employees, technology, its competitive advantage, its trade secrets and goodwill in amounts which may be impossible to determine", the company said in the court filing. Another lawsuit by Motorola against Apple for luring away the Executive Mobile Devices Mike Fenger followed (Harris, 2008). Motorola asked the court to stop Fenger from working for Apple for 2 years and to ban him from soliciting or hiring Motorola employees, or disclosing Motorola's confidential information (Keating, 2008). No further information was made public.

Opel vs. Volkswagen (2010). Probably the most recent case that caught tremendous media attention involved GM as the owner of Adam Opel AG (Opel) ${ }^{9}$ and Volkswagen. In October 2010, Hans Demant transferred from Opel to Volkswagen. Demant had worked for Opel since 1972 being in charge among others for the vehicle concept department in the pre-development division and for the successful series of the compact car 'Corsa'. The top positions he held were Vice President Engineering at GM Europe, Managing Director of Opel, and Vice President Global Intellectual Property Rights at GM. Demant, also known as "Mister Opel", thus had extensive knowledge of research, development and

\footnotetext{
${ }^{9}$ Opel is a subsidiary of General Motors Company (GM) since 1929.
} 
strategic business insights across GM businesses. Within the realm of the poach, he became International Project Coordinator at Volkswagen directly reporting to the Chairman of the Board of Management. Surprisingly, he was not restricted by a non-compete agreement that would have prevented him from sharing business secrets with Volkswagen. To absorb the severity of the hire and not to impair future cooperation, Volkswagen guaranteed to "still closely collaborate $[, . .$.$] create new business segments and to coordinate new alliances" with$ Opel, which the latter agreed with (Herz \& Schneider, 2010; Hohmann, 2010).

\section{Elements of the CR Phenomenon}

\section{Practical Elements}

The four preceding stories are vivid examples of the fact that one way to secure the best employees is through the active 'hiring away' of valuable personnel directly from competitors (Cappelli, 2008; Gardner, 2005; Somaya et al., 2008). This is especially so as the war for talent is likely to intensify in the upcoming years as a result of both demographic (supply) and economic (demand) pressures.

As suggested by our working definition of competitor recruitment and the case examples presented, we assume that the $C R$ process consists of the three steps of identification, transfer and deployment in which various parties are involved such as the hiring firm, the competitor recruit switching between the two, and - possibly - a mediating search firm ${ }^{10}$. We thereby go beyond Barber's (1998) definition of recruitment being "those practices and activities carried out by the organization with the primary purpose of identifying and attracting potential employees" by also including the deployment phase in addition to identification and attraction. We thus rather follow Gardner, Stansbury and Hart's (2010) definition of lateral hiring as "the intentional action of one employer to identify, solicit and hire ${ }^{11}$ an individual or group of employees currently employed by another firm".

Before engaging in competitor recruitment, a hiring firm first recognizes that there is a vacancy to be filled by an individual or a group of employees that fulfill certain job requirements. An HR professional then localizes the human capital needed inside the firm or decides to search outside. In case of competitor recruitment, a hiring firm with our without the help of an intermediary such as a search firm concludes that a most appropriate candidate would originate from a competing firm. Once a suitable employee or team of employees is identified, which might occur informally through personal networks or other forms of social capital, the hiring firm seeks to initiate a transfer - directly or indirectly by

\footnotetext{
${ }^{10}$ There are different types of search firms, namely contingency recruiters and retained executive search consultants. They have different approaches to working on the employer's vacancy in terms of e.g. the fee structure, approach to sourcing, level of the service offered, and specialization of the recruiters. When talking about a 'search firm' we generally include both types, however recognize that specialist and management positions are rather filled by retained executive search firms.

${ }^{11}$ Alternatively referred to as e.g. "recruitment and selection" (Boudreau, 1985).
} 
means of a search firm. After the transfer, the competitor recruit is deployed inside the new (hiring) firm by employing various human resource management practices.

Figure I illustrates the CR process and its core steps, as well as the parties involved. This dissertation leaves out the perspective of the competing firm losing an employee. Instead, the potential gains and those parties that directly determine the value captured by the hiring firm, i.e. the recruit, the search firm and the hiring firm itself, are of interest.

Figure I The Competitor Recruitment Process

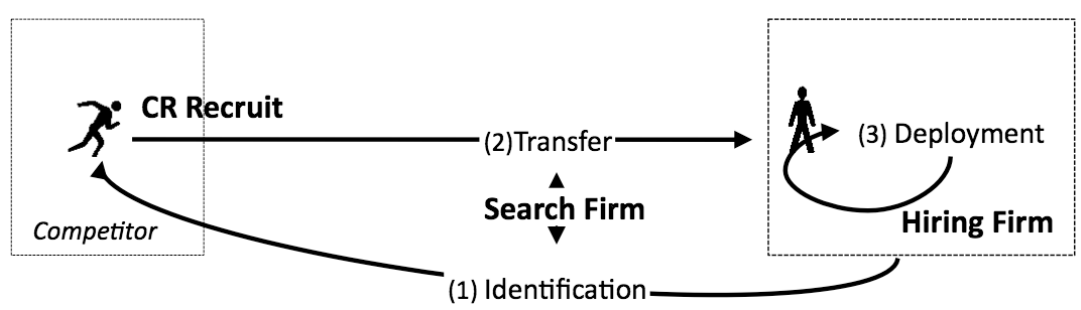

\section{Theoretical Elements}

Considering the unexplored nature of competitor recruitment, we choose for an eclectic approach towards the phenomenon by borrowing from a variety of theoretical perspectives and using different, mainly qualitative research methods. This will lead to separate chapters whose insights are intended to be integrated primarily retrospectively in the conclusion: some chapters are clearly grounded in a theoretical field (chapters 2, 4 and 5 ) while others are fully exploratory (chapters 1 and 3); one is conceptual in nature (chapter 2 ), others are empirical (chapters 1, 3-5); one looks at the value of the individual competitor recruit (chapter 2), others at the CR process (chapters 3-5), and again another at the societal context, in which CR occurs (chapter 1). In our view, taking a different perspective in each chapter first before linking insights gained from each in the conclusion allows for a distinct set of unbiased impressions being gained in the attempt to explore the potential of the specific human resource practice of CR to facilitate or inhibit the attainment of a sustained firm human capital advantage.

The following sections outline how the different theoretical perspectives that we build on complement each other and position our research in the prevailing recruitment process model literature. Recruitment research, and the human resource management literature in general, is only limitedly addressed in this dissertation since we decided for a strategic management approach. Nevertheless, we will discuss the implications of our findings for process models of recruitment in the overall discussion.

Complementary Approaches toward CR. As competitor recruitment is a phenomenon consisting of several different but interconnected processes, it cannot be captured by a single theoretical frame. Instead, we think that different theoretical perspectives need to be involved to understand it in its full richness. 
We apply primarily three theoretical perspectives, namely the resource-based (RB) (chapter 2), human capital (HC) and institutional theory (IT) (chapters 3 and 4) perspective. These strands of literature will allow us to explore when and how firms can create value from engaging in competitor recruitment. More specifically, they will help us to a) propose general characteristics that make a competitor recruit valuable and to suggest sustainable and beneficial value appropriation (RB), b) to outline specific characteristics of competitor recruits that attract hiring firms' interest $(\mathrm{HC})$, and c) to investigate environmental circumstances that steer CR conduct and determine the degree of value appropriated from CR (IT).

In particular, resource-based approaches such as the resource-based view, strategic factor market and property rights theory help to understand why and when competitor recruits add value to a hiring firm, namely when are they valuable, rare, imperfectly imitable and non-substitutable (e.g. Adegbesan, 2009; Barney, 1986; 1991; Penrose, 1959; Peteraf, 1993), how can a hiring firm take an active stance toward resource acquisition and value capture (e.g. Barzel, 1997; Foss \& Foss, 2005; Kim \& Mahoney, 2002; Oliver, 1997; Zajac \& Kraatz, 1993), and what costs are incurred to acquire and deploy employees, which actually deteriorate the potential value to be appropriated (e.g. Adegbesan, 2007; Barney, 1986; Makadok, 2001; Makadok \& Barney, 2001). This perspective does, however not specify resource attributes that make an employee with his or her distinct individual skills and competences valuable. Also, the environment is not taken into consideration but might very well influence the CR process and the extent to which estimated value can be realized. Human capital theory (e.g. Becker, 1962; 1964; Sturman et al., 2008) compensates for the former gap by suggesting a specification of a competitor recruit's valuable knowledge, skills and competences. Institutional theory (e.g. Scott, 2004; 2008) fills the latter by explaining why some HR practices turn out to be widely applied within an industry while others do not. It thus considers the external business dynamics, in which firms function.

As these elaborations show, we position our research in the strategic management literature. Given the recognition among strategic management researchers and practitioners that a sustained competitive advantage arises more from a firm's internal resource endowments and resource deployments than from the firm's product-market position (Barney, 1991; Conner, 1991; Grant, 1991), an examination of the role that HR plays in facilitating or stifling the development of consequential organizational competencies is hence certainly appreciated.

CR as a Process Model of Recruitment. As our definition of competitor recruitment suggests, this dissertation is interested in the strategic process elements of competitor recruitment rather than in single recruitment activities or specific process variables. Thereby, we position this research within the strategic elements of process models of recruitment. By looking at pre- and post-hire stages, we acknowledge the complexity of recruitment processes. 
According to Breaugh and Starke's (2000) Model of the Organizational Recruitment Process we focus on the recruitment objective of hiring high-quality candidates. We further look at strategy development (i.e. who to recruit, where from, how) and at consequential recruitment results (i.e. likely value to be appropriated from $C R$ and a CR recruit considering possible barriers to $\mathrm{CR}$ ). In more practical terms, we seek to shed light on what makes a competitor recruit to be perceived as being of high quality and, as a result, who should be competitor recruited, how, and what is the likely benefit gained (chapters 2-4). We thus do not look at specific recruitment activities that ask for a closer investigation of for example specific recruitment sources or recruiter characteristics. Also, we only limitedly consider specific intervening/process variables like recruit comprehension of recruiting messages or expectations about job requirements (except in chapter 5 where we look at commitment and willingness to switch based on recruit origin).

\section{Scope and Contingencies of the CR Phenomenon}

Before delineating how we will investigate the strategic CR process elements, this section further specifies the circumstances under which competitor recruitment might be more or less relevant, and thereby outlines the scope and focus of this research project.

First, among competitors the same business functions tend to be important for success or even survival. If success in a particular business function is highly dependent on certain individuals' personal skills, a lucrative 'transfer market' between competitors opens up for employees endowed with these vital skills. Critical business functions, however, differ between industries. For instance, in automotive it may be (low-cost) production, in the computer gaming industry (appealing) design, and in the fast-moving-consumer-goods sector (innovative) marketing. As a result, competitors in these industries are likely to be aware of each other's superior negotiators, software engineers and marketers respectively.

More generally, competitor recruitment is deemed particularly relevant for firms in dynamic and/or research-intensive industries where critical competencies are tied to scarce and deeply specialized individuals. Examples of industries where these conditions are met include industries such as automotive, chemical, pharmaceutical, engineering or computer gaming. For instance, a specialist who has long-lasting experience in technical services and application development at a chemical company advising clients on rubber recipe development or processing improvement is highly sought due to this deep expert knowledge and the potential to have a major differentiating impact for his clients as he carries unique and rare - intangible - knowledge about one particular rubber type and its characteristics. Another example can be taken from the automotive industry. Luxury cars oftentimes excel through their appealing design. Employing a star car-designer such as Walter Maria de'Silva $^{12}$, an Italian car-designer who transferred first from Fiat to Alfa Romeo and was poached subsequently by Volkswagen, can provide for a sincere and sustainable competitive advantage. Similarly, direct sales-based industries represented by firms like Hilti or Vorwerk

\footnotetext{
${ }^{12}$ see chapter 2 .
} 
would hire from competitors not with the aim of purchasing product knowledge or a feel for the market but to directly acquire a client base and sales channel knowledge. Alternatively, in the consulting sector, poaching top-level talent from rivals is common practice. One of the best UK economists, Dr. Bill Robinson, was formerly employed by PricewaterhouseCoopers and then poached by rivaling Big Four accountancy firm KPMG in 2007. Robinson joined KPMG's forensic practice as head of economics in a client-facing role without major uproar (Jetuah, 2007).

Other industries are evidently much less affected by competitor recruitment dynamics. This may be the case when critical skills are easily trainable, widely available or only exist outside the own industry. To illustrate the latter, consider the example of the German energy market. After its liberalization in the second half of the 90s, firms such as E.ON, RWE, EnBW and Vattenfall that currently control more than 80 percent of German electricity supply decided not to poach from competitors. Instead, they chose a hunting ground outside their own industry, namely geared at firms of the consumer goods sector such as Procter \& Gamble, Danone or Reckitt Benckiser. These firms were well known for generating marketing experts who know how to function in highly competitive, customeroriented markets - something unavailable among the energy market leaders but highly needed at that time. Similarly, firms within the consumer goods sector compete for employees from the automotive industry, being a reliable source of transferable insights on production process optimization due to established and long-lasting experience with 'Kaizen' or 'Kanban' processes.

Besides the knowledge sought, mutual forbearance could be another reason for not engaging in competitor recruitment. Competitors that are located within geographic proximity may (tacitly) agree through a gentlemen's agreement to cooperate instead of aggressively compete. Various small and medium sized firms of the German electrical industry such as Berker, Rutenbeck Fernmeldetechnik, Albrecht Jung, Lumberg, Günther Spelsberg, Kaiser or Busch-Jaeger Elektro all being located in a North Rhine-Westphalia region called Schalksmühle avoid poaching each other's talents in an effort to prevent a war for talent that would damage the industry due to consequent bidding wars, salary rises, and decreasing trust levels.

Finally, within-industry differences might also exist. Single firms within an otherwise aggressive industry may be relatively immune to competitor raids. Egon Zehnder International, for instance, one of the leading executive search firms in the world, has managed to establish a very strong and powerful company name since its foundation in 1964. Through this strong reputation, they manage to bind clients to the firm rather than to individual consultants so that clients would not follow a single departing consultant to a directly competing executive search firm. This effectively discourages competitors from luring away Egon Zehnder consultants when aiming to expand their client base.

The previous examples have shown that companies of different industries attribute to competitor recruitment valuable benefits for their business performance primarily 
stemming from client contacts and knowledge or insights about industry standards or practices. Other firms, however, refrain from it if respective human capital is not sought.

In this dissertation, we aim at a clarification of factors that underlie endeavors (not) to engage in competitor recruitment. In particular, we let field practitioners reflect on and determine - what competitor recruitment is, how it is experienced and what makes competitor recruits different from other external and internal recruits. We thus explore in this dissertation: Under which conditions does competitor recruitment ideally occur and how, and what are underlying motives and implications?

\section{Dissertation Outline}

This article-based dissertation seeks to explore the reasons for and characteristics and consequences of competitor recruitment for a hiring firm by considering the major parties involved, namely the recruit, the hiring firm and the search firm (see Figure II). In particular, we investigate (1) the wider trends in which competitor recruitment occurs (chapter 1 ), (2) its likely benefits and costs (chapter 2), (3) its characteristics and underlying drivers (chapter 3), (4) the conditions and context in which it - ideally - takes place (chapter 4), and (5) its potential recruit work behavior outcomes (chapter 5).

More specifically, chapter 1 sheds light on the societal context in which CR occurs and that makes firms consider CR as a recruitment practice at all, i.e. ex ante CR process step 1. Chapter 2 also takes the hiring firm perspective but looks at all process stages 1, 2 and 3 to approach expected value and cost drivers of CR theoretically. Having delineated why and when it makes sense to research CR based on current HR trends and theoretical motivations, chapter 3 investigates characteristics of $C R$ as well as hiring firm motives and impediments that precede the decision (how) to engage in $\mathrm{CR}$, i.e. the identification stage, in practice. Chapter 4 specifies the cost and value drivers that underlie a CR hiring decision that are partly implicit in the motives and impediments outlined in chapter 3 . While chapter 3 , however, generally explores antecedents to CR ex ante step 1, chapter 4 specifies those in more detail linking them to the specific process stages ex post step 3 . Chapter 5 finally investigates the CR recruit's behavior after the transfer and potential CR-typical consequences for a hiring firm, thus focuses on step 3.

The specific contents of each chapter are outlined in more detail below.

\section{CHAPTER 1: Putting CR into Perspective}

Chapter 1 takes a historical glance on recruitment practices. It investigates whether the relevance of human capital and thus the aggressiveness of external staffing practices intensified over the last 20 years. To explore these questions, (1) a content analysis of 5763 job postings posted between 1990 and 2010 in one of the most influential German newspapers, namely the Frankfurter Allgemeine Zeitung (FAZ), and (2) a keyword search in the largest German literature database, Datenbank für Wirtschaft und Soziales (WISO), is conducted. 


\section{CHAPTER 2: The Theoretical Case for CR}

In this chapter, a theoretical explanation for engaging in competitor recruitment is provided. To identify conditions that determine the final value to be captured through competitor recruitment by a hiring firm, we look at CR through the lenses of the resourcebased, strategic factor market as well as property rights theory. This comprehensive conceptual analysis of the cost and value drivers around CR serves as the basis for the empirical investigations to follow in subsequent chapters.

\section{CHAPTER 3: Characteristics and Drivers of CR in Practice}

This chapter empirically explores the type of employees competitor recruitment aims at and how, as well as the general motives and impediments that drive its occurrence. To this end, we analyze qualitative data obtained from interviews with 19 top executive search consultants in Germany.

\section{CHAPTER 4: How to Make CR Practically a Success}

Chapter 4 assigns to the specific process stages the in chapter 2 suggested theoretical value and cost drivers of $C R$ as well as the in chapter 3 outlined practical motives and impediments of CR. Therefore, chapter 3's dataset is used and data received from interviews with $9 \mathrm{HR}$ professionals added. Since the most prominent motives and impediments outlined in chapter 3 can be explained by human capital and institutional theory, these two theories are specifically used in this chapter to shed more light on the phenomenon.

\section{CHAPTER 5: CR Recruits at Work and How They Differ from Other Recruits}

This chapter proposes a new theoretical link between recruits' work context origin, their dominant type of human capital and their resulting work behavior outcomes. It explores through a survey of 63 respondents in how far the type of human capital varies between internal and external recruits, to what extent recruit origin is associated with commitment focus, and how this in turn with willingness to switch to another job or organization.

\section{CONCLUSION}

The conclusion presents an outline of the main issues covered in this dissertation, a summary of the core findings as well as a clear positioning within the literature on process models of recruitment, finally leading to an overall comprehensive model of CR. It also suggests general theoretical and practical implications of this work as well as potential areas for future research.

Figure II illustrates the CR process and its core steps, as well as the main parties involved. Only the potential gains and those parties that directly create value for the hiring 
firm, i.e. the recruit, the search firm and the hiring firm itself, are of interest. The focus of each chapter is also visualized.

Figure II The CR Perspectives Taken in this Dissertation (Ch=chapter)

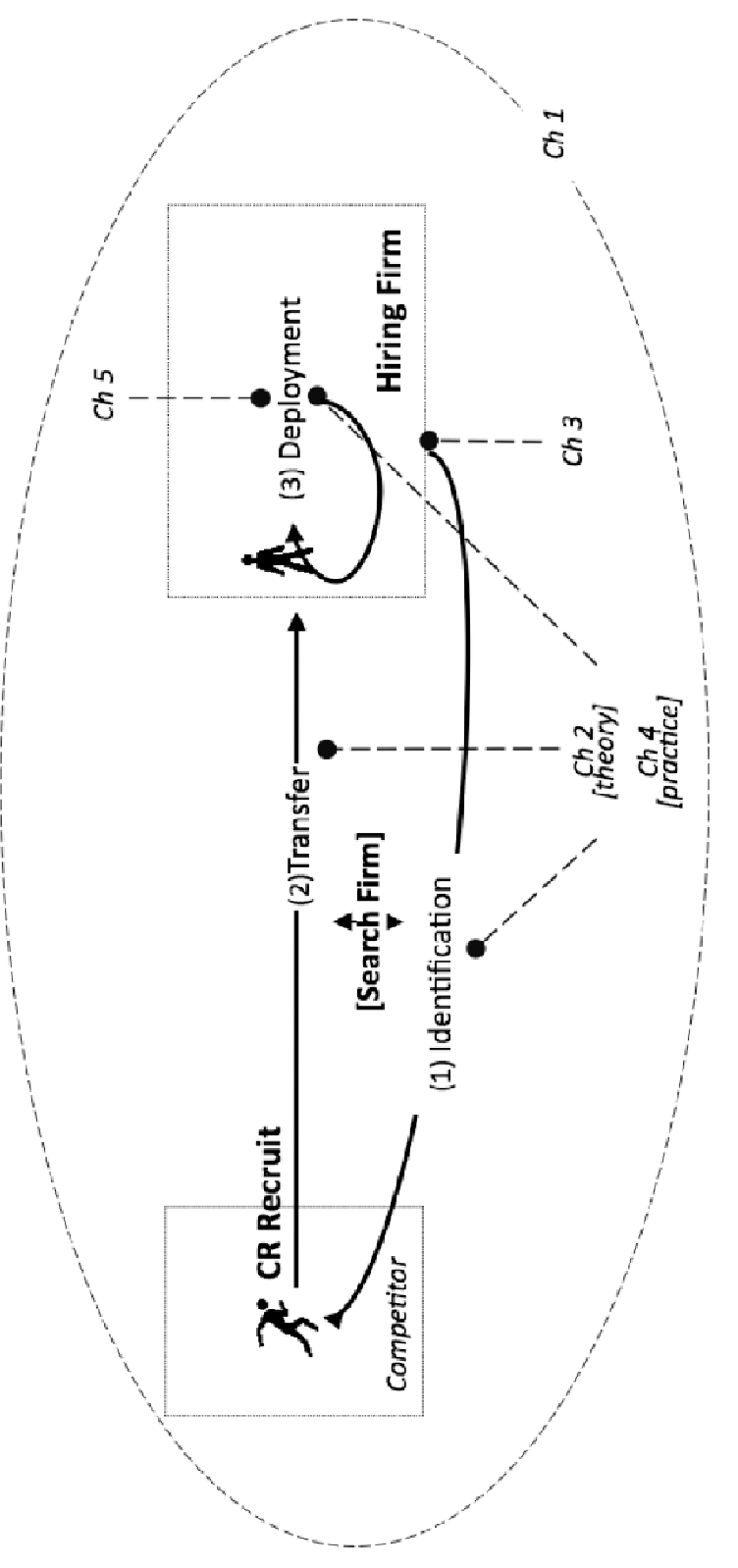





\section{1}

Putting CR into Perspective ${ }^{13}$

This study takes a historical perspective on recruitment practices. It specifically investigates the rising interest in human capital and aggressive recruitment practices over the past 20 years. To this end, we conducted a) a content analysis of a cross-section of 5982 job postings posted between 1990 and 2010 in one of the most influential German newspapers, the Frankfurter Allgemeine Zeitung (FAZ) and b) a keyword search in the largest German social sciences publication database, the Datenbank für Wirtschaft und Soziales (WISO). We had three particular issues of interest: whether (1) human capital is increasingly considered a firm value creator, (2) perceived labor market complexity has increased, and (3) recruitment practices have become more aggressive.

Findings suggest that the value attributed to human capital rose significantly and competition for labor became slightly more complex and aggressive over the period of investigation. These results support the need for further research in the field of strategic recruitment practices such as competitor recruitment.

\footnotetext{
${ }^{13}$ Many thanks to Jennifer Czaplik for highly valuable data collection and intellectual support. A great thank you also to Bart Dormans for appreciated feedback on methodology and write-up.
} 
Before assessing the characteristics and use of competitor recruitment it is worthwhile to explore the societal context in which $C R$ occurs and that makes firms consider $C R$ as a recruitment practice. To this end, we discuss the relevance of upcoming labor shortages for the occurrence of $\mathrm{CR}$ and the rising interest in human resources as firm value creators. As Germany is disproportionately affected by demographic changes, we will focus our attention on this national context.

\section{The Societal Context of CR}

Germany has had one of the lowest fertility rates in the world for nearly four decades now (Pötzsch, 2007); on average, German women do not give birth to more than 1.3 children $^{14}$ (EUROSTAT, 2008). The uncertainty after German reunification, the rising age at first marriage, childbirth at a late age, social factors like divorces, or economic pressures, all have negatively influenced fertility rates (Höhn, Mai \& Micheel, 2007). In addition, life expectancy of men and women has nearly doubled since the end of the $19^{\text {th }}$ century and is still increasing (Destatis, 2006). In 1970, life expectancy of men was 67.4 years (women: 73.8) going up to 77.6 years (82.4) in 2008. As a result, the German population will grow continuously older while the working population is shrinking. Accordingly, the popular media in Germany report an increasing lack of skilled employees. A keyword search in the 'WISO' database (Wirtschafts- und Sozialwissenschaftliche Datenbank) ${ }^{15}$ showed, for instance, that in 1990 only 53 newspaper articles dealt with the lack of qualified employees whereas in 2010 the number had risen to 9350 articles addressing this topic.

Graph 1.1 (Fuchs et al., 2008) shows the predicted age development in German society.

\footnotetext{
${ }^{14}$ For comparison: e.g. the French: 2.0 and the British: 1.8 .

${ }^{15}$ The WISO database encompasses more than 340 journals from the field of business and social sciences as well as about 88 million newspaper articles. Thereby, WISO is the most used database for German academic texts, magazines or newspapers, and comparable to the Anglo-Saxon database EbscoHost.
} 
Graph 1.1 (Forecasted) Population Aged 0-74 in 2005, 2020 and 2050 (net migration 200,000 annually ${ }^{16}$ )

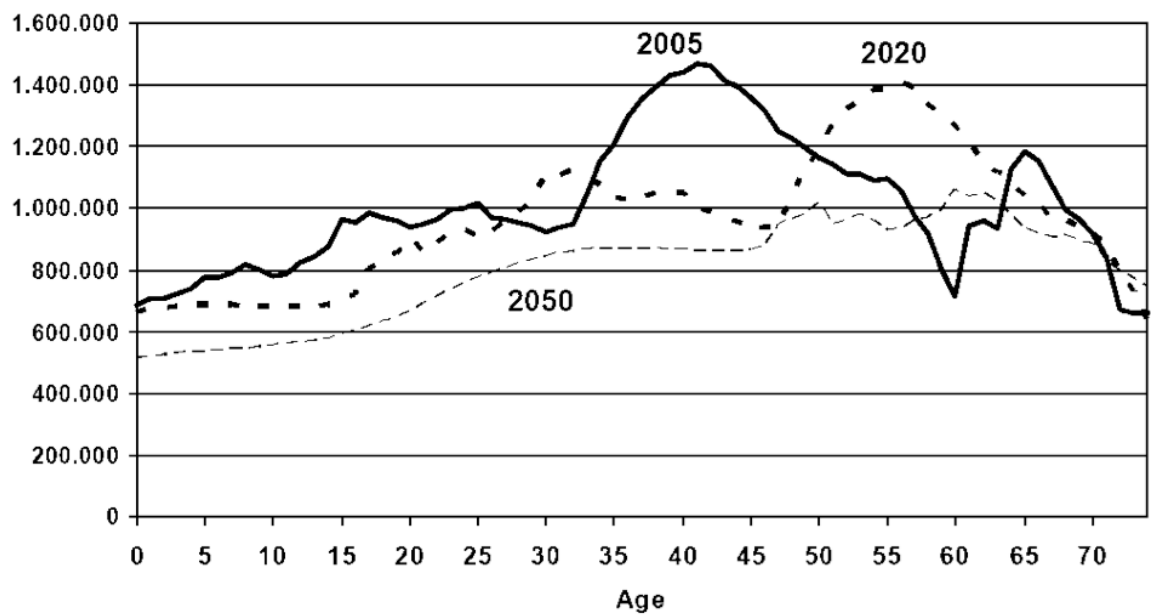

Overall, it is most probable that the total German population will decrease by approximately 13 percent until 2050 and the working age population by 24 percent (Fuchs et al., 2008). In 2006 already, three quarters of all companies who participated in a study by the German Institute for the Study of Labor (IZA) expected to be affected by the lack of skilled employees (Schneider \& Stein, 2006). This estimated lack of employees would cause a decrease in economic growth of 0.6 percent per year leading to a projected welfare loss of $€ 3.8$ trillion between 2010 and 2030 (Gramke, Gischer, Schlesinger \& Schüssler, 2009).

The United States of America are expected to have a somewhat brighter outlook with an increase of the working age population of 15 percent until 2050 due to higher fertility and immigration rates (Goldstone, 2010). Nevertheless, large companies like Microsoft or Cisco plead with the U.S. congress for an expansion of visa permits granted to skilled employees from other countries (Schuler \& Jackson, 2010), which hints at the fact that U.S. American companies also suspect to be affected by a similar demographic trend and consider increased migration numbers a solution. Accordingly, the Bureau of Labor Statistics predicts for the American economy continued growth at the rate of 2.4 percent per year for the next eight years while the labor force is only expected to expand by 1.2 percent per year (Rappaport et al., 2003; Streb et al., 2007). Demographic changes thus seem to lead to - feared - labor scarcities around the globe (Bhatnagar, 2007; Cappelli, 2000; Ducanes \& Abella, 2008; Fuchs et al., 2008; Gramke et al., 2009; Schuler \& Jackson, 2010) and labor shortage rather than unemployment will become the key problem and a prime source of competitive advantage (Ackermann, Borghardt \& Mai, 2007; Gandossy \& Kao, 2004;

\footnotetext{
${ }^{16}$ Since foreigners moving to Germany are on average younger than those leaving the country, migration dampens the ageing process (Fuchs, Söhnlein \& Weber, 2008). Without the assumed migration numbers of 200,000 annually the development of the age structure would be even more severe.
} 
Michaels et al., 2001; O'Leary, Lindholm, Whitford \& Freeman, 2002; Schneider \& Stein, 2006; Staudinger, 2008; Streb et al., 2008; Tucker, Kao \& Verma, 2005).

Suggestions made by the German government to fight this trend are to increase the number of women participating in the labor market (e.g. Destatis, 2006; Ehrentraut \& Fetzer, 2007; Fuchs et al., 2008; Larwood \& Gutek, 1987; Simpson \& Altman, 2000), to raise lifetime work hours by encouraging people at younger ages to participate in the labor market (e.g. Armutat \& Jera, 2010), to keep employees who are older than 64 years ${ }^{17}$ engaged in the labor market (e.g. Hutterer, 2010; FAZ, 2010; Fuchs et al., 2008; Gramke et al., 2009) and to boost immigration ${ }^{18}$ (e.g. Fuchs et al., 2008; Schneider \& Stein, 2006). Still, none of the so-suggested solutions can entirely resolve the immediate problems caused by demographic changes.

It is essential for companies to be aware of and understand these current labor market developments in order to be able to foresee potential personnel needs and be prepared to address them. We therefore aim to sketch HR trends of business organizations in Germany of the past 20 years. We assume that this will allow us to determine the relevance and occurrence of more aggressive employee sourcing practices such as competitor recruitment. In particular, this study seeks to explore whether over time (1) the value of human capital gained in recognition among companies, (2) labor markets became more complex and (3) recruitment practices became more aggressive.

To this end, we first provide hypotheses to be tested based on current developments in the German labor market. Second, a qualitative content analysis of job postings of one of the most influential German newspapers as well as a keyword count of representative phrases in the largest German database of academic and popular press releases is conducted to see how recruitment practices have changed between 1990 and 2010. A discussion of the major findings follows and issues for further research are discussed.

\section{Hypotheses}

In Germany, the public and academic debate about the role of human resources for economic growth reached its climax in the year 2004 when 'human capital' was elected "faux-pas word of the year" ${ }^{19}$ (FAZ, 2005) while the academic literature attributed highly

\footnotetext{
${ }^{17}$ Only 15 percent of employees between the age of 60 and 65 years have a full-time position; a higher retirement age will increase the working population by approximately 2.5 million employees until 2050, which cannot even roughly compensate the lack of 5.5 million employees until 2030.

${ }^{18}$ Whereas the first two reactions rather concerned a redistribution of people who are already part of the German population, this suggestion asks for an inflow of employees from the outside. Calculations made by the German institute for labor market and job research (Institut für Arbeitsmarkt und Berufsforschung - IAB) show that a net migration of at least 400,000 people per year is necessary to fight the population shrinkage in Germany without drastic policy changes. This scenario is unlikely to occur though since net migration in the past 50 years was on average not more than 190,000 per year and even lower in recent years. In e.g. 2006, net migration was below 23,000 (Fuchs et al., 2008).

${ }^{19}$ The Association of the German Language (GfdS) agrees each year since 1991 upon a '(faux-pas) word of the year' that has formed public discourse. The GfdS chose 'human capital' (German: Humankapital) based on the fact that the term would degrade employees to objects tradable in an economic context.
} 
positive connotations to the concept. Since the 1980s, scholars increasingly perceive employees as valuable resources who have the potential to create a sustained firm competitive advantage (Barney, 1986; 1991; Wernerfelt, 1984). The value of human capital is generally described to follow from the stock of knowledge, skills, abilities or other attributes $(\mathrm{KSAO})^{20}$ controlled by an individual that was obtained through education, training and experience, and that is valuable in an economic context (Becker, 1962; 1964; Foss, 2008; Hitt, Bierman, Shimizu \& Kochhar, 2001). It consists of valuable soft (e.g. foreign language competences or leadership ability) and hard (e.g. education or work experience) skills (Kran, 2009; Litecky, Arnett \& Prabhakar, 2004; Muzio \& Fisher, 2009) that an employee owns and potentially carries along from one firm to another.

Gary Becker $(1962 ; 1964)$ initially declared that investing money in the education of employees eventually pays off because highly qualified workers add value to a company and to society as a whole. The value of human capital has been defined to consist of general, firm-specific and industry-specific skills that make an individual distinctively valuable in a specific context (Groysberg, McLean \& Nohria, 2006; Sturman et al., 2008). Nevertheless, the work of human resource managers has often been viewed as a cost factor in companies as the benefits they deliver are mostly indirect and hard to measure otherwise. Countering this view, Ulrich (1997) among others coined the model of 'HR business partnering' to make HR an appreciated and value-adding function. A rise of $\mathrm{HR}$ business partnering in practice can be witnessed since then (Caldwell, 2008; Ulrich \& Brockbank, 2009). Rather than being a mere cost factor and concentrating solely on traditional HR duties such as benefits, payroll and employee relations, in the HR business partner model the HR department seeks to add value to the company by participating in strategic resource and capacity planning and by overseeing all recruiting, training, advancement or placement efforts regarding new and current employees to help the business meet present and future corporate goals. Accordingly, employees are increasingly perceived as a key, multifaceted resource also in practice, and the term human capital began to circulate more and more with a positive connotation (Gardner, 2002).

We thus propose that:

Hypothesis 1: The value attributed to human capital has increased between 1990 and 2010.

Next to an increase in the value that companies attribute to human capital, changing career perceptions and demands might have led to more complex searches for the 'right' human capital carriers (Johnston, 1992).

Traditionally, employers expected to deal with linear careers with employees being employed at one or at most two firms until the end of their working life (Levinson, 1978). If

\footnotetext{
${ }^{20}$ The terms human capital, knowledge, skills, abilities and competences are used interchangeably throughout this thesis.
} 
one was loyal to one's company, job security was essentially guaranteed. The longer one stayed with the same company, the further one climbed up the hierarchy and the more benefits were earned. This traditional career model, however, seems to have been replaced by the so-called 'boundaryless career' model (Arthur, Khapova \& Wilderom, 2005; Sullivan, 1999). Accordingly, employees are increasingly willing to change firms to boost their careers instead of waiting for seniority-related promotions (Hamori, 2010). In fact, about two-thirds of all open positions will be filled by externals in the future, a trend, which is gaining in prevalence in Germany (Bhatnagar, 2007; Hamori, 2010; Sullivan, 1999). This leads employees to invest in the development of skills that are transferrable to different companies and industries rather than in firm-specific competences. As a result, many companies cannot meet their demand for highly qualified managers and specialists anymore through internal succession management (Hamori, 2010). The resulting pressure to hire externally requires a new approach to hiring (Cappelli, 2003). This is, however, more challenging as potential recruits are now 'hidden' in employment and spread across a variety of firms rather than being openly on the job market.

In addition, globalization encourages labor mobility across geographic and cultural borders and creates international competition for labor (Baruch, Budhwar \& Khatri, 2006). After all, global labor competition and mobility are possible with minor barriers, and with people being more willing to relocate outside their home countries (Tung \& Lazarova, 2007). Consequently, companies also increasingly have to manage dissimilar employee populations, markets, cultures and modes of work.

Next, educational tracks have been diversifying especially since the initiation of the Bologna process in 1999 (Bologna Declaration, 2011). The Bologna Declaration among others introduced a higher educational system of two phases and (financially) incentivized the mobility of students across universities and national European borders due to credit transfer options. It thereby made students switch not only universities but also subjects more often, or to receive education in different steps with phases of social or practical work in between (Potter, 2005). This individualization of résumés and biographies challenges standardized career paths and makes it more difficult for companies to make the right hiring decisions.

Finally, work models become more diverse. Women have been increasingly entering the labor market on a full-time basis while men ask for part-time employment also on senior positions (Beechler \& Woodward, 2009). In addition, employees more and more desire to work from home, partly to be able to combine family and work life. This requires companies to rethink their hiring and deployment practices as well as previously defined characteristics of so-called ideal candidates displaying full flexibility, mobility and availability.

Considering these trends, we suggest that:

Hypothesis 2: The complexity of employee sourcing has increased between 1990 and 2010. 
The rising difficulty of filling jobs has certainly fostered organizational attention to the importance of well-chosen recruitment activities (Breaugh \& Starke, 2000). There from follows that companies look for alternatives to internal sourcing of employees to win the war for talent and to shift their focus from hiring employees from pools of available job seekers to hiring 'bound', employed and experienced employees (Beechler \& Woodward, 2009; Cappelli, 2003; Gardner, 2002). Outside hiring is becoming more and more a necessity and "open competition for other companies' people, once a rarity in business, is now an accepted fact" (Cappelli, 2000; Strack, Baier \& Fahlander, 2008). Lateral hiring (from rivals) might thus be a specific alternative to cope with labor scarcities (Cappelli, 2000; Gardner, 2005), which can be considered an especially aggressive form of personnel acquisition as retaliatory actions of the company losing an employee such as lawsuits filed or other measures taken might follow, especially if a competing company is involved (see examples given in the Introduction) (Gardner, 2005; Gardner et al., 2010).

Furthermore, an rising focus on retention efforts such as the use of financial incentives (e.g. golden handcuffs), non-compete clauses or non-solicitation agreements suggests that companies are more and more aggressively fighting to retain core employees (Beechler \& Woodward, 2009; Cappelli, 2000; Fernarndez-Araoz, 2007; Ritter \& Rosenberg, 2007). For example, total compensation packages increasingly constitute a determining factor in attracting and retaining high performing employees (Fay \& Thompson, 2001; Giancola, 2009; Gross, Bundy \& Johnson, 2011; Taft \& Powell, 2005; Zingheim \& Schuster, 2008). Thereby, companies aim to be and stay attractive to the best talent - also globally.

In addition, companies increasingly seek to bind students in the early stages of their studies by offering pre-master programs, early intern experiences or internal alumni networks among others (DiLorenzo-Aiss \& Mathisen, 1996; Gupta \& Govindarajan, 2002; Marshall, 2007). Robert Bosch $\mathrm{GmbH}$, for instance, one of the largest automotive suppliers and most popular employers of Germany, has started 10 years ago to recruit candidates internationally, to partner with elite scholarship institutions like e-fellows ${ }^{21}$, or to offer internal scholarships directly or company-based $\mathrm{PhD}$ programs to highly capable engineers (Boeker, 2002).

As a result, we finally hypothesize that:

Hypothesis 3: Personnel acquisition practices have increased in aggressiveness between 1990 and 2010.

\footnotetext{
${ }^{21}$ e-fellows offers scholarships for highly qualified students of various disciplines Europe-wide and intermediates between those students and attractive employers by offering services and a unique network to rely on during one's studies or professional career (e-fellows, 2010).
} 


\section{Method}

\section{Data Collection}

Context. The German labor market will be used as the context of analysis since Germany is a demographic forerunner. It faces population trends that will be representative for many other countries in the future. As shown, Germany is severely affected by demographic changes (Fuchs et al., 2008; Gramke et al., 2009) leading to employee scarcities, which become more and more visible (Koppel, 2010). Besides, Germany is one of the countries that have been shifting from manufacturing to service and information-based economies, thereby making jobs more complex and knowledge-based and requiring more highly qualified employees over time (Gramke et al., 2009).

Data. We decided to study job postings of one of the major daily newspapers in Germany, the Frankfurter Allgemeine Zeitung (FAZ). Since companies advertise vacancies by listing the skills that they need when searching for potential candidates to signal the recruit profiles sought we considered this a valid approach (Dobbs, Sun \& Roberts, 2008; for a review of signaling theory see Connelly, Certo, Ireland \& Reutzel, 2011). The FAZ newspaper was selected for four reasons. First, it is one of the biggest and most established newspapers in Germany. The FAZ Group that publishes the FAZ newspaper has been elected "most respectable media company" in $2008^{22}$ (Döhle \& Werres, 2008) and the newspaper itself has a readership of more than 900,000 people (AWA, 2007) per day on average (among them more than 250,000 executives). Second, it provides the largest amount of job postings of all German newspapers each Saturday (AWA, 2007). Third, it is published nationwide, and fourth, it focuses on better-paid jobs such as higher management and specialist positions, which are primarily affected by the demographic changes just described (Schneider \& Stein, 2006).

Following Abrahamson and Eisenman (2008), and Leung and Law (2010), a second type of data was added. We chose to use a count of words or phrases of scientific and newspaper articles to explore the "zeitgeist" during the period. Since it is assumed that a topic that is relevant at a certain point in time also receives corresponding media or scholarly attention, academic and press publications of the same years published in the German online database WISO (Wirtschafts- und Sozialwissenschaftliche Datenbank) ${ }^{23}$ were scanned.

Sampling. The sample consisted of a cross-section of job postings of FAZ issues taken from the years 1990, 1995, 2000, 2005 and 2010. The period between 1990 and 2010 was considered appropriate since this is the period in which public awareness for potential labor scarcities began to spread ${ }^{24}$. The first Saturday issue of February and September of

\footnotetext{
${ }^{22}$ By the German Manager Magazin.

${ }^{23}$ see $^{15}$

${ }^{24}$ The assumption is based among others on a Google search per year for "Talent Management": 1990: 99,000; 1995: 99,200; 2000: 98,100; 2005: 173,000; 2006: 320,000; 2007: 582,000; 2008: 1,250,000; 2009: 2,740,000; 2010: 9,870,000 hits, while recognizing that there might be a strong correlation between popularity of the Internet and the number of hits shown. As a result, the WISO database was used for the main study instead.
} 
each year was included in the analysis (see highlighted section in Table 1.1) to control for seasonal employment. We focused on the Saturday/weekend edition of the FAZ because it contains the special supplement "Beruf und Chance" (Job and Opportunity) that offers most of the job postings published in the FAZ per week. Jobs offered by private people (e.g. families looking for housekeepers or nannies) were not incorporated in the sample. All other job postings were photographed in the archive of the FAZ in Frankfurt, Germany, and then scanned and analyzed on-screen. Additionally, FAZ employees working for the archive or media services were regularly consulted during the process of data collection.

Thus, in total, 10 data collection points in five-year intervals, two per year, were analyzed beginning with the first February issue of 1990 published in week 1 and ending with the first September issue of 2010, equally published in the first week of the month. Finally, the data obtained from both issues of a given year were merged and compared per anno.

Table 1.1 \#Pages of Job Postings per Issue ${ }^{25}$ (shaded area indicates analyzed range)

\begin{tabular}{lcccccccccc}
\hline & \multicolumn{2}{c}{1990} & \multicolumn{2}{c}{1995} & \multicolumn{2}{c}{$\mathbf{2 0 0 0}$} & \multicolumn{2}{c}{2005} & \multicolumn{2}{c}{$\mathbf{2 0 1 0}$} \\
& Feb & Sep & Feb & Sep & Feb & Sep & Feb & Sep & Feb & Sep \\
\hline Issue Week 1 & 119 & 106 & 73 & 88 & 163 & 144 & 27 & 33 & 17 & 10 \\
Issue Week 2 & 119 & 110 & 69 & 85 & 163 & 147 & 38 & 41 & 8 & 17 \\
Issue Week 3 & 105 & 107 & 74 & 86 & 179 & 157 & 43 & 49 & 12 & 14 \\
Issue Week 4 & 66 & 91 & 50 & 80 & 156 & 130 & 36 & 35 & 12 & 12 \\
Issue Week 5 & - & 95 & - & 72 & - & 115 & - & - & - & - \\
\hline
\end{tabular}

The number of in-print job postings reached a peak in 2000 with 1421 jobs offered in the first issue of February 2000 and then dropped dramatically afterwards to less than 248 in February 2005 and 86 in September 2010. According to the FAZ, this trend has occurred due to the increased use of the Internet instead of newspapers for advertising job postings ${ }^{26}$. The 'populations' of print and online ads, however, were said not to differ in target group or hiring firm characteristics. We are hence convinced to have collected representative data even though some companies might have fully switched from print to the online job market (Backhaus, 2004). Including earlier years in the analysis would have distorted the results of the investigation since the total number of job postings as well as the types of jobs that were offered and sought varied before and after reunification (i.e. 1990).

To investigate whether our sample is representative of the German population we conducted crosstabulation checks before the actual analysis. To this end, we first assigned one out of thirteen different industry clusters according to the Standard Industrial Classification (SIC) of All Economic Activities Revision 4 manual (United Nations, 2011) to each job posting. A full list of industries with respective section titles can be found in Table

\footnotetext{
${ }^{25}$ Only information on \#pages rather than \#job postings was available for all issues since 1990.

${ }^{26}$ Taking the first issue of February and September together, 1785 jobs were advertised online in 2007, 1459 in 2008, 4981 in 2009, and 2208 in 2010. Here, issue refers to job postings accessible on the first weekend of either February or September, but having been potentially published already during the week before.
} 
1.2. Second, we specified firm size. The institute for SME research (Institut für Mittelstandsforschung Bonn - IfM) describes German SMEs as companies with less than 500 employees and an annual turnover not exceeding $€ 50$ million (IfM, 2002). This definition is widespread in the German economy and used to define the often referred to "Mittelstand". As most companies do not mention their annual turnover in job postings, only the first part of the definition is relevant here. As a result, in this study, SMEs are defined as occupying less than 500 employees. Finally, job levels are determined. Entry-level jobs refer to those requiring less than 2 years and non-entry-level jobs to those requiring more than 2 years of practical experience. This decision was made because many companies like Unilever, McKinsey or BMW Group take on average two years or several internships as a cut-off level to differentiate graduates without practical experience from those with.

Table 1.2 outlines the characteristics of our sample by presenting the proportion to which each industry, firm size and job level is represented. 


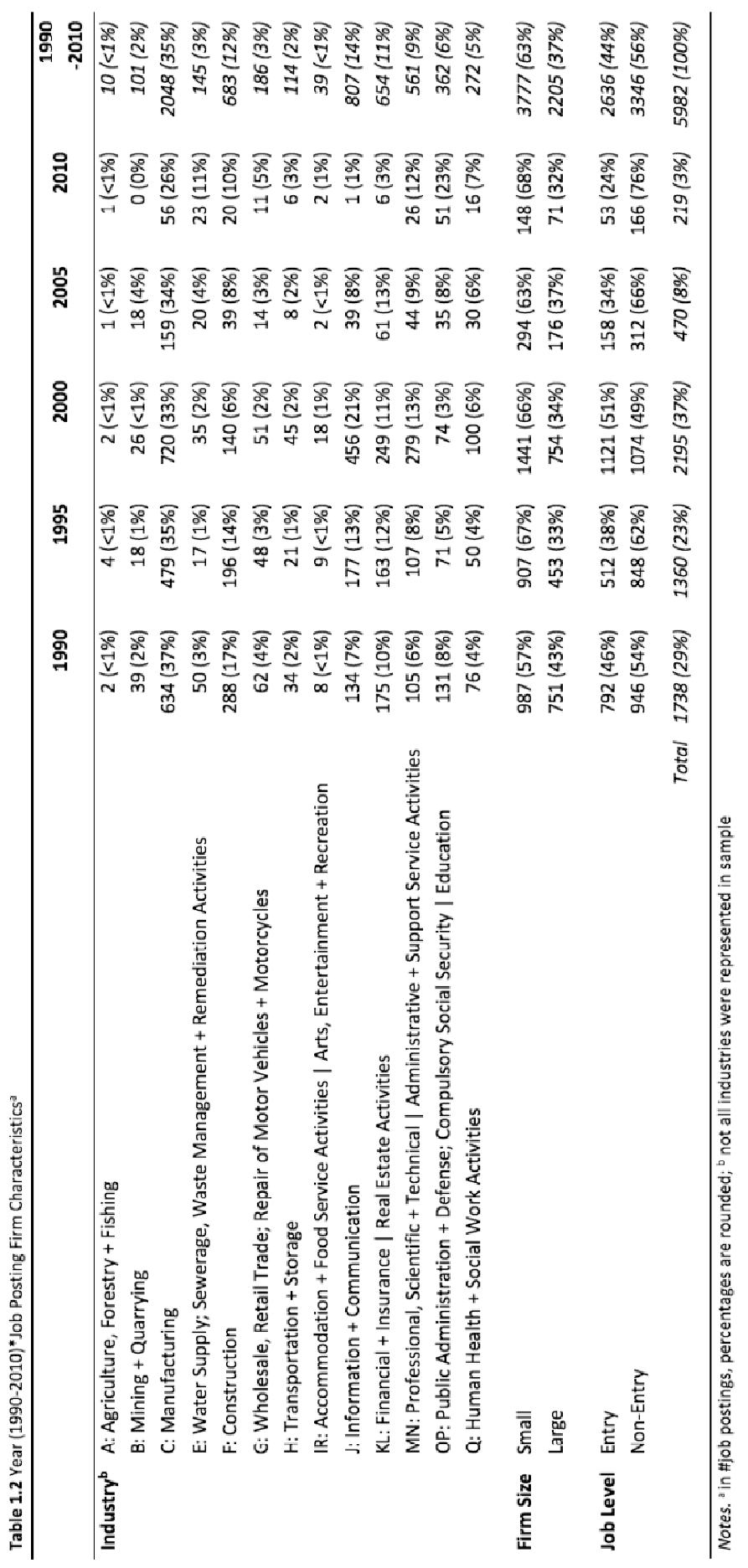


Manufacturing (industry $\mathrm{C}$ ) is predominantly represented, followed by information and communication (industry J), and construction (industry F) respectively. The proportion to which manufacturing and construction comprise the sample is rather stable over time while information and communication is not. This seems to reflect the fact that Germany has been and still is a location for engineering businesses (industries $\mathrm{C}$ and $\mathrm{F}$ together cover 47\%). SMEs are responsible for about 63 percent of all job postings in our sample. This proportion was also rather stable over time. Since about 65 percent of all employees in Germany work at SMEs (IfM, 2005; 2009), our sample seems to represent the German labor market fairly well also in this regard. Finally, only slightly more non-entry-level jobs are advertised in the FAZ than entry-level jobs throughout most years except 2000. Most employees of a society, however, work on non-entry-level jobs. This suggests that senior level positions are likely to be filled through other sourcing channels (Zottoli \& Wanous, 2000) such as search agencies, referrals or internal promotions. Consequently, we consider our sample to a large extent a reasonable reflection of all firms based in Germany and searching externally for employees, and thus as helpful in yielding valuable first insights on HR trends in Germany.

Operationalizations. A full list of measures of all our variables can be found in the coding scheme (see Appendix 1).

Value Attribution to Human Capital (H1). We assume that as the value attributed to human capital increases, the number of skills that companies ask from potential future employees do as well since companies' make more efforts to find the 'right' candidate and formulate more precise job postings (Dobbs et al., 2008). We thus suppose that the more value is attributed to human capital by hiring firms in a given year, the more skill requirements will be specified in the job postings analyzed. As a result, to test hypothesis 1 , we assessed the value attributed to human capital in a given year by retrieving the average number of skill requirements specified in all respective job postings. To this end, we count the requirements that are listed in each job posting manually to indicate the value that is attributed to human capital by a single firm and then take th average of all job postings of a given year. A priori, two broad categories of human capital types were discerned and labeled 'soft' and 'hard' skills (see coding scheme; Appendix 1). Both, the number of soft and hard skills that are mentioned in each job posting were individually counted but then summated to represent human capital.

Employee Sourcing Complexity (H2). Hiring through an intermediary will be used as an indicator for firms experiencing more complexity in sourcing employees. Search firm engagement is measured by counting the frequency with which a) the terms 'Personalvermittlung' and 'Headhunter' representing the involvement of a search agent occur in the WISO search per period and b) job searches in the same periods are mediated by an intermediary, with mediated cases being coded as 1 and non-mediated as 0 . Examples of terms that suggest the use of an (executive) search firm in a job posting are words or phrases such as "unser Klient" (our client) or "die von uns beauftragte Personalvermittlungsagentur" (the commissioned personnel consulting agency). We test the overall perceived 
employee sourcing complexity by a) counting the absolute number of publications that refer to one of the key terms specified in a given year and b) by taking the mediation/nonmediation ratio. The assumption is that the more a) often either term occurs in publications and b) cases are mediated, the higher the perceived employee sourcing complexity in a certain period.

Personnel Acquisition Practice Aggressiveness (H3). We consider competitor recruitment as an indicator for the degree of personnel acquisition practice aggressiveness since it has been described in the literature as an especially aggressive form of poaching. Competitor recruitment use is measured by counting the frequency a) of the terms 'Mitarbeiter Abwerben' (employee poaching) and 'War for Talent' in publications of the WISO database and b) with which companies address employees who have previously worked for or are currently employed at a competitor. Keywords like "Branchenkenntnis" (industry knowledge) or "Insider-Kenntnisse" (knowledge or insights about business secrets) in job postings are considered to point at CR cases. Cases are designated as CR if job postings clearly ask for related competences or experiences ("Branchenkenntisse unabdingbar" [essential]) or indicate preference for candidates with equivalent skills ("idealerweise [ideally] Branchenkenntnisse"). Cases that aim at CR are assigned a 1, the others a 0. We thus overall assume that the more a) often the terms outlined occur in WISO publications and b) job postings aim at competitor recruitment, the higher the aggressiveness of personnel acquisition practices in a given year.

\section{Data Analysis}

To test the hypotheses, we decided to conduct a) a keyword search as well as b) a qualitative content analysis (QCA) of job postings. As the analysis of the keyword search data is rather straightforward, we focus our description of the data analysis process on the job postings data.

Methodology. We analyze the job postings with the help of a qualitative content analysis, which is "a research technique for making replicable and valid inferences from texts [...] to the context of their use" (Krippendorff, 2004). ${ }^{27}$ QCA allows for the isolation of small text units and for displaying trends (Weber, 2010). This method is empirically grounded, exploratory in process and predictive in intent (Krippendorff, 2004). Thereby, this technique combines qualitative and quantitative traditions as predictive data can be extracted by exploration from qualitative texts such as newspapers, speeches or transcribed interviews (Palrecha, Spangler \& Yammarino, 2010; Weber, 1990).

We consider the use of QCA in this study appropriate for three reasons. First, the field that is investigated suffers from a clear lack of direct observational evidence about the value attributed to human capital, perceived labor market complexity or the degree of

\footnotetext{
${ }^{27}$ Other definitions have been used by e.g. Weber (1990) who defines content analysis as "a research method that uses a set of procedures to make valid inferences from text" or earlier by Holsti (1969) who defined it as "any technique for making inferences by objectively and systematically identifying specified characteristics of messages".
} 
aggressiveness of recruitment practices. In other words, these three phenomena can neither be counted nor measured directly and unequivocally. Rather, they refer to underlying perceptions or behaviors of HR professionals and thus require an indirect approach. Second, QCA can be used to analyze factual data in retrospect over a period and does thereby not rely on the recollections of people. Third, it "yields unobtrusive measures in which neither the sender nor the receiver of the message is aware that it is being analyzed" (Weber, 1990) resulting in limitedly biased data. As the main purpose of this research is to retrieve longitudinal, large-scale data from available and ideally unbiased texts, the use of QCA is considered suitable.

Coding Procedure. The data collected in a QCA can be processed, i.e. coded, in two different ways: manually or computer-aided (Palrecha et al., 2010; Weber, 1990). In this study, a manual content analysis was conducted for several reasons. First, the job postings were only available in printed (hard-copy) form. As a result, they could not easily be prepared for a computer-aided analysis process. Second, with this manual approach, distinct word combinations could be taken into consideration. Computers are not useful if words have different meanings in different contexts, i.e. differ in time and space (such as the word "undertaker", which referred to an entrepreneur in the past but to a funeral director today), or when idioms are used (e.g. "Sie wollen in den nächsten Gang schalten" [literally translated: you want to change into the next gear] implying that the search addresses candidates with major professional experience). Third, computer-aided techniques are not yet able to appreciate the context in which words appear (Conley \& Tosti-Kharas, 2010; McClelland, Liang \& Barker, 2009). For instance, the word "young professional" may appear in different contexts such as "we are looking for young professionals", "young professionals are also welcome" or "this job is not offered to young professionals". The word "young professional" would thus not be sufficient for a computer to decide on who is addressed. Thus, although we ran the risk of incurring counting errors through manual coding, the choice of a manual coding process with two coders seemed less risky and justifiable.

The first step of the coding process was to develop a coding scheme ${ }^{28}$ (see Appendix 1) that could be applied to all job postings. To this end, the author and a research assistant independently read a selection of job postings to generate a list of words, phrases or symbols (i.e. a dictionary) that could be used to test the hypotheses (Weber, 1990). The process was continued until we reached consensus on a set of keywords (McClelland et al., 2009). Despite the attempt to code text as objectively as possible, the data generated in a content analysis is always subjective to a certain extent (Jauch, Osborn \& Martin, 1980).

\footnotetext{
${ }^{28}$ A coding scheme for a content analysis typically includes a dictionary, which "consists of category names, the definitions or rules for assigning words to categories, and the actual assignment of specific words" (Weber, 1990). The use of a dictionary is part of a qualitative content analysis and can be constructed from existing literature or from an exploration of a small sample of text that is relevant for the analysis (McClelland et al., 2009; Palrecha et al., 2010; Todd, McKeen \& Gallupe, 1995). The latter was done for this study.
} 
Therefore, it was essential to develop an exhaustive coding scheme, which was valid, reliable and agreed-upon among the coders.

The job postings that were used to generate the dictionary were from other FAZ issues than the specified ones and did not appear in the final sample. The iterative pilot coding process led to all job vacancies being categorized along three variables, namely the (1) amount of (soft and hard skill) requirements, (2) mode of recruitment (mediated or unmediated) and (3) desired recruit origin (from a competitor or non-competitor). We then applied the coding scheme to another 140 job postings outside the sample independently with phases of comparison and discussion in between, and alterations to the coding scheme being made if necessary. Once the coding scheme was considered to capture all variables in an exhaustive and mutually exclusive manner, we started coding the 5982 job postings in total. The author was consulted regularly to discuss the coding procedure and in 337 cases in specific to assist the process. Thereby, we attempted to maximize inter-rater reliability (Weber, 1990).

Testing. As the assumptions of normality did not hold in our case as became evident after conducting a Kolmogorov-Smirnov Test, a Kruskal-Wallis One-Way Analysis of Variance Test was chosen to conduct the analysis. A Kruskal-Wallis Test is a non-parametric independent group comparison that allows for the comparison of more than two independent groups (years in our case). It is used when seeking to compare three or more sets of (ordinal) scores (our dependent variables) from different groups. In particular, the Kruskal-Wallis Test evaluates whether the population medians on a dependent variable (skills, mediation or competitor recruitment) are the same across all levels of a factor (year). As the Kruskal-Wallis Test applies ranks to the data rather than their raw values to calculate the statistics, it does not assume equality of variance in the data and is much less sensitive to outliers, which suits our sample. A $\chi 2$ distributed statistic (Kruskal-Wallis H) is used to evaluate differences in median ranks to assess the null hypothesis that the medians are equal across the groups (i.e. years). The $p$ value for the $\chi 2$ approximation test is quite accurate if the number of cases is greater than or equal to 30 , which is the case in this study.

Tamhane's Multiple Comparisons Test then serves to probe differences of medians between adjacent years. A Jonckheere-Terpstra Trend Test follows to test the hypothesis that these population medians change in an ordered sequence, in this case that the value attributed to human capital (hypothesis 1), employee sourcing complexity (hypothesis 2 ) and hiring aggressiveness (hypothesis 3) increases from 1990 until 2010. Z-scores (z) of MannWhitney tests are used to calculate the respective effect sizes $r$.

\section{Results}

Of the 6652 job postings that were part of the initial sample, 5982 (89.9\%) could be finally analyzed. 10 percent of all job postings could not be incorporated due to (1) non-readability (e.g. badly printed job posting or copy) or (2) incompleteness (e.g. referring to another [web] source with full information about the vacancy). If a job posting did not allow for the 
retrieval of information regarding each variable, it was coded as missing value and deleted from the sample.

Table 1.3 presents a crosstabulation of all variables included in this study. Overall, a frequency count reveals that since 1990 steadily more skills have been specified in job postings evolving from about 5 to 10 on average. Whereas hard skills only slightly increased, soft skills did severely from around 2 to over 5 per job posting. As a result, the total value attributed to human capital rose. This is in line with various research findings that suggest that firms ascribe more and more value to human capital (e.g. Barner, 2000; Castrogiovanni, 2002; Gardner, 2002; 2005; Streb et al., 2007). The percentage of mediated searches initially rose and then dropped to 21 percent in 2000 before increasing again to 36 percent in 2010. Equally, the relative number of CR cases plummeted until 2000 but increased again (tremendously) until 2010.

Table 1.3 Year (1990-2010)*Job Posting Characteristics

\begin{tabular}{|c|c|c|c|c|c|c|c|}
\hline & & 1990 & 1995 & 2000 & 2005 & 2010 & $\begin{array}{r}1990 \\
-2010 \\
\end{array}$ \\
\hline \multirow[t]{3}{*}{ Skills ( $\emptyset)$} & Total & 5.28 & 6.50 & 7,42 & 9.18 & 10.55 & 6.84 \\
\hline & Hard & 3.02 & 3.41 & 3.36 & 3.87 & 5.10 & 3.38 \\
\hline & Soft & 2.25 & 3.09 & 4.07 & 5.33 & 5.47 & 3.47 \\
\hline \multirow[t]{2}{*}{ Mediated Search ${ }^{\mathrm{ab}}$} & No & $\begin{array}{r}1237 \\
(71 \%)\end{array}$ & $\begin{array}{r}934 \\
(53 \%)\end{array}$ & $\begin{array}{r}1731 \\
(79 \%)\end{array}$ & $\begin{array}{r}353 \\
(75 \%)\end{array}$ & $\begin{array}{r}139 \\
(64 \%)\end{array}$ & $\begin{array}{r}4394 \\
(74 \%)\end{array}$ \\
\hline & Yes & $\begin{array}{r}501 \\
(29 \%)\end{array}$ & $\begin{array}{r}426 \\
(47 \%)\end{array}$ & $\begin{array}{r}464 \\
(21 \%)\end{array}$ & $\begin{array}{r}117 \\
(25 \%)\end{array}$ & $\begin{array}{r}80 \\
(36 \%)\end{array}$ & $\begin{array}{c}1588 \\
(26 \%)\end{array}$ \\
\hline \multirow[t]{2}{*}{ Competitor Recruitment $^{\mathrm{ab}}$} & No & $\begin{array}{r}1682 \\
(97 \%)\end{array}$ & $\begin{array}{r}1315 \\
(97 \%)\end{array}$ & $\begin{array}{r}2169 \\
(99 \%)\end{array}$ & $\begin{array}{r}453 \\
(96 \%)\end{array}$ & $\begin{array}{r}169 \\
(70 \%)\end{array}$ & $\begin{array}{r}5788 \\
(97 \%)\end{array}$ \\
\hline & Yes & $\begin{array}{r}56 \\
(3 \%)\end{array}$ & $\begin{array}{r}45 \\
(3 \%)\end{array}$ & $\begin{array}{r}26 \\
(1 \%)\end{array}$ & $\begin{array}{r}17 \\
(4 \%)\end{array}$ & $\begin{array}{r}50 \\
(30 \%)\end{array}$ & $\begin{array}{r}194 \\
(3 \%)\end{array}$ \\
\hline
\end{tabular}

Notes. ${ }^{\mathrm{a}}$ in total \#job postings; ${ }^{\mathrm{b}}$ percentages compare \#no/yes cases per year

Table 1.4 shows the means, standard deviations and correlations for all variables in this study. All variables correlate with each other significantly. Correlations are positive, except mediation with time, thus the proportion of mediated searches rather seems to decrease over time. 
Table 1.4 Variables, Means, Standard Deviations and Correlations ${ }^{\mathrm{ab}}$

\begin{tabular}{|c|c|c|c|c|c|c|c|}
\hline & M & SD & 1 & $1 \mathrm{a}$ & $1 b$ & 2 & 3 \\
\hline \multicolumn{8}{|l|}{ Dependent Variables } \\
\hline \multicolumn{8}{|l|}{ Value Attributed to Human Capital ( $\varnothing \#)$} \\
\hline 1. Total \#Skills & 6.84 & 3.75 & & & & & \\
\hline 1a. \#Hard Skills & 3.38 & 2.18 & $.65^{* * *}$ & & & & \\
\hline 1b. \#Soft Skills & 3.47 & 2.85 & $.81^{* * *}$ & $.09^{* * *}$ & & & \\
\hline \multicolumn{8}{|l|}{ Employee Sourcing Complexity } \\
\hline 2. Mediated Search $(\mathrm{No}=0 / \mathrm{Yes}=1)$ & .27 & .44 & $.10^{* * *}$ & $.11^{* * *}$ & $.05^{* * *}$ & & \\
\hline \multicolumn{8}{|c|}{ Personnel Acquisition Practice Aggressiveness } \\
\hline 3. $\mathrm{CR}(\mathrm{No}=0 / \mathrm{Yes}=1)$ & .03 & .18 & $.12^{* * *}$ & $.16^{* * *}$ & $.04^{* * *}$ & $.10^{* * *}$ & \\
\hline \multicolumn{8}{|l|}{ Independent Variable } \\
\hline 4. Year (1990-2010, 5-Year Intervals) & 2.34 & 1.09 & $.35^{* * *}$ & $.15^{* * *}$ & $.35^{* * *}$ & $-.04^{* * *}$ & $.08^{* * *}$ \\
\hline
\end{tabular}

Notes. ${ }^{a} \mathrm{n}=5982 ;{ }^{b}$ \#observations per year vary, dispersion thus skewed to the left, meaning that first years have more weight than later years; ${ }^{* * *}$ correlation is significant at the .01 level (2-tailed)

\section{Test of Hypotheses}

Analysis of FAZ Job Postings. We proposed that the value attributed to human capital (hypothesis 1), perceived employee sourcing complexity (hypothesis 2) and aggressiveness of personnel acquisition (hypothesis 3) increased between 1990 and 2010. A Kruskal-Wallis Test was conducted to evaluate differences among the five years included in the analysis $(1990,1995,2000,2005,2010)$ on change in a) mean total\# (hard or soft) skills specified, b) total\# mediated searches and c) total\# competitor recruitment cases.

The results of a Kruskal-Wallis indicated that there is a statistically significant difference in the medians for each dependent variable (skills, mediation and CR). Hence, at least two groups between the years (1990-2010) differ significantly from each other for each dependent variable. As one cannot conclude from the Kruskal-Wallis Test the exact years, which significantly differ from each other, follow-up tests need to be conducted to evaluate pairwise differences among the five years. The Tamhane Multiple Comparisons Test is used to specify which sampled groups differ at the .05 significance level. The Tamhane adjustment is a flexible post-hoc method that does not assume equal variances and ensures a familywise type II error rate no greater than $\alpha$ after all comparisons are made. We only report differences between adjacent years. The results of the test indicate mixed findings (see Table 1.5). 
Table 1.5 Tamhane's Multiple Comparisons Test for Equality between the Years

\begin{tabular}{|c|c|c|c|c|}
\hline & (I) year & (J) year & $(\mathrm{J}-\mathrm{I})$ & $r^{a 29}$ \\
\hline \multirow[t]{4}{*}{ Total \#Skills } & 1990 & 1995 & $1.22^{* * *}$ & -.19 \\
\hline & 1995 & 2000 & $.93^{* * *}$ & -.13 \\
\hline & 2000 & 2005 & $1.75^{* * *}$ & -.16 \\
\hline & 2005 & 2010 & $1.37^{* * *}$ & -.14 \\
\hline \multirow[t]{4}{*}{ \#Hard Skills } & 1990 & 1995 & $.39^{* * *}$ & -.09 \\
\hline & 1995 & 2000 & -.05 & -.02 \\
\hline & 2000 & 2005 & $.51^{* * *}$ & -.08 \\
\hline & 2005 & 2010 & $1.23^{* * *}$ & -.27 \\
\hline \multirow[t]{4}{*}{ \#Soft Skills } & 1990 & 1995 & $.83^{* * *}$ & -.17 \\
\hline & 1995 & 2000 & $.98^{* * *}$ & -.17 \\
\hline & 2000 & 2005 & $1.26^{* * *}$ & -.14 \\
\hline & 2005 & 2010 & .14 & -.00 \\
\hline \multirow[t]{4}{*}{ Mediated search } & 1990 & 1995 & .03 & -.03 \\
\hline & 1995 & 2000 & $-.10^{* * *}$ & -.11 \\
\hline & 2000 & 2005 & .04 & -.04 \\
\hline & 2005 & 2010 & $.12^{* * *}$ & -.12 \\
\hline \multirow[t]{4}{*}{ Competitor Recruitment } & 1990 & 1995 & .00 & -.00 \\
\hline & 1995 & 2000 & $-.02^{* * *}$ & -.07 \\
\hline & 2000 & 2005 & .02 & -.07 \\
\hline & 2005 & 2010 & $.19^{* * *}$ & -.30 \\
\hline
\end{tabular}

Notes. ${ }^{* * *}$ difference is significant at the .05 level; ${ }^{a}$ effect size $r$ calculated based on Mann-Whitney scores with $z / V(n 1+n 2)$, whereby 1 stands for one and 2 for the follow-up year (e.g. 1=1990 and $2=1995$ ); small effect size: $r=.10-.23$, medium: $r=.24-.36$, large: $r=.37$ or larger (Cohen, 1992)

The results suggest that there is a statistically significant difference between each year for total \#skills. When splitting up the sample into hard and soft skills, no significant difference exists between the years 1995 and 2000, and 2005 and 2010 respectively, however. The effect sizes that were calculated based on Mann-Whitney tests in four runs suggest that primarily small effects can be detected for human capital value, largely following from an increase in soft skills (see Table 1.5).

\footnotetext{
${ }^{29}$ We obtain only negative r's because all Mann-Whitney z-scores received (not given in the table) are negative following from the formula used to calculate the $z$-score (with $W=\mu$ ):

$$
\begin{aligned}
& z=\frac{X-\bar{X}}{s}=\frac{W_{\mathrm{s}}-\bar{W}_{\mathrm{s}}}{S E_{W_{\mathrm{s}}}} \\
& \bar{W}_{\mathrm{s}}=\frac{n_{1}\left(n_{1}+n_{2}+1\right)}{2} \quad[\text { highest rank] } \\
& {[=\text { lowest rank - highest rank } / \mathrm{sd}]}
\end{aligned}
$$

"[W]hen the groups have unequal numbers of participants in them then the test statistic $\left(W_{\mathrm{s}}\right)$ is simply the sum of ranks in the group that contains the fewer people" (Field, 2009). Since it is thus always the case that the lowest rank serves as the test statistic, the whole formula turns out to be negative. Now, considering the calculation of the $r$ as $z / V(n 1+n 2)$, the negative sign is explained. To interpret the findings however, the sign is ignored.
} 
The picture looks somewhat scattered for mediated search and competitor recruitment with every second adjacent year not displaying statistically significant differences and one association being negative in each case. Besides, the effects found are negligible with $r \leq .1$.

It is nevertheless worthwhile to look at the Jonckheere-Terpstra Trend Test additionally to explore whether a trend can be observed over time. Indeed a statistically significant trend is revealed with total [hard and soft] skills ( $z=26.24$ [9.67 and 26.23], $r=.34$ [.13 and .34]) and competitor recruitment ( $z=3.27, r=.04)$ increasing from 1990 until 2010, and mediated searches decreasing throughout this measurement period $(z=-3.92, r=-.05)$ (see Table 1.6). Effect sizes $r$ for total \#skills and \#soft skills are moderate, though small for \#hard skills, and again rather negligible for mediated search and competitor recruitment.

Table 1.6 Jonckheere-Terpstra Trend Test $(\mathrm{J}-\mathrm{T})^{30}$

\begin{tabular}{|c|c|c|c|c|c|}
\hline Year $^{a}$ & Total \#Skills & \#Hard Skills & \#Soft Skills & Mediated & $\begin{array}{l}\text { Competitor } \\
\text { Recruitment }\end{array}$ \\
\hline Std. J-T' Statistic & $26.24^{* * *}$ & $9.67^{* * *}$ & $26.23^{* * *}$ & $-3.92^{* * *}$ & $3.27^{* * *}$ \\
\hline$r^{c}$ & .34 & .13 & .34 & -.05 & .04 \\
\hline \multicolumn{6}{|c|}{$\begin{array}{l}\text { Notes. }{ }^{* * *} \text { statistics are significant at the } .01 \text { level (2-tailed); }{ }^{\text {a }} \text { grouping variable: year } 1990-2010 ;{ }^{b} \mathrm{Z}^{-} \\
\text {scores can be compared to values of a normal distribution with } 1.65 \text { for a significance value of } .05 . \text { A } \\
\text { positive value indicates a positive trend, a negative value a negative trend; }{ }^{c} \text { effect size } r \text { calculated } \\
\text { based on J-T } z \text {-scores with } \mathrm{z} / \mathrm{V}(5982) ; \text { small effect size: } r=.10-.23 \text {, medium: } r=.24-.36 \text {, large: } r=.37 \text { or } \\
\text { larger (Cohen, 1992) }\end{array}$} \\
\hline
\end{tabular}

A visualization of the findings can be found below. Though the Kruskal-Wallis as well as the Jonckheere-Terpstra Trend Test suggests that the years significantly correlate and display a certain trend, the Tamhane Multiple Comparisons Test only partly revealed significant findings for adjacent years, which explains the low effect size overall. In the following graphs, we marked only those adjacent years that were found to display a significant difference.

Graph 1.2 shows a clear significant trend of increasing average numbers of skills specified in job postings. This counts equally for hard and soft skills, though less linearly. Graphs 1.3 and 1.4 illustrate a somewhat less clear and less steady though positive trend for the use of mediated searches and competitor recruitment respectively. A likely reason why we received a negative $z$-score $(=-3.92)$ for mediated search nevertheless (see Table 1.6 ) might be due to the highly decreasing number of job postings overall from 2005 to 2010 implying that earlier years have more weigh in the trend analysis than later years.

\footnotetext{
30 When conducting the analysis between the years 1990 and 2005 only instead of until 2010 (considering that sample size and selectivity in 2010 might be a concern), the results are the same, except that for competitor recruitment a negative trend is found at a .01 significance level also.
} 
Graph 1.2 Skills per Year (

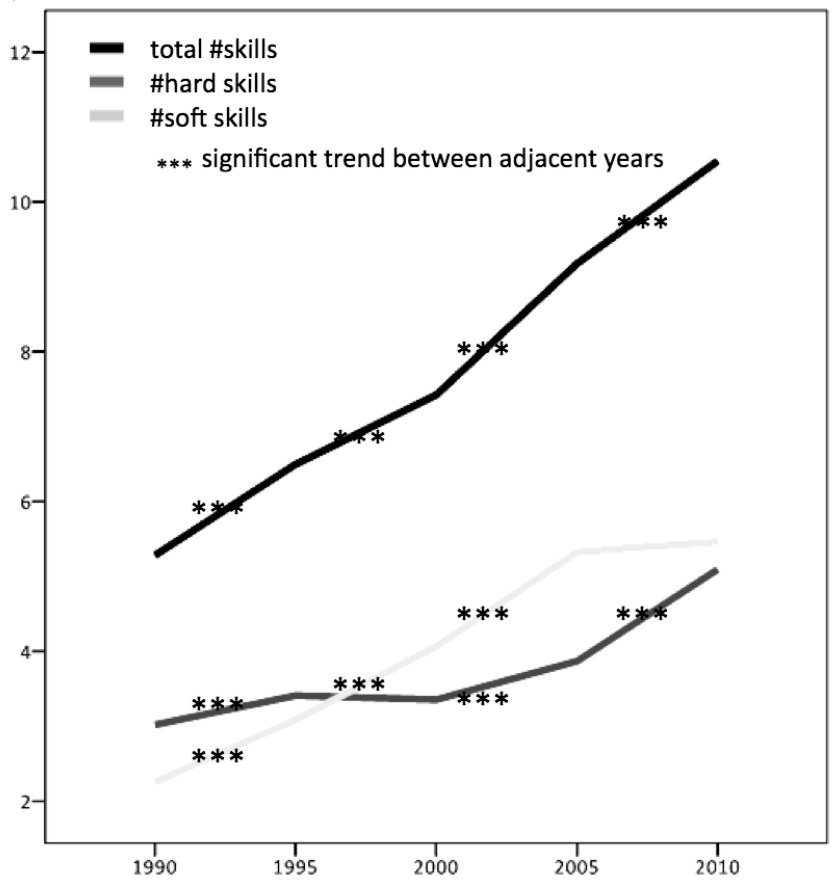

Graph 1.3 Mediated Searches per Year (\%)

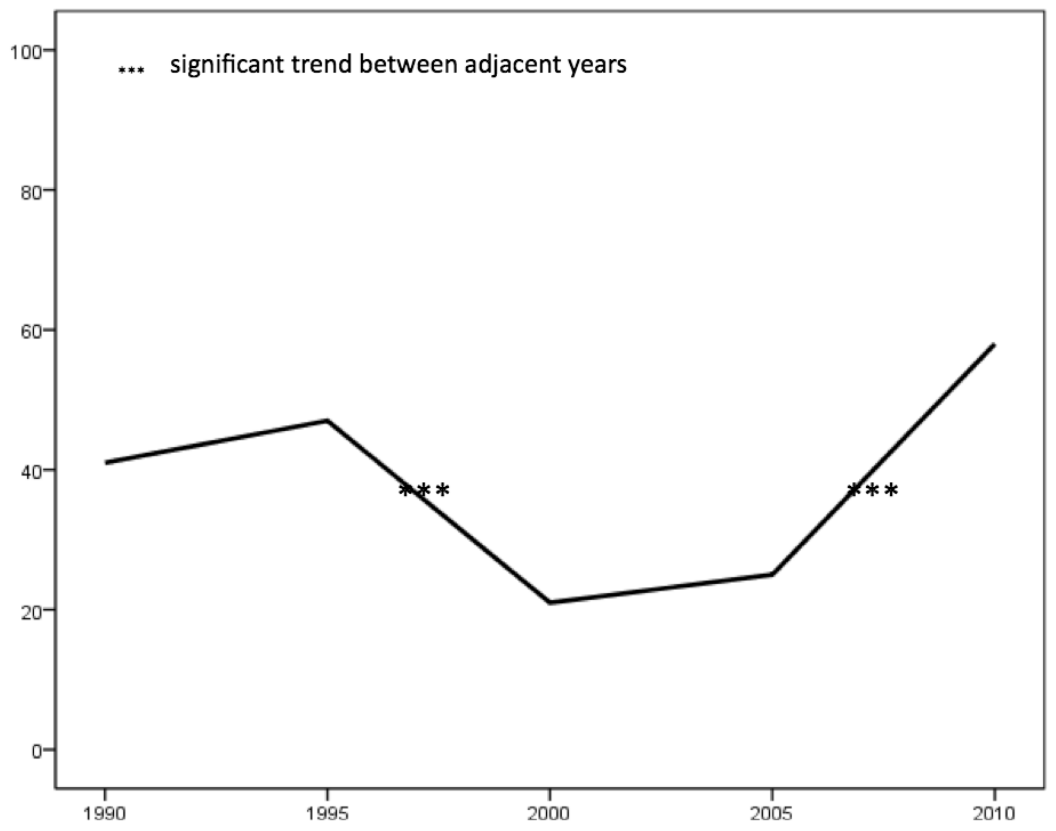


Graph 1.4 Competitor Recruitment Cases per Year (\%)

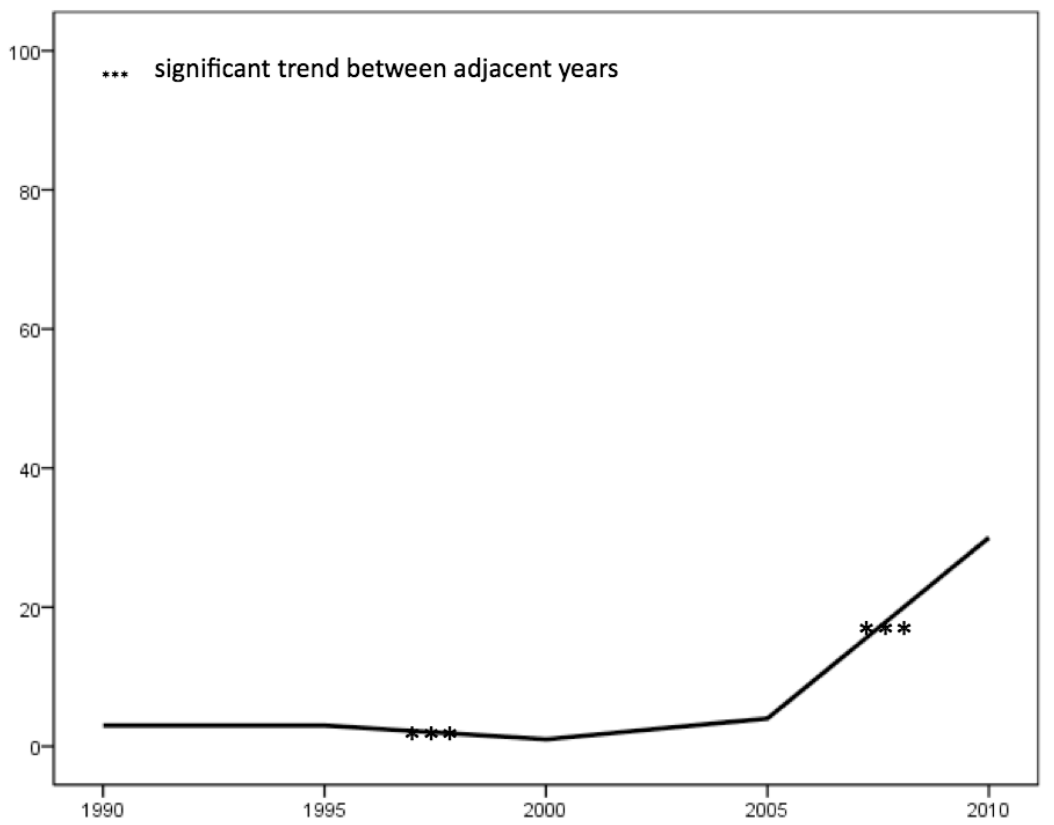

Analysis of WISO Database Publications. The keyword search in the WISO database investigating the increase of mediated search efforts also led to insightful results. The use of the keywords 'Headhunter' and 'Personalvermittlung' (executive search) has steadily increased since 1990 (see Graph 1.5a). The frequency of the term 'Headhunter' is particularly salient. Whereas in 1990 it has been used 16 times in newspaper articles, the number has risen to 830 in 2010 . These findings suggest that personnel acquisition practices indeed have become more aggressive over time.

Graph 1.5a \#Publications per Year and Keyword

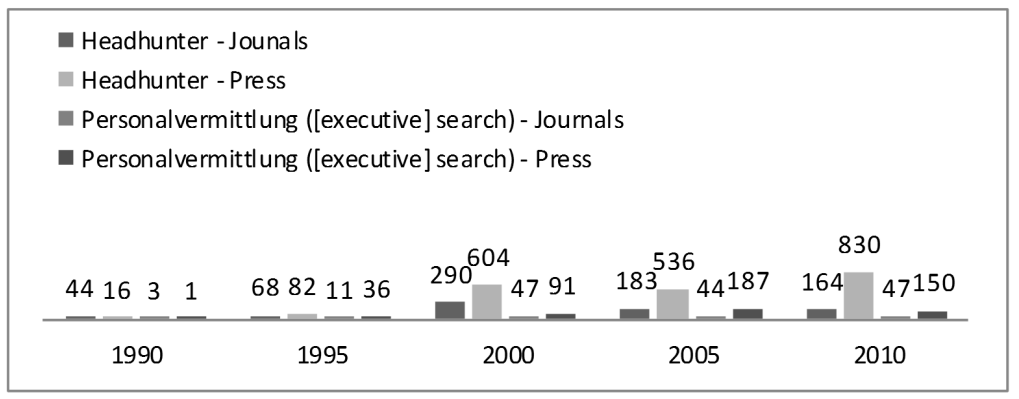

In contrast, the term 'War for Talent' could not be found in any German newspaper or specialist journal in the 1990s yet (see Graph 1.5b). Since 2000, the term has 
been used several times but overall not very often. In contrast, 'Mitarbeiter Abwerben' (employee poaching) became much more relevant in the German press over the years. Especially in 2000, poaching employees was a relevant topic with 175 hits in total. Nevertheless, a steady trend does not display. Overall, each term received major attention around $\mathbf{2 0 0 0}$ potentially correlating with the increased gain in legitimacy of executive search firms, but since then seems to have lost in importance. This keyword search does hence not indicate an increase in personnel acquisition practice aggressiveness.

Graph 1.5b \#Publications per Year and Kevword

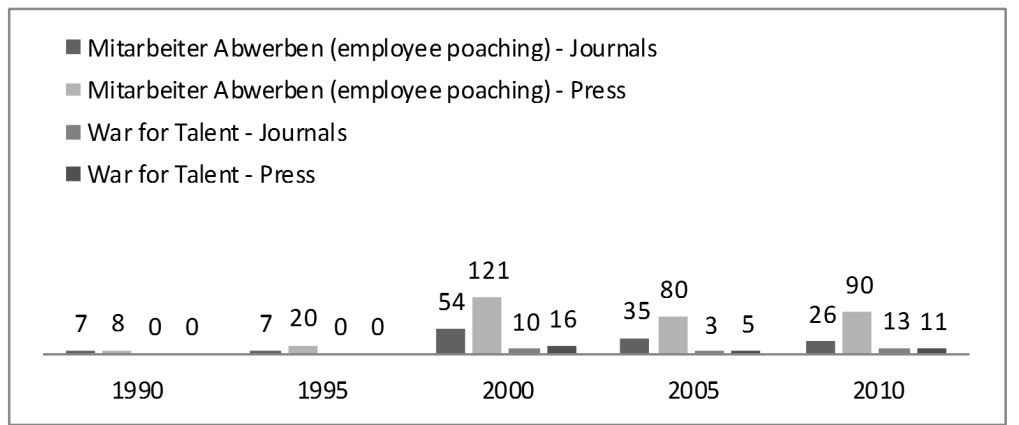

Overall, the results of the QCA support hypothesis 1 . Companies seem to recognize increasingly the value of hiring the right employees and of fully exploiting the variety of skills that they carry by more and more specifying applicants' ideal human capital profiles. Soft skills appear to play a predominant role in this regard.

Concerning hypothesis 2, the QCA and the keyword search show a similar overall trend though slightly differ in the extent, which they suggest. While the press releases with the term 'Personalvermittlung' steadily rose, the number of mediated cases as well as publications with the term 'Headhunter' slightly fluctuated. The number of mediated searches even reached a dip in 2000 although in this year, publications on each term peaked. A possible explanation is that the real trends do not fully display in print job postings as jobs are mediated more and more through online media or direct search (Murmann, 2009). What this nevertheless shows is an increasing recognition of the relevance of search agency involvement, especially in the past 5 years.

In contrast to what we suggested in hypothesis 3 , the relative total number of $\mathrm{CR}$ cases severely increased since 2005 only though this statement needs to be made with care considering the large decrease in job postings analyzed in the given year. The WISO search proposes that personnel acquisition practices became already more aggressive since 2000. A possible explanation is that publications report on certain - potentially upcoming - trends thereby triggering their occurrence. In any case, these results suggest that personnel acquisition practices are becoming more aggressive recently, possibly due to a rising awareness of intensifying labor shortages. 


\section{Post-Hoc Analysis}

The effects found in this study might generally be moderated by contextual factors such as the size of the hiring firm or the level of the vacancy to be filled. A post-hoc analysis in the form of a selective crosstabulation supports these assumptions (see Table 1.7).

For instance, companies within manufacturing ask for lesser soft skills than companies within the communication and information industry. Non-entry-level jobs require more skills than entry-level jobs, and SMEs are less demanding than larger companies. Likewise, it seems that SMEs are more likely to involve personnel search agencies, and that non-entry-level jobs tend to be filled through intermediaries more often than entry-level jobs, and within manufacturing more than within the communication and information industry, for example. A similar pattern is revealed for competitor recruitment activities. Thus, as intermediated searches and competitor recruitment are by far most popular in the manufacturing industry, findings might imply that talent scarcities do not affect every sector or job type equally.

Moreover, firms different in size might not (perceive to) be affected by labor scarcities equally. Larger companies might be more concerned with a globalizing business context leading to more complexity to be managed. In addition, as they, in absolute terms, are in need of more employees, they might benefit from economies of scale when engaging a search agency in recruitment processes. Besides, executive search firms favor to work for large companies as job changes to larger organizations hold more promotion opportunities and higher salaries for potential candidates and thus commissions (Hamori, 2010). On the other hand, larger firms have their own personnel departments and experts, as well as a major market presence, and might hence be less dependent upon search agencies in finding and attracting a suitable candidate (Cable \& Turban, 2003), while small or medium-sized firms are generally limited by their reputational resources (Barney, 1986; Barney, Wright \& Ketchen, 2001). Equally, the level of experience required of a vacancy might determine the need for a search agency engagement (Hamori, 2010). Simply put, the lower the job level and the more general the knowledge or skills required to do the job well, the easier it is to find a matching candidate since the less restricted the respective labor market is.

These additional insights underline the relevance of certain contextual factors such as firm size, existing firm resources, industry, business context or job position, or others not mentioned here such as age or career stage for research in the field of recruitment. Some of those factors will be further addressed in following chapters. 


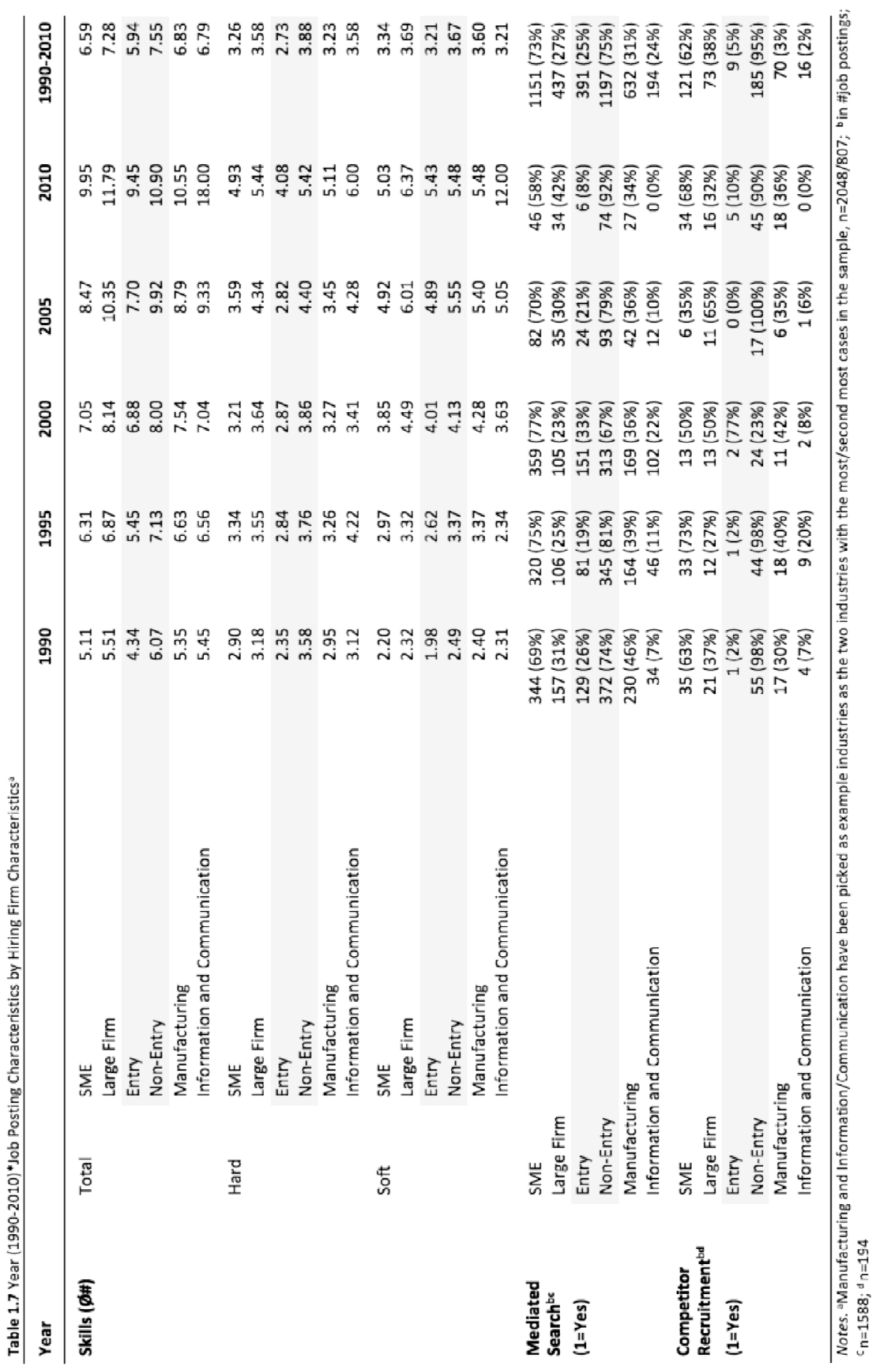




\section{Discussion}

Due to demographic changes, qualified employees become scarcer in many developed countries. These changes have severe influences on the German labor market. A qualitative content analysis of job postings of one of the major German newspapers (FAZ) as well as a keyword search of a large German publication database (WISO) has been conducted to explore whether the value attributed to human capital, the perceived complexity of employee sourcing and the aggressiveness of personnel acquisition practices indeed increased between 1990 and 2010.

The results of this study partly corroborate the assumptions made. The rising recognition of specific human capital requirements unambiguously reflects in the job postings as well as in the WISO database. Since 1990, the average total number of skills required by companies nearly doubled. This shows a growing awareness of companies for the need to specify clearly different requirements of a vacancy and to invest in employee search and attraction. In contrast, the overall increase of mediated search assignments and competitor recruitment throughout the years was found to be only small to marginal and did not substantially increase until 2005, but only after. Though results from our WISO search indicate major attention to these issues since 2000. Generally, the trends discovered thus show up primarily in recent years.

The fact that our findings from the QCA and the keyword search are slightly inconsistent raises questions that might be clarified by considering the following two contextual circumstances. First, the economy was growing in 2000 suggesting that highly qualified employees were either satisfyingly employed or could find alternative employment opportunities by themselves. Cutbacks that were made during the upcoming years of recession might have resulted in employee dissatisfaction, higher unemployment rates and fewer vacancies, leading to a) an increased willingness to switch employers and b) a need of employers to involve search agencies to identify 'hidden' candidates (Mattioli, 2010). Second, poaching employees (from rivals) was long perceived as being unethical (Nash, 1989) and even referred to as "stealing employees" (Gardner et al., 2010; Sullivan, 2008). Companies might have, thus, reacted to the ongoing controversial public discussion on aggressive recruitment and search agency involvement, and refrained from related practices in an attempt not to be associated with this topic. The change in general opinion on these issues due to an increase in boundaryless careers and the intensifying need for aggressive staffing might potentially explain the rise in mediated recruitment and competitor recruitment from 2005 to 2010.

\section{Limitations and Future Research}

Though displaying very interesting findings on labor market trends based on a large longitudinal sample, this study is also subject to several limitations.

As mentioned, we only took into account printed job postings from the FAZ, i.e. online job postings or other newspapers were not considered. The rise of the Internet as a source to reach employees, however, has changed the way of recruiting employees. Most 
search firms nowadays use online job portals ${ }^{31}$ to advertise their job postings next to using newspapers or addressing candidates directly (Murmann, 2009). At the same time, we do believe that the direction of the effects discovered reflects the societal developments and zeitgeist, also since our sample represents the German company population fairly well in terms of industry, firm size and level of job advertised. Nevertheless, we strongly recommend future research to add not only online job postings but also executive search assignments and other competing newspaper postings such as those of the Süddeutsche Allgemeine Zeitung to the analysis to obtain representative findings and to control for the variance in search tool preference. Those studies should then take into consideration that the number of requirements specified and other characteristics of a job posting can, of course, correlate with the overall length of a job posting, economic circumstances, or with the company that posts it. One could control for these issues by looking at the ratio of skills specified and the number of words of the ad, GDP, unemployment rates, prices per ad space (which might fluctuate over time due to rising competition from online databases and search agencies), or publisher of the ad (some firms might structurally be more specific or elaborate in their vacancy description than others).

Besides, the year 2010 might be a concern in terms of sample size and selectivity (see footnote 30). It makes us wonder why the number of job postings aiming at CR has so tremendously increased from 2005 to 2010. Is it that CR disproportionately involves newspaper advertisement? So, do the characteristics of online ads and the target groups aimed at actually differ from print ads in contrast to what has been claimed by the FAZ, and are maybe specialists and executives more likely to be addressed through print than through online media? In other words, do maybe source and search strategy interact? Or has CR indeed gained in prevalence, but occurs more through other channels such as personal contacts and executive search firms, which do not use job postings as a recruitment source? These remaining doubts question the choice of analyzing job offerings in newspapers. Our data does not allow us to draw any specific conclusions on this matter.

A deeper look at how certain firm-specific factors might influence the trends discovered might be worthwhile. The value attributed to human capital, perceived employee sourcing complexity or personnel acquisition aggressiveness might not be equal for all. Put differently, "the recruitment of new employees for critical positions at the company [becomes generally] more difficult", but for some companies more than for others (Strack et al., 2008). An example is Germany's engineering industry, which faces a pressing lack of qualified engineering graduates while having too many unskilled workers (Strack et al., 2008). In Germany, the gap between the supply and demand of engineers has been extremely severe for years. In 2002 already, 6,500 engineering graduates had to fill 13,000 open positions (Wucherer, 2005). In 2009, there was a lack of engineers of nearly 34,200.

\footnotetext{
${ }^{31}$ The biggest German online job portals Monster and StepStone launched their homepages at the turn of the millennium (Monster, 2011; StepStone, 2011). StepStone, for instance, offers 50,000 job postings on average while it focuses on highly skilled employees and managers (StepStone, 2011).
} 
For the German economy, this has caused a loss in economic value added of about $€ 3.4$ billion (Koppel, 2010). As a result, one could argue that the search for employees in highly technical industries in Germany is more complex and aggressive than in others ${ }^{32}$. The opposite might apply to the labor market for lawyers where the supply severely exceeds the demand (Gostomzyk, 2006). In addition, some industries are more dynamic than others, and firms in less dynamic industries might be willing to use more aggressive personnel acquisition practices to secure a competitive advantage over time ${ }^{33}$. In addition, certain institutional factors might be more common in some industries or for some positions than for others. As the Introduction has shown, gentlemen's agreements for instance exist at some firms and are common in certain industries or regions (see Schalksmühle), but not in all (see the Apple/Palm case).

A decade's zeitgeist, partly following from legal regulations (Rosen \& Mericle, 1979; Schwab, 1982) might especially influence public discourse. For example, the decision made by the regional court Landesgericht Mannheim that poaching employees by calling them at their working place is allowed in principle (see ${ }^{3}$ ) might have resulted in an increase in or at least further public presence of mediated search firms. Additionally, the current zeitgeist might have influenced the focus on certain words - and thus their inclusion in the coding scheme as well as the method chosen. The term 'headhunter' for instance might not have been a representative term for mediated search in 1990 as much as it was in 2010, when the study was conducted.

\section{Conclusion}

This study suggests the need for further research in the field of aggressive recruitment practices such as lateral hiring (from rivals). Though not found to be on the rise continuously, poaching efforts clearly seem to be growing recently. Whether this is demand or supply-driven, i.e. fostered by companies to boost their human capital pool and their competitive (human capital) position or due to (feared) labor shortages, still needs to be explored. Our results, however, suggest that CR would be used even without prevailing labor scarcities as the zeitgeist has changed over the last 20 years and the value attributed to human capital has clearly increased.

\footnotetext{
${ }^{32}$ We considered industries in the field of (electrical) engineering, construction, mining, automotive, production, shipping or chemicals highly technical ( $n=3356$; non-technical $n=2407)$. Correlations with our operationalization of aggressiveness (competitor recruitment) were insignificant at the .05 level. Mediation as our proxy for employee sourcing complexity was, however, positively and significantly correlated with technical releance in an industry at the .00 level with Pearson's $r=.14$. Thus, companies in technical industries seem to make more use of intermediaries than companies of non-technical industries.

${ }^{33}$ We considered industries in the field professional services, media and marketing or communications as dynamic ( $n=1355$; non-technical $n=4408)$. Correlations with our operationalization of aggressiveness (competitor recruitment) were, however, insignificant at the .05 level. In contrast, mediation as our proxy for employee sourcing complexity was surprisingly negatively and significantly correlated with dynamism at the .00 level with Pearson's $r=-.11$. Thus, companies in dynamic industries seem to make less use of intermediaries than companies of non-dynamic industries.
} 



\section{2}

The Theoretical Case for $\mathrm{CR}^{34,35}$

This chapter presents a theoretical approach to the phenomenon of competitor recruitment. We argue that the final value gained from an employee hired through CR is determined by the expected recruit's human capital benefit at firm entry and complementarities created once internalized, minus any hidden and explicit costs of acquiring and deploying the employee.

Next to reviewing the existing literature in the field, we identify conditions that determine the final value to be captured by a hiring firm using resource-based, strategic factor market and property rights theory. This comprehensive theoretical analysis serves as the basis for a conceptual model illustrating how human capital value can be captured through CR.

\footnotetext{
${ }^{34}$ This chapter is based on:

Horn, S., W. van Olffen \& Heijltjes, M.G (2010). Competitor Recruitment: A Theoretical Analysis of an Emerging HR Practice Seeking to Capture Human Capital Value. Academy of Management Annual Meeting (OMT Division).

${ }^{35}$ I thank Prof.dr. Gerard Pfann, Dr. Marc van Wegberg, Dr. Boris Blumberg and three anonymous reviewers for valuable feedback on previous versions of this chapter.
} 
Despite the rise in value attributed to human capital as outlined in the previous chapter and the assumption that the right mode of staffing can be a strategic tool to achieve a competitive advantage (Gardner, 2002, 2005; Rynes, Brown \& Colbert, 2002), focused research into the matter is lacking to date. This chapter therefore aims at (1) showing that it theoretically makes sense to study competitor recruitment and (2) outlining the core conditions that determine the extent to which a hiring firm can capture strategic value from competitor recruitment. To this end, we ask how and when firms can obtain a competitive human capital advantage in specific product markets through the acquisition of one or more employees from a rival firm. This leads to a theoretical framework of competitor recruitment from which we derive an agenda for further research.

We begin with a short review of the concept of competitor recruitment, followed by a theoretical discussion on why competitor recruitment occurs at all and under which conditions potential human capital value can be expected. Having specified the phenomenon theoretically, we forward a conceptual model that provides an overview of the factors that determine the likely profitability of competitor recruitment. A discussion of the model as well as of possible managerial and research implications rounds off this chapter.

\section{Competitor Recruitment: A Review}

Researchers primarily from the field of strategic management increasingly acknowledge the importance of understanding how firms compete for the most productive human capital (Gardner, 2002; 2005; Lepak \& Snell, 1999; Sturman et al., 2008). External staffing practices such as competitor recruitment are one way to do so (Somaya et al., 2008). Nevertheless, competitor recruitment attracted only limited academic interest in the past decades. Labor economists undertook some first steps by investigating the effect of labor 'poaching' on employee productivity and efficiency (e.g. Lazear, 1983), but it took many more years before the notion of poaching gained recognition among practitioners (e.g. Sullivan, 2008). Only recently, organization and strategy researchers have started to pay attention to this issue mostly by looking at performance implications of labor mobility between rivals (e.g. Gardner, 2005; Rao \& Drazin, 2002; Song, Almeida, \& Wu, 2003; Sturman et al., 2008; Wezel et al., 2006). They reason that a major part of an organization's knowledge is embedded in individuals, and that, once these individuals move to another firm, this knowledge presumably transfers along (Argote $\&$ Ingram, 2000). Although the competitive value of employees is emphasized in resource-based approaches (Barney, 1991) and in popular media, strategy scholars have devoted few research efforts to competitive implications of the loss of key employees to competitors, let alone the active initiation of such transfers between competing companies. Core research that addressed antecedents and/or implications of labor mobility between rivals is reviewed below.

Rule and Irwin (1988) were the first to show that recruiting employees from rivals is one of the best ways to promote product innovation. Boeker (1997) initially demonstrated that transferred managers who had had prior exposure to certain product strategies were more likely to enter related product markets in their new firm as well. These effects were 
stronger when the managers came from R\&D or engineering functions, when they had had close communication channels with the chief executive in the former firm and when they had accumulated a reasonable amount of industry experience. In other words, recruiting an executive from a direct competitor was shown to facilitate the hiring firm's entry into the rival's product markets.

Rao and Drazin (2002) suggested that the recruitment of managers may be an important method by which new and poorly connected firms reduce resource constraints on innovation. Recruiting talent from competitors would after all serve to get access to resources and routines not available in-house. To this end, new firms recruit veterans familiar with certain routines while poorly connected firms hire recruits from larger organizations who bring in social capital. Thereby, competitor recruitment may serve to fill internal resource and/or capability gaps.

In order to trace interfirm knowledge flows, Song, Almeida and Wu (2003) looked at patent data and citations in the global semiconductor industry. They concluded that employee mobility could serve as a mechanism for the acquisition of externally developed knowledge, especially if the expertise carried by the recruit is distant from that of the hiring firm and breaches into a different domain within the industry. Firms can thus "learn-byhiring".

Similarly, Rosenkopf and Almeida (2003) found that mobility leads to interfirm knowledge flows regardless of geographic distance of the rival firms. They demonstrated that the benefits of mobility positively correlate with technological distance. Attracting an employee from either a geographically close or a distant rival might thus be especially beneficial if he or she carries knowledge other than that existing in the hiring firm.

Wezel, Cattani and Pennings (2006) discussed competitive implications of interfirm mobility and were particularly interested in the consequences of inter-rival moves on the replication of routines in the hiring firm's context. They assumed that human capital such as social ties or competences is usually attached to individual employees and therefore more likely to be copied once employees that carry it move to another firm. On the other hand, they suggest that this might lead to increased similarity and thus competitiveness between the rivals concerned. Accordingly, mobility between rivals is not necessarily desirable if seeking to reduce overall costs by limiting market competitiveness.

Somaya, Williamson and Lorinkova (2008) explored in how far labor mobility between competitors and/or potential cooperators such as clients differs with regard to social capital gained or lost. Their results demonstrate that external social ties that transfer to the hiring firm can have significant effects on firm performance, whereby it seems to matter where recruits are hired from, i.e. whether from a competitor or a cooperator. They conclude that hiring from competitors can lead to the acquisition of external social ties and, hence, be beneficial because valuable human capital is acquired and the rival firm is weakened at the same time.

In contrast to various positive conclusions concerning labor mobility between competitors, some researchers have claimed that labor mobility, even if it is highly qualified 
employees that transfer, does not necessarily lead to performance enhancements or additional human capital gained. Gardner (2005), for instance, tested a model of interfirm competition for human resources. He suggested that hiring firms decide on whether to recruit from a rival depending on whether the target firm would defend itself and/or even retaliate against this action. After all, recruiting from rivals can have severe negative consequences in terms of competitive dynamics in an industry, as Wezel et al. (2006) already suggested.

Groysberg, Lee and Nanda (2008) found out that star security analysts who switched employers experienced an immediate decline in performance. This was especially the case for those who transferred as individuals, not as a team, and to firms with lesser capabilities. Those moving between firms with similar capabilities also experienced a decline, which however only persisted for two instead of five years. Only those analysts that switched as a team to firms with better capabilities did not experience any significant drop in performance. This shows that the receiving social context is important. Groysberg, Lee and Nanda (2008) concluded from their results that firm-specific skills and hiring firms' capabilities matter and that hiring a top performer, even if coming from a competitor, is not necessarily a blessing.

Similarly, Aime, Johnson, Ridge and Hill (2010) recently clarified, taking the perspective of the rival organization, that when an organization with an advantageous set of routines loses a key employee to a competitor, the rival organization's competitive position is weakened vis-à-vis the hiring firm, but that the hiring firm still does not necessarily gain an advantage. Eventually, a hiring firm may gain competitive strength against the competing firm due to gained familiarity with existing routines. Additional organizations learn to cope with the rival's routine too though due to increased exposure following from the diffusion of the practices in the competitive landscape through employee mobility. They hence conclude that internal routines are robust to the loss of key employees whereas the advantages derived from those routines that are potentially carried to a rival are not, as competitors might implement those previously superior routines as well.

Table 2.1 provides an overview of the nine major studies just addressed that empirically investigate employee transfers between competing firms. Most of the studies that we reviewed focus on the implications of key employee mobility for hiring organizations and suggest that competitor recruits add value to a hiring firm when they provide access to (1) the means to enter new product markets, (2) internally non-existing knowledge or (3) social capital. However, this value may only be realized when the transfer does not lead to intensified competition between rivals and when internal circumstances allow the recruit to be productively employed. 


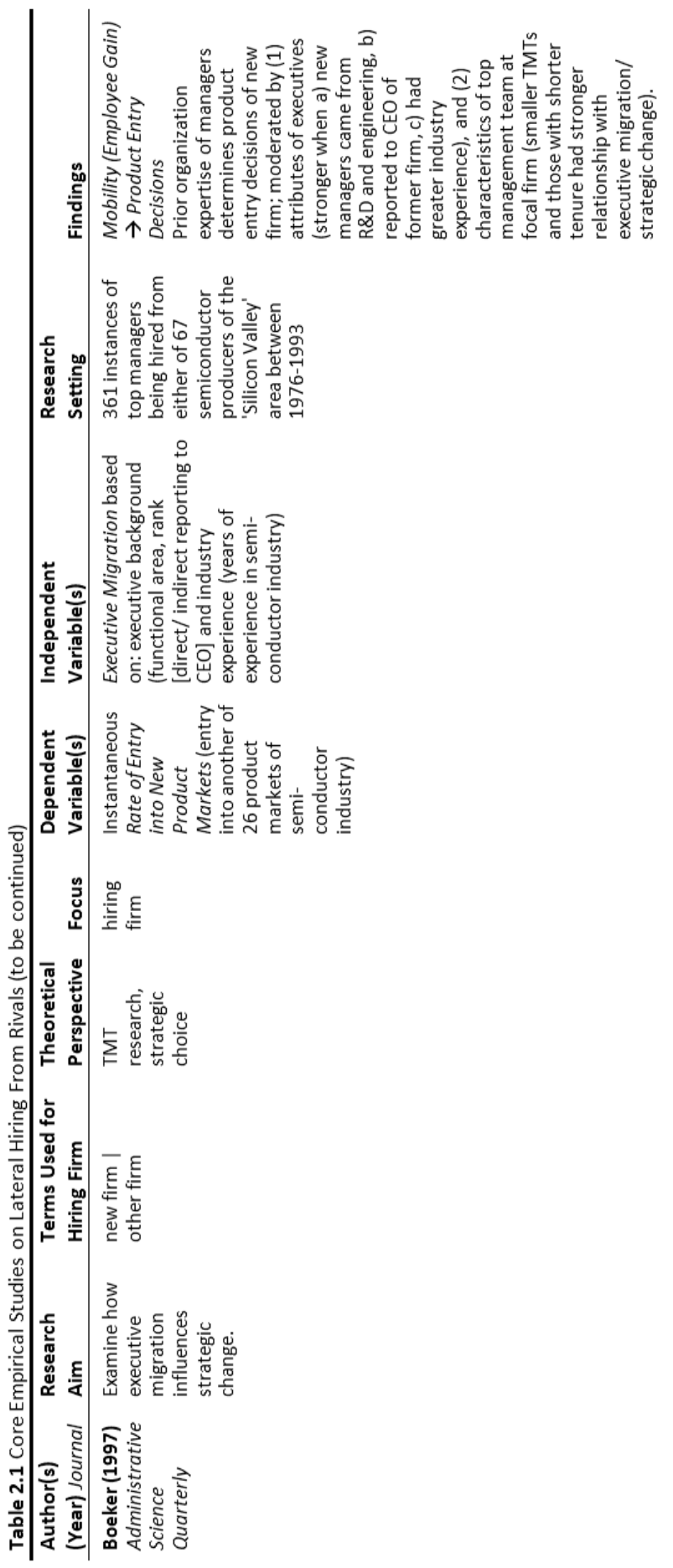




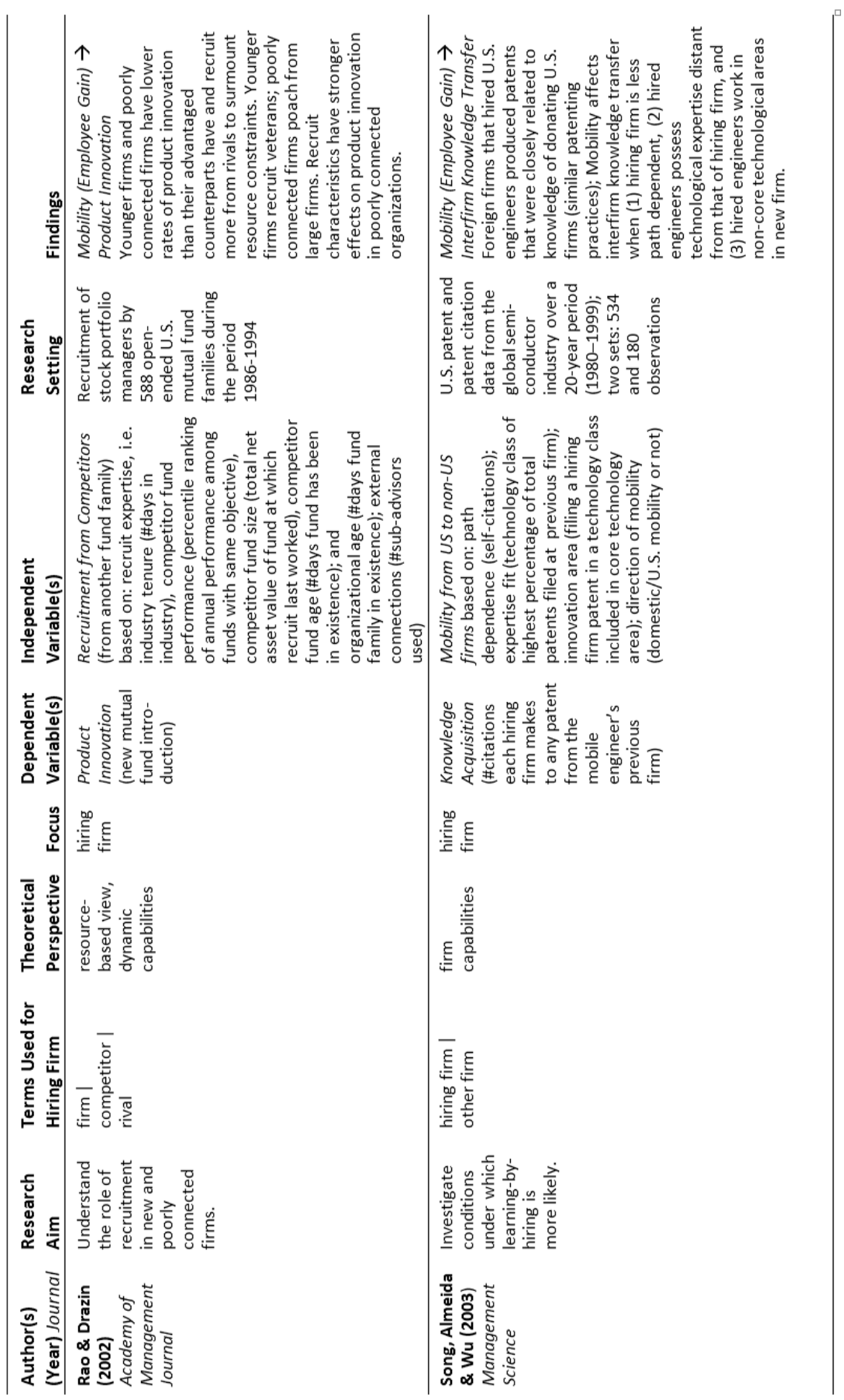




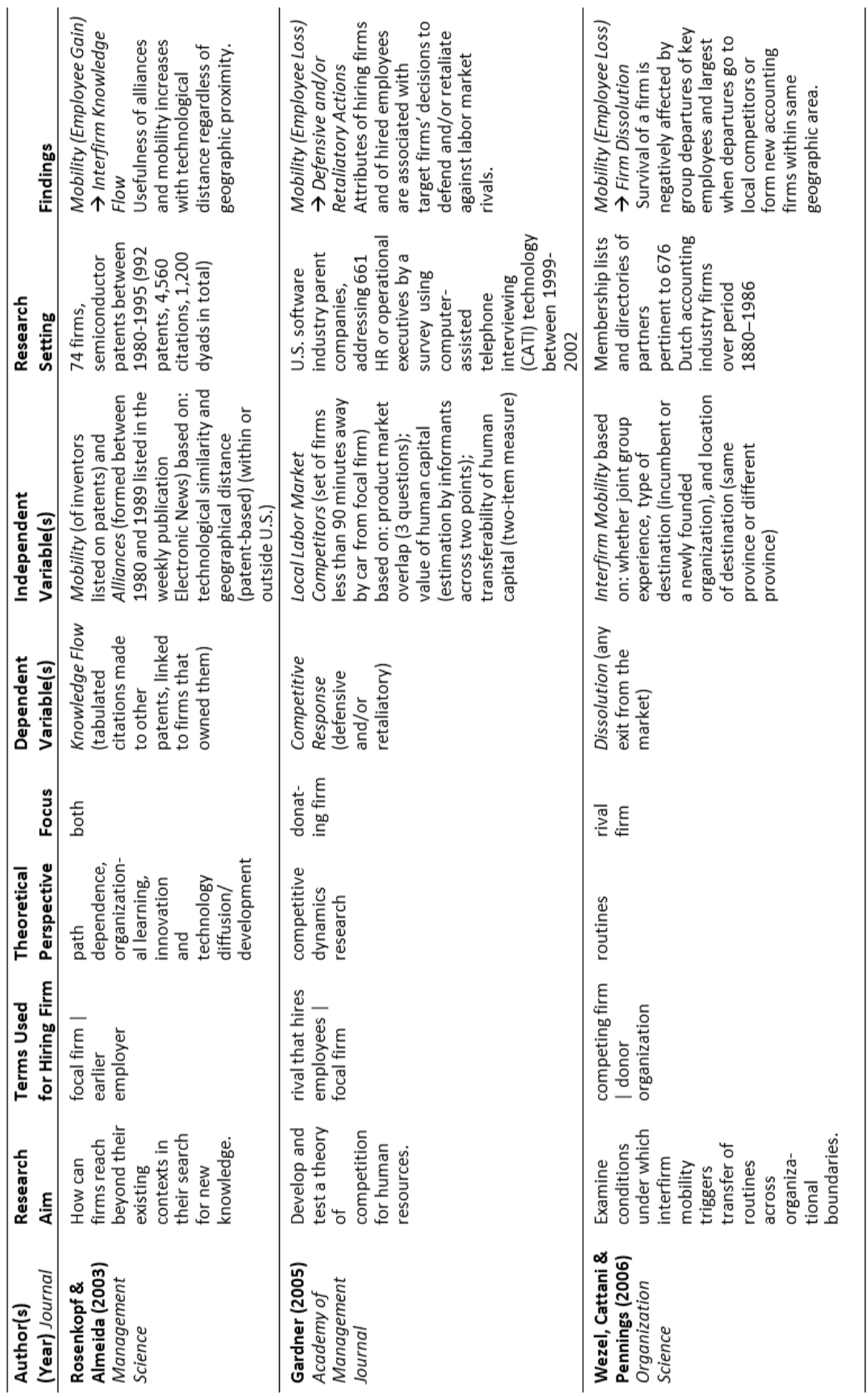




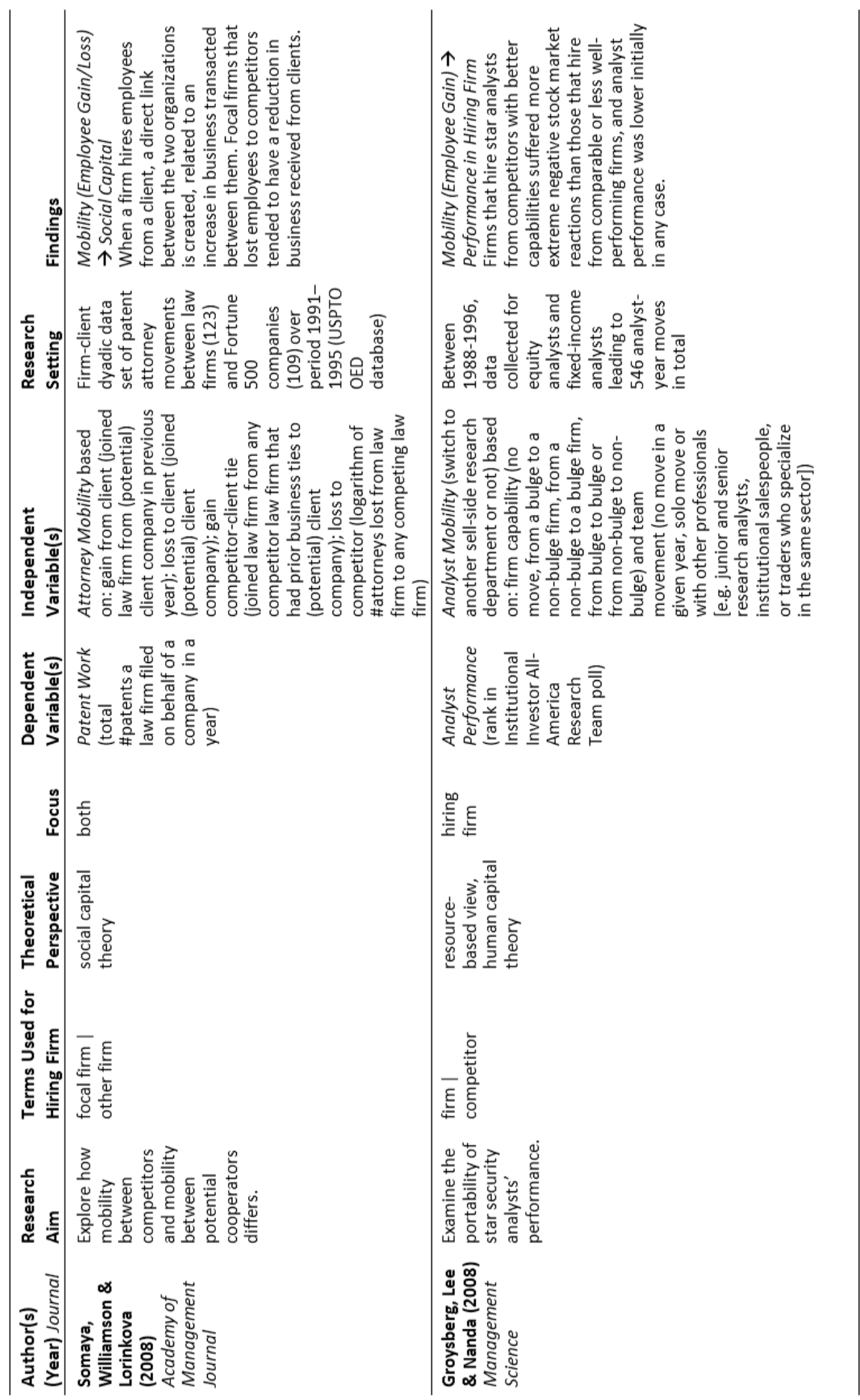




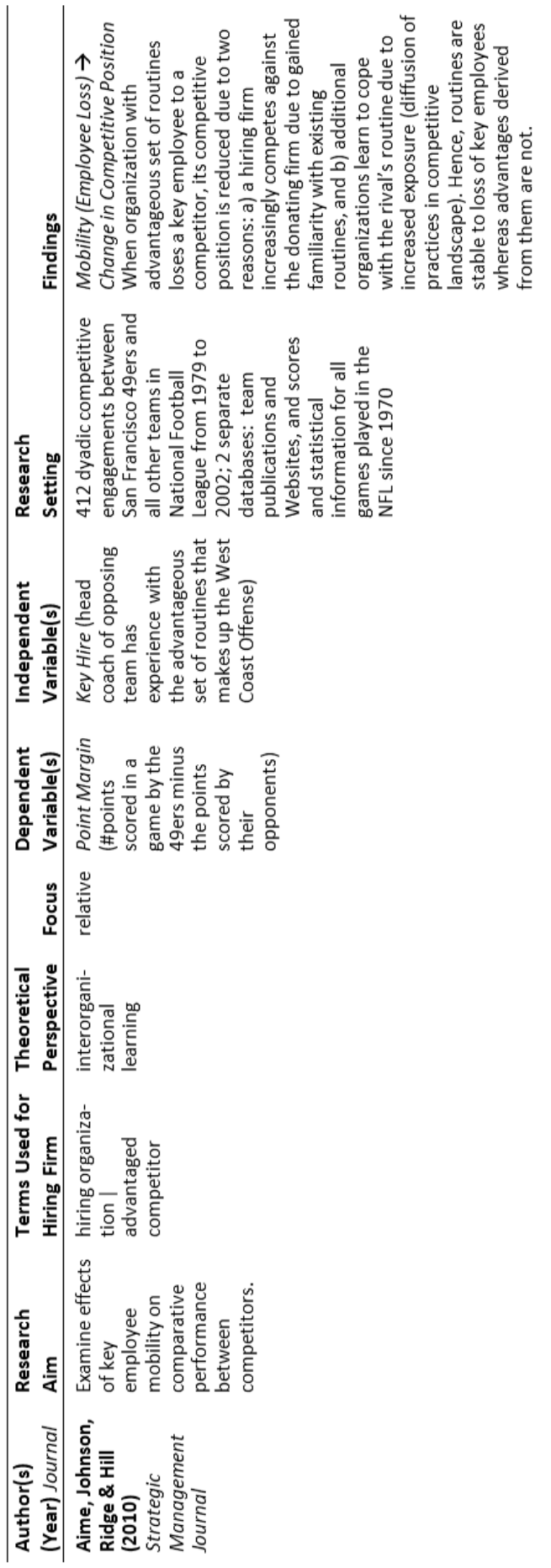




\section{Theoretical Perspectives on Competitor Recruitment}

Though providing great insights for the field, existing research on labor mobility between rivals misses not only a focus on antecedents of $C R$ and implications for the rival firm and the recruit, but an aligning theoretical foundation that links the studies to begin with. The latter is what we aim to provide in this chapter not only by reviewing the core empirical studies on lateral hiring but also by providing a theoretical perspective on the matter of competitor recruitment as a specific case of poaching. As mentioned, strategy scholars have devoted few research efforts to antecedents of successful competitive advantages gained from the acquisition of key employees from competitors. We thus seek to shed light on this issue by specifying characteristics of recruits that make them valuable in a competitive sense and that allow for a competitive human capital advantage being gained over time.

As competitor recruitment is a phenomenon consisting of several different but interconnected processes, it does not lend itself to being captured in a single theoretical frame. Instead, we think that different theoretical perspectives need to be involved to understand it in its full richness. In particular, elements from resource-based (RBV), strategic factor market (SFMT) and property rights (PRT) reasoning seem to bear significant relevance for explaining the CR phenomenon (e.g. Coff, 2010; Foss \& Foss, 2005; Kim \& Mahoney, 2002; Okhuysen \& Bonardi, 2011). After all, firms need to define (RBV), pick and integrate (SFMT), and employ a valuable recruit while minimizing any transaction costs incurred (PRT) in the process of identifying, transferring and deploying a competitor recruit. We will combine insights from these three strands of literature in order to generate propositions on when and how firms can create value from hiring a competitor recruit. Specifically, we seek to outline the sources of (1) value and (2) recruitment and deployment costs that are incurred in the process. This helps to identify the conditions that determine the likely value appropriated and human capital advantage gained.

The main endeavor of the resource-based view is to explain to what extent internal resources can lead to or help retain a competitive advantage in product markets (Markman, Gianiodis \& Buchholtz, 2009). It thereby takes an inside-out view assuming that strategic hiring decisions should flow primarily from the analysis of a hiring firm's existing internal resources. As competitor recruitment is aimed at the acquisition of external employees that can be deployed with existing internal resources to gain a human capital advantage, the resource-based view qualifies to understand why and when competitor recruits add value to a hiring firm (Adegbesan, 2009; Barney, 1986; 1991; Penrose, 1959; Peteraf, 1993). The RBV, however, misses several elements that are crucial to determine the value that a firm can finally capture from a competitor recruit. First, it does not allow for a more active stance toward resource acquisition and value capture because it is not a dynamic theory, that is it does not consider how organizations acquire resources (i.e. employees) and deploy them over time (Oliver, 1997; Zajac \& Kraatz, 1993). Second, it does not inform us about the costs that are incurred to acquire and deploy employees, which actually deteriorate the potential value to be appropriated. Eventually, firms can only obtain returns from a competitor recruit when the costs of recruiting and deploying are lower than the recruit's economic value 
contributed (Hoopes, Hadson \& Walker, 2003). Third, the resource-based view treats resources as holistic entities rather than recognizing that value could follow from different hidden - attributes combined in one resource. Employees, for instance, consist of various human capital attributes such as skills, abilities, personality characteristics or knowledge that only transfer in combination while being embodied in the same individual (Becker, 1962; Dierickx \& Cool, 1989; Lippman \& Rumelt, 2003; Peteraf, 1993). Consequently, frictions in deploying all potentially valuable resource attributes might lead to a gap between expected and realized value, which the resource-based view does not fully account for (Kim \& Mahoney, 2002).

Strategic factor market theory (Adegbesan, 2007; Barney, 1986; Makadok, 2001; Makadok \& Barney, 2001) fills the first two gaps by proposing, on the one hand, how any costs involved can be outweighed by value gained. On the other hand, SFMT as a dynamic theory tells us how market dominance can be obtained by creating resource complementarities as well as by exploiting asymmetric information efficiently over time (Markman et al., 2009).

Property rights theory (Barzel, 1997; Kim \& Mahoney, 2002) addresses the third gap. PRT acknowledges that it is in the hands of the resource owner, i.e. the hiring firm, to maximize the value captured from a competitor recruit and to minimize the costs that the process demands. It is the hiring firm, after all, that can and needs to identify the different attributes that characterize a competitor recruit and to make sure that the employee works in a value-maximizing context during his time of employment. The value captured of an employee is, thus, in essence an outcome of the process of discovering valuable human capital characteristics and deploying them post-hire, and of economizing on any costs incurred in identifying and exploiting these attributes over time (Foss \& Foss, 2005).

Figure 2.1 provides a preview of the overall analysis to follow. It visualizes the conditions that lead to a (sustainable) human capital advantage through competitor recruitment by specifying value-deteriorating and value-adding drivers.

Pre-hire elements play a role ex ante the identification stage of CR and allow for a first estimation of the likely value to capture, while post-hire elements consider the actual value captured based on costly value appropriation investments made during the whole $C R$ process, i.e. the identification, transfer and deployment stage. 
Figure 2.1 Determinants of the Value Appropriated from Competitor Recruits

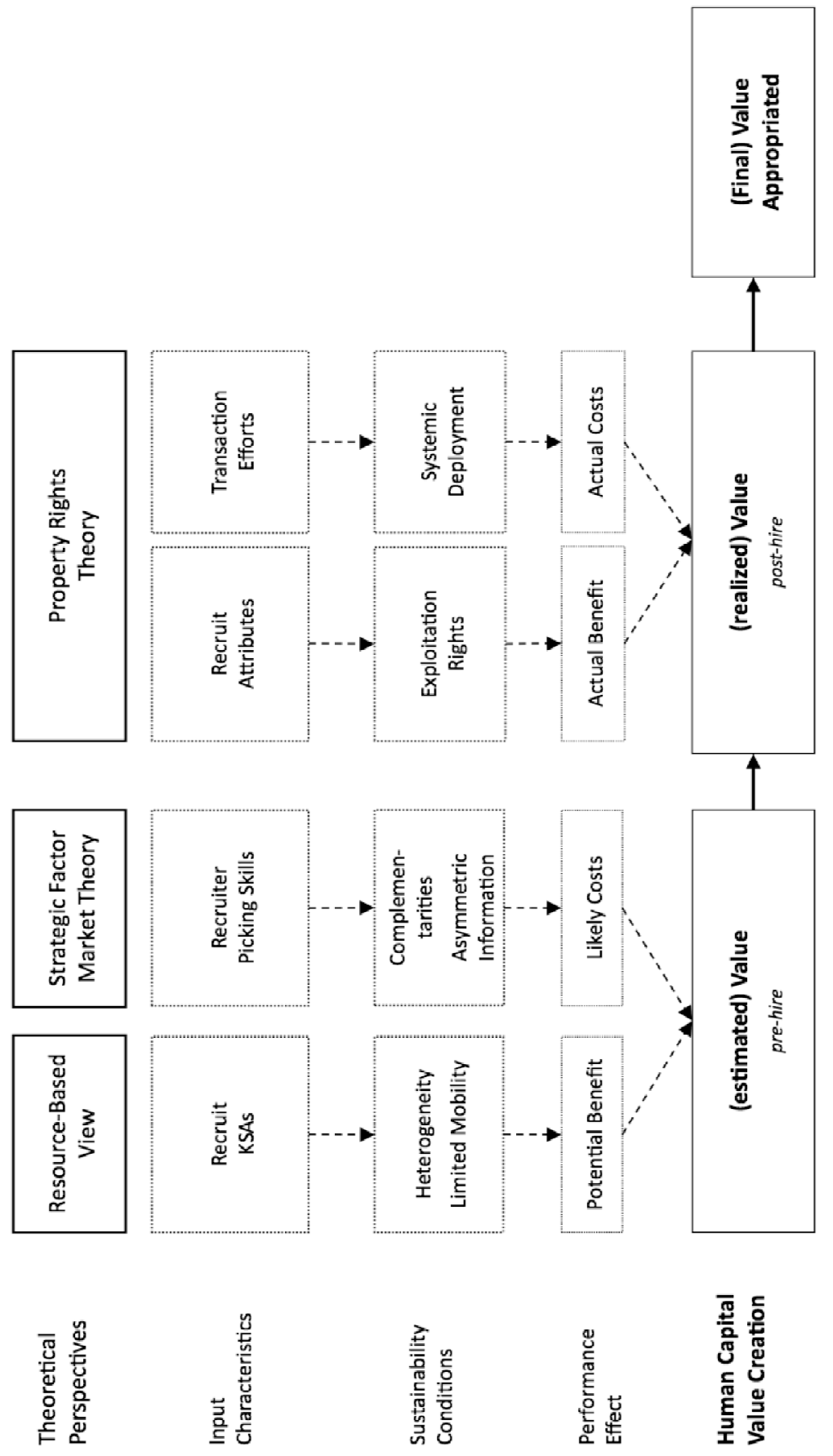




\section{Estimating Competitor Recruit Value}

A recruit's value contribution at the hiring firm is expected to be his or her productivity level as observed at the former employer. Commonly, this 'reputational' productivity attracts attention in the first place. Resource-based thinking helps to explain the in situ value of a (strategic) human resource by explicitly outlining characteristics that make it potentially valuable by focusing on firm-based and firm-bound resources.

VRIN Criteria Applied to CR Recruits. According to RBV, resources only lead to a competitive advantage ${ }^{36}$ if they are valuable (i.e. contribute to internal firm productivity) and rare (i.e. not widely held among competitors). In order for the advantage to be sustainable, resources additionally require to be inimitable (i.e. not easily replicable by competitors) and non-substitutable (i.e. other resources cannot fulfill the same function) (Barney, 1991; Hoopes et al., 2003; Kim \& Mahoney, 2002). The four resource ('VRIN') criteria are multiplicative rather than additive (Barney, 1991) meaning that a sustainable competitive advantage might follow if, and only if all the before-mentioned conditions are met and interact synergistically. Below we describe how each VRIN criterion plays out in the CR context.

Valuable Recruit. Employees who fulfill a critical function are considered valuable for a firm (Badders, Cottom-Clark \& Wright, 2007; Lepak \& Snell, 1999). Value is contextdependent and determined by the market environment through threats and opportunities that all competitors face similarly (Priem \& Butler, 2001). In other words, an employee is valuable if he helps to prevent a threat or to seize an opportunity. Poaching a valuable employee from a rival does not only lead to a stronger market position due to the possibility to make use of certain opportunities otherwise not attainable. It weakens the competitive party at the same time, thereby having a double effect. Examples of valuable employees are CEOs or R\&D specialists like Mark Papermaster, former Senior Vice President at Apple and executive at $\mathrm{IBM}^{37}$, who carry industry-specific knowledge such as market insights, strategic product knowledge or customer relationships, and so strongly contribute to firm performance (Sturman et al., 2008).

Rare Recruit. Employees are considered rare when they, i.e. their portfolio of competences, skills or abilities, are of limited availability in the labor market. Rareness stems from an extreme either in-depth or in-breadth specialization of a person's talents, e.g. having extremely deep insights into the specifications of one product or extremely broad insights about all products of an industry respectively. Making a rare employee such as a specialist in a field or a manager with a unique combination of industry, country and product experience transfer has value-adding potential since it allows for differentiation or growth. An example would be Walter Maria de'Silva, an Italian car-designer with expert knowledge and experience in a variety of automotive companies who is currently in charge of the design of all Volkswagen passenger car brands including Audi, Volkswagen, SEAT, Škoda as well as

\footnotetext{
${ }^{36}$ Here, competitive advantage is defined as "implementing a value-creating strategy that is not simultaneously implemented by any current or potential competitor" (Barney, 1991).

${ }^{37}$ see Introduction.
} 
Bentley, Lamborghini and Bugatti. The rarity criterion is gaining in relevance since it is ever more challenging to attract employees who guarantee high performance levels in the organization due to the labor market's increasing heterogeneity and labor shortages (De San-Perez \& Garcia-Falcon, 2002; Rynes \& Barber, 1990).

Imperfectly Imitable Recruit. Employees' inimitability emerges from the difficulty in duplicating a person's human capital through, for instance, training and development efforts, thereby being an ex post barrier to competition. Inimitability in the case of CR exists for two reasons. First, it follows from causal ambiguity regarding the source of the current human capital portfolio. The more tacit and socially complex an employee's human capital in the form of skills, abilities, experience, personality or competences is, the more difficult and costly it is for a competing firm to imitate the employee's productivity level. This is exacerbated once it is not obvious which human capital attributes lead to the performance level observed and which do not. Second, CR might be inevitable due to the path-dependent development or growth of the specific candidate throughout his professional career, which may not be replicated or pursued by any other employee in a similar manner and with the same results (Barney, 1991; Mahoney \& Pandian, 1992). Eric E. Schmidt, the former CEO of Google Inc. (2001-2011), for instance, was responsible for building the corporate infrastructure and, in that way, had had a strong impact on Google's current performance. His experience as an engineer having hold various specialist, executive and board positions with IT companies such as Xerox, Novell, Sun Microsystems or Apple, or serving on the boards of trustees for Carnegie Mellon and Princeton University caused his unique competences and mindset with which he approaches business tasks. He invented among others the $70 / 20 / 10$ model $^{38}$, which is a business resource management model that determines how time at a company should be utilized to cultivate innovation, to which Google's success in the recent past is attributed (Battelle, 2005).

Non-Substitutable Recruit. Some employees are difficult to replace by either technologies or other employees that, in combination, have the same performance effects. This means that the individual qualities of an employee are so unique and interdependent that no combination of other (human) resources could reasonably substitute them. Managers such as Josef Ackermann ${ }^{39}$, the CEO from Deutsche Bank since 2006, previously Credit Suisse, carrying accumulated social capital and experience stemming from many years of practice in a specific firm and industry environment, might be very hard to substitute by another person since it is not necessarily observable of whom the employee's network consists, how he or she built it up and what relationships he or she owns. This might also be the reason why it took many years to find a successor for Ackermann who will resign in

\footnotetext{
${ }^{38} 70$ percent should be dedicated to core business tasks, 20 percent to projects related to the core business and 10 percent to unrelated tasks

${ }^{39}$ Josef Ackermann has 32 years of professional experience in the banking sector and is affiliated with organizations such as the Swiss Army, Siemens AG, Royal Dutch Shell, London School of Economics, the Federal Association of German Banks, the Institute for Corporate Culture Affairs, or the Bilderberg Group.
} 
2012, and that Deutsche Bank finally decided for dual leadership of investment banker Anshu Jain and head of the German branch Jürgen Fitschen while Ackermann probably remains in an influential role as the chairman of the supervisory board afterwards (Deutsche Welle, 2011). Assuming that direct competitors have more similar work contexts, product markets and client groups in comparison to non-competitors, competitor recruitment might be a rather safe and effective way of filling a vacancy that demands a high amount of tacit knowledge, for instance in the form of client relationships, business contacts or industry experience, if a position cannot be filled from internally (Preston, 2008).

For internal resources to create real sustainable competitive value, the RBV states two additional requirements: resource heterogeneity (i.e. variation in resources and capabilities across firms) and imperfect mobility of these resources (Barney, 1986; 1991; Penrose, 1959; Peteraf, 1993).

Human Resource Heterogeneity and Imperfect Mobility. According to RBV, performance variation between firms is a result of the heterogeneous distribution of assets that are imperfectly mobile (Helfat \& Peteraf, 2003). In other words, firms own distinct sets of resources and capabilities, which make no two organizations the same. RBV focuses on factors that cause these differences to exist and/or persist (Mahoney \& Pandian, 1992). Human resources, in particular as "bundles" that create synergies, differ across firm boundaries in terms of the potential productivity level displayed. On the one hand, synergies can follow from employees supporting each other in fulfilling their job assignments due to complementary skills and competences. For example, if integrated or challenged well within a team or department, a larger percentage of the human capital carried will be shared and exploited (Groysberg \& Lee, 2008). On the other hand, synergies can be created by providing supportive working conditions for employees (e.g. latest equipment technologies or office location), budgets, existing partnerships, client relations or benefits packages (e.g. childcare or company sports). As a result, an external resource has distinct value potential in different firm contexts due to distinct potentials for synergy creation (Adegbesan, 2009; Barney, 1991). These firm differences imply different degrees of firm value creation through new recruits during deployment, and firms thereby remain heterogeneous (Peteraf, 1993). In the context of competitor recruitment, resources (i.e. competitor recruits) that are perceived as valuable are imported from a rival and deployed in a company environment that differs from the previous one. In case value is appropriated as expected, conditions that impair or block further mobility might be set in place, for example in the form of 'non-compete' provisions (Marx, Strumsky \& Fleming, 2009). After all, human resources, and competitor recruits in specific, need to be imperfectly mobile ex post in order to create value over time.

To conclude, resource-based thinking expects VRIN resources to create a competitive advantage. This means that - in principle - poaching a VRIN competitor recruit destroys value at the rival firm and creates it at the hiring firm when the resource is embeeded appropriately. Thus, to expect a competitor recruit to carry major benefits, we propose that the following conditions need to hold: 
Proposition 1: Like from any resource, a firm can capture sustainable value from a competitor recruit if the recruit's human capital is valuable, rare, inimitable and nonsubstitutable, and if the value captured is heterogeneously distributed and imperfectly mobile across firms.

\section{Estimating Competitor Recruitment Costs}

Once the potential value of a competitor recruit is determined, the costs that are involved to find and attract the recruit need to be specified. Strategic factor market theory claims that analyzing own and needed firm resources leads to expectations about the potential value of an external resource currently in a strategic factor market i.e., a market where the resources necessary to implement a strategy are acquired. If strategic factor markets are perfect, then the cost of acquiring strategic resources will approximate the economic value of those resources once used to implement product market strategies. Different firms in the same competitive environment have, however, different expectations about the (future) strategic value of a resource such as an employee due to distinct existing internal resources and capabilities, and prevailing environmental uncertainty (Barney, 1986). As a result, companies use different lenses when screening the labor market and come to distinct conclusions. Different expectations may follow for instance when a firm already controls many resources needed to implement a strategy, when it controls unique, i.e. VRIN, resources otherwise necessary to implement a certain strategy, when only a small number of firms attempt to implement a strategy, or when some firms have access to lower cost capital than others (Barney, 1986).

Investments in labor market screening, and in hiring and deploying a human resource that is perceived as valuable, can hence pay off and lead to a human capital advantage due to two main industry conditions, namely asymmetric information and the option for creating complementarities (Makadok \& Barney, 2001). Specifically, a human capital advantage can follow if a firm has superior skills in a) collecting, filtering, and interpreting costly information about the future value of an employee and is hence better than others in selecting and picking employees of high premium value, and b) combining existing and new employees to create synergies at limited costs (Adegbesan, 2007; Amit \& Shoemaker, 1993; Barney, 1986; Makadok, 2001; Makadok \& Barney, 2001; Penrose, 1995; Peteraf, 1993; Wernerfelt, 1984). We will explore these two conditions in more detail.

Asymmetric Information. Due to information asymmetries, firms make different assumptions regarding the factors that determine the productivity level of a specific employee at another firm and the likely value he or she could contribute as an external recruit inside the own firm context. More specifically, a hiring firm can only imperfectly estimate the likely value appropriated once transferred since it faces two main impediments: (1) low observability of the recruit in the old context and (2) uncertainty about the deployment potential post-hire. Hence, a hiring firm can never be fully assured that a recruit will be equally productive once employed. 
To reduce this uncertainty, costly information search investments are necessary that allow a firm to a) make a better recruitment decision than its competitors and b) dominate the contractual negotiations with the rival firm and/or the recruit afterwards. To achieve the former, firms can collect information and conduct a resource fit analysis through, for example, an external service provider such as an executive search consultancy (Coff, 1997). Though costly, a bad investment can thereby be avoided even though interfirm advantages may only be temporary when competitors pursue equal investments in reducing their information deficits and uncertainty. In case rival firms conclude that the same candidate would show a profitable fit also in their firm context, they might try to hire away the recently transferred employee at a later stage. Thus, although superior information might lead to a human capital advantage at first instance, this advantage is not necessarily sustainable. Still, firms that recognize a future value creation potential of a competitor recruit before rival firms do (in the so-called ex ante resource competition process of the identification stage; Barney, 1986; Peteraf, 1993) can potentially secure rents. Equally, firms that foresee value creation potential of a candidate before the current employer or the recruit does himself, can appropriate higher rents when negotiating over rents while saving unnecessary costs in the form of e.g. transfer fees or pecuniary compensation in the transfer and deployment stage. This is in line with Coff's (2010) proposition that "[s]takeholders who benefit from knowledge asymmetries [...] use this to position themselves for rent appropriation before others [e.g. the recruits] are even aware of the value creation potential" (Coff, 2010).

(Human) Resource Complementarities. Making accurate estimates not only of possible internal resource synergies but also of likely resource complementarities and then also realizing those has long-term value creation potential (Barney, 1986; Porter, 1980). After all, if resources are assembled in a way that they complement each other and they are fully exploited, additional resources otherwise employed become superfluous, and thus unnecessary costs of owning, buying or fostering those are saved. The best consultancies, for instance, compose their advisory teams in a way that individual expertise is assigned to the projects where it is most needed and in which individual weaknesses can be compensated by other team members' competences or are irrelevant. It is, however, not always obvious to what extent complementarities can be created and which resources are exactly needed to provide favorable resource conditions, and several firms might bid for the same candidate (Adegbesan, 2009).

It follows that a firm can gain a competitive human capital advantage if it has both superior resource-picking skills in an environment of asymmetric information and potential for complementarities. When engaging in competitor recruitment, it is thus crucial to invest time and money in defining the top performers at competing firms and making them transfer. Thereby, hiring firms do not only acquire competent employees that improve their market position partly by complementing internal resources. In addition, direct competitors are potentially weakened due to the loss of valuable knowledge or clients, and the costly need to find a replacement. It therefore follows that: 
Proposition 2: Like from any practice, a firm can capture value through competitor recruitment if the expected benefits gained are higher than the costs involved in exploiting an informational advantage and initializing internal resource complementarities.

\section{Realizing the Estimated Competitor Recruit Value}

Successful CR hinges not only on proper estimation of value and cost of attracting recruits pre-hire, but also on their effective and efficient placement and deployment posthire. While recruiting the 'right' employee is a matter of finding and using the appropriate sources of information that help in estimating the likely value and cost of competitor recruitment, it is furthermore essential to minimize costs during the process of deploying human capital value internally. Property rights theory takes a dynamic view on resource value appropriation and reminds us that value can only be captured when costs (of investments in resource appropriation) are kept low post-hire in a continuous effort (Foss \& Foss, 2008). It is the value of the rights to exploit and discover certain resource attributes over time that determines the potential value of the recruit captured, not the human capital carried per se (Demsetz, 1988). PRT thus complements the resource-based view as it deals with appropriating economic rents over time (Kim \& Mahoney, 2002). Exploiting all attributes post-hire is not guaranteed in case, for instance, non-compete clauses or other barriers exist that were not foreseen or considered pre-hire.

According to PRT, the hiring firm thus has two roles when engaging in competitor recruitment. On the one hand, it has to find ways to minimize any transaction costs that are incurred in the process of identifying, transferring and deploying a competitor recruit's attributes. On the other hand, it has to make sure that all potentially valuable attributes of a competitor recruit are discovered and appropriated. Hence, not only the human capital as such but also its appropriation process offers opportunities for increasing value capture or limiting value deterioration (Foss \& Foss, 2005).

Minimizing Transaction Costs. Every firm faces transaction costs in the process of recruiting and deploying its employees. These transaction costs follow partly from HR practices such as compensation, training, development or retention efforts, and partly from the fact that not all present and future resource usages are known upfront: many of them will only show up 'along the way' through for example investments in retraining (e.g. Cantrell \& Smith, 2010). This leaves room for a hiring firm to decide on which transaction costs to incur in seeking to increase the net resource value gained (Foss \& Foss, 2005).

Since hiring firms might refuse to hire an employee when they expect transaction costs to be higher than the value gained, transaction costs constrain strategic factor mobility. Property rights might be limited by law or interfirm agreements that influence how much value a resource owner can actually appropriate from the acquired resource. Noncompete and non-disclosure clauses are good examples of this mechanism as they usually prohibit the transfer to and application of industry-specific knowledge at a competitor (Marx et al., 2009). Therefore, some firms would not poach a blocked candidate since the risk and related transaction costs of being sued or being otherwise limited in capturing value are 
perceived as too high. Others might start negotiations with the current employer while being willing to incur additional costs of contractual negotiations and redemption fee payments, thereby accepting value deterioration, in expectance of higher value gain in the future.

Maximum Exploitation of Valuable Recruit Attributes. The discovery and appropriation of resource attributes post-hire can help firms extract additional, potentially unexpected, value from competitor recruits. As much as firms differ in the extent to which value is deteriorated in the process of deployment, they vary in their capabilities to create opportunities for capturing resource value (Foss \& Foss, 2005; Pfeffer \& Sutton, 2006).

Detecting employee attributes can be promoted through orientation programs or employee trainings, which might help to let hidden attributes surface. The full utilization of an employee's known human capital throughout employment can be further encouraged through practices such as incentive schemes, appraisals or promotions, for instance, as they potentially increase motivation, commitment or desired task prioritization. Although these types of HR practices require financial investments that in turn deteriorate value, the overall net value gained might still be positive as they help a firm to use (additional) skills and competences more effectively if property rights are kept and the employee retained. As a result, we finally suggest that:

Proposition 3: Like from any resource, a firm can capture value from competitor recruitment if it owns the unique rights to exploit competitor recruit value as well as the means to protect its exploitation over time under conditions of transaction costs being lower than the value gained from all competitor recruit attributes to which property rights are held.

\section{Discussion}

We have explored the drivers of both benefits and costs of competitor recruitment using insights from the resource-based, strategic factor market and property rights theory. Borrowing from each of the theories helped us to analyze the phenomenon of CR and to provide a conceptual framework for value capture through CR.

We can conclude with two major outcomes. First, the degree to which a CR recruit is perceived as valuable, rare, inimitable and non-substitutable, and offers the option of synergistic effects under conditions of heterogeneity and imperfect mobility results in the overall value to be captured. Second, the resource-picking skills of the hiring firm and its capability to exploit existing human resource attributes minus the costs that follow from the identification, transfer and deployment process determine the final net value gained. We might add that when the final value appropriated exceeds any simultaneous equivalent value gained by competitors, a competitive human capital advantage is obtained.

This chapter has made three major contributions. First, we have provided a theoretical basis for doing research in competitor recruitment. Second, by looking at value and cost-causing factors theoretically, we outlined why competitor recruitment can be considered a valuable recruitment practice that deserves further empirical as well as practical attention. We did not only provide a review of the related literature but also 
isolated some driving parameters to be investigated in future work in this area. Third, we demonstrated that resource-based, strategic factor market and property rights thinking can be combined and complement each other in the context of strategic human resource management. Particularly, by applying the three theoretical perspectives to the context of competitor recruitment, we have provided on a more abstract level an example of how they can be complementary and useful when investigating current labor mobility phenomena in particular. Besides, our theoretical framework might serve as an example for further strategic management analyses that seek to combine the theoretical lenses borrowed from in this chapter.

\section{Further Research}

The propositions as presented here might be considered bordering tautological reasoning. Since the purpose of this chapter was not to offer testable propositions but to outline a frame of reference for understanding $C R$ and general theoretical conditions and under which competitor recruits, and competitor recruitment as a sourcing practice, can add value to a firm - as a basic theoretical foundation of chapters of this dissertation to come this is not so much of a concern at this stage. In order to build a specific CR theory though it is important to dive deeper into the specific key success factors of competitor recruitment by for instance proposing particular conditions under which a competitor recruit is likely to be VRIN plus exhibit heterogeneity and imperfect mobility. Specific factors fostering newness (e.g. through complementarities) or the creation of outcome supportive work contexts (e.g. that minimize transaction costs) might for instance drive the success of CR.

This chapter has theoretically analyzed the process of individual employees transferring between rival firms. It has not explicitly discussed teams of employees venturing out through CR. In some cases, however, whole teams might be poached or an individual recruit is asked to address his or her colleagues to transfer along. Team transfers might be a way of acquiring firm-specific knowledge, which is commonly regarded as immobile and worthless for other firms (Aime et al., 2010). A team that transfers to another firm in essence takes the context, that makes human capital firm-specific, with (Beckman, 2006; Groysberg \& Abrahams, 2006; Sherer, 2008). Research has shown, for instance, that the survival of progeny organizations is enhanced by large transfers of employees from a parent firm (Phillips, 2002; Wezel et al., 2006). As thus the co-transfer of co-specialized assets such as former team members might be essential for the success of the $C R$ recruit in the new hiring firm context (Aime et al., 2010; Groysberg et al., 2008; Somaya et al., 2008), this subissue of single versus team transfers and the nature of the human capital carried along deserves particular attention when exploring the CR phenomenon (see chapter 3 ).

Once a human resource need is defined, a firm has to decide where to source a suitable candidate from and whether to engage in competitor recruitment. Questions that arise before the identification stage are whether internal or external sourcing, or outside or inside-industry hiring, is more appropriate. Do so-called talent-generators like PepsiCo or General Electric who are popular for generating generalists that are highly valuable, also for 
jobs across industry boundaries, constitute an appropriate target (e.g. Cappelli, 2008; Handfield-Jones, Michaels \& Axelrod, 2001)? Or would an employee with deep industry experience be more promising due to previously accumulated knowledge and insights at different firms within the same industry (e.g. Somaya et al., 2008)? Is resorting to CR indicative of failure of internal succession planning, or is it really a strategic choice of some firms who assume that it is the best way to fill a current vacancy? We have discussed the impact of individual recruits transferring between direct competitors allowing for the acquisition of valuable human capital in the form of client contacts and other social capital, product insights or market knowledge. We broadly discussed a motive behind the competitor recruitment practice, namely to acquire valuable human capital. We have not yet specified, however, the prime type of human capital that actually makes a CR recruit valuable. We have also not explicitly specified the exact origin of value creation and costs, i.e. all motives and impediments toward engaging in $\mathrm{CR}$, neither the supportive conditions for organizations to resort to $C R$ in practice. These are questions worth exploring though, in order to define the core parameters involved in competitor recruitment that also make it different from other recruitment endeavors (see chapters 3 and 4).

A final interesting issue for further research is the potential barriers to incur that are typical to $\mathrm{CR}$, which might follow from the specific institutional context in which a firm functions. Non-compete agreements, for instance, might impair the transfer of a candidate who, though identified, cannot easily switch employers or work on positions as desired due to a contractual clause (Marx et al., 2009). The existence of non-compete or non-solicitation agreements, cancelation periods or payback clauses might thereby constitute a barrier to value appropriation and lead to an increase in costs due to consequential intensified negotiation efforts or limitedly available knowledge of the recruit once hired (see chapter 4).

As our elaborations have shown, a firm can approach an estimation of the expected value of a competitor recruit upfront. A hiring firm is, however, neither in full control of the transaction process, nor aware of all favorable and unfavorable contingencies that determine the net value to be appropriated from a competitor recruit eventually. In other words, whether a firm will actually succeed in capturing the estimated value of a CR recruit depends among others on the resources already controlled by a hiring firm, existing firm capabilities to adjust and recombine internal resources if necessary, and supportive HR practices applied during the recruitment and deployment process (Cappelli, 2008; Dierickx \& Cool, 1989; Pfeffer \& Sutton, 2006). For instance, a well-planned orientation and effective socialization program was shown to help newcomers to become quickly deployable and to foster intentions to stay, i.e. value appropriation over time (Allen, 2006). Thus, how value and cost drivers of $\mathrm{CR}$ unfold in practice should be subject of future research projects. We make a first stride in this direction by investigating to what extent recruit origin (whether from a rival firm or not) is linked with a recruit's human capital profile, and how this in turn is associated with commitment focus and willingness to switch jobs or employers (see chapter 5). 
Scholarship within the labor mobility field has suggested that firms can benefit from labor mobility and external recruitment in specific, and has asked for further related research. This chapter supports this view and even argues for the active initiation of mobility of key human resources from rivals that can potentially enhance a hiring firm's performance.

Borrowing from different theoretical RBV viewpoints provides valuable first insights while introducing complexity at the same time. As a result, this chapter constitutes the beginning of a much larger research agenda for RBV research in general (see Barney, Ketchen \& Wright, 2011), and CR in particular. There is a clear need for unpacking these complex relationships between the different parties and value and cost drivers involved to develop a more robust theory of how competitor recruitment affects team and firm performance of both the hiring and competing firm. 


\section{3}

\section{Characteristics and Drivers of CR in Practice ${ }^{40,41}$}

This study empirically investigates whether competitor recruitment is a common recruitment practice, how it can be characterized and what drives its occurrence. To this end, we use interview data from 19 consultants working for top executive search firms in Germany.

Results indicate that CR oftentimes affects individuals or teams of middle or higher managers and specialists with a strong industry-specific knowledge component but that the balance between motives and impediments determines the occurrence in the end. Despite existing impediments against $C R$, our data suggest that $C R$ can be a valuable tool to cope with internal talent shortages and to strengthen a firm's competitive position, and may take place directly or indirectly with the help of a personnel search firm.

\footnotetext{
${ }^{40}$ This chapter is based on:

Horn, S., Heijltjes, M.G. \& van Olffen, W. (2010). Help on the Hunting Trail: An Exploratory Analysis of Mediated Labor Poaching from Competitors. Academy of Management Annual Meeting (HR Division).

${ }^{41}$ Thanks to anonymous reviewers for valuable feedback on a previous version of this chapter and to Christine Nickels for assisting this study.
} 
Looking at the Apple/IBM example of CR elaborated upon in the Introduction, the question emerges of why Apple was so persistent in making Mark Papermaster move besides the theoretical reasons we outlined in chapter 2. Which factors made his transfer so highly attractive? What exactly did he have on offer that was believed to either strengthen Apple severely or weaken IBM, which then again would change competitive dynamics in the market for servers and chips for handheld devices? Is this a unique case or do inter-rival transfers occur more often or even structurally? If they do, what types of firms initiate them, why, and under which conditions?

With competitor recruitment being an uncharted phenomenon probably because it is regarded a rather sensitive issue that is risky and thus concealed by the parties concerned, an exploratory approach was considered appropriate (Edmondson \& McManus, 2007). We decided to analyze qualitative interview data collected from observers involved in the recruitment process, namely German executive search firm consultants. We specifically wondered what the reasons of firms are (not) to engage in CR and how CR exactly unfolds. We aimed our research efforts toward three main questions in particular. Under which conditions do hiring firms intent to engage in competitor recruitment, how, and at whom is it directed?

We approach these issues in a qualitative manner. To this end, we first present the method used, followed by a presentation of our findings, and a visualization and discussion of the motives and impediments that determine when a hiring firm intents to engage in CR.

\section{Method}

We chose to explore our research question from the intermediary's perspective for three major reasons. First, consultants whose daily business it is to screen the labor market and to mediate between potential recruits and hiring firms are not only accessible but also considered highly knowledgeable due to their role as observers. Second, they work with clients of different industries and job positions and can hence compare various cases based on first-hand experience. Third, we expected them to be less likely to underplay or hide inferior motives such as the weakening of a rival firm in case it exists.

In contrast to the method used in chapter 4 where we apply an inductivedeductive procedure, we here fully inductively approach the data collected (Bryman \& Burgess, 1994; Dey, 1993; Pratt, 2009). A research assistant was involved in the coding as well as the data collection process to facilitate data interpretation and to cross-validate the results (Green, Willis, Hughes, Small, Welch, Gibbs \& Daly, 2007). To this end, we split the task of conducting the interviews into two, with half of them being conducted by the author and the other half by the assistant. Both, however, analyzed all data. To check for practical relevance, we presented our results to several practitioners in the field afterwards.

\section{Data Collection}

The Context. We collected data on the German executive search market for the following reasons. First, Germany is one of those countries that are severely affected by 
demographic changes in terms of specialist and management shortages in the next 20 years (Schneider \& Stein, 2006; Staudinger, 2008). Considering the lively discussions in the German media regarding this issue in the recent past, we assumed to encounter informed respondents in this national setting. Second, the executive search industry grew early on in Germany like in those countries that are considered forerunners of this industry such as Great Britain or the United States. Consequently, German employees as well as employers are rather open to aggressive human resource practices, and consultants in this setting certainly experts in the field. As such, the German context seems to allow for an in-depth study of the CR phenomenon (see chapter 1 for more elaborate explanations).

The Sample. We conducted in-depth interviews with experienced executive search consultants since we expected them to be knowledgeable observers and informants (Murphy \& Poist, 2007; Wengraf, 2001). Initially, 3 personal interviews served as pilot interviews to inform the research design; two with consultants employed by one of the top 5 executive search firms ${ }^{42}$ in the world; a third interview involved a medium-sized German search firm primarily involved in national projects. Those pilot interviews are excluded from any reports that follow, except when explicitly mentioned.

Subsequent to these pilot interviews, we determined key informants based on several criteria related to age, tenure and breadth of industry experience. In specific, we considered those consultants credible experts who (1) had worked for at least two different search firms for at least 5 years, (2) had gained insights into various industries, and (3) are currently employed by one of the top 18 executive search firms of Germany (cf. Consulting Star, 2009). We began with using a combined purposeful sampling strategy and changed to snowball sampling as the study progressed by incorporating recommended informants of actual interviewees (Patton, 2001; Pratt, 2009). This resulted in a final sample of 19 consultants between the age of 35 and 65, 14 of which were employed by one of the top 18 German executive search firms ${ }^{43}$. The remaining 5 consultants worked for one of the 25 most popular HR consultancies of Germany (All Headhunters, 2009). Positions regularly filled by these consultants ranged from managerial level 1 to 4 , i.e. from top management to lower management and specialist positions with a yearly income of $€ 80,000$ or more. Predominating sectors of expertise were the financial services and real estate, energy and utilities, consumer goods and retail, industrial goods as well as automotive. The diverse characteristics of the sample reflect a reasonable coverage of industry sectors (see Table 3.1).

\footnotetext{
${ }^{42}$ The top five executive search firms in Germany are Egon Zehnder, Odgers Berndtson, Heidrick \& Struggles, Heads and Russell Reynolds respectively (Consulting Star, 2009).

${ }^{43}$ According to Consulting Star (2009) which publishes a ranking of search firms annually based on financial turnover and number of assignments filed.
} 
Table 3.1 Interview and Interviewee ${ }^{a}$ Characteristics $^{44}$

personal + transcribed

$\begin{array}{llllllllllllllllllll}1 & 2 & 3 & 4 & 5 & 6 & 7 & 8 & 9 & 10 & 11 & 12 & 13 & 14 & 15 & 16^{\mathrm{b}} & 17^{\mathrm{b}} & 18^{\mathrm{c}} & 19^{\mathrm{c}} & \Sigma\end{array}$

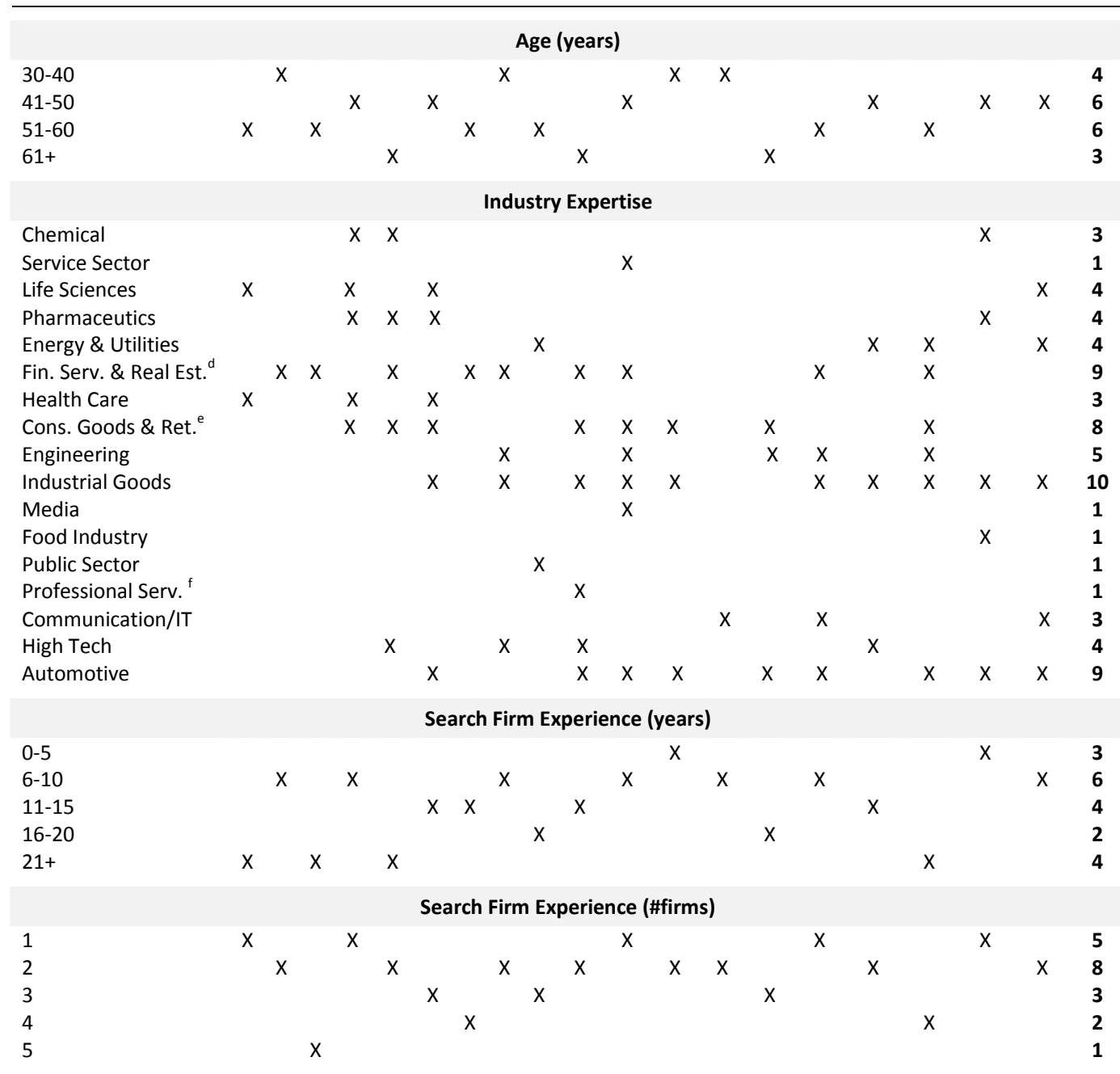

Notes. ${ }^{\mathrm{a}}$ interviewees as respondents 1 to $19 ;{ }^{\mathrm{b}}$ personal interviews + notes; ${ }^{\mathrm{c}}$ phone interviews + notes;

${ }^{d}$ Financial Services and Real Estate; ${ }^{e}$ Consumer Goods and Retail; ${ }^{f}$ Professional Services

Interview Questions. Given the research objectives, in-depth interviews were considered the most appropriate method of data collection. In-depth interviews allow study participants to address the topics that matter most to them within the realm of the study's

\footnotetext{
${ }^{44}$ We promised anonymity and confidentiality as a precondition for reporting. We will hence not reveal any details regarding the size, expert area or ranking position of any of the employing consultancies. Although this is a disadvantage for the reader, the study certainly still provides unique and valuable insights (Yin, 2003).
} 
interest. At the same time, flexibility regarding the process and content is preserved (Richardson, 2003). This approach thus enables a more personalized account of individual experiences (Blumberg, Cooper \& Schindler, 2005). As a result, an interview agenda, rather than a specific set of questions, supported consistency but allowed the interviewer to be flexible in the interview situation and to focus on those issues that the interviewee considered relevant or that turned out most relevant throughout the process.

All interviews were carried out between April and July 2009. An interview scheme of 10 questions and optional follow-up questions was designed based on key themes identified from issues prevalent in the research literature and from the analysis of the pilot interviews (see Appendix 2a). Example questions are "What are the success factors of engaging in CR according to your experience?", "What types of firms use CR as a recruitment practice?" or "Why do firms engage in CR/what do firms expect from CR?". We attempted to keep the questions as open as possible to circumvent any leading questions or the creation of an "unreal reality" within the interview environment (Rapley, 2001). Although many respondents were unfamiliar with the term 'competitor recruitment', all recognized the CR phenomenon clearly when it was described to them. To understand the respondents reasoning, we constantly asked for concrete case examples or personal experiences rather than for general statements that only reflected assumptions, ideas or hypotheses such as "I can imagine that it takes place" or "it will probably occur most often in this or that industry". As a result, the interview data collected reflects the interviewee's reality as present outside the interview situation (Rapley, 2001) judging from statements such as "now as you define it, I can see it happen" or "I wasn't aware that there is a specific term for this practice". Remarkably, almost all interviewees rejected the existence of competitor recruitment as a strategic tool at first. After a while, however, once interviewees started to relate to the term, critical incidents were identified and described, and the phenomenon as such less severely rejected. Still it did seem to carry a negative connotation for most interviewees. We will return to this finding in the chapter's conclusion.

The actual duration of the interviews varied between 45 and 150 minutes. The interviews took an average of $1 \frac{1}{2}$ hours while the telephone interviews took 45 minutes on average. The actual length of the interviews varied between 30 minutes and $21 / 2$ hours while personal interviews usually lasted the longest. Fifteen interviews were tape-recorded and fully transcribed verbatim. In case of three personal interviews tape-recording was not permitted, and two were non-recorded telephone interviews. Extensive notes were taken however during and directly after these five interviews (see Table 3.1). All interviews were conducted in German.

\section{Data Analysis}

Having transcribed the interview data verbatim with the help of the software program Express Scribe, we started the coding process. Thereby, the raw text was structured and patterns could emerge from the data. 
Coding Process. Throughout the data analysis process, we used qualitative data analysis software, namely QSR International's NVivo 8, a computer-aided text analysis (CATA) software program. With the help of NVivo, all interview transcripts were microanalyzed (Strauss \& Corbin, 1998). To this end, we scrutinized every line and assigned words, sentences or fragments inductively to newly developed or existing categories in order to identify patterns along the way. Such a software-based inductive coding process allows for direct engagement with the data leading to a consistent review of categories (Richardson, 2003). At the same time, it offers insights into dominant or less relevant categories (Miles \& Huberman, 1994; Strauss \& Corbin, 1998). Here, 'categories' refer to major themes consisting of so-called 'nodes' with the latter containing quotes, i.e. 'codes', which reflect the meaning of each category (Thomas, 2006). Thereby, the same semantic sections, i.e. phrases, words or sections of text from any interview source, are collected as codes within different nodes. A first creation of a node typically is a 'free node'. Free nodes are initially listed until they are converted into hierarchically organized 'tree nodes' that provide structure to the free nodes. One or several tree nodes together represent a category within a general theme. Generally, one text segment could be coded into more than one node or category, and a considerable amount of text may not be assigned to any category if considered irrelevant (Thomas, 2006). The coding process was inspired by Thomas (2006) and Mayring (2002), and consisted of several steps that we outline below.

Already during the data collection process, we read the first interview transcripts to get initial insights into the data. With the research questions in mind, we then created a first coding scheme consisting of free nodes and categories. Besides, we identified fields of interest that required more detailed questions in the pending interviews. All this was done based on the data obtained rather than prior ideas, expectations or theories as in more deductive approaches (as in chapter 4).

Once all interviews had been conducted, we started the coding of 3 interviews based on the initial coding scheme. We coded the interview with the longest duration first because of the likelihood that most of the relevant categories would be discovered in there already. If so, this would lead to valuable additions to the coding scheme and serve as a good basis for the coding of the transcripts to follow. Next, we discussed the perceived relevance of each free node established in the initial coding scheme and structured them into tree nodes, i.e. hierarchical categories.

Afterwards, we independently (Green et al., 2007) coded all remaining transcripts while assigning additional codes mostly to a previously created node and only rarely created a new one if the meaning was not covered by any node in the coding scheme. After several rounds of coding, the most important categories were charted and results discussed one last time. Specifically, in a procedure of consensual validation, the fragments selected and codes assigned were compared critically. Where differences were identified, we read the relevant parts of the transcripts again. We then discussed dissonances until agreement by means of renaming, specification or connotative adjustment was reached and a final version of the 
coding scheme could be developed. Categories were combined that reflected the same underlying ideas and split where more distinctions were considered useful.

After the coding process was concluded, the categorization system was revised in terms of (1) its correspondence with the aim of the research, (2) its completeness, (3) the independence, distinctiveness and mutual exclusivity of the proposed categories, and (4) its multi-dimensionality (Holsti, 1969). The coding process was thus concluded when we felt to have captured all relevant issues that emerged from the interviews and after they had checked for consistency within the nodes to maximize intra and inter-rater reliability.

Finally, the results were presented to several practitioners in the field. These validation interviews were conducted in person by the author and lasted approximately 30 minutes each. Those interviews helped to articulate clearly the categories of the analysis and reassured that the consultants' experiences had been captured properly.

\section{Results}

The resulting categories and nodes describe the characteristics of $\mathrm{CR}$ as well as the forces motivating or impeding it. The final document consisted of 25 nodes assigned hierarchically to 9 so-called higher-order categories covered under the three major themes of (1) The CR Concept, (2) CR Motives and (3) CR Impediments.

In the following section, we will address each node that emerged from the data with a representative quote. The number of respondents is added in brackets in the text that describes the respective quote category. The brackets following each quote refer to the respondent and the node label. Table 3.2 (see end of this section) provides an overview of all themes, categories and nodes outlined.

\section{The CR Concept}

Three categories stood out when discussing the nature of $C R$ with our informants. These are the targets of CR, the CR transfer mode, and the goals of CR.

Targets of CR. Our interviews suggested that competitor recruitment is a very common phenomenon. All respondents claimed that they "primarily", "usually" or "most of the time" mediate between direct competitors. Competitor recruitment is observed in automotive, engineering, financial, IT/high-tech, pharmaceutics and health care, and professional services sectors. Some job positions are, however, more affected by CR initiatives than others. Whereas 20-30 percent ${ }^{45}$ of all searches on the top management level were said to be competitor-focused, more than 75 percent of all searches on lower management levels and specialist positions were described as competitor recruitment. Specialists of any kind (e.g. R\&D specialists or top sales representatives) and middle or higher management jobs are thus likely to be filled through competitor recruitment in

\footnotetext{
${ }^{45}$ Percentages of positive respondent answers add up to more than 100 percent as most respondents referred to more than one issue.
} 
contrast to general business-related functions such as finance or controlling, human resources or marketing, or top management positions.

"At the top level rather less likely and predominating than at the specialist level, because specialist jobs require a certain know-how, which is essentially carried by only those employees who have built up their human capital and gathered industry experiences at direct competitors. "(14) (specialists as targets)

"Those [employees] who function at the middle management level or are on the higher middle management positions...here it is indeed possible that they [the clients] say...that 80 percent is indeed two-fisted competitor recruitment." (8) (middle or higher managers as targets)

Usually, individual star performers are asked to transfer. Dragging a few colleagues along might, however, be a welcome or even desired side-effect of addressing a single employee. Sometimes, entire teams are approached. This is especially so if, for instance, the knowledge sought is not located within one employee only, or if the need for firm-specific human capital requires the transfer of the previous firm's context.

"It is rather stars that are addressed." (18) (individual stars as targets)

"As I said before, this really malicious type of poaching occurs once in a while, and we know three, four corresponding court decisions which affected big IT firms... where people were addressed and asked to also involve colleagues." (1) (1+more targets)

"If a firm for instance says 'we want to enter a new market' but does not have the expertise yet...for example, if you are in the trademarked article sector and produce shower gel or so, and have the idea to also sell perfumes but do not have any real expertise in this field, then we might recruit a whole team from another firm." (6) (team as target)

CR Transfer Mode. Ambiguity predominates on whether competitor recruitment is done directly or through intermediaries. Many respondents (11) claimed that mostly a search firm mediates CR, among others because client companies prefer the "dirty" tasks to be done by external consultants. Others (8) suggest that information about external candidates in the same industry is often readily available in industry reports and analyses. Additionally, employees meet each other at board meetings or congresses, or other industry events. Thereby, potential candidates could easily be addressed directly and informally. The quotes $^{46}$ below represent the two perspectives while equally suggesting that the choice of a recruiter can make a difference (Breaugh \& Starke, 2000; Rynes, Bretz \& Gerhart, 1991):

\footnotetext{
${ }^{46}$ All quotes were translated from German to English and then re-translated from English to German by an independent researcher to check for the validity of the quotes presented.
} 
"Most of the time we are asked to put certain firms at the top of the search list, since they [the clients] do not dare to address them [the candidate] themselves." (11) (mediated transfer mode)

"[Employees of direct competitors] know each other from boards; it therefore would rather take place directly." (16) (direct transfer mode)

Goals of CR. Finally, according to all respondents, competitor recruitment has as its prime and only goal the strengthening of the hiring firm by filling a vacancy. It is apparently never done with the sole goal of weakening a rival. Instead, it is at most a desired secondary outcome or a tolerated side-effect as claimed by the majority.

"If you plan upfront to weaken the rival completely,...no, not to weaken. To strengthen yourself, that is the only aspect that is part of every placement." (2) (goal to strengthen)

"It is indeed possible that my direct competitor has the crucial team that I need, that has advanced the market, and then you will try to attract it...but definitely not to purely weaken the rival." (7) (weaken if necessary)

"It is [...] always this duplicity [...] maybe it's a welcome side-effect that you weaken your direct competitor." (7) (welcome side-effect)

Apparently, the major concern is to acquire highly qualified employees by potentially weakening the rival firm at the same time, but weakening by itself is never the main endeavor.

Respondents also indicated why they would (not) expect a strengthening effect to occur through CR and referred to a range of reasons that speak for (motives) or against (impediments) an engagement in competitor recruitment.

\section{CR Motives}

Need for Industry-Specific Knowledge. The most frequently mentioned issue that motivates a firm to engage in competitor recruitment is the type of knowledge that is required to fill a hiring firm's vacancy. Generally, a need for industry-specific knowledge strongly favors CR.

Almost all respondents (15) claimed that market-related knowledge acquired over time leading to a tacit grasp of 'how things work' in the industry is a core driver.

"[...] you need market knowledge...you need to know how the market functions; what are the industry mechanisms... who are the major players in terms of clients as well as competitors." (1) (marketrelated knowledge motive)

The majority (13) considered a client base or other business-related relationships transferring along with the recruit a relevant force behind engaging in CR. 
"I think that especially when it comes to sales positions, the issue of $C R$ is very relevant. Simply due to the networks that these recruits carry along, contacts that transfer along." (12) (social capital motive)

Many (12) emphasized also technical industry-specific skills such as process insights that are related to specialist job requirements.

"[That a client says] 'I heard, at this and this competitor is a good candidate...', yes, that is actually quite common. But the intention is a different one. The intention refers to the technical hard skills, not to the need to acquire market share or to weaken the other party." (2) (technical skills motive)

And some respondents (5) mentioned insights about clients like contact details or product and purchasing preferences as an incentive to recruit from a direct competitor.

"[When] we need somebody who has specific competences, [...] who knows certain industryspecific processes, [...] we need somebody who previously has sold similar products to the same clients, who had the same suppliers etc. And then it makes sense to do competitor recruitment." (6) (client intelligence motive)

Concluding from these statements, competitor recruitment is primarily driven by the endeavor to acquire so-called industry-specific knowledge such as client knowledge, a client base or market insights. A possible explanation for why this is so can be found in the following statements.

Need for 'Plug-and-Play'. According to our respondents, an engagement in CR is oftentimes preceded by the expectation that the new recruit will adjust to the new environment and be productive much faster (6) and that the risk of misfit is lower than if recruiting an employee from outside the industry (6). A CR recruit can, in other words, be plugged in and play immediately.

"They said maybe, we go for ' $b$ ' since he is equally competent as ' $a$ ' and additionally is from a direct rival who knows our market well and can be productive very quickly. That's why we pick him." (6) (fast adjustment motive)

"But when approaching a decision, this so-called conclusion by analogy - he does something similar - is taken as a safe argument. Right, [...] he cannot be fully surprised about what we do here while he works for the same clients or has the same product or the same sales channels." (9) (high fit probability motive)

\section{CR Impediments}

In addition to reasons that motivate a firm to engage in competitor recruitment, several counter-indicants were provided as well.

Outside-Industry Knowledge. Firms that are in need of "fresh blood", that is, outside industry knowledge, to circumvent routine-blindness will not hire from a competitor 
since this would exclude the acquisition of other industry insights eventually. The majority of respondents (13) mentioned this issue as a prime force that makes a hiring firm refrain from engaging in competitor recruitment.

"There are many who specifically say: 'you are not allowed to and shall not look at a direct competitor... we (hiring firm) do not want market inbreeding. In other words, we (hiring firm) want the know-how from other industries, about what they do better."' (11) (fresh blood impediment)

Barriers due to Norms and Regulations. Also according to our respondents (10), some transfers are subject to legal restrictions such as explicit non-compete clauses or tacit agreements among firms of the same industry, which block (successful) competitor recruitment transfers. Non-compete clauses typically hamper employees from working for a competing company or unit within a certain period after quitting a job. Tacit agreements in contrast are norms within an industry, which are not legally enforceable. Both agreements constitute a barrier to competitor recruitment due to the likely costs to ransom an employee or likely relational damage a poaching firm has to fear when it violates norms.

"I believe it is nowadays not so easy anymore to pull somebody out of one company to - let me exaggerate slightly - engage in some type of industry espionage. First, there are non-compete clauses which are extremely well polished... there is usually no way to attack any of these key positions. Besides you need to act upon the assumption that the real linchpins are protected through highly competitive compensation packages...and through other protecting mechanisms." (2) (legal restrictions impediment)

"There are some [firms] who have informal agreements (with each other not to poach) and stick to them." (17) (tacit agreements impediment)

Risk of Employment Hurdles. Strong commitment of clients or recruits to the competing organization might lead to (1) clients not transferring along if the recruit transfers to the hiring firm and/or (2) a recruit not feeling comfortable "cheating" on a previous employer by transferring and hence displaying below-potential productivity post-hire. Both consequences were claimed by some respondents (6) to impede the competitor recruitment practice.

"Somebody who has been wearing hat $x$ and now tries on hat $y$ and then visits his clients... oftentimes, clients do not like that, neither do the candidates. [...] Actually, I think I also could not justify that in front of myself if I now moved to one of our direct competitors. My clients also would not understand it." (1) (rival firm loyalty impediment)

In addition, recruits from direct competitors were claimed (5) to sometimes be confronted with fiercer job competition than if moving to a non-rival because of two reasons: internal employees either feel that they are now competing with the new employee 
who carries similar knowledge for the same job advancements or they were hoping for a job change or promotion by filling the vacancy themselves. This again might cause a bad climate, diminished knowledge sharing or teamwork, and lower productivity of all parties involved.

"It can also have very natural reasons [that a placement fails]. For instance that there are certain oppositions in the direct environment of the vacancy..., for example that certain people in this environment were hoping to switch to that position but that then the board decided to fill the position with an external recruit." (8) (internal conflict impediment)

Fear of Retaliation. Alternatively, concerns about potential negative consequences of $\mathrm{CR}$ make recruiters or intermediaries refrain from an engagement in CR. Undesired consequences mentioned by some respondents were industry damage (5), knowledge theft (3) or image loss (1).

The risk of industry damage following from increased recruitment or employment costs through bidding wars or high salary levels respectively might hinder firms to use aggressive HR practices.

"Some clients already claim upfront that there is no [suitable candidate]: 'don't go to competitors, or we damage the whole industry'." (16) (industry damage impediment)

Poaching firms run the risk of losing knowledge through espionage either within the recruitment process by interviewing and sharing business insights with a candidate from a rival who in the end does not switch to the hiring firm, or after the transfer in case the recruit is hired back.

"There is also a trap: somebody comes, stays for a year, and then goes back to his old employer. I then have weakened myself. In the application talks already, both candidate and firm need to be careful on what type of information to share. If the candidate changes his mind [...] and has already opened his mouth about everything concerning strategies of the rival firm [...], then it can get problematic." (6) (knowledge theft impediment)

Finally, starting a talent war and using aggressive recruitment practices might lead to reputational damage of the poaching firm by sending a signal of not being able to perform without the use of aggressive business practices. A firm also runs the risk of destroying its alliances or trust relationships with its competitors or suppliers.

"Generally, I would say, the higher-up the vacancy to fill, the less likely [a hiring firm] is to intentionally recruit somebody from a rival. It is a certain image issue after all. [...] And if I recruit from my competitor, I put myself below him." (8) (image loss impediment)

Table 3.2 lists the themes, categories and the number of respondents (i.e. \#sources out of 19) that addressed each sub-category (i.e. 'nodes') as well as the number of times the 
respective issue was referred to in total by all respondents (i.e. \#codes) (from least to most important node per category). Some respondents mentioned the same node several times and multiple answers within the same category could occur (thus \#codes may be higher than \#sources). The number of sources refers to whether a specific respondent referred to an issue at all, regardless of how often. The more respondents addressed a certain issue, the more generally relevant it seems to be. The number of sources is thus the predominant indicator for the relevancy of a category.

Table 3.2 CR Characteristics, Motives and Impediments (sorted by \#sources from highest to lowest as the prime indicator for relevancy)

\begin{tabular}{|c|c|c|c|}
\hline Categories & Nodes & \#Sources & \#Codes \\
\hline \multicolumn{4}{|c|}{ The CR Concept } \\
\hline \multirow[t]{5}{*}{ Targets of CR } & middle or higher managers & 12 & 18 \\
\hline & specialists & 9 & 16 \\
\hline & individual stars & 12 & 21 \\
\hline & teams & 11 & 26 \\
\hline & $1+$ more & 10 & 13 \\
\hline \multirow[t]{2}{*}{ CR Transfer Mode } & mediated & 11 & 20 \\
\hline & direct & 8 & 9 \\
\hline \multirow[t]{4}{*}{ Goals of CR } & to strengthen & 16 & 29 \\
\hline & to weaken if necessary & 11 & 21 \\
\hline & welcome side-effect & 11 & 21 \\
\hline & only to weaken & 0 & 0 \\
\hline \multicolumn{4}{|c|}{ CR Motives } \\
\hline \multirow[t]{4}{*}{ Industry-Specific Knowledge (need for) } & market-related knowledge & 15 & 45 \\
\hline & social capital & 13 & 18 \\
\hline & technical skills & 12 & 30 \\
\hline & client intelligence & 5 & 6 \\
\hline \multirow[t]{2}{*}{ Plug-and-Play (need for) } & fast adjustment & 6 & 13 \\
\hline & high fit probability & 6 & 10 \\
\hline \multicolumn{4}{|c|}{ CR Impediments } \\
\hline Outside-Industry Knowledge (need for) & fresh blood & 13 & 23 \\
\hline \multirow[t]{2}{*}{ Norms \& Regulations (barriers due to) } & legal restrictions & 10 & 17 \\
\hline & tacit agreements & 10 & 17 \\
\hline \multirow[t]{2}{*}{ Employment Hurdles (risk of) } & enduring rival firm loyalty & 6 & 9 \\
\hline & internal conflict & 5 & 6 \\
\hline \multirow[t]{3}{*}{ Retaliation (fear of) } & industry damage & 5 & 5 \\
\hline & knowledge theft & 3 & 4 \\
\hline & image loss & 1 & 1 \\
\hline
\end{tabular}

The frequencies presented in Table 3.2 help us to understand better the underlying reasons and concerns surrounding CR. Specialists and middle and higher managers are equally addressed through CR; the process is often mediated but candidates might also be 
approached directly. The major incentive is never to only weaken a competing firm, but always to strengthen the hiring firm's own human resource base.

The latter two themes taken together can be used to construct a scale to indicate a firm's likely intention to engage in competitor recruitment. Figure 3.1 lists all motives and impediments identified in this study, and weighs them according to their relevance in determining a hiring firm's intention to engage in competitor recruitment.

Figure 3.1 CR Hire Intention of Firms Following from Weighing Motives and Impediments (sorted from most to least important based on Table 3.2)

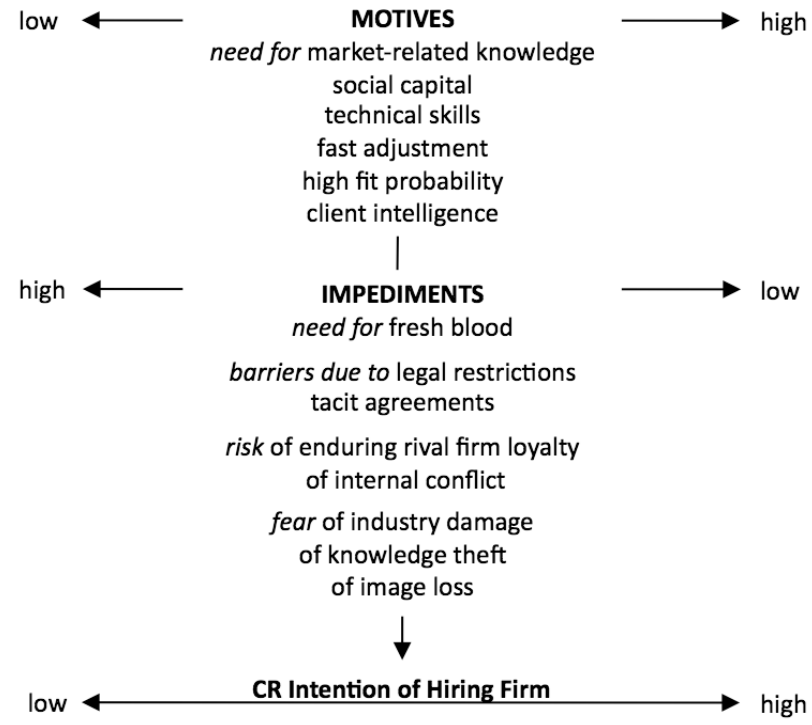

\section{Discussion}

This study suggests that CR appears to be a worthwhile recruitment practice under certain conditions and that the choice for a specific recruitment practice should be in accordance with prevailing contextual circumstances.

We began this chapter with several open questions, which we can now provide a first answer to. First, when and why does competitor recruitment take place? It takes place when firms do not fear retaliation or institutional barriers to $C R$, and are in need for human capital that can only be built up at a competing firm. Firms rely on CR to strengthen their human resources portfolio and to acquire highly valuable employees, either directly or through intermediaries. Second, what types of employees does it aim at? It primarily aims at specialists and mid to higher-level managers who carry industry-specific knowledge.

In this chapter, we outlined major motives and impediments for hiring firms (not) to engage in CR. Firms who consider competitor recruitment as a tool to acquire a new employee might benefit from reflecting on whether the single motives and impediments play a rather major, moderate or minor role, and then, based on the tendency evolving, 
conclude whether to poach from a rival or not. Specifically, a hiring firm's intention to engage in competitor recruitment is stronger when (1) the need for market-related knowledge, technical skills, social capital, fast adjustment, high fit probability and client intelligence is high and (2) the need for 'fresh blood', legal restrictions and tacit agreements, the risk of enduring rival firm loyalty and internal conflict, and the fear of industry damage, knowledge theft and image loss is low. Many informants agreed in various respects on the motives and impediments that surround a CR engagement. Those motives (e.g. need for market-related knowledge, social capital or technical skills) and impediments (e.g. tacit agreement and legal restrictions) that were mentioned by the majority of consultants seem to be prevailing heuristics that steer a recruitment decision toward or away from $C R$ regardless of context, individual differences or situational circumstances.

Generally, those motives and impediments mentioned less often might be more context-dependent. For example, the internal work contexts of competing companies are not necessarily similar, and hence do not facilitate the 'likelihood of fit' or a 'fast adjustment' to a job. Clearly, Audi, Volkswagen, BMW or Daimler do not all have the same corporate culture and work processes although they are facing the same challenges such as the coordination of model cycles or heavy price wars. Even though, Audi and Volkswagen might have a more similar work culture than Skoda and Toyota assuming that national cultures form business cultures (Hofstede, 1991). Also, some consultants considered 'client intelligence' a motive probably when they had a sales position in mind that is filled through CR, while others did not. Also, 'industry damage' or 'image loss' might only have been referred to if the industry in mind can be characterized by prevailing gentlemen's agreements such as at the conglomerate at Schalksmühle (see Introduction). Thus, overall, some motives and impediments seem to be more universalistic than others.

Human capital (Becker, 1962; 1964; Sturman et al., 2008) as well as institutional theory (e.g. Scott, 2004; 2008) thinking would probably help to explore our findings in more detail. The lens of human capital theory can serve to outline where to source a certain type of knowledge, skill or experience from based on the career path and education an employee has gone through (Becker, 1962; 1964) and the degree to which value can be reaped from engaging in e.g. competitor recruitment (Castanias \& Helfat, 2001; Sturman et al., 2008). If for instance a sales person is sought who ideally carries client contacts, a certain degree of knowledge about the product that is to be sold and a good feel for the market, industryspecific human capital should be aimed at (see 'market-related knowledge motive', 'technical skills motive', 'client intelligence motive'). If an executive is sought who brings in insights from another industry and thereby an open mindset to analyze current business practices, this executive should originate from a firm that functions in an industry different from the hiring firm's (see 'fresh blood impediment'). Institutional theory in contrast could help to explain how and to what extent regulative (see 'legal restrictions', 'tacit agreements'), normative (see 'fear of industry damage', 'knowledge theft', 'image loss') or cultural-cognitive (see 'internal conflict', 'rival firm loyalty') forces determine a hiring firm's intention to engage in competitor recruitment (see chapter 4). 
One insight of this research is especially salient. Respondents equally emphasized that the weakening of a rival firm is never a prime objective of strategic recruitment. Even the opposite seems to be true: the weakening aspect does not seem to play a core role at all when it comes to a hiring decision. Even when an employee occupied at a rival is approached, the ultimate end is the strengthening of the hiring firm's position and the filling of a vacancy with the best fitting available candidate. From a resource-based perspective, this is surprising though. Resource-based theorists claim that companies can obtain a competitive advantage under conditions of resource heterogeneity and imperfect mobility once they manage to create value with internally existing or internalized resources (Barney, 1986; Penrose, 1959; Peteraf, 1993). Looking at employees as human resources, one can argue that once a highly-educated employee, i.e. a valuable and scarce human resource in RBV terms, leaves a company to work for a direct competitor the hiring firm faces a resource gain whereas the rival firm registers a resource loss. This should potentially lead to a shift in relative market strength. Still, the latter aspect does not seem to constitute a key criterion in practice when deciding about from which firm to recruit. Based on our data, we can imagine three reasons for this contradiction between theory and practice.

First, several respondents claimed that a valuable candidate makes sure that a successor is in place. Accordingly, poaching a valuable candidate would never have a severe weakening effect on a 'prepared' rival firm. Thus, a reason for firms to neglect the weakening aspect could be that "every good candidate makes sure that a successor is already waiting to take over" (respondent 19). In other words, when a candidate is transferred but a successor prepared to replace him, the poaching firm does not damage the rival firm necessarily. Whether this is true remains to be investigated by future research taking the perspective of the competing firm.

Second, firms might be more concerned about securing a 'successful catch' rather than about the potential gap that they cause at a rival. After all, "it is not always clear whether the hired recruit will depict exactly the same productive behavior at the hiring firm as at his or her former employer. The fit is crucial and oftentimes the reason behind failure" (7). Put differently, the success of a placement depends on various characteristics of a competitor recruit and the hiring firm, not just the human capital carried. As Groysberg, Lee and Nanda (2008) have shown, not every recruit is fully deployable from the start - and maybe not even in the mid-term. But whether and how long it takes until a recruit is fully deployable certainly matters in terms of post-hire costs and productivity losses incurred (see chapter 2). Therefore, firms might be more concerned about and challenged enough with picking a recruit that fits their own firm context. Unfortunately, Groysberg et al. only looked at one type of professional, namely star analysts, with distinct and thus probably not generalizable characteristics. It would however be interesting to see to what extent these findings can be transferred to other industries or positions.

Third, and in line with the previous remark, a hiring firm is never fully aware of how critical the role the potential recruit plays in the rival firm's context is. In other words, due to limited observability it is hard to estimate for a hiring firm whether a weakening 
effect will occur at all. As one respondent stated, "whether you will really weaken your competitor, you never know, you are not involved enough in their corporate structures". Future research should thus look at the real effects that competitor recruitment might have on a poached firm and the degree to which it can actually be used as a strategic tool by a hiring firm. To this end, we suggest that future efforts are dedicated toward the inquiry of the conditions under which competitor recruitment can indeed cause a shift in competitive positions and hence a creation of a human capital advantage for the hiring firm.

\section{Limitations and Future Research}

Although our sample consisted of a relatively small number of respondents, we are confident to have exhausted the possible number of themes and viewpoints as we have reached a saturation point throughout the interviewing process with repetitive examples and information being provided. Still, some limitations should be borne in mind by future researchers in the field.

We have among others addressed whether CR is done directly or through intermediaries. The sample itself consists of intermediaries though. This might raise the question whether our respondents were actually able to assess what is done directly although they claimed to have regular contact with clients and are thereby also informed about recruiting processes that are undertaken directly. Equally, looking through the eyes of executive search consultants who have their own stake in mediating a competitor recruit transfer might have disguised hidden motives behind competitor recruitment, such as the weakening of a rival. Social desirability bias may have caused respondents to be concerned about portraying the executive search industry in a favorable manner or to overestimate the (number of) cases in which $C R$ is mediated. One respondent even emphasized that he "appreciate[s] this research being done to improve the image of the executive search industry". We tried to circumvent the social desirability bias by phasing similar question differently at several points in time. This indeed caused a number of respondents to refer to example cases after a while though they were very defensive initially. Future research should take the potential sensitivity of this topic or likely bias of certain stakeholders into consideration when setting up data collection methods.

As executive search firms' field of activity is restricted to managers and specialists earning a yearly income of or above $€ 80,000$ our sample does not fully represent the whole labor market. Employment agencies that deal with graduates, young professionals or generally employees from other than managerial or specialist positions are excluded. We do not consider this a real limitation to the findings as it was shown in previous chapters that primarily specialist and mid to higher-level management positions are concerned. Further research into the type of positions filled through CR is still recommended potentially with the addition of other viewpoints. We recognize that our (small $n$ ) research might suffer from "single perspective bias" lowering the validity of our data. After all, the research does not include the recruit's, neither the rival firm's nor the hiring firm manager's perspective, which would however certainly enrich the findings. Future research could thus apply the same 
methods to a different setting, e.g. a sample of internal HR professionals to cross-validate the results (see chapter 4).

Having covered all industries and a wide array of positions above a yearly income of $€ 80,000$ through a sample of key informants, our findings are transferrable to other $C R$ hire situations. We are even convinced that the basic premises apply to any poaching situation. In other words, whether mediated or not might depend less on the recruit profile and company than on the financial resources available at the hiring firm at that time. This is especially so because HR professionals might be torn regarding whether to involve an intermediary or not. On the one hand, the more varied and complex a job is, the more demands there will be on the selection process, the more beneficial it can be to cooperate with a search firm (O'Leary et al., 2002; Wilk \& Cappelli, 2003). On the other hand, information about external candidates of the same industry might be readily available because of industry reports or analyses, leading to potential candidates being addressed rather informally under conditions of lower costs (Bailey \& Helfat, 2003). Further research should thus investigate the frequency with which $C R$ occurs through direct channels and whether those cases differ from those in which an intermediary is involved, for instance in terms of the enforceability of a non-compete clause. Non-presented parts of the current data suggest that an intermediary might be involved if (1) the hiring firm does not have any social capital or industry insights itself, which would allow for an informal recruiting process, (2) the hiring firm does not want to "dirty their hands" with unpleasant tasks such as poaching from rivals or (3) HR managers are not considered competent enough by higher management professionals to arrange the hire. It deserves further clarification when executive search consultants are and should be employed. A great start was made by Monika Hamori (2010) who found that executive search firms tend to help individuals move between industries but not across job functions or to new roles, which would suggest that $\mathrm{CR}$ relatively less often occurs with the support of a search firm. 


\section{4}

\section{How to Make CR Practically a Success ${ }^{47,48,49}$}

Recent research focusing on human capital transfers did not yet look at the real benefits of competitor recruitment. Building on the broad findings of chapter 3 and the fact that the most prominent motives and impediments outlined can be well explained by human capital as well as institutional theory, we used these two theories in this chapter to shed more light on the phenomenon of $C R$, and its cost and value drivers.

We offer an empirical exploration of these drivers through the same interviews with the 19 consultants of the top 25 German executive search firms of chapter 3 and additional $9 \mathrm{HR}$ managers from different companies.

We find that competitor recruits are indeed highly beneficial since they carry valuable industry-specific human capital. Whether the hiring firm can appropriate this human capital, however, depends largely on certain here-outlined costly HR practices employed by the hiring firm primarily post-hire in a specific institutional context. Generally, it seems that the higher the fit between the recruit and the organizational environment, the lower the costs incurred and hence the higher the value captured.

\footnotetext{
${ }^{47}$ This chapter is based on: Horn, S., W. van Olffen \& Heijltjes, M.G (2010). An Empirical Investigation of How Firms Succeed in Capturing Competitor Recruit Value. Southern Management Association Annual Meeting (Human Resources | Careers Track).

${ }^{48}$ I am very thankful for highly insightful, considerate and thorough conference feedback received by Prof.dr. David Allen on a previous version of this chapter.

${ }^{49}$ I also thank Christine Nickels and Georg Zysk for helpful support in data collection and coding.
} 
Although the current economic slowdown has resulted in layoffs of highly educated workers, firms remain concerned about demographic changes and the quality and distinctiveness of their employees (Leisy \& Pyron, 2009). This continues to feed the war for talent (Cappelli, 2000; Gardner, 2002). For example, in Germany, the supply of both executives and specialists will remain constant until the year 2015 before shrinking and creating a gap of about 350,000 employees by 2025 and close to 1 million by 2050 (Schneider \& Stein, 2006). As previous chapters have also suggested, human capital is thus gaining in recognition, and practitioners and researchers alike acknowledge the importance of understanding how rival firms engage and succeed in acquiring and deploying the 'best' human capital carriers (e.g. Barney, 1991; Beechler \& Woodward, 2009; Gardner, 2005; Lepak \& Snell, 1999; Offstein, Gnyawali \& Cobb, 2005; Pfeffer, 1994; Sturman et al., 2008).

Although recent research has looked at human capital transfers, it did not yet investigate this specific case of competitor recruitment as a strategic staffing practice. Primarily, implications of CR, like product market entry, product innovation or client ties transfer (Aime et al., 2010; Boeker, 1997; Gardner, 2005; Groysberg et al., 2008; Rao \& Drazin, 2002; Rosenkopf \& Almeida, 2003; Somaya et al., 2008; Song et al., 2003; Wezel et al., 2006), or barriers to $C R$, such as non-compete agreements or ethical concerns (Gardner et al., 2010; Marx et al., 2009), have been described (see chapter 2 for a more elaborate review). A full picture, including antecedents to CR (see chapter 3 ) and how CR processes differ from other recruitment initiatives especially in terms of value creation over time have been left out though. Such a comparative process consideration is crucial however since identifying a recruit with valuable human capital is necessary but not sufficient to obtain a human capital advantage since also costs are involved in the identification, transfer and deployment stage that potentially lower the overall value captured in the end (Foss, 2008).

This chapter seeks to fill this gap by empirically shedding light on three main issues. We investigate (1) what type of human capital is most susceptible to poaching from rivals, (2) what potential institutional barriers to CR exist, and (3) what factors finally allow hiring firms to appropriate the estimated human capital value at a cost/benefit ratio that truly creates value over time. We expect our findings to not only present the parameters that make a competitor recruitment process successful but to show that recruiting employees from rivals can constitute a major source of value creation.

We build upon insights gained from chapter 3 . While chapter 3 explored reasons (not) to engage in CR (ex ante the identification stage) and suggested that they can to a large extent be understood through the lens of human capital and institutional theory, chapter 4 now uses these theoretical lenses to deduce more specific factors that determine the final value that can practically be captured from CR ex post the transfer stage, and assesses those in practice.

To this end, we will first shortly review the assumptions of human capital as well as institutional theory and apply them to the context of competitor recruitment. This will generate insights that are visualized in a model outlining the relevance of human capital for $C R$ success and the costs or barriers involved in the $C R$ process partly stemming from 
prevailing institutional forces. Subsequently, we present the qualitative methodology used to explore the model components, followed by an outline of the results and a discussion. Finally, the implications of this study, existing limitations and suggestions for further research are described and a conclusion is drawn.

\section{Reviewing the Value of Competitor Recruit Mobility}

The strategic management literature has been arguing that an integrative linkage between strategy formulation and implementation is essential for the attainment of a competitive advantage (e.g. Cohen \& Cyert, 1973; Hitt \& Ireland, 1985). Human resource managers face a similar challenge when seeking the creation of a human capital advantage (e.g. Bamberger \& Meshoulam, 2000; Devanna, Fombrun \& Tichy, 1981). Eventually, deciding to engage in CR to fill a specific vacancy is not sufficient but requires additional supportive conditions during the subsequent recruitment and deployment stages to capture the expected human capital in the end. The following sections theoretically review human capital value and cost drivers of $C R$ as well as potential institutional barriers to $C R$.

\section{Human Capital Benefit of Competitor Recruits ${ }^{50}$}

The notion has emerged that different aspects and types of human capital may be unequally valued (e.g. Gardner, 2002; 2005; Groysberg et al., 2006; Sturman et al., 2008). Examining competitor recruitment in light of this assumption is therefore an interesting issue to address.

As delineated in chapter 1 already, human capital can be defined as the stock of valued knowledge, skills, abilities or other attributes (KSAO) controlled by an individual that was obtained through education, training and experience, and constitutes the characteristics of an individual that are valuable in an economic context (Becker, 1962; 1964; Foss, 2008; Hitt et al., 2001). But rather than subdividing human capital into soft and hard elements as we did for chapter 1's study purpose, recent authors have decomposed human capital into what is valuable to a specific employer and what has value in the broader labor market. Sturman, Walsh and Cheramie (2008) among others identified human capital as a key resource, for which organizations compete. They differentiated the value firms place on human capital as a function of its transferability and specificity. Human capital specificity refers to the degree to which an individual's knowledge, skills, abilities, and other competencies are rare or unique and generate above-average rents for the firm at which they are currently employed. Human capital transferability in contrast refers to the degree to which human capital is portable and deployable by another firm. Sturman et al. (2008) conclude with a continuum of transferability (left) and specificity (right) arraying general, industry-specific, firm-explicit and firm-specific human capital (from left to right) (Castanias \& Helfat, 1991; 2001; Hatch \& Dyer, 2004; Hitt et al., 2004; Wang \& Barney, 2006).

\footnotetext{
${ }^{50}$ Specifies the origin of CR value as described in chapter 2.
} 
General human capital that encompasses the softer skills like leadership abilities or social competence as well as technical or business basics is not dependent on any firm or professional background, and is essentially of use to any firm (Acemoglu, 1997; Bailey \& Helfat, 2003; Offstein et al., 2005; Sturman et al., 2008). In contrast, firm-specific human capital at the other end of the continuum is only valuable to the firm currently employed at because it includes knowledge about procedures and routines, systems or processes that are unique to a specific company context (Bailey \& Helfat, 2003; Becker, 1962; Groysberg et al., 2006; Sturman et al., 2008; Castanias \& Helfat, 1991; 2001). Industry-specific human capital contains technical, regulatory, customer or supplier knowledge that is useful to all companies of the same industry, whether product or industry rival (Bailey \& Helfat, 2003; Castanias \& Helfat, 1991; 2001; Groysberg et al., 2006). Finally, firm-explicit human capital is knowledge that is also highly context specific and has limited transferability (Sturman et al.; 2008) as it is associated with knowledge about strategic trends, past or current projects or plans, or customers or client contacts, all of direct competitors (Seibert, Kraimer \& Liden, 2001). In addition, it entails negative knowledge (i.e. knowledge about what does not work), which involves knowledge gained through research, experiments and experience discovering dead ends, pitfalls, and faulty processes that fail to produce valued business outcomes (Stone, 2002). It thereby incorporates knowledge that is beneficial only to a firm and its direct product-market competitors. Firm-explicit as well as industry-specific human capital are both considered a reliable source of value acquisition and creation because both incorporate knowledge that is highly beneficial to a firm in a competitive context (e.g. Combs \& Skill, 2003; Schneider \& Stein, 2006; Song et al., 2003; Sturman et al., 2008). The types of jobs that require either type of human capital are predominantly specialist and managerial level positions (Schneider \& Stein, 2006). Generally, industry-specific human capital is somewhat more difficult to protect by non-compete agreements since two firms could be in the same industry but not be direct competitors. But since the difference is minor and most authors do not differentiate between firm-explicit and industry-specific human capital as both have the same competitive implications (e.g. Castanias \& Helfat, 1991; 2001; Bailey \& Helfat, 2003), this dissertation has and will apply the more widely used term industryspecific human capital to imply both types.

Since competitor recruitment as we sketched it in chapter 3 primarily aims at employees who carry industry-specific human capital, which they have accumulated in previous jobs in the same industry ${ }^{51}$ (e.g. Combs \& Skill, 2003; Schneider \& Stein, 2006; Song

\footnotetext{
${ }^{51}$ In Porter's (1985) five-forces model, industry refers to firms with whom one is specifically competing. Some have consequently defined industry-specific human capital as experience gathered in firms with the same three-digit SIC code (e.g. Harris \& Helfat, 1997); others have used broader definitions, using two-digit SIC codes (e.g. Hatfield, Liebeskind \& Opler, 1996). Tang and Tseng (2004) used an even broader conceptualization of industry, providing categories somewhat between one- and two-digit SIC codes, such as "agriculture, forestry, and fishing"; "energy and mining"; and "construction" as we did in chapter 1 . Thus, scholars in the field have not necessarily been referring to the same specificity of skills and knowledge when referring to industry-specific human capital. We follow the theoretical framework as proposed by Castanias and Helfat (2001) and Sturman et al. (2008) when referring to industry-specific
} 
et al., 2003; Sturman et al., 2008), it is most likely a very valuable personnel acquisition strategy. After all, industry-specific human capital implies limited transferability and rather high specificity, i.e. value and rarity (e.g. Adegbesan, 2009; Barney, 1986; 1991; Penrose, 1959; Peteraf, 1993), and cannot be acquired otherwise.

\section{Costs of Competitor Recruitment ${ }^{52}$}

CR Process. In an effort to realize the human capital value expected through an engagement in CR costly investments in recruitment and utilization efforts are required. Recruitment costs are mostly predictable and incurred only once, and follow from identification (e.g. computational costs of estimating potential recruit value, employing a search agency) and transfer (e.g. moving allowance; golden hellos, negotiation of contractual terms) efforts. Rarely, recruitment costs are unpredictable. An example, however, would be relational damages that follow from bidding wars. Utilization costs follow from investments in deploying the recruit and are partly one-off costs (e.g. start-up investments, outfitting costs for offices or equipment, organizational adjustments, orientation programs) and partly recurring due to productivity enforcement efforts such as compensation (e.g. variable/fixed pay), training (e.g. technical skills), monitoring (e.g. performance management) or retention (e.g. golden handcuffs).

Identification. Having established recruitment objectives, an organization develops a strategy for filling the vacancy by deciding on when to begin recruiting, what message to communicate to potential recruits, and whom and how to recruit (Breaugh, 2008). Identifying a recruit primarily involves the search through one or more suitable channels, such as databases, referrals or search firms. In the case of competitor recruitment, major recruiting skills are required since employees who carry valuable industry-specific human capital are generally higher managers or specialists that are not necessarily on the job market but hidden in fixed employment contracts. They tend to be difficult to find through job advertisements or recruiting events, but rather through personal networks or wellrespected consultants. As a result, an engagement in competitor recruitment constitutes particular challenges and might require a costly reliance on discrete recruiters or search firm consultants who have the skills, necessary contacts and industry insights.

Transfer. Once an attractive candidate is identified, he or she is contacted and assessed for suitability. If a hire is desired, the candidate needs to be motivated to transfer to the hiring firm, which might involve contract or pay negotiations, or simply the provision of information about the firm or work environment. In the context of competitor recruitment, this transfer process might involve CR-typical issues such as negotiations over (how to circumvent) payback, non-compete or non-solicitation clauses. Generally, approaching an employed candidate, especially at a competitor, might be a sensitive issue

human capital, and suggest that this type of human capital can be acquired at a company within the same one-digit SIC code.

${ }^{52}$ Specifies the costs discussed in chapter 2 in practical terms. 
and needs to be dealt with competently and carefully, not to run the risk of reputational damage or fiercer labor market competition.

Deployment. Many firms hire experienced professionals and expect them to "plugand-play" (Fernandez-Araoz, Groysberg \& Nohria, 2009), i.e. to be productive right from the start. Still, 40 percent of new hires that depart within two years do so because of integration difficulties that are not sufficiently taken care of by responsible HR professionals (FernándezAráoz et al., 2009). The degree of deployability of a newcomer, therefore, depends largely on the HR practices employed to support a fit between the recruit and the hiring firm posthire (Kor \& Leblebici, 2005; Kristof-Brown, Zimmerman \& Johnson, 2005). After all, the CR process does not stop once the CR recruit is identified and transferred but instead a hiring firm needs to foster human capital appropriation as well as staying intentions (e.g. Allen, 2006; Boudreau \& Ramsted, 1997; Coff, 2010; Foss, 2008; Groysberg et al., 2008). It is, therefore, not only important to define the potential human capital value pre-hire and initiate a transfer, but costly efforts should also be directed at the deployment of an employee's human capital post-hire and over time.

\section{Institutional Barriers Moderating CR Value Appropriation}

Institutional barriers can aggravate costs of $\mathrm{CR}$ - also unexpectedly. These barriers can be so severe as to block the process fully (e.g. non-abolishable non-compete agreements) or at least impair the process, and then require additional costly investments to be made (e.g. moving fee, socialization practices). Institutional factors might thus play a role in determining the occurrence of competitor recruitment and its prize.

The field of institutional theory can be characterized by a variety of ideas, findings and opinions. What all scholars agree upon is the fact that companies have to "adapt to and be consistent with their institutional environment" to survive (e.g. Björkman, Frey \& Park, 2007; DiMaggio \& Powell, 1991; North, 1971; Scott, 2008; Williamson, 1975). Organizations are, thus, part of a social environment that influences business processes or practices such as human resource management policies relied upon (e.g. Boon, Boselie \& Den Hartog, 2009; Farndale \& Paauwe, 2007; Meyer \& Rowan, 1977; Paauwe, 2004; Paauwe \& Boselie, 2003; Powell, 1998; Scott, 1987; Wright \& McMahan, 1992). Scott (2004) created one of the core pieces in the field by identifying three major institutional forces, namely the regulative (e.g. North, 1971; Williamson, 1991), the normative (e.g. March \& Olsen, 1984; 1989) and the cultural-cognitive (e.g. DiMaggio \& Powell, 1991; Scott, 2001). The three resulting forces do not necessarily reinforce each other but stand for themselves (Scott, 2004; 2008). The following sections illustrate the potential impact of each institutional factor on competitor recruitment.

Regulative Factors Influencing CR. Regulative processes are about informal and formal rules as well as their execution as rooted in law, politics or economics. Practical examples would be property rights, legislation and court decisions (Orr, 2004; Scott, 2004). A 
non-compete clause is one of the major regulative factors affecting competitor recruitment. In Germany, for instance, both contractual and post-contractual non-compete clauses ${ }^{53}$ are applied. These clauses suggest that an employee is not allowed to work for a competing party either during or ex post employment.

In addition to formal agreements, informal agreements among competitors might prevent poaching each other's human capital (Gardner et al., 2010). The US Justice Department recently investigated a case involving the IT giants 'Google', 'Apple' and 'Yahoo' who mutually agreed on not wooing away each other's top employees (Kang, 2009). With these agreements, firms run the risk, however, to be sued because of illegal corporate behavior (Kang, 2009; Maisto, 2009; Gardner et al., 2010).

Normative Factors Influencing CR. Besides regulative factors, industry norms and values that translate into perceived norms or standards might also limit the occurrence of $\mathrm{CR}$. The normative pillar includes "rules that introduce a prescriptive, evaluative, and obligatory dimension into social life" (Scott, 2008). Practical examples are protocols, codes of conduct or industry standards that guide human behavior (Orr, 2004).

Practices that are applied by many organizations in an industry might for instance be based on recommendations of consultants (Harcourt, Lam \& Harcourt, 2005; Scott, 2001). If, for instance, leading consultancies evaluate competitor recruitment as ineffective or unethical while promoting internal recruitment instead, it is less likely that CR is - openly applied among organizations. Vice versa, the more professionals, consultants and scholars active in the field of HR management regard competitor recruitment as a favorable talent management strategy or even a best practice, the more it will be regarded as beneficial and legitimate, and therefore applied (Wright \& McMahan, 1992). Best practices are an example for how practices have developed into a widely accepted industry standard over time (Harcourt et al., 2005).

On the organizational level, codes of conduct or codes of ethics might hinder the occurrence of CR. Part of the Daimler Corporation's code of ethics, for example, is the mutual agreement that competitive advantages should not be achieved through the application of unlawful or unethical business practices (Daimler, 2011). CR would be restricted under such a code of conduct if perceived as an unethical business practice internally.

Cultural-Cognitive Factors Influencing CR. Looking at how actors make sense of the world, the cultural-cognitive pillar explores "tacit human belief systems, scripts, identities, schemas and roles" that underlie human behavior (Orr, 2004; Scott, 2008). A practical example here would be a firm's corporate culture that promotes certain values or

\footnotetext{
${ }^{53}$ Post contractual non-compete clauses for instance are anchored in $\S 74 \mathrm{ff} \mathrm{HGB}$ (Handelsgesetzbuch). To be operative, a few requirements have to be fulfilled. (1) the employer has to agree on offering a compensation package for the time the employee is bound to a specific firm, (2) the clause has to be remarked in written form and be limited to two years, and (3) the non-compete clause has to protect a justifiable business interest. In case of non-compliance, the employer can sue out an action for an injunction and ask for indemnities (Chamber of Commerce, 2009).
} 
other unwritten guidelines for behavior. If a firm's HR professionals attract the best and most productive people from rivals, CR might become part of a firm's corporate culture once these HR professionals recommend $C R$ to $H R$ colleagues in turn without any written or explicit statements or guidelines following from it.

Cognitive factors that are transmitted over time and manifest themselves in people's thinking and competences might play a role, too. If competitor recruitment is evaluated as a risky undertaking, a recruiter might rather refrain from it. Even more elementary, organizations have to be aware of the existence and acceptance of this practice and be skilled and able to execute it. If CR is not widely understood and acknowledged as a useful practice, it is not taught in business schools, internal trainings or during adjustment phases of new colleagues, thereby not being institutionalized within a certain (educational) business context.

Figure 4.1 illustrates the main relations between the forces described constituting a refinement of Figure I as presented in the Introduction. While constituting essentially a general recruitment model, specific implications follow for competitor recruitment endeavors, as was and will be shown.

As outlined in chapter 2, firms need to balance benefits with costs clearly when making the decision to engage in competitor recruitment (Kim \& Mahoney, 2006). In other words, recruitment and utilization costs need to be lower than the value captured from a CR recruit's human capital in order to appropriate a positive net value in the end. Therefore, they need to invest in scanning the labor market, evaluate recruit information and initiate a transfer on the one hand (recruitment costs). On the other hand, to capture value over time, the hiring firm has to apply effective HR practices that support the deployment process of a CR recruit (utilization costs) while keeping costs lower than value. Recruitment costs follow from the identification and transfer stage, and are normally one-off costs, as they only require one-time investments. Utilization costs in contrast are recurring and tend to arise repeatedly during the deployment stage. Institutional barriers prevailing in the organizational environment moderate the degree of costs to incur. 
Figure 4.1 Factors Influencing the Final Value Appropriated by CR

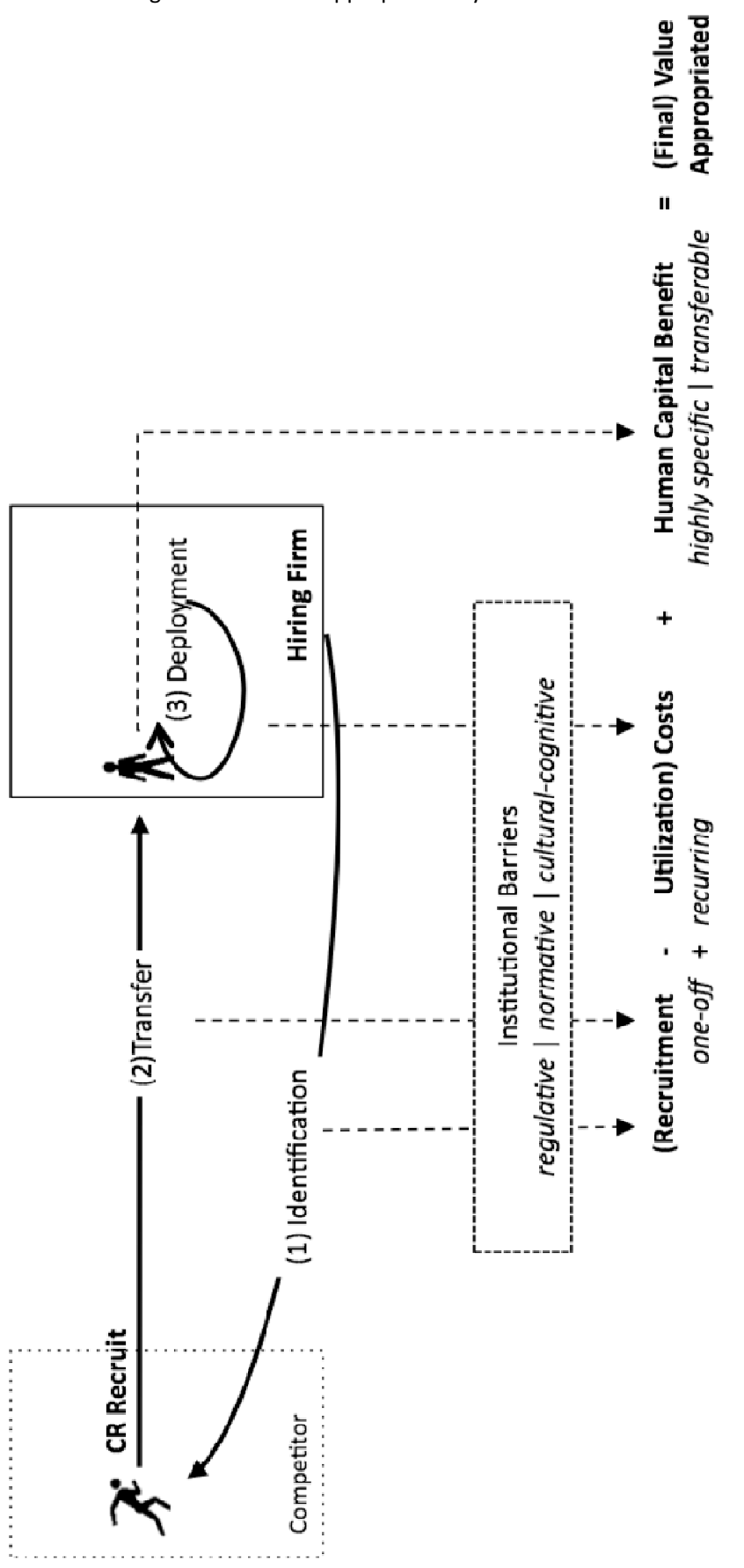




\section{Method}

As in chapter 3, a qualitative research design was considered appropriate for our research purpose aiming to gain an in-depth understanding of the core forces influencing mobility between rivals (Thomas, 2006). Two research assistants were involved in the coding as well as data collection process of two different datasets to facilitate data interpretation and increase the reliability of the results (Green et al., 2006). The period of the two subsequent data collection phases was April 2009 until January 2010.

\section{Data Collection}

In total, two datasets were collected through interviews conducted with (1) mediating search firm consultants and (2) HR professionals. Dataset (1) was already used for our study of chapter 3 .

To support the process of sample and method choice for the second dataset, initial insights about the issue were acquired by launching threads and participating in discussion forums on the German business platform ' $\mathrm{XING}^{54}$. Since no specific population could be identified, which is primarily concerned with and knowledgeable about the issue of competitor recruitment, a sample covering various industries, company sizes and HR positions was considered most appropriate. Since the discussions on XING also suggested that competitor recruitment is a topic that requires a confidential environment, we decided to pursue convenience sampling.

The geographic focus for this work was also Germany in order to obtain results that are comparable with others of this dissertation, and because Germany is forecasted to be severely affected by demographic changes and resulting labor shortages in the future, as outlined before. All participants thus worked in German companies or German subsidiaries of international companies at the time of data collection.

Samples and Sampling Strategy. We retrieved first insights from the interviews conducted with the executive search consultants for chapter 3 (for respondent profiles see Table 3.1). We additionally decided to collect data from a different source and to obtain first-hand insights on the subject of interest to be able to shed light also on more tacit issues. This was achieved through in-depth interviews with $9 \mathrm{HR}$ professionals.

All 9 interviewees were required to have previously dealt with operative and strategic recruitment issues, either as a member of an HR-related function or as the respective business manager. Besides, respondents ideally had built up experience within the recruitment field over various years reflected by their level of seniority. Accordingly, participants held positions as recruiting manager, HR business partner, vice president executive staffing, head of HR or CEO, working on the job for three years or longer. To cover diversity in terms of industry affiliation, participants had different industry backgrounds such

\footnotetext{
${ }^{54} \mathrm{Xing}$ is comparable to the internationally recognized platform 'LinkedIn'. Threads were posted in several out of the more than 30,000 discussion forums, namely 'Human Resources', 'HR in Europe', 'Application and Recruiting' or 'Personnel'.
} 
as information technology, consulting, financial services, logistics, renewable energy, brewery and mechanical engineering. Three representatives were chosen from firms of less than 500 employees, three of firms between 1000 and 10000, and three of firms of more than 10000 employees (see Table 4.1).

Table 4.1 HR Professionals' Profiles

\begin{tabular}{|c|c|c|c|c|c|c|c|c|c|c|}
\hline & $a^{a}$ & $b^{b}$ & $c^{b}$ & $d^{b}$ & $e^{b}$ & $f^{b}$ & $g^{b}$ & $h^{b}$ & $i^{b}$ & $\Sigma$ \\
\hline \multicolumn{11}{|c|}{ Role Title } \\
\hline CEO & & & & & & $\mathrm{X}$ & & & & 1 \\
\hline Vice president Executive Staffing & $x$ & & & & & & & & & 1 \\
\hline Human Resources Manager & & & & $\mathrm{x}$ & & & $x$ & & & 2 \\
\hline Head of HR & & & & & & & & $x$ & $x$ & 2 \\
\hline Recruiting Manager & & $x$ & & & & & & & & 1 \\
\hline Head of Personnel Development & & & & & $x$ & & & & & 1 \\
\hline Leader Recruitment Germany & & & $x$ & & & & & & & 1 \\
\hline \multicolumn{11}{|c|}{ HR-Experience (years) } \\
\hline $0-5$ & & $x$ & & & & & & & & 1 \\
\hline $6-10$ & & & & $\mathrm{X}$ & $\mathrm{X}$ & $\mathrm{x}$ & & & & 3 \\
\hline $10+$ & $\mathrm{x}$ & & $\mathrm{X}$ & & & & $\mathrm{X}$ & $\mathrm{x}$ & $x$ & 5 \\
\hline \multicolumn{11}{|c|}{ Industry } \\
\hline Logistics + SCM ${ }^{\mathrm{C}}$ & $x$ & & & & & & & & & 1 \\
\hline Financial Services & & $\mathrm{x}$ & & & & & $x$ & $\mathrm{x}$ & & 3 \\
\hline IT & & & $\mathrm{x}$ & $\mathrm{x}$ & & & & & & 2 \\
\hline Engineering + Industrial Goods & & & & & $x$ & & & & & 1 \\
\hline Brewery & & & & & & & & & $x$ & 1 \\
\hline Renewable Energy & & & & & & $x$ & & & & 1 \\
\hline \multicolumn{11}{|c|}{ Company Size } \\
\hline $0-500$ & & & & $x$ & $x$ & $\mathrm{x}$ & & & & 3 \\
\hline $1000-10000$ & & & & & & & $x$ & $x$ & $x$ & 3 \\
\hline $10000+$ & $x$ & $x$ & $x$ & & & & & & & 3 \\
\hline
\end{tabular}

Notes. ${ }^{a}$ personal + transcribed; ${ }^{b}$ phone interviews + notes; ${ }^{c}$ Supply Chain Management

Interview Process. Interview protocols were pre-tested for each sample. The four personal pilot interviews with the executive search consultants of chapter 3 were used again as well as two additional interviews with HR professionals from medium-sized firms. Except when explicitly mentioned, the pilot interviews are excluded from the following report.

Information on the interview process with the executive search consultants can be retrieved from chapter 3 . The duration of the interviews with the HR professionals varied between 30-60 minutes. Eight of them were conducted via phone while one was conducted at the respondent's working place. Each interview was tape-recorded as a precondition for the inductive coding process to follow verbatim. All interviews started with a short introduction to the topic of barriers to $\mathrm{CR}$, followed by questions reflecting the different institutional pillars. Examples of questions were "How would you prevent one of your 
employees from being poached by a competitor?", "What is your personal attitude toward competitor recruitment and where does it come from?" (reflecting cognitive and cultural issues respectively) or "Can you think of general rules or values that constrain CR?" (reflecting regulative and normative issues respectively) (see Appendix $2 b$ ).

The interviewer was an open listener and only directed the conversation to cover the main themes. Only if interviewees were short in their answers, specific keywords were provided to trigger further responses. Interviewees were informed that the purpose of this research was to investigate personal experiences with the practice of competitor recruitment and that there were, thus, no 'right or wrong' answers. Probing questions were used to verify the interviewer's interpretation of answers (Kvale, 1996). Some 'critical incidents', i.e. examples, were introduced at times to facilitate the understanding of the questions (Flanagan, 1954). Emerging ideas that were not initially covered were followed-up in subsequent interviews. Confidentiality was ensured to all respondents, and private and sensitive issues were avoided at all times. Interviews were again conducted in the German language.

\section{Data Analysis}

The data analysis process followed the procedure as described by Thomas (2006). We thus used a hybrid approach of inductive and deductive data analysis. This approach allows the tenets of existing research on external labor mobility to be integral to the process of deductive thematic analysis while allowing for themes in the specific, unexplored context of competitor recruitment to emerge directly from the data by engaging in so-called general inductive coding. "Data analysis is [thus] determined by both the research objectives (deductive) and multiple readings and interpretations of the raw data (inductive)" (Thomas, 2006).

The main endeavor of this approach was to a) condense our raw textual data, b) establish clear links between the research objectives and the raw data, and c) develop a framework of the underlying structure that seems to guide firms in engaging in competitor recruitment (Thomas, 2006). Initial themes (i.e. benefits, costs and institutional barriers), categories and hierarchical nodes were hence clearly pre-defined in a coding scheme that guided the coding process ex ante data analysis. We still allowed additional categories to emerge (non-institutional barriers) like in chapter 3 . The coding process followed the same procedure as the coding procedure described in chapter 3.

\section{Results}

In the following section, each category and node that emerged from the data analysis is addressed with a representative quote ${ }^{55}$. The brackets following each quote refer to the respondent that made the respective quote (letters are used for consultants and numbers for HR professionals) and to the node names. The final document consisted of 30 nodes that

\footnotetext{
${ }^{55}$ Codes were translated from German to English and cross-checked by an independent researcher.
} 
were assigned hierarchically to 8 so-called higher-order categories covered under the three major themes of (1) Human Capital Benefits of Competitor Recruits, (2) Costs of Competitor Recruitment and (3) Barriers to Competitor Recruitment.

Table 4.2 (see end of this section) provides an overview of all themes, categories and nodes outlined.

\section{Human Capital Benefits of Competitor Recruits}

Competitor recruits are beneficial to a hiring firm when they carry both industryspecific as well as non-industry-specific (general) human capital. Although non-industryspecific human capital is carried by all employees whether coming from a rival or not, it can also make competitor recruits especially attractive. The below given quote illustrates that it is industry-specific human capital though that is the prime motive when addressing competing firms, while non-industry-specific human capital is rather a hygiene factor and only considered, but nevertheless relevant, when industry-specific skills are given.

"Concerning hard skills [industry-specific human capital] such as the production processes for engineering, sales channels for sales and marketing, simply the knowledge about [specific] processes, this is what is valuable....Soft skills [non-industry-specific human capital] are looked at only next." (12)

Industry-Specific Human Capital. Interviewees ${ }^{\mathbf{5 6}}$ considered the acquisition of industry-specific human capital a core motive encouraging competitor recruit solicitation. By addressing employees from competing firms, hiring firms expect to gain business insights about sales channels or processes that are related to the industry environment, or valuable contacts such as customer profiles or client relationships that lead to a gain in additional market share once transferred along with a recruit.

The majority of respondents noted that a client base or other business-related relationships, namely social capital, are a relevant performance factor that can only be acquired through candidates who have built up tacit knowledge within the same industry.

"Value-increasing factors are contacts, which are not existent at the hiring firm and which the candidate has." (19) (social capital)

Market knowledge relates to human capital that allows an employee to have a tacit grasp of 'how things work' in an industry.

"Of course, it is about knowledge [about the industry]...the goal is to advance the company. [...] You hire an employee in order to initiate a knowledge transfer." (10) (market knowledge)

\footnotetext{
${ }^{56}$ Since two datasets were combined (Consultants + HR Professionals), absolute numbers would not serve to illustrate the relative importance of a certain category. As a result, terms such as "some" or "a few" should simply be seen as indicating lower relevance than the terms "most" or "many".
} 
Non-Industry-Specific Human Capital. This category depicts the HC requirements that are not related to a specific industry and could alternatively be summarized as general human capital requirements, such as a recruit's adaptability, leadership skills, social competence, team orientation and entrepreneurial thinking.

A few respondents emphasized entrepreneurial thinking as a distinctive value factor referring to cost-consciousness and risk affinity. Entrepreneurial thinking is especially relevant for employees who have to take on budgetary and personnel responsibility.

"[T]he 'entrepreneur within the company' is always requested." (3) (entrepreneurial thinking)

Some interviewees especially emphasized team orientation. Team working skills refer to the skill to build and motivate a team, and to work with different members of an organization or department.

"Team orientation is surely decisive nowadays. The company is only as successful as the smallest team." (14) (team orientation)

Many interviewees additionally accentuated a competitor recruit's social competence as a core requirement. Globalized environments demand to work in diverse teams and in different cultures. Specifically, communication skills and the ability to network are indispensible to create business opportunities and to be able to seize them, and to get one's job done as efficiently and effectively as possible.

"It (the work environment) is going to be more global. You, thus, need to understand and deal with diversity...also the assignments are going to be more complex and international... you need to handle different approaches." (4) (social competence)

Interviewees also emphasized the importance of a competitor recruit's leadership skills. He or she needs to function as a role model within a company thereby supporting the successful execution of tasks and assignments.

"[Since an employee] might work with virtual teams for a certain period of time...to find one's way in those structures, to give people a lead, and to assume a kind of role model function in such situations...good leadership qualities are what you need everywhere and that is always in limited supply." (1) (leadership skills)

Finally, the majority of respondents proposed adaptability as a relevant characteristic of a valuable recruit. Adaptability is related to a candidate's flexibility in terms of working hours, task requirements, team compositions as well as work locations regardless of family status or other personal circumstances. 
"I believe it is always important that the recruit has the ability to adapt; has a special kind of openness to adjust relatively quickly to the new company." (12) (adaptability)

These insights show that competitor recruits are considered attractive when they own (1) industry-specific human capital such as market insights and business contacts as well as (2) general human capital like entrepreneurial or teamwork competences. Firm-specific skills were not mentioned and hence considered irrelevant, which is in line with our theoretical argumentation. Companies, however, seem to be interested in acquiring general human capital despite its high transferability as long as it is combined with industry-specific human capital, as the first quote suggests.

\section{Costs of Competitor Recruitment}

A hiring firm can encourage a competitor recruit to employ his human capital by investing in costly intrinsic as well as extrinsic human resource practices (Gardner et al., 2010). The latter are amenable to instrumental transactions, while the former are directly valuable to the self and tend to form socio-emotional connections between exchange partners (Hart \& Thompson, 2007). HR practices such as compensation, integrating actions or training and development facilities constitute extrinsic motivators; socialization, internal communication, and accordance with promises form intrinsic triggers of productivity. The underlying assumption is that once the recruit feels valued, he or she is willing to reciprocate through productivity.

Extrinsically Valuable Practices. Some respondents mentioned that financial compensation is a factor that influences the degree of deployment of competitor recruits. Companies can pay a premium fixed salary or incentivize competitor recruits through other variable pay components.

"The [hiring] firm truly needs to create an environment in which he (the recruit) is incentivized to bring in everything he has, his human capital. This might be achievement-oriented payment." (13) (pecuniary compensation)

Another mentioned factor relevant for deploying competitor recruits are institutionalized integrating actions, such as orientation or welcome programs. Oftentimes, new colleagues are not informed or oppose against 'outsiders', maybe due to a fear of more severe competition for promotion or intellectual espionage. If this happens, the newly hired recruit may miss the working conditions that would allow him to engage in knowledge exchange (quickly) and to be motivated to be productive.

"[C]ompanies who acted wrongly within the integration phase [fail]. At this stage you need to be very sensitive with new employees." (13) (institutionalized integrating actions)

Many respondents emphasized the necessity to offer personal training and 
development to recruits. Employees should receive as much training as needed to do a job well and apply their human capital. Without offering required training and development productivity might be below the recruit's potential performance level.

"At the end of the day, possibilities for development are first priority for most candidates at the positions we fill." (pilot interview) (training and development)

Intrinsically Valuable Practices. Some respondents claimed that open communication is a key factor for successful deployment. If recruits are not well-informed about their responsibilities, tasks and career opportunities, or about roles, processes and structures within the hiring organization, a firm runs the risk that a recruit feels lost, and that commitment or motivation levels of the recruit diminish.

"If they (the company) promised: 'we will assign responsibility', but thought: 'only after 3 months... he should get to know the company first'...the employee gets frustrated while this was not properly communicated (to him). If they had spoken about this [in advance] it might have worked out fine. [...] it is important to put the cards on the table." (6) (open communication)

Respondents mentioned several times that non-institutionalized integrating actions are of high importance for a successful placement. If recruits feel respected and as part of an organization or team, and get along well with their supervisors and colleagues, they might be more willing to work hard and to share their human capital.

"[W] What are the criteria for success? Long term prospects in every respect: long term success, fit with the team or to be accepted by the team." (7) (non-institutionalized integrating actions)

Partly also implicit in the previous statement, neglecting promises earlier made is a key factor for employees to leave a firm (Breaugh \& Starke, 2000; Rousseau, 1995).

"Maybe promises that are not kept (managerial responsibility, fancy company car) or the job content is not correct anymore... where the recruit may say: this is not what I came here for; that was discussed in a different way." (6) (accordance with promises)

All extrinsically as well as intrinsically valuable human resource practices mentioned are linked to the deployment process and success. This implies that if the estimated productivity level is not reached, recruit needs post-hire might not be met or barriers to appropriation prevail, causing higher recurring utilization costs.

\section{(Institutional) Barriers to Competitor Recruitment}

Barriers to competitor recruitment potentially affect the final value that can be appropriated. They can originate from the institutional environment in which the hire takes 
place, as deduced above, or from the degree of (mis)match between the recruit and the organizational environment. This latter category emerged from the data.

Institutional Factors. Institutional barriers to the occurrence of $C R$ can be clustered into three major forces: regulative, normative and cultural-cognitive (Scott, 2001). All factors can arise at multiple levels, e.g. the recruit, firm, industry or strategic group level, and have the capacity to block competitor recruitment initiatives fully or at least cause a more laborious and, thus, costly CR process.

The identification stage is potentially influenced by factors, such as inter-rival gentlemen's agreements or hiring firm policies (regulative), ethical standards, industry customs, advisory unit customs, inter-rival relationship standards, recruiter competences (normative), or recruiter morale, recruiter presumptions, hiring firm values and national values (cultural-cognitive); the transfer stage by recruit incentives to stay, recruit period of cancelation and recruit non-compete clauses (regulative), or recruiter competences (cultural-cognitive). The same factors like in the transfer stage still apply in the deployment stage if restrictive clauses or conditions could not be fully abolished or circumvented prehire.

Regulative. Regulative barriers are formally or informally agreed-upon rules or regulations, either between firms or between a firm and an individual.

Some respondents referred to a period of cancelation, which determines the period between an employee's handed-in notice of cancelation and his last working day at the current employer, as a force restricting CR to occur. After all, hiring firms are not always willing to wait several months to fill their vacancy if rival firms stick to the contract as they signed.

"Long periods of cancelation are also such a formal criterion (that constrains CR). Managers [...] oftentimes have very long periods of cancelation." (i) (recruit period of cancelation)

Internal firm policies might also constrain the use of CR. Respondents mentioned an 'Internals First Policy' as well as a 'No CR Policy' in particular. Whereas the former refers to the rule to always prefer an internal candidate for a vacancy unless no internal employee suits the position or is interested, the latter relates to the order of higher management to poach employees never from rival firms.

"Actually we have an 'internals first policy', meaning that we would in essence always prefer an internal [candidate], because we also primarily appreciate internal development, an internal career path...this is also a signal for our existing staff." (g) (hiring firm policies)

One third of all HR professionals mentioned opportunity costs as a force that might prevent recruits from switching. These costs are related to e.g. forgone compensations or penalties incurred when moving to a competing firm. Company stock options that would foreclose when quitting before expiry of a certain working period are one example. Payback 
clauses bound to earlier pursued development programs are another example of an incentive to stay. In this case, an employee would have to pay a development program that was originally financed by the employer himself retrospectively.

"We simply say that - if you move with a package of $€ 100,000$ or $€ 200,000$ of stock options through our company - the stock options would expire if you leave the company." (g) (stock options as recruit incentive to stay)

"One constrain, of course, can also be if we have let someone develop for a long period of time, let's say in an advancement training, for example, or a personnel development program, that we include payback clauses [that a leaver would have to pay back] of a few thousands of Euros." (i) (payback clauses as recruit incentive to stay)

Another labor contract tool to hinder employees to leave and work for a competitor is the non-compete clause, which is signed by recruits as part of the contractual negotiations pre-hire and therefore normally legally binding. Nearly all HR professionals stated that this affects either every competitor or is phrased with reference to specific firms.

"[T]here were phases when we applied non-competes; sometimes the non-compete clause concerned concrete companies, i.e. a list of specific firms, [...] sometimes it simply excluded all competitors." (g) (recruit non-compete clauses)

To prevent poaching each other's employees, firms might covertly fix unwritten agreements, resulting in restricted hire lists. According to various interviewees, they can emerge in different forms: either among subsidiaries of the same corporate group, among direct competitors or among business partners.

"Yes, we have [gentlemen's agreements]. That was also new for me when I started here. So, there is another local competitor, and apparently there is an agreement between the two CEO's not to poach each other's personnel." (e) (inter-rival gentlemen's agreements)

Normative. Normative factors are rules and regulations that members of a group, society or organization follow but are not legally binding. Norms in the form of industry standards establish over time, but might originate from outside industry environments. The occurrence of $\mathrm{CR}$ can for instance be determined by consultants or academia. If practices are recommended by such management fashion setters (Abrahamson, 1996), they mgith become accepted, recognized and finally used.

"Well, if it was academically sound, I would use [CR]." (h) (advisory unit customs)

Collaborations with competitors can also lead to an avoidance of aggressive sourcing practices such as CR. The fear that it could damage interfirm business relationships 
or result in retaliatory actions seems widespread. The danger of risking knowledge exchange with competitors was addressed by more than two thirds of the HR professionals.

"I, thus, think that it is an unwritten law that you don't do that (CR) and everybody sticks to it. It is not formulated anywhere, there is no official arrangement, it's just an unwritten law." (h) (inter-rival relationship standards)

Any society, industry or company shares certain ethical standards. More than two thirds of the interviewees mentioned such ethical standards as a factor restricting CR. CR is oftentimes perceived as misconduct since it has the potential to harm the competing firm severely.

"I think that there are issues such as betrayal, dissemination of insider information, distortion of competition, [...] and that this leads to feelings of guilt also among people that initiated it...in the sense that 'I do something unethical since I take something from someone else'." (i) (ethical standards)

Similarly, most of the interviewees brought up the fear of image damage following from a $C R$ initiative, if $C R$ is not a custom in the industry. Firms then fear negative press coverage or a loss in employer or client attractiveness as a potential consequence.

"Absolutely crucial in this context is the fear of image damage. That people bad-mouth our company makes us use it (CR) less often." ( $g$ ) (industry customs)

Cultural-Cognitive. Cultural-cognitive factors were shown to play a role in determining the occurrence of $\mathrm{CR}$ as well. Whereas cultural factors stem among others from the national or corporate cultural environment, cognitive factors refer to how someone views, understands and makes sense of the world. The former is related to cultural values of social collectives, while issues following from individual competences or prejudices reflect the latter.

Without an educational infrastructure to equip recruiters with the cognitive skills that an engagement in competitor recruitment demands, a recruiter might not consider $C R$ as a recruitment practice due to a fear of failure, inability, or simply unawareness.

"[M]anaging externals through such a (transfer) process, we do not have any experience with that whatsoever." (g) (recruiter competences)

Alternatively, presumptions about the CR process or its likely consequences can constrain HR professionals from applying CR. Here, assumptions regarding whether top managers support competitor recruitment, whether CR recruits would be well-integrated by future colleagues post-transfer, or whether retaliatory actions or competing firms are likely play a role, for instance. 
"I consider the as-is situation [of not engaging in CR] [...] as positive since we would otherwise end up in a cut-throat poaching competition in my opinion. This would certainly have large-scale impacts." (h) (recruiter presumptions)

National cultural standards also have the potential to constrain CR. As the national context for this work is Germany, respondents emphasized German cultural values such as lifelong loyalty and ethical business practice as barriers.

"From my point of view, it is rather that German values and virtues constrain [the occurrence of CR]. I think there are countries in which this issue is dealt with much more openly and aggressively than here." (i) (national values)

Finally, all HR professionals except one mentioned internal cultural standards as a factor preventing CR. Hiring firm cultural values can either be incorporated in a top-down approach and prescribed by top management or emerge bottom-up through day-to-day behaviors, actions and discourse.

"[W]ell, my boss is one of the executives and [...] he said it (CR) is not conceivable for us." (topdown) (d) (hiring firm values)

As the above quotes suggest, institutional barriers to competitor recruitment can have a value-deteriorating effect, as they require additional investments in human capital appropriation to be made. Equally, a lack of fit between the recruit and the broader organizational environment can impair the process and cause unexpected costs. Vice versa, of course, if the fit is higher and institutional barriers are of less impact than previously expected, employees might require less costly investments in the deployment stage than initially anticipated and, hence contribute more value. We, however, argue from the assumption that hiring firms tend to rather underestimate than overestimate barriers and costs due to limited observability and information.

Person-Environment Fit. Fit can be evaluated on different levels, i.e. with the environment, the job, the supervisor or the organization. For illustration purposes, we provide two quotes one for the relationship between the recruit and the supervisor, and one for the relationship between the recruit and the work group respectively.

"[W]e take a good look at the future supervisors because they are the ones that they (the candidates) have to get along with in the first place." (6) (person-supervisor fit)

"There is always this diffuse factor of how to cooperate with the others (team members). You are hired by your skills und mostly fired by your attitude. That's the way it is. You part with people you do not get along with." (10) (person-group fit) 
Overall, the conditions for value appropriation outlined in this section were partly competitor recruitment specific and partly applicable to any external staffing decision. It appears, however, that the factors identified may play a more severe role in the competitor recruitment environment.

Table 4.2 provides an overview of all categories and nodes mentioned as well as the number of respondents (\#sources) that addressed each node (from least to most important node per category). The number of times a particular issue was referred to in total by all interviewees (\#codes) suggests the weigh that individual respondents assigned to a specific category. Multiple answers within one category or node could occur since some interviewees mentioned the same issue more than once. The number of sources shows whether a specific respondent mentioned an issue in a specific sub-category at all, irrespective of frequency. The number of sources is thus the predominant indicator for the relevancy of a category. 
Table 4.2 Categories Reflecting Conditions for Value Appropriation (sorted by \#sources from highest to lowest as the prime indicator for relevancy)

\begin{tabular}{|c|c|c|c|}
\hline Categories & Nodes & \#Sources & \#Codes \\
\hline \multicolumn{4}{|c|}{ Human Capital Benefits of Competitor Recruits } \\
\hline \multicolumn{4}{|l|}{ Human Capital } \\
\hline \multirow[t]{2}{*}{ Industry-Specific } & market knowledge & 10 & 18 \\
\hline & social capital & 2 & 2 \\
\hline \multirow{5}{*}{ Non-Industry-Specific } & adaptability & 9 & 14 \\
\hline & leadership skills & 8 & 16 \\
\hline & social competence & 7 & 10 \\
\hline & team orientation & 6 & 6 \\
\hline & entrepreneurial thinking & 3 & 5 \\
\hline \multicolumn{4}{|c|}{ Costs of Competitor Recruitment } \\
\hline \multicolumn{4}{|l|}{ Deployment Practices } \\
\hline \multirow[t]{3}{*}{ Extrinsically Valuable } & training and development & 9 & 13 \\
\hline & institutionalized integrating actions & 7 & 9 \\
\hline & pecuniary compensation & 5 & 5 \\
\hline \multirow[t]{3}{*}{ Intrinsically Valuable } & accordance with promises & 9 & 10 \\
\hline & non-institutionalized integrating actions & 7 & 9 \\
\hline & open communication & 2 & 2 \\
\hline \multicolumn{4}{|c|}{ (Institutional) Barriers to Competitor Recruitment } \\
\hline \multicolumn{4}{|l|}{ Institutional Factors } \\
\hline \multirow[t]{5}{*}{ Regulative } & recruit non-compete clauses & 8 & 16 \\
\hline & inter-rival gentlemen's agreements & 6 & 9 \\
\hline & recruit incentives to stay & 3 & 4 \\
\hline & hiring firm policies & 2 & 6 \\
\hline & recruit period of cancelation & 2 & 3 \\
\hline \multirow[t]{4}{*}{ Normative } & industry customs & 7 & 29 \\
\hline & ethical standards & 7 & 18 \\
\hline & advisory unit customs & 7 & 13 \\
\hline & inter-rival relationship standards & 7 & 13 \\
\hline \multirow[t]{4}{*}{ Cultural-Cognitive } & hiring firm values & 7 & 19 \\
\hline & national values & 7 & 8 \\
\hline & recruiter presumptions & 5 & 9 \\
\hline & recruiter competences & 2 & 9 \\
\hline \multirow[t]{4}{*}{ Person-Environment Fit } & person-organization fit & 19 & 56 \\
\hline & person-group fit & 15 & 30 \\
\hline & person-job fit & 14 & 28 \\
\hline & person-supervisor fit & 13 & 19 \\
\hline
\end{tabular}




\section{Discussion}

This study illuminated the major factors by CR process stage that determine the likely value captured from competitor recruitment. Overall, our results indicate three major themes, namely the (1) Human Capital Benefits of Competitor Recruits, (2) Costs of Competitor Recruitment and (3) (Institutional) Barriers to Competitor Recruitment that moderate the impact of (2). The themes provide insights about a) the type of human capital of competitor recruits that is valuable and can positively contribute to a hiring firm's performance and b) the factors that determine to what extent this value can be appropriated without incurring higher costs than benefits. Particularly, value follows from industry and nonindustry-specific human capital but is likely to be deteriorated because of additional investments required primarily during the deployment stage in the form of one-off and recurring extrinsically and intrinsically valuable human resource practices. The severity of these investments depends on the prevailing (institutional) barriers that impair the process.

The fact that respondents emphasized the value of industry-specific human capital leads us to conclude that competitor recruits have a distinct value that makes them especially attractive to competing firms, also in practice. This confirms our initial assumption that competitor recruitment is a specific recruitment practice that can add value in an idiosyncratic manner. At the same time, various barriers were proposed that make competitor recruitment also a risky and potentially a more costly undertaking than other recruitment efforts under certain (institutional) circumstances.

As demonstrated, competitor recruitment is valuable only when the value captured exceeds the investments made. Since initial costs of recruitment such as employing a search agency or paying allowances are relatively high, it follows that competitor recruitment pays especially off when a competitor recruit is retained inside the hiring firm for a longer period, also since productivity increases occur only after the dip during the adjustment phase (Groysberg et al. 2008). After all, the costs-per-day diminish over time until reaching a productivity peak (e.g. Lazear \& Moore, 1984; Sturman, Trevor, Boudreau \& Gerhart, 2003).

\section{Theoretical and Managerial Implications}

Regardless of how generally valuable a competitor recruit's human capital is, this research has shown that what seems to matter in any case is the incurred costs partly following from the fit between the recruit and the organizational context. In particular, the fit with the job, group, organization and supervisor was claimed to be crucial for a successful appropriation of a competitor recruit's human capital. This is in line with previous research claiming, for instance, that existing firm structures and the extent to which the recruit fits to these structures influence the deployment process (e.g. Purcell, Kinnie, Hutchinson, Rayton \& Swart, 2003). Examples are decision processes, the line of command or procedures for promotion. On the department level, the dyadic relationship between a recruit and the supervisor was given specific attention. The behavior of the direct supervisor, for example in terms of providing feedback or support, is indeed a major driver of productivity (e.g. Kristof- 
Brown et al., 2005; Meyer \& Smith, 2000; Meyer, Stanley, Herscovitch \& Topolnytsky, 2002; Nohria, Groysberg \& Lee, 2008; Thornhill \& Saunders, 1998). Furthermore, the receiving team has a direct effect on the recruit's productivity level while team dynamics and climate influence a recruit's motivation, work satisfaction and knowledge sharing behavior (e.g. Groysberg \& Lee, 2008; 2009; Werbel \& Johnson, 2001). On the individual level, employees' knowledge, skills, and abilities as well as individual needs, desires or preferences need to correspond with job requirements (e.g. Edwards, 1991; Kristof-Brown et al., 2005). Accordingly, Groysberg and Lee (2008), Lazear and Shaw (2007) or Pfeffer (2001) argue that it is not necessarily companies with the best talents that beat the competition. Instead, productivity is a result of the fit between a firm and the employee, and follows from the functioning within the overall organizational system of relationships, capabilities or resources implying that a great team can serve as a substitute for individual talent (Cable \& Parsons, 2001; Pfeffer \& Sutton, 2006; Van Maanen \& Schein, 1979). This research has clearly contributed to this discussion on estimating and influencing star recruit performance.

Similarly, research on strategic selection and staffing (Gerstein \& Reisman, 1983; Olian \& Rynes, 1984) suggests that organizations who take a holistic approach to personnel selection, emphasizing the alignment of the 'whole' person (rather than KSAOs) and the whole organization (rather than the requirements of a specific job) are more successful in retaining employees that want to be retained (e.g. Bowen, Ledford, \& Nathan, 1991; Chatman, 1989). Regarding the latter, Allen, Bryant and Vardaman (2011) wrote an interesting paper addressing among others the misconception that employee turnover is always bad as well as the fact that managers cannot do much to foster retention of valuable staff. Equally, they shed some light on the complexity of determining and understanding turnover costs. They conclude that there are no one-fits-all boundary conditions for successful retention measures but that instead researchers should focus on "in-depth qualitative research that provides rich data about a very specific [recruitment and retention] context". Considering the nature of this dissertation, we fully support this call and recognize that much more needs to be done also in the field of labor mobility and competitor recruitment in particular that provides such data.

While most researchers take a human capital or resource-based approach to the issue of labor mobility, using institutional theory as a lens, though atypical, has however clear value in that it explains why some practices turn out to be widely applied and even become best practices within an industry while others do not. After all, rather than arguing from a firm's strategic goals and opportunities, this theoretical perspective considers the external business context in which firms function.

Practitioners benefit from our findings as they help to reflect upon competitor recruitment as a strategic hiring practice and its potential barriers. Being aware of the barriers might help HR professionals to engage in CR at a cost/benefit ratio that really creates value in the end, but also to retain internal employees through the sound employment of non-compete or gentlemen's agreements, or the contractual inclusion of periods of cancelation or payback clauses. Recent surveys show that only half of the firms 
ask their future employees to sign non-compete agreements (Sturman et al., 2008); even one third of CEO contracts do not include non-compete agreements (Schwab \& Thomas, 2006) partly due to the assumption that those restrict an individual employee's personal right to move to any workplace desired (Gardner et al., 2010). Regarding this assumption, this chapter raises attention to the fact that the use of some business practices may be 'just' a matter of personal preconceptions or competences, or cultural norms and values, rather than rational decision-making, and that business practices hence should regularly be questioned. Perhaps most recruits would welcome CR as a chance to advance in their professional career!

\section{Limitations ${ }^{57}$ and Further Research}

Our qualitative approach revealed major factors involved in capturing value through competitor recruitment. Our results are however also affected by two prime limitations that should be considered by future researchers in the field.

First, although institutional theory constitutes a valuable theoretical stance to investigate labor transfers between rivals, it suffers from theoretical flaws, which might impair the transferability and validity of the findings. The most important impediment is that theoretical inconsistency prevails among institutional theory researchers who only seem to agree on the fact that social structures influence firm behavior (e.g. Hall \& Taylor, 1996; Kato, 1995; Peters, 1999). How the classification of certain forces in the context of social structures is defined remains unclear though. Researchers borrowing arguments from institutional theory in the future should, thus, be very clear on how they define each institutional factor and in what way they expect them to influence labor mobility. Another critique of institutional theory has been that it is almost inherently static while what it seeks to explain is dynamic. Existing types of structures may change or be differently perceived over time or space. It is, hence, very well conceivable that HR professionals perceive the relevance of certain institutional factors differently nowadays than at the time of data collection because of the type of media attention that CR has received back then. Or large multinational organizations evaluate and incorporate existing norms and values differently in their business practices than small companies with only a national reach. Consequently, the institutional environment our respondents function in might have framed their perceptions and judgments. Studies that explore the value and cost drivers of competitor recruitment across different institutional contexts might as a result equip the field of labor mobility with additional insights on how a human capital advantage can be captured and to what extent certain practices are transferrable and applicable - also across (national) contexts. Especially in times of intensifying globalization and an increase in cross-border labor mobility, respective research projects are desirable.

Second, by having found that a recruit's human capital can be deployed to the fullest only if he or she fits the hiring firm's environment, we hypothesize that it is not only

\footnotetext{
${ }^{57}$ Further limitations regarding the data set can be found in the discussion of chapter 3.
} 
the portability of the human capital carried that determines the degree of value creation per se but also its fit with the organizational context post-transfer. Thus, maybe the human capital carried determines the propensity to fit to a specific organizational context! And mabe this fit in turn determines employee behavior e.g. in the form of commitment ex post transfer! Finding an answer to these claims is crucial as only the deployment over time, of not only competitor recruits but all employees, allows for value creation, as outlined earlier. We will provide a first approach to this question in the following chapter.

\section{Conclusion}

All HR professionals claimed that poaching competitors is controversial when done directly, but acceptable and even the norm when an intermediary such as an executive search firm or recruiter is involved as the following quote illustrates: "[I]t is important to clearly distinguish [the potential negative consequences]. [They would not occur when recruiting] through headhunters, because that is normal." It hence seems that it is rather a question of how than of whether CR is applied.

Companies are more and more dependent on the acquisition and retention of valuable human capital carriers. Since our findings suggest that institutional factors might block or at least impair an engagement in competitor recruitment regardless of its likely value, we argue that $H R$ professionals should aim at abolishing barriers to $C R$ in order to minimize internal labor shortages and gain a human capital advantage. Companies who will thrive and win the war for talent in the future will certainly be those that have built up expertise and above-average competences in applying certain (aggressive) HR practices first and more effectively and efficiently than others. 


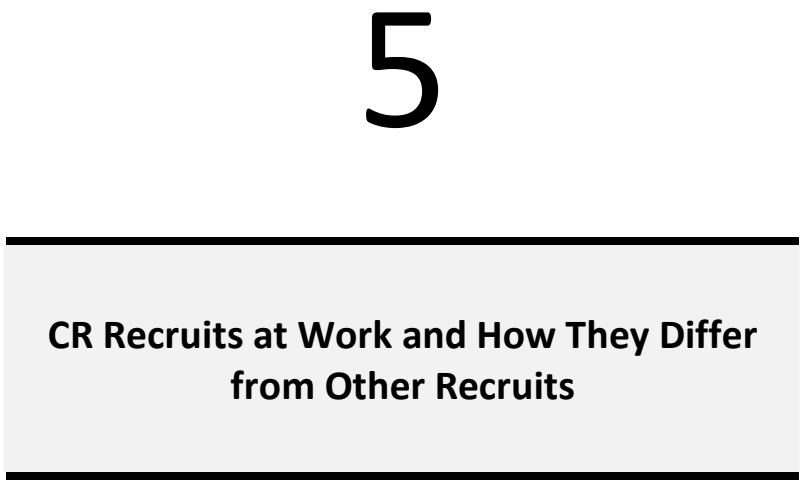

This chapter proposes a new theoretical link between recruits' work context origin, their dominant type of human capital carried and work behavior outcomes. Specifically, it explores the extent to which human capital varies between recruits with different work context origins, how this is related to their commitment focus and in turn to their willingness to switch to another job or organization.

Analysis of our survey data of 63 cases demonstrates that competitor recruits carry relatively more industry-specific human capital than non-competitor recruits. Surprisingly, we did not find any significant relation between dominant human capital carried and focus of commitment nor between the latter and willingness to switch work contexts. For organizations this implies that the supposed risk of hiring a competitor recruit - due to a different commitment focus - is not corroborated by our data. 
As suggested in previous chapters, interfirm mobility is increasingly important for firms and employees as employee transfers enable the acquisition of beneficial resources (Bidwell \& Briscoe, 2009; Phillips, 2002; Wezel et al., 2006). Vice versa, the loss of employees can have a significant negative effect on the execution of companies' business plans and may eventually cause a decline in productivity (Cascio, 1998). Especially when highly valuable specialists or managers are concerned (Benkhoff, 1997; Waldman, Kelly, Arora \& Smith, 2004) employee departures can include severe costs of separation (e.g. administration costs associated with turnover), replacement and hiring (e.g. cost of employing a search agency or restructuration), formal and informal training (e.g. orientation programs or mentoring) or learning curve costs (i.e. productivity lost in (re)adjustment) (Allen, Bryant \& Vardaman, 2001; Cantrell \& Smith, 2010; McEvoy \& Cascio, 1987). Consequently, employee retention like acquisition constitutes a critical workforce management challenge for HR departments.

Commitment toward the employing organization was found in extant research to be an important determinant of turnover (Cohen, 2003; Solinger, Van Olffen \& Roe, 2008). As committed employees typically wish to remain with their employing organization (Griffeth, Hom \& Gaertner, 2000; Herscovitch \& Meyer, 2002; Mathieu \& Zajac, 1990; Mowday, Porter \& Steers, 1982; Schweiger \& Goulet, 2005; Thompson \& Van de Ven, 2002; Van Maanen, 1975), securing and fostering commitment among employees is critical. This especially applies to employees originating from competitors, as they allegedly possess a high value-creating potential.

Previous research has shown that work experiences can serve as antecedents to commitment, and then voluntary turnover (Becker, 1962; Meyer \& Allen, 1991; Mowday et al., 1982; Wiener, 1982). One type of work experience is a learning and development program that leads to human capital acquisition. Human capital accumulated over one's professional life was however never investigated as a direct antecedent to commitment. This despite the fact that one could easily argue that the different types of human capital, e.g. firm-specific, industry-specific or general human capital (Sturman et al., 2008), might determine the commitment focus displayed and influence whether an employee feels primarily attached to an organization, a profession or an industry (Meyer \& Allen, 1991). Our interviews with executive search consultants and practitioners (see chapters 3 and 4) clearly corroborate this idea. The interview data revealed that firms tend to reject an engagement in competitor recruitment partly due to a fear of lower organizational commitment of competitor recruits than of non-competitor recruits and a higher tendency to take the human capital to yet another rival firm (see e.g. 'enduring rival firm loyalty'; chapter 3).

Thus, in order to avoid this double misery of losing a competitor recruit with valuable human capital during the deployment phase to a competing firm, it is imperative to attract competitor recruits that are strongly and sustainably committed to their new employers. To do so, firms need to be aware of the antecedents of strong and sustainable commitment of competitor recruits. There is no empirical evidence yet, however, on for instance whether and how recruit work context origin (i.e. whether from a competitor or 
non-competitor) and/or human capital carried is associated with commitment focus or willingness to switch work contexts.

We thus investigate in this chapter whether internal, competitor and noncompetitor recruits carry different types of human capital that are associated with different commitment foci, and whether this in turn is related to a recruit's willingness to switch the current work context. The existence of such a relationship would confront human resource managers with a paradox of hiring: recruiting somebody of high value from a competitor but with an increased risk of voluntary turnover, which introduces uncertainty on the long-term benefit of the acquisition (Lee et al., 2008).

In the first part of this chapter, we review the core elements of our research question. More specifically, we present a literature review and hypotheses on associations between recruit work context origin, type of human capital, commitment focus and willingness to switch the current work context. Subsequently, we test our hypotheses with survey data of both external (competitor and non-competitor) and internal recruits. Finally, we outline and discuss our findings, and offer an overall conclusion of this study.

\section{Literature Review and Hypotheses}

\section{Recruit Work Context Origin and Type of Human Capital Carried ${ }^{58}$}

Employees both cultivate new knowledge, skills and abilities and refine existing human capital over time that may be leveraged by current and future employers (Judge, Shaw, Jackson, Scott \& Rich, 2007; Schmidt, Hunter \& Outerbridge, 1986). As a result, management scholars and human resource professionals are interested in the relationship between prior work experience and future performance (e.g. Becker, 1964; Groysberg \& Lee, 2009; Hitt et al., 2001; Judge et al., 2007; Ployhart, Weekley \& Ramsey, 2009; Quinõnes, Ford \& Teachout, 1995).

Previous research has suggested that an employee's past work engagements determine the value of the human capital carried (Bailey \& Helfat, 2003; Combs \& Skill, 2003; Schneider \& Stein, 2006; Song et al., 2003; Sturman et al., 2008; Wang \& Barney, 2006). We more specifically expect recruit work context origin to be associated with the predominant type of human capital carried at the point of transfer, namely industry-specific or general human capital. We distinguish between two external work context origins. Noncompetitor recruits are employees who have previously worked at a firm outside the current industry and tend to carry the most general type of human capital. In contrast, competitor recruits are employees who were formerly employed by a firm from the same industry and are characterized by industry-specific human capital (Lee et al., 2008; Sturman et al., 2008).

The subsequent section outlines more elaborately the dominant nature of human capital typically possessed by competitor recruits and non-competitor recruits respectively.

\footnotetext{
${ }^{58}$ Note that by definition, at the moment of hiring, individual external recruits from either origin (competitors or not-competitors) do not carry any firm-specific human capital, whereas internal recruits do. Therefore, firm-specific human capital is not part of hypothesis 1 that follows from this section.
} 
Competitor Recruits. We define competitor recruits as employees who transfer between firms competing in the same industry. This migrating behavior and consequential industry tenure presumably makes competitor recruits accumulate primarily industryspecific human capital over time. As a result, they are typically valuable for and employed on jobs that have a strong client or customer focus or that require a close involvement in industry-specific business processes. Examples of a competitor recruit might be a specialized product engineer, purchasing officer, salesperson or business strategist.

Non-Competitor Recruits. In contrast, we assume that non-competitor recruits carry human capital that is rather general. They have worked in different sectors and hence acquired insights that can be transferred across contexts. As a result, employees with primarily general human capital have minor difficulties fitting their competences to jobs outside and across industries while advancing professionally. Examples of these types of employees are a (general) business secretary, market researcher or financial accountant.

Based on the arguments outlined above, we infer the following relationship between recruit work context origin and the prime human capital type carried:

Hypothesis 1: Recruit work context origin is associated with the dominant human capital carried, whereby a) competitor recruits carry relatively more industry-specific human capital and b) non-competitor recruits carry relatively more general human capital.

\section{Dominant Human Capital and Commitment Focus}

Much of the interest in commitment stems from reports on its antecedents and positive consequences for employee behavior (Brierley, 1996; Dishon-Berkovits \& Koslowsky, 2002; Meyer \& Allen, 1997). Concerning the latter, Meyer and Allen (1997) for instance suggested that employees with strong commitment to the organization would be more valuable than those with weak commitment. Similarly, Randall's (1990) meta-analysis noted positive relationships between organization commitment and remaining with the organization. Reviews on antecedents of organizational commitment generally identify five sets of factors (e.g. Mathieu \& Zajac, 1990; Mowday, Steers \& Porter, 1979). These factors are biographical characteristics, such as age and educational level; structural features such as organizational size and hierarchy; experiences regarding the extent to which pre-joining expectations have been met; role experiences, in particular scope to exercise responsibility and opportunities for development; and human resource practices such as those that promote a sense of fairness of treatment (Sturges \& Guest, 2001). Our study, by investigating associations between human capital and commitment foci, can be assigned to the studies of biographical characteristics.

In the past two decades, the discussion in the field of commitment increasingly focused on defining its characteristics and on the assumption that commitment can have different competing objects or foci, i.e. another focus than the organization (Baugh \& Roberts, 1994; Gunz \& Gunz, 1994; Mathieu \& Zajac, 1990; Wallace, 1995; Wang \& Armstrong, 2004). Researchers initially have made the distinction between cosmopolitan 
and local workers that reflects different levels of commitment toward a profession versus an employing organization respectively (Gouldner, 1957; Tuma \& Grimes, 1981). These two value systems were claimed to be inconsistent or even in conflict with each other, resulting in what is referred to as a commitment dilemma or organizational-professional conflict (Gunz \& Gunz, 1994).

Other scholars have claimed that commitment is not necessarily one-focused; neither are different foci antithetical to each other but positively related (Baugh \& Roberts, 1994; Ellemers, De Gilder \& Van den Heuvel, 1998; Wang \& Armstrong, 2004). For example, in a meta-analysis of eleven published studies, Wallace (1995) found that there was a moderately strong, positive association between professional and organizational commitment. Mathieu and Zajac (1990) reported a similar level of association between the two foci.

We build on both views and assume that there is no either-or differentiation, but that the focus and the degree of co-occurrence depend on characteristics such as the human capital carried. The relationship between the dominant type of human capital acquired and commitment focus displayed was already indirectly suggested by past studies. Somech and Bogler (2002), for instance, found that an employee's participation in technical decisions was a significant predictor of professional commitment, whereas participation in managerial decisions was more significantly related to organizational commitment. Another example is studies regarding the role of education. Education was found to be a moderately negative predictor of organizational commitment (Mathieu \& Zajac, 1990) with the level of education, reflecting the degree of specialization in a certain profession, being positively related to professional commitment (Wang \& Armstrong, 2004).

From a recruit's perspective, the reasoning is as follows. When employees switch jobs or employers, they run the risk of depreciating their value. As they will attempt to prevent this, they will seek to work in jobs or for organizations in which they can retrieve the highest benefit in pay or other rewards from the type of human capital that they have on offer and display (Becker, 1962; 1964; Eby, Butts \& Lockwood, 2003; Judge, Boudreau, \& Bretz, 1994; Judge, Cable, Boudreau \& Bretz, 1995). Thus, the relationship between human capital carried and commitment focus will be driven by arguments of value maximization (Boeker, 1997; Sullivan, 1999). In the following paragraphs, we elaborate on the specific relationships between different commitment foci and types of human capital.

Organization Commitment. An organization focus of commitment is exclusively directed at one's current employer, i.e. at one's employing organization. In the threecomponent model of commitment, the concept of organizational commitment is conceived of as including three forms that may co-occur: affective, normative and continuance commitment (e.g. Mathieu \& Zajac, 1990; Bentein, Vandenberg, Vandenberghe \& Stinglhamber, 2005; Cohen, 2003; Greenberg \& Baron, 2003; Solinger et al., 2008). Affective commitment plays a central role in commitment research but the other two forms also received attention in past research (Jaros, Jermier, Koehler \& Sincich, 1993; Chen, Hui \& Sego, 1998; Griffeth et al., 2000; Igbaria \& Greenhaus, 1992; Igbaria \& Guimaraes, 1999; 
Mowday et al., 1979; Solinger et al., 2008). Affective commitment is defined as an emotional attachment to an organization that includes support for organizational objectives and activities (Meyer \& Allen, 1984). An affectively committed employee commits to the organization because he or she 'wants to'. Continuance commitment, on the other hand, refers to one's perceived psychological and economic investments in the organization. These result in perceived costs of exit that may follow from e.g. a loss of friendship ties with coworkers, of firm-specific skills' value or status, or a change in pay, mortgage rates, pension accruals, responsibility, or development opportunities (Becker \& Billings, 1993; Hrebiniak \& Alutto, 1972). Consequently, one 'needs to' stay with the organization in order to (re)cover or to avoid costs. When being normatively committed, the individual commits to and remains with an organization because of feelings of obligation rather than a fear of loss or attachment. These feelings may derive from many sources. For example, the organization may have invested in trainings of an employee who then feels a moral obligation to put forth effort in the job and stay with the organization to repay any debts. It may also reflect internalized norms developed through socialization processes that imply that one should be loyal to one's organization. The normatively committed employee stays with the organization because he or she 'ought to' (Blau, 1964; Homans, 1961).

We expect that employees are primarily organization focused when they can reap major benefits within the same firm. This is the case when employees carry knowledge about internal business processes or company secrets, that is: when the predominant human capital type carried is of firm-specific nature. For example, an internal HR consultant might have acquired insights on what training measures work well for a specific firm considering a firm's corporate culture, strategic endeavors and training needs. During many years of working as an internal consultant for this one company, he supervised and observed many training measures being assigned and accomplished, and how they turned out to be useful and had an impact on every-day business. Only over time, he could develop a feeling for which initiatives are effective within this specific company and for the people employed and pay off, and which are not. Having built this specific expertise, commitment is likely to focus more on the current organization ("I am a training specialist in company X.") than on any particular industry, as the expertise acquired is not fully transferrable to another firm ${ }^{59}$. Employees with primarily firm-specific human capital are hence highly dedicated to their current employer as this is where their employment pays off the most (Becker, 1962; 1964; Sturman et al., 2008).

Industry Commitment. What we call 'industry commitment' in the following sections has neither been researched nor defined in the past yet. We were inspired to propose this concept by a) the idea of industry-specific human capital as a distinct form of human capital and b) by the concept of professional commitment referring to a commitment towards one's profession regardless of industry affiliation (Morrow \& Wirth, 1989; Somech \& Bogler, 2002; Wang \& Armstrong, 2004). Professional commitment is considered a critical

${ }^{59}$ Clearly, some jobs provide more opportunities for developing deep content-specific skills than others. 
career attitude nowadays since a large proportion of today's workforce includes highly educated employees who rely on their qualifications and practical experience as the main factors that promote their life and career goals (Cohen, 2003). They are less dependent upon their employing organization and more willing to change employers when their professional and financial expectations are not met. For such employees, it is their commitment to their profession that will affect their stay-or-leave behavior regardless of their level of commitment to a specific organization. Professional commitment thus disregards a commitment to a specific organization but allows for job switches across industries as long as the profession ex ante and ex post the transfer is the same. (Morrow \& Wirth, 1989; Somech \& Bogler, 2002; Wang \& Armstrong, 2004). It does, however, not consider those employees who strongly identify with a specific industry. An example for professional commitment might be a biochemical researcher who might be equally willing and able to work in the pharmaceutical as well as the food industry. In contrast, other people strongly identify with a certain industry but not their profession as such. For instance, a person might strongly commit to working for a non-governmental organization but is indifferent about the role to pursue.

Insights on the existence and relevance of industry commitment might help to understand underlying drivers of switching behavior of specialists and managers, thus of those employees who largely carry industry-specific human capital, and who are hence of prime value to any competitor within a specific industry. We thus define industry commitment as an attachment to and identification with a certain industry.

We expect this particular type of commitment to be built by investments in deep industry-specific knowledge and skills, that is: by the accumulation of industry-specific human capital. The expertise in this case is created around a specific context: the industry. For instance, in contrast to the earlier example, an HR consultant might have accumulated a broad set of insights on prevalent HR practices and processes about a specific industry such as telecommunications in which the issue of customer management constitutes a core HR challenge by having worked for different Telco companies. This consultant would essentially be competent in advising any telecommunications provider on related HR issues such as training, hiring, retention or employee performance management systems. Having built this specific expertise, commitment is likely to focus more on the industry ("I am a Telco HR specialist.") than on any particular organization or subject ${ }^{60}$. Employees who are primarily industry committed are thus assumed to carry industry-specific human capital to a large extent as this justifies their endeavor to work for any firm as long as it functions in the same industry.

Overall, we thus suggest that the commitment focus of a recruit will be influenced by the recruit's dominant type of human capital carried. The specific relationships that we suggest are summarized as follows:

\footnotetext{
${ }^{60}$ Clearly, some industries such as those that are R\&D or direct sales intensive provide more opportunities for developing such deep context-specific knowledge than others.
} 
Hypothesis 2: The dominant human capital type carried is associated with the commitment focus displayed, whereby a) firm-specific human capital dominance is associated with a relatively higher organization commitment and b) industry-specific human capital dominance with a relatively higher industry commitment.

\section{Dominant Commitment Focus and Willingness to Switch}

Extant research found that commitment toward the employing organization is an important determinant of turnover decisions (e.g. Cohen, 2003; Solinger et al., 2008). Organizational commitment, for instance, was shown to relate negatively to turnover suggesting that employees who are not committed to the organization are very likely to leave in search of other employment (Steers, 1977). Vice versa, individuals who are highly committed to their organization will be less likely to leave (DeCotiis \& Summers, 1987; Igbaria \& Greenhaus, 1992; Igbaria \& Guimaraes, 1999; Iverson \& Buttigieg, 1999; Mathieu \& Zajac, 1990; Mowday et al., 1979).

From there it follows that depending on the degree of commitment an employee displays toward the employing organization, he or she prefers to stay with the organization (and potentially changes jobs within) or leave the organization and change employers. We additionally propose that this association does not only exist with organization commitment but also other foci of commitment such as industry commitment. We thus hypothesize that the dominant commitment focus of an employee is associated with the domain within with an employee is willing to switch.

Willingness to Switch Jobs Internally. In line with previous research, we assume that if an employee displays primarily organization commitment, he or she will be inclined to stay with the organization and will thus limit him or herself to switching behavior inside the same company.

Willingness to Switch to a Competitor. In contrast to employees with organization commitment, employees with dominant industry commitment are proposed to be indifferent between switching to a job internally and switching to a competitor. After all, under both circumstances, their commitment focus is taken into consideration.

Consequently, we finally propose that the commitment focus is associated with the scope within which the employee is willing to switch and hypothesize that:

Hypothesis 3: Commitment focus is associated with the domain within which a recruit is willing to switch, whereby organization commitment focus is associated with a higher willingness to switch to another job internally than to a competitor, and thus to remain with the current firm. In contrast, industry commitment focus is not more associated with a higher willingness to switch to another job internally than to a competitor since both would warrant to remain within the current industry.

To illustrate our hypotheses, we provide the following prototypical examples of recruitment managers. First, recruitment manager 1 has worked for the same firm for more 
than 20 years. During that time, she has accumulated in-depth and detailed knowledge on the functioning, strengths and weaknesses of internal employees. This expertise has led to internal promotions and currently, she is responsible for supervising all internal succession management processes and decisions, and can do so very well, as she has met most employees throughout her career. This recruitment manager has thus accumulated firmspecific human capital making her human capital most valuable within her current organization. As a result, she will be highly committed to her current employing organization and most interested in switching jobs internally. Recruitment manager 2 has worked in different HR departments of different automotive companies over his 20-year professional career. Currently he is responsible for staffing the top positions within the organization. This position thus requires an in-depth understanding of the industry's key employees and the contexts in which they work to be able to assess their suitability for the position to be filled. Due to his long-lasting experience within the same industry, this recruitment manager has accumulated substantial industry-specific human capital over time and is of high value to all players of the automotive industry. His focus of commitment is thus directed toward the industry and he is equally willing to switch to a competitor or remain at his current employer. Recruitment manager 3 has gained some internal as well as external recruitment experience during her 20-year career in different business units and industries of large firms. She is known for her knowledge of graduate recruitment and an expert in assessing internal and external candidates' competences. Consequently, the value of her dominant human capital type does not specifically lie within the organization nor within the industry but both; she can create value from her rather general knowledge in any recruitment-related HR position but equally reap benefits for the current organization.

\section{Method}

\section{Data Collection}

Sampling Method. Employees with different work context origins had to be detected that were willing to share personal information with us. As information on commitment or willingness to switch to another organization, for instance, is oftentimes considered a sensitive issue even when anonymity is guaranteed, we thought that involving own contacts in data collection would increase the probability that questionnaires are fully completed. As a result, we chose a snowball sampling approach starting from our own network contacts and initially mailed the questionnaire to 71 recipients.

Questionnaire Design. The questionnaire sought to obtain data on as many recruitment events as possible and was thereby aimed at any employee currently in a dependent employment relationship who had switched employers at least once in working life. It was set up in the German language since the target group was German employees.

The questionnaire was designed to take 15 minutes and to cover information on career history, current level of organization and industry commitment, and willingness to switch. Concerning the former, we worked with an open question to be able to fully sketch career paths and retrieve information on e.g. main industry worked in, years in that industry 
or in working life overall. Commitment was measured by 18 closed questions in total to retrieve an average value of both industry and organization commitment in the end. Additionally, two closed questions were asked on willing to switch to another context (see Appendix 3).

Measurement Timing and Operationalizations. For hypothesis 1 , we looked at the last recruitment event, compared the current and the former employer of a respondent, and explored the human capital profile carried at that time, i.e. at time-of-hire. For hypothesis 2 , current commitment focus is measured, as we are interested in the current commitment focus displayed at the current employer, based on the current human capital displayed. Thus, here, the full human capital profile as it stands today is taken into consideration rather than just the human capital offered in the past at time-of-hire. Hypothesis 3 takes the same measurement point for commitment focus as hypothesis 2 and additionally uses the data received on current willingness to switch jobs or to a competitor. Hence overall, hypothesis 1 takes a retrospective perspective - looking at recruit origins - while hypotheses 2 and 3 consider the current time at point of measurement.

Recruit Work Context Origin. The variable recruit work context origin looks at the latest recruitment event that a recruit faced and classifies all respondents who have switched employers at least once into one of two external recruit categories: competitor recruit or non-competitor recruit. In particular, recruits were classified based on the career path outlined in the questionnaire as non-competitor recruits (0) if the most recent switch occurred between firms of different industries and as competitor recruits (1) if the last switch occurred between firms of the same industry.

Human Capital Carried ${ }^{61}$. The human capital type at time-of-hire (H1) is measured as two different scale variables first, namely industry-specific and general human capital. The current dominant human capital type $(\mathrm{H} 2)$ is similarly measured as two different scale variables first, namely firm-specific and industry-specific human capital. Both are then further transformed into a categorical variable of two categories based on ranked data respectively to compare group means.

The initial scale variables were calculated based on distinct formulas. The data needed to do so was retrieved from the respondents' indicated career paths based on the open questionnaire item "Please indicate your career path since entering your working life as a full-time employee (from quarter/year until quarter/year)". Firm-specific human capital is defined as any knowledge about internal (hiring firm) company practices, idiosyncratic processes and procedures that can optimally be acquired and exploited by working with the current and same employer only, and was hence measured as

\#years at current employer

(H2 only, i.e. after hire by current firm)

\footnotetext{
${ }^{61}$ We assume that human capital accumulates over time rather than that 'new' human capital (partly) "overwrites" 'old' human capital.
} 
The assumption is that an employee has accumulated more firm-specific human capital, i.e. knows the internal company processes and procedures better, the longer he has worked for this firm. An employee with 15 years of working experience within one company would accordingly have more firm-specific human capital than an employee with only 10 years of experience in the same firm. This variable was left out for $\mathrm{H} 1$, as external recruits would obviously score 0 by definition (see footnote ${ }^{58}$ ).

General human capital is defined as a broad set of skills and knowledge that is acquired through variation in general business experience that can be exploited by any company across firm boundaries. It is thus measured as

\#firms worked for $\mathrm{X}$ \#industries worked in

(both time-of-hire for $\mathrm{H} 1$ and current time for $\mathrm{H} 2$ )

We, here, follow the assumption that the more diverse the working contexts are that an employee has been confronted with during his working life, the more general human capital he has accumulated over time. An employee with work experience in two different firms and industries would thus have more general human capital than an employee with experience in two firms but only one sector.

Industry-specific human capital, defined as any knowledge about industry practices, business secrets or processes that can optimally be acquired and exploited by working in the same industry environment, was then measured as

\#years in current industry $\mathrm{X}$ \#firms of that same industry worked for (both time-of-hire for $\mathrm{H} 1$ and current time for $\mathrm{H} 2$ )

The assumption here is that an employee has accumulated more industry-specific human capital, the longer he has worked in this industry and the more different companies of the same industry he has worked for. Accordingly, an employee with 10 years of working experience in a single company would carry less industry-specific human capital than an employee with 10 years of working experience in two companies of the same industry.

The resulting ratios have different minimum and maximum values. As a result, we next relativized the variables to allow for proper comparison. Human capital variables then took on a percentile value between 1 and 100, with 1 representing the lowest proportion of the respective human capital type and 100 the highest proportion relative to the other respondents of the study sample. This is done by dividing each rank by the number of cases and multiplying it by 100 .

Categorical variables were created finally, one for $\mathrm{H} 1$ based on ranked general and industry-specific human capital at time-of-hire and one for $\mathrm{H} 2$ based on ranked current firmspecific and industry-specific human capital. We assigned categorical values of 0 or 1 depending on which human capital type dominated. For $\mathrm{H} 2$, when firm-specific human capital scored the highest rank a 0 was assigned, when industry-specific human capital had 
the highest rank a 1 was given (for $\mathrm{H} 1$ it was 0 for general and 1 for industry-specific human capital). For instance, if a case scored a fractional rank value of 23 for firm-specific human capital and 89 for industry-specific human capital, the recipient was assigned a 1, implying that the dominant human capital type carried relative to the other respondents was industry-specific human capital.

Generally, the different types of human capital may correlate but one does not necessarily cause the other. An HR consultant can, for example, accumulate industry-specific human capital by working for different companies of the same industry over time while enhancing his general skills set of analytical competence by doing his job.

Commitment Focus. We measured organization and industry commitment by using and adapting the set of items for measuring commitment as specified by Mowday, Steers and Porter (1979). As industry commitment has not been measured before, we thus adapted the established Organizational Commitment Questionnaire (OCQ) scale to our context of industry commitment as it was validly transferred to different contexts before (Irving, Coleman \& Cooper, 1997; Meyer, Allen \& Smith, 1993; Stinglhamber, Bentein \& Vandenberghe, 2002). Scales were adjusted in wording to be applicable to any business context. For instance, "I talk up the industry I work in to my friends as a great industry to work in" was used for the industry commitment scale and "I talk up this firm to my friends as a great organization to work for" as a statement for measuring organization commitment (see Appendix 3).

Results of reliability and item analyses suggested that the short form of the OCQ (i.e. using only the 9 positively worded items instead of all 15) is an acceptable substitute for the longer scale when questionnaire length is a consideration, which it is in our case (Mowday et al., 1979). As a result, our version had 9 items each for organization and industry commitment. Responses were measured on a 7-point scale with scale point anchors labeled (1) strongly disagree and (7) strongly agree. High values reflected high degrees of commitment; low scales low degrees of commitment. Cronbach's $\alpha$ for each of our commitment scales was 89 .

Based on the scale indications, we calculated an average mean per case for both organization and industry commitment next. To this end, we added all values per scale and then divided the value by 9 (the number of questions per scale) leading again to a value between 1 and 7 . We then measured degree of focus by subtracting organization commitment from industry commitment. Considering the set-up of the scale and the meaningful differences between each interval 1 to 7 , we assumed that when the scale mean absolute difference was $<0.5$, commitment is unfocused. We ignored those cases for the analyses of the respective hypotheses. Cases with differences of $\geq 0.5$, were designated either as industry focused or organization focused, depending on which score was highest. We assorted each case that had a higher mean average organization commitment than industry commitment a 0 , the others a 1.

Willingness to Switch. Willingness to switch a) to another job internally or b) to a competitor was measured as two different 7-point Likert scale questions. Questionnaire 
items were "Would you be willing to switch to another job within your current firm?" and "Would you be willing to switch to a competitor?" respectively.

We created a dummy variable to determine the prime willingness to switch. When scale indications overlapped, e.g. very few respondents assigned the same willingness to stay with the current employer as well as to switch to a competitor, we decided to assign categorical values in relative terms. To this end, we fractionally ranked the scale values. This lead to all scale values being assigned a value between 0 and 100, which again allowed for a direct comparison of the answers given by the respondents. We created a new categorical variable by assigning a value of 0 for willingness to switch jobs internally and 1 for willingness to switch to a competitor.

\section{Data Analysis}

We sought to investigate whether an external recruit of a certain origin carries a specific human capital type $(\mathrm{H} 1)$, whether the dominant human capital type carried is associated with the focus of commitment $(\mathrm{H} 2)$ and whether the dominant focus of commitment is linked to the willingness to switch to a specific work context (H3).

In order to test our hypotheses, we initially apply crosstabulations that lead to a 2 by 2 matrix of two categorical variables that visualizes how cases disperse across different categories. Besides, it provides a $\chi^{2}$ value that informs us on whether the pattern observed in the data is significant, i.e. not due to chance variation. In case of significance, we follow up our analysis with a between-groups comparison of means.

\section{Results}

Of the 126 returned surveys between April 1 and May 1, 2011, $63^{62}$ could be finally used for the analysis. We included, however, different sub-samples in the analysis depending on the hypothesis explored. As a result, for hypothesis 1, we worked with 45 cases, 22 noncompetitor and 23 competitor recruits. For hypotheses 2 and 3 , we used 41 (partly different) cases based on the categories explored. Since the sample characteristics were not significantly different, we report the descriptives of the total sample.

78 percent of respondents were male and 22 percent female. The average age was 35 , the average number of years in business life 10.4, and the average income (based on 50 responses) of the sample was $€ 79,192$. 39.3 percent of all respondents worked in small to medium sized, the rest in large companies. Only 16 of these companies acted locally, 6 were involved in export activities and 41, thus 65 percent, were global or multinational firms (see Table 5.1).

\footnotetext{
${ }^{62}$ Since the initial network consisted of many former student colleagues or self-employed under the age of 30 , most direct contacts were not eligible to participate in the study but rather asked to forward the questionnaire to suitable recipients. This might have caused the relatively small response rate.
} 
Table 5.1 Total Sample Characteristics $(n=63)$

\begin{tabular}{|c|c|c|c|c|}
\hline & Min. & Max. & M & SD \\
\hline Age & 24 & 62 & 35.05 & 9.16 \\
\hline Years in Working Life & .50 & 38.0 & 10.44 & 8.25 \\
\hline Job Level & 1 & 3 & 2.57 & .69 \\
\hline Firm Size $^{a}$ & 0 & 1 & .60 & .49 \\
\hline Business Scope $^{b}$ & 0 & 2 & 1.40 & .87 \\
\hline Gender $^{c}$ & 0 & 1 & .78 & .42 \\
\hline Gross Salary & 27,000 & 240,000 & $79,192.62$ & $35,298.11$ \\
\hline
\end{tabular}

Notes. ${ }^{\mathrm{a}}<500=0,>500=1 ;{ }^{\mathrm{b}}$ local $=0$, export $=1$, multinational $=2 ;{ }^{\mathrm{c}} \mathrm{f}=0, \mathrm{~m}=1$

Most respondents worked full-time (95\%) and on unlimited contracts (89\%). 11 percent fell under the category of senior management or higher, 21 percent were specialists and 68 percent other employees. All industries are represented, though professional services dominate the sample with 42.9 percent. Similarly, all functions are represented while IT and Business Consultancy dominate. The highest degree of most respondents was a university degree (94\%), of which 12 percent additionally held a PhD, professorship and/or MBA.

Table 5.2 shows the means, standard deviations and minimum and maximum values for all variables in this study.

Table 5.2 Means, Standard Deviations and Min./Max. Values for all Variables ${ }^{\text {a }}$

\begin{tabular}{|c|c|c|c|c|c|}
\hline & & Min. & Max. & M & SD \\
\hline 1. & $\begin{array}{l}\text { Recruit Work Context Origin }(\mathbf{H} 1) \\
((0) \text { non-competitor }=22 / 48.9 \%,(1) \text { competitor=23/51.1\%) }\end{array}$ & 0 & 1 & .53 & .51 \\
\hline \multirow[t]{4}{*}{2.} & Human Capital Type (H1) & & & & \\
\hline & 2a. General Human Capital (ranked) & 14.5 & 45.0 & 23.0 & 11.14 \\
\hline & 2b. Industry-Specific Human Capital (ranked) & 9.5 & 45.0 & 23.0 & 12.70 \\
\hline & 2c. Dominant (General $=0$, Industry-Specific $=1)^{b}$ & 0 & 1 & .49 & .51 \\
\hline \multirow[t]{4}{*}{3.} & Human Capital Type (H2) & & & & \\
\hline & 3a. Firm-Specific (ranked) & 1 & 63 & .32 & 18.32 \\
\hline & 3b. Industry-Specific (ranked) & 1.5 & 63 & .32 & 18.33 \\
\hline & 3c. Dominant (Firm-Specific $=0$, Industry-Specific $=1)^{b}$ & 0 & 1 & .46 & .50 \\
\hline \multirow[t]{4}{*}{4.} & Commitment Focus ( $\mathrm{H} 2 \mid \mathrm{H} 3)$ & & & & \\
\hline & 4a. Organization $(\mu)$ & 2.11 & 6.22 & 4.71 & 1.03 \\
\hline & 4b. Industry $(\mu)$ & 2.0 & 7.0 & 4.25 & 1.15 \\
\hline & 4c. Dominant (Organization=0, Industry=1) & 0 & 1 & .29 & .46 \\
\hline \multirow[t]{4}{*}{5.} & Willingness To Switch (H3) & & & & \\
\hline & 5a. Job Internally & 0 & 7 & 4.62 & 1.83 \\
\hline & 5b. Competitor & 0 & 7 & 4.30 & 1.89 \\
\hline & 5c. Dominant (Job Internally=0, Competitor $=1$ ) & 0 & 1 & .14 & .35 \\
\hline
\end{tabular}


Table 5.3 presents the respective correlations.

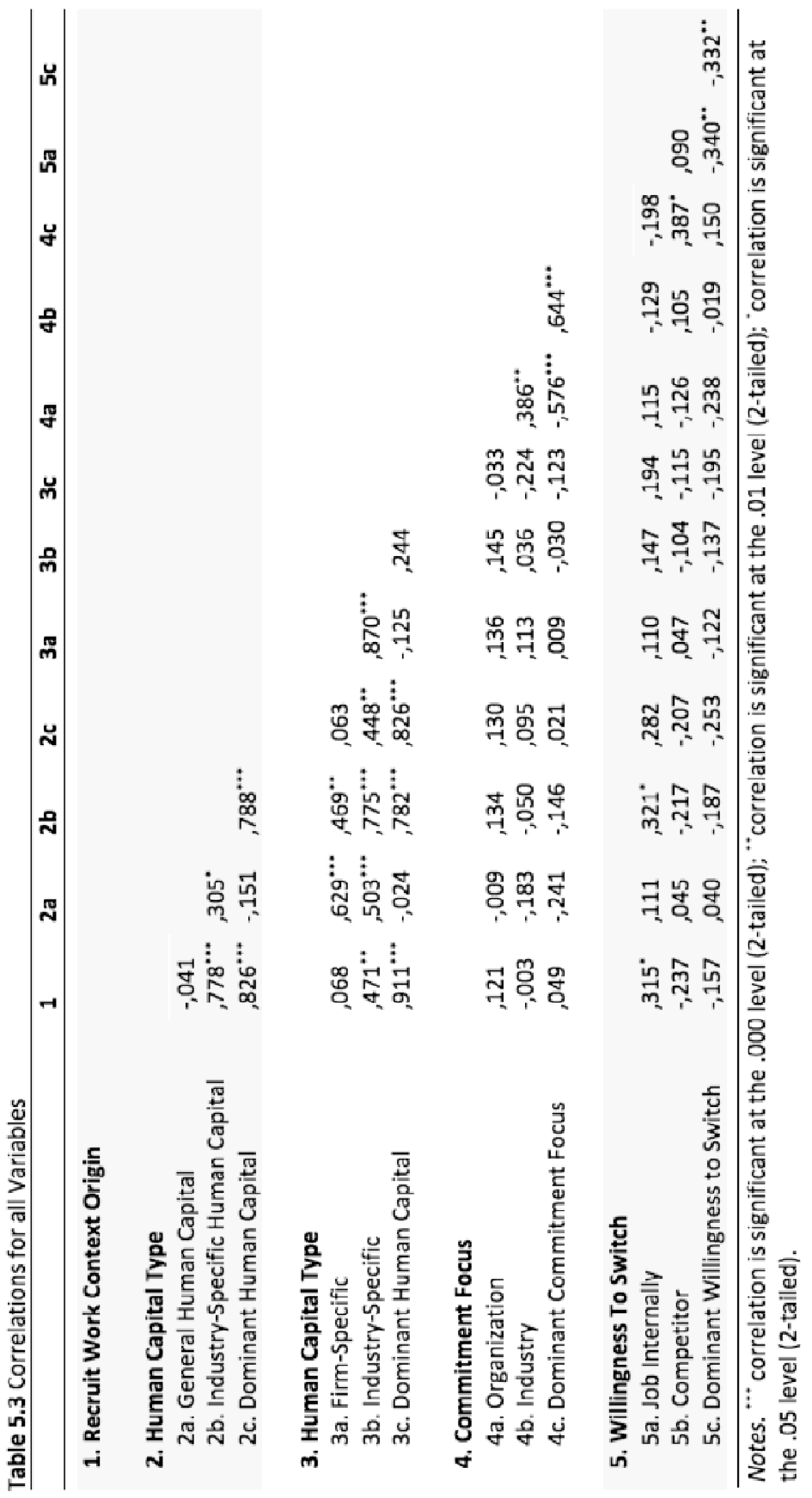




\section{Test of Hypotheses}

To test our hypotheses we conducted a crosstabulation analysis first for each hypothesis with the relevant categorical variables to examine frequencies of observations that belong to respective categories. This allows for a first identification of relations between the variables of our study. If the chi-square test indicated a significant pattern, we continued with an independent samples test by using respective categorical variables as independent variables and (ranked) scale variables as dependent variables.

Hypothesis $\mathbf{1}(\mathbf{a}, \mathbf{b})$. In hypothesis 1 , we proposed that recruit work context origin is associated with the human capital carried, whereby a) competitor recruits own relatively more industry-specific human capital and b) non-competitor recruits more general human capital.

The descriptives drawn from a crosstabulation analysis presented in Table 5.4 give a first indication of the human capital type that dominates per recruit group. We used recruit work context origin (categorical) as grouping variable and dominant human capital (categorical) as dependent variable. Considering the \% within recruit work context, general human capital is primarily carried by non-competitor recruits (95.2\%) and industry-specific human capital by competitor recruits (87.5\%).

Table 5.4 Dominant Human Capital*Recruit Work Context Origin

\begin{tabular}{ll|ccr}
\hline $\begin{array}{l}\text { Dominant } \\
\text { Human Capital }\end{array}$ & $\begin{array}{l}\text { Recruit Work } \\
\text { Context Origin }\end{array}$ & Count & $\begin{array}{c}\text { \%within Recruit Work } \\
\text { Context Origin }^{c}\end{array}$ & $\begin{array}{r}\text { \%Total } \\
\text { Sample }\end{array}$ \\
\hline General & $\begin{array}{l}\text { Non-Competitor } \\
\text { Competitor }\end{array}$ & 20 & $95.2 \%$ & $44.4 \%$ \\
& Complustry-Specific $^{\text {Ind }}$ & 1 & $4.8 \%$ & $6.7 \%$ \\
& Non-Competitor $^{\mathrm{a}}$ & 3 & $12.5 \%$ & $2.2 \%$ \\
& Competitor $^{\mathrm{b}}$ & 21 & $87.5 \%$ & $46.7 \%$ \\
\hline
\end{tabular}

Notes. ${ }^{a} \mathrm{n}=23 ;{ }^{b} \mathrm{n}=22 ;{ }^{c}$ recruits for which the specific human capital type is the dominant category

The crosstabulation analysis was significant at the .000 significance level with a Pearson $\chi^{2}$ of 30.68. As the $\chi^{2}$ test measures the discrepancy between the observed cell counts and what one would expect if the rows and columns were unrelated, the differences outlined are real rather than due to chance variation. As results thus show, a significant pattern exists between recruit work context origin and the prime human capital displayed.

To what extent this pattern significantly applies to each human capital type and whether group means differ, was investigated next. In particular, we used a non-parametric 2 -independent samples test as the assumption of normality was violated ${ }^{63}$. The KolmogorovSmirnov Z Test was considered suitable for the post-hoc analysis as it is useful when 2 groups of small sample size $(n<25)$ are compared (the Kruskal-Wallis Test that was used in chapter 1 in contrast allows for the comparison of 3 groups or more as long as $n>30$ ).

\footnotetext{
${ }^{63}$ Normality tests indicated a .000 significance level for both groups individually and when used as factors.
} 
Two-Sample Kolmogorov-Smirnov Z Test. As we had two groups with small sample sizes to compare, we conducted a two-sample Kolmogorov-Smirnov $Z$ test rather than a Mann-Whitney Test as it has more power with small sample sizes (Field, 2009). The aim was to explore the means between the two groups (competitor and non-competitor recruits) for each human capital type based on the ranked scale data and to find out how exactly they deviate. To this end, we used recruit work context origin (categorical) as grouping variable and this time the ranked scale variables of the two different human capital types rather than the categorical as dependent variables ${ }^{64}$.

Table 5.5 Two-Sample Kolmogorov-Smirnov Z Test: Recruit Work Context Origin*Human Capital

\begin{tabular}{llr}
\hline & Recruit Work Context Origin \\
\hline General & Z & .66 \\
Human Capital & Asymp. Sig. & .781 \\
& $\mathrm{r}$ & .10 \\
Industry-Specific & $\mathrm{Z}$ & 2.87 \\
Human Capital & Asymp. Sig. & .000 \\
& $\mathrm{r}$ & .43 \\
\hline
\end{tabular}

Results indicate that the means of the recruit groups significantly differ for industry-specific human capital $(Z(2)=2.87, p<.05, r=.43)$ but do not for general human capital $(Z(2)=.66, p>.05, r=.10)$ (see Table 5.5). The differences in ranked values, which made us categorize all respondents as either having a general or industry-specific human capital dominance, were obviously only significant in the former case. This also explains the striking difference between Table 5.4 and Table 5.5.

Hypothesis $\mathbf{2}(\mathbf{a}, \mathbf{b})$. Hypothesis 2 stated that the prime human capital type carried is associated with the focus of commitment, whereby a) firm-specific human capital is associated with a relatively higher organization commitment and b) industry-specific human capital with a relatively higher industry commitment.

The results presented in Table 5.6 give a first indication of the commitment focus that occurs depending on the degree to which each form of human capital is carried. This time, we used the other categorical dominant human capital type variable ( 2 categories) as the grouping variable and commitment focus (categorical) as dependent variable. Considering the \% within dominant human capital, employees regardless of human capital type seem to be committed more likely to the organization than to the industry (firmspecific human capital=65.0\%, industry-specific human capital=76.2\%).

\footnotetext{
${ }^{64}$ Results with non-ranked scale variables were the same. Mann-Whitney Tests also led to similar results in each case, with the means between the two groups regarding industry-specific human capital carried being highly significant while those regarding general human capital being insignificant.
} 
Table 5.6 Dominant Human Capital*Commitment Focus

\begin{tabular}{|c|c|c|c|c|}
\hline $\begin{array}{l}\text { Dominant } \\
\text { Human Capital }\end{array}$ & $\begin{array}{l}\text { Commitment } \\
\text { Focus }\end{array}$ & Count & $\begin{array}{l}\text { \%within Dominant } \\
\text { Human Capital }\end{array}$ & $\begin{array}{l}\text { \%Total } \\
\text { Sample }\end{array}$ \\
\hline \multirow[t]{2}{*}{ Firm-Specific } & Organization $^{\mathrm{a}}$ & 13 & $65.0 \%$ & $31.7 \%$ \\
\hline & Industry ${ }^{b}$ & 7 & $35.0 \%$ & $17.1 \%$ \\
\hline \multirow[t]{2}{*}{ Industry-Specific } & Organization $^{\mathrm{a}}$ & 16 & $76.2 \%$ & $39.0 \%$ \\
\hline & Industry ${ }^{b}$ & 5 & $23.8 \%$ & $12.2 \%$ \\
\hline
\end{tabular}

Notes. ${ }^{a} \mathrm{n}=29 ;{ }^{b} \mathrm{n}=12$; ${ }^{\mathrm{c}}$ cases in which the specific commitment focus is the dominant category

As the crosstabulation analysis was, however, insignificant this time with a Pearson $\chi^{2}$ of $.62, p=.43$, the differences outlined seem to occur at least partly due to chance variation ${ }^{65}$. As a result, hypothesis 2 had to be rejected.

Hypothesis 3. Hypothesis 3 assumed that the commitment focus displayed defines the domain within one is willing to switch. Specifically, we hypothesized that organization commitment focus is associated with a higher willingness to switch to another job internally than to a competitor and thus to remain with the current firm. In contrast, industry commitment focus was claimed to be not more associated with a higher willingness to switch to another job internally than to a competitor since both would warrant to remain within the current industry. We hence expect that the groups only significantly differ from each other when organization commitment is the dominant focus of commitment.

We used the 2 categorical commitment focus variables as grouping variables and dominant willingness to switch (categorical) as dependent variable. The descriptives presented in Table 5.7 give a first indication of the willingness to switch work contexts by commitment focus.

Table 5.7 Commitment Focus*Dominant Willingness to Switch

\begin{tabular}{ll|ccr}
\hline $\begin{array}{l}\text { Commitment } \\
\text { Focus }\end{array}$ & $\begin{array}{l}\text { Dominant } \\
\text { Willingness to Switch }\end{array}$ & Count & $\begin{array}{l}\text { \% within Dominant } \\
\text { Commitment Focus }\end{array}$ & $\begin{array}{r}\text { \%Total } \\
\text { Sample }\end{array}$ \\
\hline Organization & Job Internally $^{\mathrm{a}}$ & 27 & $93.1 \%$ & $65.9 \%$ \\
& Competitor $^{\mathrm{c}}$ & 2 & $6.9 \%$ & $4.9 \%$ \\
Industry & Job Internally $^{\mathrm{a}}$ & 10 & $83.3 \%$ & $24.4 \%$ \\
& Competitor $^{\mathrm{c}}$ & 2 & $16.7 \%$ & $4.9 \%$ \\
\hline
\end{tabular}

Notes. ${ }^{a} \mathrm{n}=37 ;{ }^{b} \mathrm{n}=4 ;{ }^{c}$ percentage of cases in which specific willingness to switch is the dominant category

In contrast to our hypothesis, commitment focus does not seem to be related to an employee's willingness to switch work contexts. The crosstabulation analysis was insignificant with a Pearson $\chi^{2}$ of $.92, p=.34$. A two-sample Kolmogorov-Smirnov test confirms these findings with $(Z(2)=.63, p>.05)$ for willingness to switch to another job

\footnotetext{
${ }^{65}$ A Kruskal-Wallis-Test using the mean scale values of commitment focus rather than the categorical variable equally led to insignificant results.
} 
internally and $(Z(2)=.43, p>.05)$ for willingness to switch to a competitor. As a result, hypothesis 3 also had to be rejected.

\section{Discussion}

As our research has revealed, competitor and non-competitor recruits significantly differ in terms of industry-specific human capital at time-of-hire, but do not differ in the general human capital carried. Hypothesis $1 \mathrm{~b}$ was thus supported. Contrary to our expectations, the commitment focus displayed is not significantly associated with the human capital carried or the willingness to switch jobs or employers. This may signal to HR managers that a likely switch either internally or externally is not related to employees' commitment orientation.

\section{Limitations and Further Research}

The most evident concern of this study is that it is difficult to specify whether our insignificant findings follow from the (low) number of observations, (cross-section selfreport) data, high variance, a lack of control variables, or (inappropriate indirect) proxies.

Thus, although our findings might suggest that industry-specific human capital can be primarily acquired at competitors, this is not necessarily the case as this might also follow from the way we measure human capital. In other words, doubts may be justified about whether recruit work context origin is measured independently from the forms of human capital carried. A person who is a non-competitor recruit will almost by definition score higher on general human capital when recruited since the number of industries worked in increases by 1 . Equally, a competitor recruit will automatically have industry-specific human capital increased since the number of firms of the same industry worked for goes up with 1. A way to partly solve this issue is to apply measures that proxy the amount of human capital at the moment of transfer. Concerning general human capital, for instance, one could subtract 1 from the number of industries (in case a person's last switch entailed a move to an industry he or she has never entered before). Unfortunately, we were not able to approach the matter ourselves since most of our respondents have only switched employers once or twice (which is one element of the inappropriateness of the sample).

This is related to our sample size and its characteristics. By using snowball sampling as data collection method we ended up with respondents early in their professional careers. In other words, we did not reach the group of employees that we were aiming at. The large majority of respondents considering age and experience is likely not to have been CRapproached in the original sense ever in their career. They might have switched jobs between competing firms, but not necessarily because they were aggressively motivated to do so. Generally, we do not consider snowball sampling an inappropriate method though for the purpose of this subject per se, which is rather sensitive and oftentimes treated confidentially. But future researchers need to make sure that the 'snowball' is forwarded by and to the 'right' people.

With regard to our commitment variable, many questions arose too. To begin with, we measured commitment at the current point in time, i.e. post-hire. How long this actual 
hire was ago, is, however, not considered. Maybe differences in commitment are only initially high, but approximate each other a while after. This would be in line with Koster, de Grip and Fouarge's (2011) findings that firm investments in general skills increase workers' commitment to a firm in accordance with social exchange theory. As a result, recruit origin may not matter much in the long-run for the degree of commitment displayed. What this would suggest is that initial commitment does differ but that new recruits may 'catch up' very fast. To test this hypothesis, a longitudinal approach is necessary. Points-ofmeasurement would then be point-of-hire with several intervals to follow afterwards. This would help to shed light on how (differently) commitment focus changes over time depending on work context origin.

To this end, confounding factors like other individual characteristics, such as an employee's current career stage, should be considered in addition (Cheramie et al., 2007). It has been suggested that the link between organizational commitment and turnover intentions may be strongest early in the career when commitment is still being developed, for instance (Meyer \& Allen, 1988), and employees who aim for more senior positions in their career tend to remain longer inside the same firm (Hamori \& Kakarika, 2009). This implies that it is indeed not an employee's human capital profile but other factors such as age, gender, or career stage and endeavors that influences one's focus of commitment and willingness to switch work contexts (for a review of turnover predictors see Allen, Bryant \& Vardaman, 2011).

Further research could also explore whether it is the actual difference between different commitment foci that matters or the overall degree. There might be a clear difference between somebody displaying a level of organizational commitment of 5 and of industry commitment of 3 on a 7-point Likert scale, and somebody with scores of 7 and 5 respectively. Though the former has equally more organization commitment than the latter, the total level of commitment of the latter is much higher. Also, would an employee with both an organization and industry commitment level of 4 be dually committed, torn, or rather not committed at all?

Our commitment measures themselves might have blurred the results. Asking for a direct indication of industry as well as organization commitment in the same 15-minutes survey might have let respondents confuse the two. Accordingly, the distinctiveness of the single items could not be shown when further exploring with a Kendall's $W$ test whether the scale items of cases differing by less than 1 on average in their industry and organization commitment are statistically indifferent. We found that only the difference of item 2 of industry and organization commitment was insignificant at the .05 level with $W=.09$, as well as of item 3 with $W=.00$, item 7 with $W=.05$, and item 9 with $W=.08$. Thus, although the OCQ scales used are highly established and can be characterized by large Cronbach $\alpha$ 's, future research in the field of multi commitment foci should consider to work with scales that offer even clearer differentiations in wording to avoid nuisance.

Further research could also investigate whether industry commitment as a separate and exclusive commitment focus next to organization or professional commitment 
exists at all. To the extent that certain activities are more characteristic of or exclusively relevant to a single industry (e.g. policy broker), commitment to the industry might overlap with that to the profession.

Although our sample was diverse in terms of industry experience, gender or education, our group of respondents overall had relatively little work experience - 10.5 years on average. Findings might have been different with a more experienced and/or aged sample. Previous research hints in that direction as initial employment tenure was shown to determine commitment and switching behavior. For instance, the pattern of change of organization and professional commitment is complementary within the first 14 months of employment only (Chang \& Choi, 2007), and organizations keep just 50 percent of their graduate recruits 5 years or longer (Sturges \& Guest, 2001). Besides, the more often a single respondent has changed employers or jobs, the more 'recruitment events' can be drawn from the biographical data and explored.

This study used biographical factors like work context origin to explain work behavior outcomes. In practice, many forces influence employee movements from one organization to another or between jobs internally. If future research could expand upon this method by also collecting attitudinal data from job movers and non-movers, a more complete understanding not only of turnover predictors in general, but on the antecedents and consequences of work context switches such as a move between firms of different industries could be developed. Also, involving applicants who competed for a job at time-ofhire but were not recruited for a specific job in the end might be worthwhile to consult. Thereby, conclusions could be drawn about why certain recruitment decisions are made, and whether they are undertaken because of the specific human capital type carried or expected commitment levels and foci. We will tentatively suggest in the following section that employees do not make rational employment decisions based on whether their value potentially reaped from their human capital is high or not. But does the same also apply to companies? Do companies always choose the applicant with the 'most' valuable human capital in absolute terms? Or do other intervening or process factors play a - more important - role such as fit?

Generally, the lack of significant results might besides those limitations as well stem from assumptions we based this study upon. We made two main assumptions. Our first assumption was that employees are rational beings that choose and commit to the job or organization in which they can valorize their human capital the most. But what if employees consider being rational something different than hiring firms? What if employees commit to a certain job or organization due to other factors such as age, work location, family circumstances, compensation or organizational health (Cheramie, Sturman \& Walsh, 2007) - which from their point of view might still be rational and correspond to value maximization? What value maximization hence means for organizations, namely an utmost productivity level following from the human capital carried, might differ from what employees consider as maximizing value. This was already suggested earlier within the realm of boundaryless career model research, which claims that individuals seek to manage their 
own careers by taking advantage of opportunities to maximize their personal success, which is not necessarily equal to productivity but also incorporates issues such as pay, work-lifebalance or other non-pecuniary benefits (Arthur et al., 2005; Eby et al., 2003; Heslin, 2005; Judge et al., 1994; Judge et al, 1995). This would potentially explain why there are no significant differences in terms of willingness to switch to a competitor or job internally. At the same time, it would support the call for effective top-down workforce management, i.e. for assuring that people are put on positions that allow them to use their full human capital potential, since employees themselves might not demand it. Especially in times of labor scarcities, systematic workforce planning might constitute a solution to otherwise incurred productivity or labor gaps (Cappelli, 2009; Huselid, Beatty \& Becker, 2005).

A second assumption we followed was that the prime human capital a recruit carries is cumulative over time and determined by the work environment to which he or she has been exposed. Accordingly, the longer an employee stays within one organization, the more firm-specific human capital he would proportionately display. Our human capital equations equally assume that human capital accumulates in the same way whether one is working for the second or tenth firm or industry. But the gain from working in the tenth firm may be smaller or larger than from working in the second firm. So what if previous experiences become irrelevant for one's performance on a job, or if human capital is not accumulated and parts of it are rather 'dormant'? This would imply that the traditional way of measuring human capital types (such as firm-specific human capital through firm tenure), is not necessarily measuring the real value creating potential. Certain recruit characteristics or deployment factors (see chapter 4) might moderate the degree to which a specific type and amount of human capital is employed at work, implying that a recruit's human capital value is not fixed or static. An example would be an employee taking up a study in between work engagements, and changes professional interest or expertise as a result.

\section{Conclusion}

This work has added insights to the problem of measuring human capital in the field of organization studies. Former research has only distinguished between general and firm-specific human capital, and limited research exists that actually tries to measure both directly while ignoring industry-specific human capital totally. Considering the partial significance of hypothesis 1 , there may be a clear not only theoretical, but also statistical difference between general and industry-specific human capital, as Sturman et al. (2008) already conceptually proposed. These findings suggest that future research in the field of human capital that aims at defining the antecedents of valuable and non-valuable employees should explore related differences further and clarify the taxonomy of human capital with which scholars in this field work. 
Conclusion 
Demographic changes and impending labor shortages are expected to pose severe challenges to firms in filling key vacancies. Competitor recruitment might constitute a worthwhile tool to fight the resulting talent crunch.

This article-based dissertation has made a first promising stride toward the phenomenon of competitor recruitment through both a theoretical exploration and an empirical assessment of $\mathrm{CR}$ theory and practice. We specifically aimed at a clarification of factors that underlie endeavors (not) to engage in competitor recruitment as well as of preconditions for a successful process. For this purpose, we let field practitioners reflect on and determine - what competitor recruitment is, how it is experienced, when appreciated or condemned, and what makes competitor recruits different from other (external and internal) recruits.

Throughout the dissertation, we followed the framework of competitor recruitment that was presented in the Introduction (Figure I) to approach the phenomenon. Accordingly, in chapter 1 , we sketched the societal context in which CR occurs by analyzing job postings and conducting a word count of publications published during the past 20 years. Chapter 2 then looked at all process stages 1, 2 and 3 (identification, transfer and deployment respectively) to theoretically map expected value and cost drivers of $C R$ for a hiring firm. Having delineated why it makes sense to research CR based on current HR trends and theoretical motivations, we investigated in chapter 3 the general motives and impediments of hiring firms that precede the decision (how) to engage in $C R$, i.e. the identification stage. Chapter 4 then took a combined search and hiring firm viewpoint to further specify the CR motives and impediments that were identified in chapter 3 in terms of cost and value drivers in practice. Finally, chapter 5 explored the CR recruit's behavior during deployment and investigated potential CR-typical consequences for a hiring firm (step 3). Most of our analyses in the different chapters were fueled by resource-based firm-level theories such as the resource-based view, strategic factor market or property rights theory, as well as by the human capital and institutional theory perspective.

Overall, we found that (1) the value attributed to human capital rose significantly and that the competition for labor became slightly more complex and aggressive over the past 20 years (chapter 1), (2) CR often concerns individuals or teams of middle or higher managers and specialists and is applied both directly and indirectly with the help of a personnel search firm. The prime aim is to strengthen own resources, which may follow when driven by specific motives, such as the need for industry-specific human capital or a fast integration process (chapter 3), (3) whether the hiring firm can appropriate the expected human capital depends to a large extent on the fit between the recruit and the organizational environment and certain costly deployment practices employed by the hiring firm (chapter 4), and (4) competitor recruits carry relatively more industry-specific human capital than non-competitor recruits. Differences in terms of level or focus of commitment and willingness to switch work contexts between $C R$ recruits and other external or internal recruits could not be detected (chapter 5 ). 
Thus overall, we identified theoretical conditions that determine the final value to be captured from CR by a hiring firm as well as empirically explored and provided insights on the phenomenon of competitor recruitment in practice.

Table II presents an overview of this dissertation and outlines the main themes of each chapter, research question(s) explored, approaches taken, data and methods used, propositions or hypotheses investigated, findings obtained, major contributions made, and important remaining gaps that partly determined the set-up of follow-up chapters. 


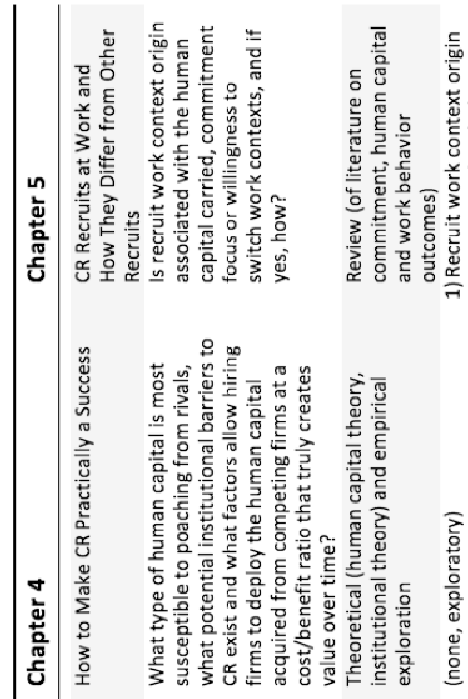

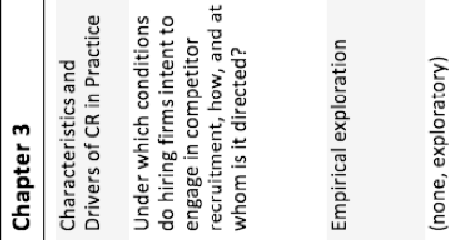

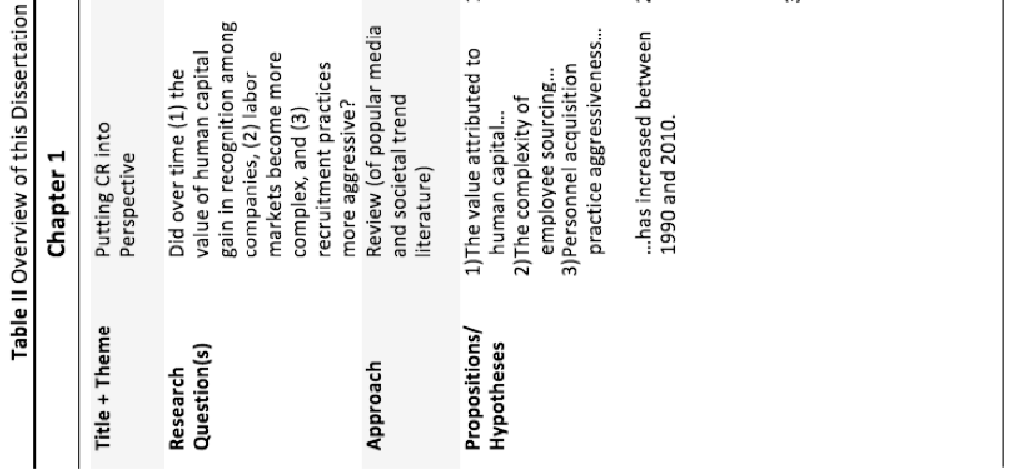




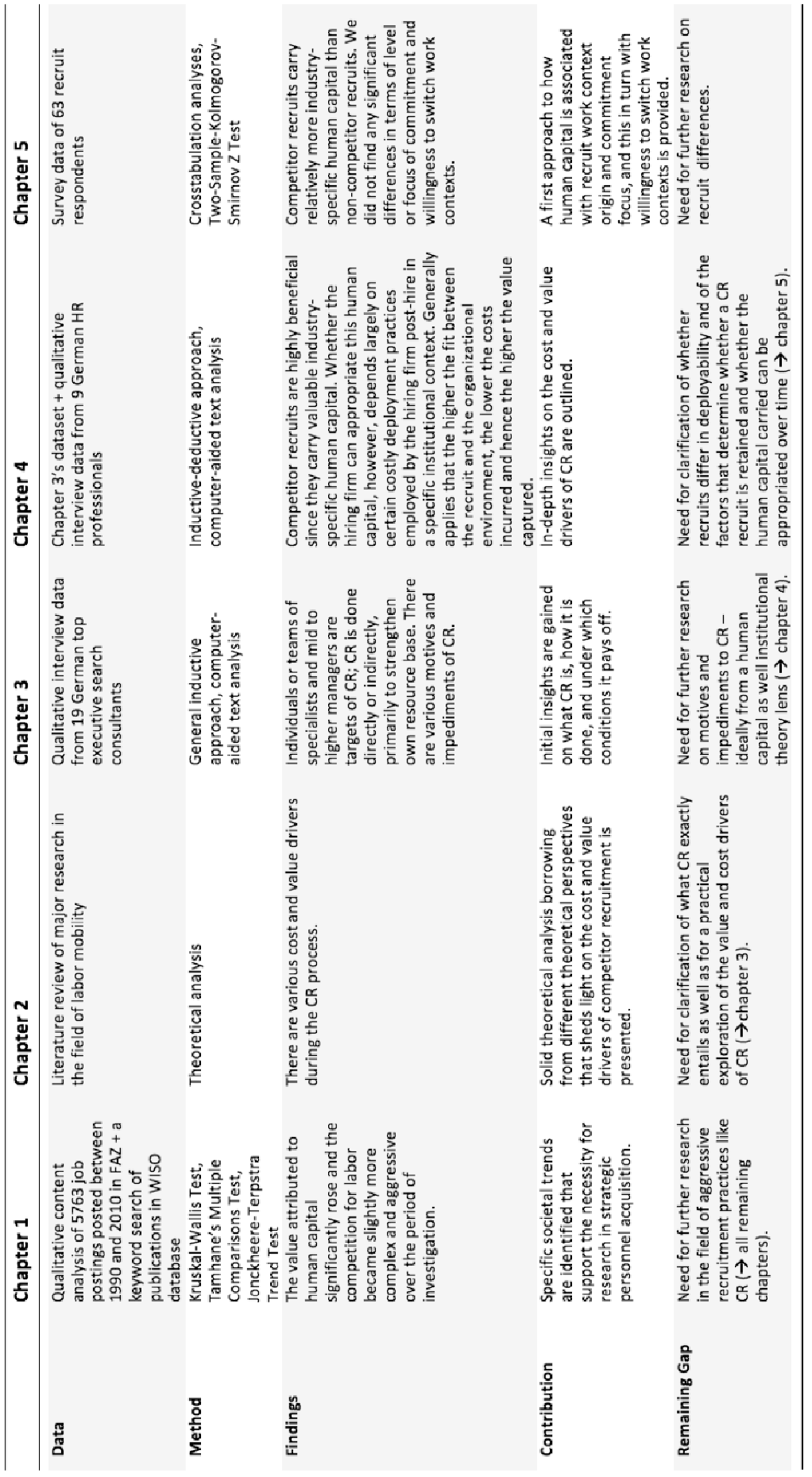




\section{Bringing It All Together}

This section will outline a comprehensive model of $C R$ based on the findings of this dissertation. It combines the main impressions gained and visualizes how they have informed us about competitor recruitment.

The dominant perspective is that of the hiring firm. Since chapter 1 looked beyond the hiring firm at the societal context of CR and chapter 5 within the individual recruit, these two chapters are excluded from the comprehensive picture. They primarily served to define the complexity of the CR phenomenon. The perspectives taken are outlined in Figure III.

Figure III Perspectives of this Dissertation

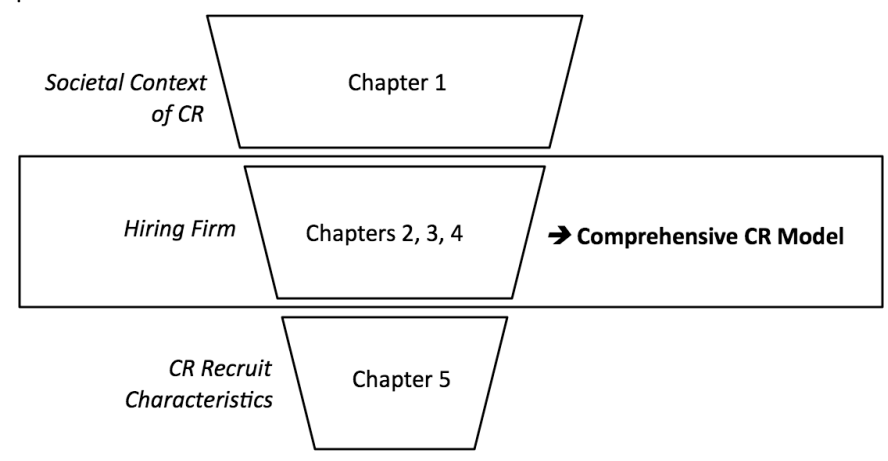

Practically, our model of CR (see Figure IV) consists of four major building blocks representing the insights gained from chapters 2, 3 and 4. As mentioned in the overall Introduction, this thesis primarily aimed at shedding light on three process model stages as described by Breaugh and Starke (2000), namely Recruitment Objectives, Strategic Development and Recruitment Results (see grey dotted boxes). Findings are arranged according to these stages. We have ignored specific Recruitment Activities and Intervening/Process Variables for the sake of taking a strategic approach. Obviously, recruitment results can be defined in various different ways, such as turnover rate or productivity. Here, we focused on the human capital value gained from CR.

Chapter 2 contributes to the model the idea of both a pre-hire (estimate) and a post-hire (realize) stage (see black dotted boxes). Each implies different cost and value drivers that follow from a CR initiative (see black dotted arrows). A reference is made to specific CR parameters discussed in chapters 3 and 4 (see small boxes connected by grey, framed arrow signs and further described by grey letters below each column of boxes on the left [chapter 3] as well as smaller grey boxes on the right [chapter 4]). Chapter 3 adds to the model by describing characteristics of $C R$ recruits and the $C R$ process, thereby outlining recruitment objectives and strategic development considerations around CR. Chapter 4 is of value to the model by specifying contextual factors of $C R$ that determine the overall value captured, i.e. the recruitment result. The single process stages are further described in black, bold, italic letters. 
Figure IV The Comprehensive CR Model

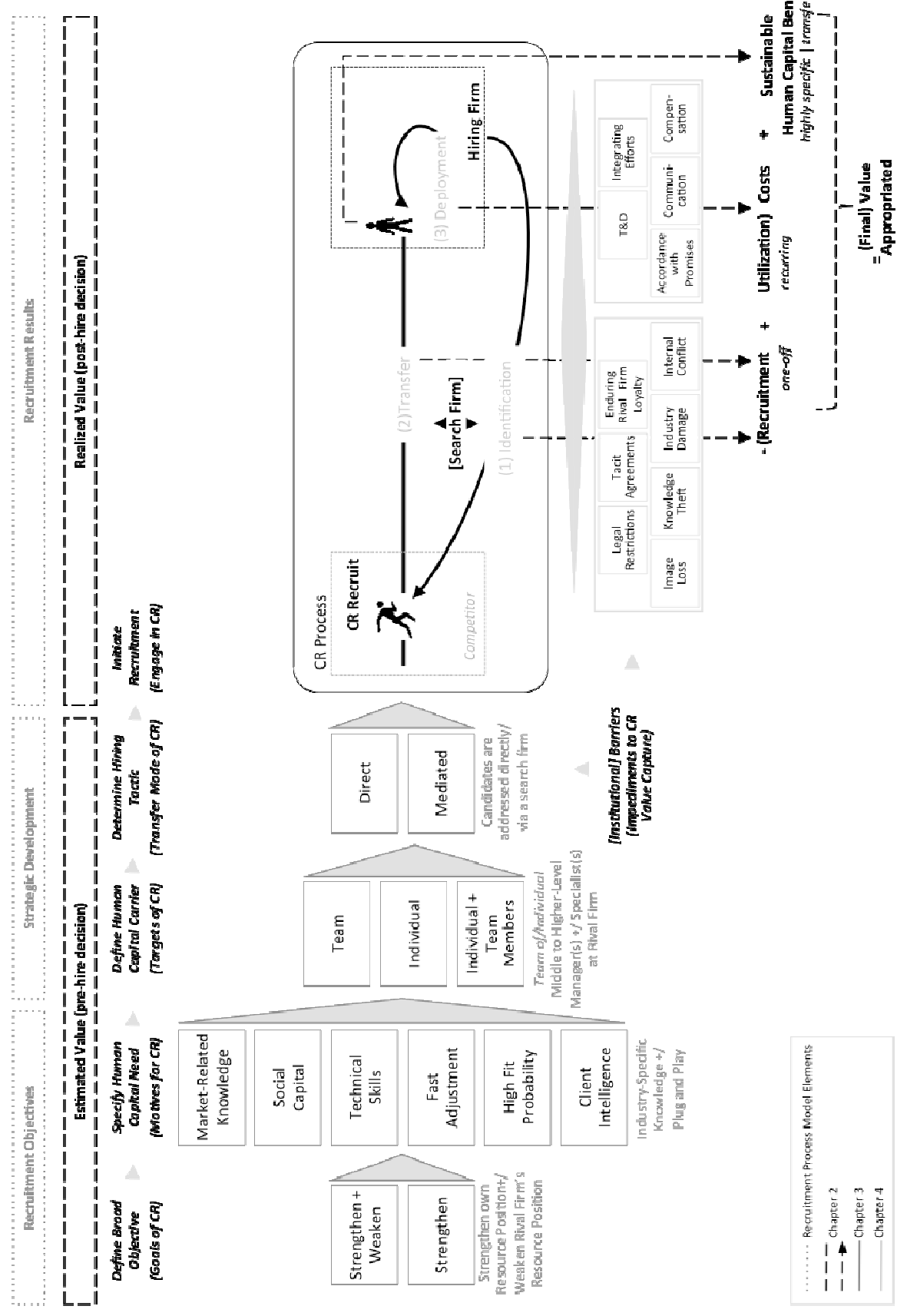


Our CR model begins ex post the decision for CR was made and thus presumes that the general questions that a hiring firm faces are why, what, where and how to engage in CR not if at all. Why do I engage in CR: only to strengthen my current resource position or also to weaken a competitor? What are my major motives? To acquire market-related knowledge or a client base, or to recruit an employee that is able to quickly adjust to a new work environment and fulfill the job requirements? Where do I find the needed human capital: only in a team of employees or an individual, or should I poach an individual with the request to tag former colleagues along? How should I go about considering my recruitment objectives? Rather do it directly, through my own network, a job posting or referrals? Or should I better involve a search firm that owns social capital, knowledge about my industry's major players and that carries the skills to handle the CR process smoothly and with the required discretion - fearing consequences of prevailing barriers like tacit agreements or non-compete clauses? And how do I make sure that the value I expect from engaging in CR is actually warranted? In other words, which factors do I need to consider during deployment to make sure that the employee is retained and remains productive and valuable?

Overall, this dissertation, and our comprehensive CR model, provides first answers to these questions and helps to understand the full CR process by outlining key success factors to the use of $C R$.

\section{Limitations and Future Research Areas}

We have broadly and exhaustively explored competitor recruitment theoretically and practically, and have thereby created with this dissertation a solid basis for future studies in the field of labor mobility - between industry rivals in particular. The main focus of this dissertation was the hiring firm and the different process stages it goes through when engaging in $\mathrm{CR}$.

Given the exploratory, comprehensive nature of this work we obviously could not study all aspects in depth. As a result, our findings should be regarded as a starting point for more in-depth work. Our prime contribution hence is to have identified a foundation which to base future research on. This section will discuss those elements of our comprehensive CR model that we did not yet fully cover (see dotted boxes; Figure V). Further elaborations on each matter can be found below the figure. 
Figure V Future Research Areas

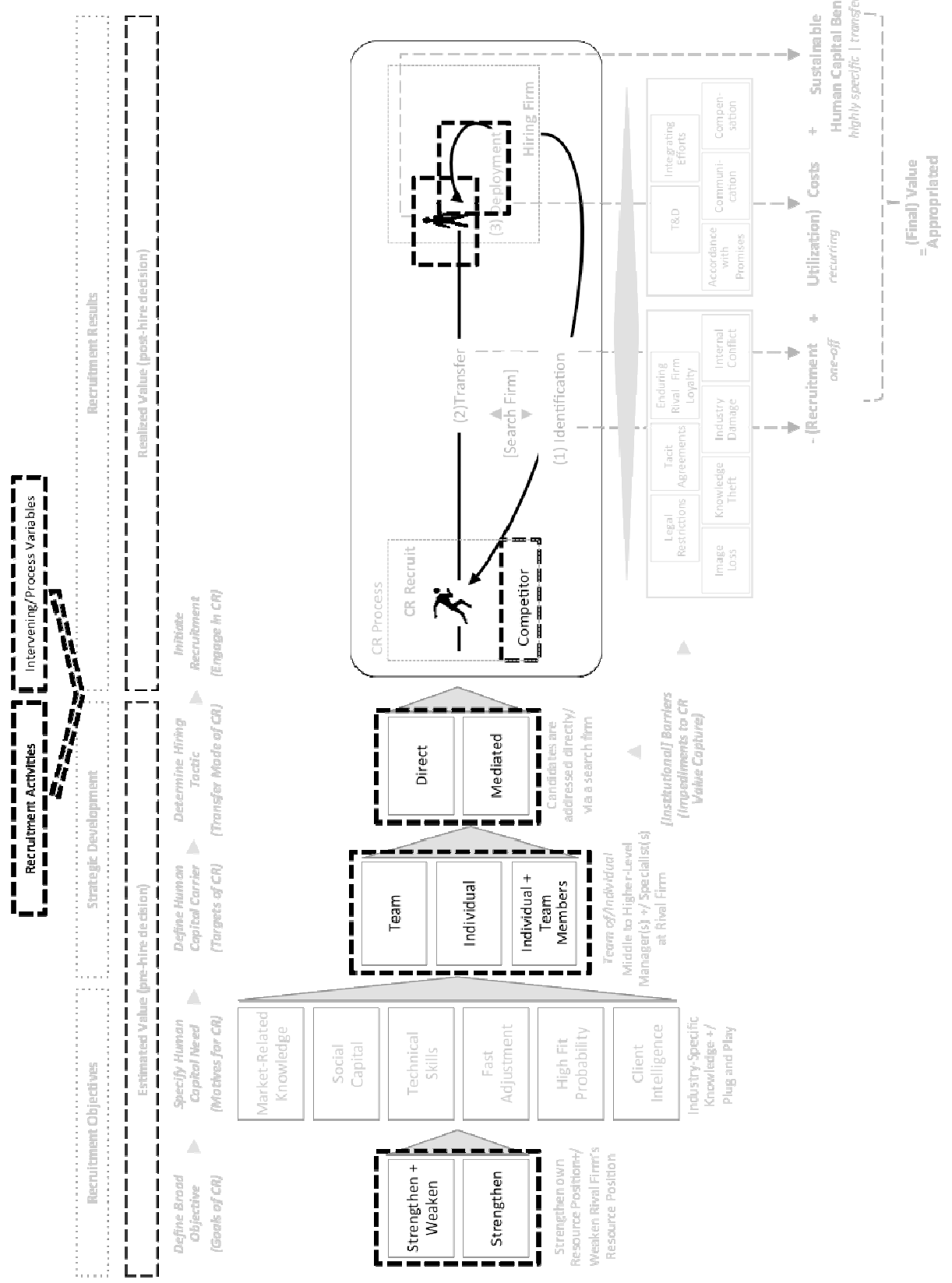


We have only limitedly regarded the role of competitor recruit characteristics and interests during each of the process stages of identification, transfer and deployment. How do competitor recruits perceive the process? How much bargaining power do they have when addressed by a rival, directly or indirectly, and how do and should they behave and react? What long-term career implications might a switch between competing firms have and what does it signal to future employers? Issues shortly addressed in chapter 3 were 'enduring rival firm identification' and 'internal conflict' that both constitute special barriers to the integration of competitor recruits - partly due to current employees being skeptical towards the newcomer. Competitor recruits might thus experience a process of deployment differently than other types of recruits. Future studies should further investigate these dynamics. After all, if competitor recruits differ from other recruits in the way they undergo the recruitment process, recruit work context origin might constitute a helpful heuristic for estimating the investments required until a recruit can be fully deployed and thus for predicting the likely value captured. Findings would be attractive to executive search consultants and onboarding specialists to clarify their role.

Another party that would be interesting to look at is the competing firm that loses an employee. How do competitors perceive the process? How much power do they have with regard to retaining a valuable employee and why? Does this differ between indirect and direct approaches of hiring firms? How should managers behave and react - also toward remaining employees? Or to what extent does the behavior of competitors determine the likely value gained from a CR initiative? We did not use competing firms as a data source in this project as we were primarily interested in the implications for hiring firms. Incorporating this perspective in future studies, however, would enrich the findings and also shed light on the degree to which a rival firm can actually block or hamper a poach, or be harmed through the employee loss in the long-run.

Moreover, the process and key success factors might vary depending on whether the CR initiative is done directly or indirectly. For instance, if a search firm is involved a core success criterion might be the extent to which a search consultant is trustworthy and competent, i.e. avoids legal missteps and charges a fair fee for a most optimal solution. If the poach is done directly, the degree to which the HR professional or executive is familiar with key industry players and owns social capital that helps to identify 'right' recruits in the first instance might matter most. In other words, social capital might play an important role in the identification stage and likely value of CR. Similarly, an issue of interest not investigated in this dissertation is whether there is a difference between a hiring firm deciding to poach a specific employee at a rival firm and involving an intermediary compared to a firm asking an intermediary to fill a position and the intermediary decides to address someone at a competitor. In other words, does strategic intent of the hiring firm matter for the actual recruitment process as well for the decision of a search firm to accept the order?

Furthermore, we chose not to study differences between whether an individual $C R$ recruit is poached or whether a whole team is motivated to transfer. Prime issues of relevance would be the degree of human capital that can be transferred, the risk of violating 
legal rulings, or the ease of transition and adjustment at the hiring firm. For instance, concerning human capital, not only general and industry-specific human capital can be transferred when a whole team is hired but also firm-specific human capital since parts of the work context transfer along (see chapter 2). The assumption that an employee is more productive the more of his or her human capital is applied might suggest that it is always advisable to poach a team rather than an individual. This however increases the risk that non-compete agreements or gentleman agreements are violated, or at least that the act of hiring is perceived as unethical. Equally, a team might be more productive at first instance, but less so in the long-run while seeing less the need to fully assimilate with, adjust to and accept the new work environment of colleagues, processes and routines. We hence wonder under which conditions it is most advisable to hire a team, and under which an individual recruit should be transferred, as well as how the related recruitment processes differ.

We have also not specified the context in which CR takes place. Although we have concluded that it is primarily specialists and middle to higher managers that are recruited through $\mathrm{CR}$, based on our data we could not clearly determine the specific functions, professions or industries in which it occurs and why. Also, we have conducted this research within the German context and have only suggested based on secondary data that differences exist across countries such as the US and Germany (see chapter 1 ). Whether this is really the case though and causes recruitment processes to differ remains unclear. As a result, we still wonder to what extent corporate culture matters as proposed in chapter 4, but also national culture or country-specific regulations. Comparative studies of competitor recruitment would help to understand these dimensions.

This dissertation presents valuable guidelines for HR professionals or other practitioners that make recruitment decisions by outlining the ideal conditions under which to recruit from rivals. What we have not dealt with, however, is how to prevent competitor recruits from being lured away by rival firms in turn. This is, however, an important matter in times of increasing voluntary turnover and labor shortages. After all, employee retention is a precondition for the attainment of a human capital advantage as it keeps valuable human capital inside the firm and prevents newly acquired knowledge to be carried to (other) competitors (in turn) (in case of competitor recruitment). It is hence crucial for companies to understand and use the mechanisms that allow them to retain competitor recruits for the time needed to realize the estimated human capital value. Is it compensation, training and development or other benefits that make competitor recruits stay within the hiring firm? Do demands of competitor, non-competitor and internal recruits differ at all? Further insights into this matter would be valuable to practitioners and researchers alike as it would help to understand the dynamics of employee deployment and the real impact individual stars or teams of stars can have on overall firm performance.

We decided to not investigate specific recruitment activities or intervening/ process variables according to Breaugh and Starke's (2000) process model of recruitment. It is however also worthwhile to explore their effect on the success of a CR recruitment process. Recruitment activities refer among others to the choice of recruitment sources, 
characteristics and behaviors of recruiters, and the recruitment messages being sent (Breaugh \& Starke, 2000). Questions that could be addressed in the context of competitor recruitment might be: What are the most useful channels through which a search should be conducted beyond asking the question of whether to involve a search agency (e.g. referrals, newspapers advertisements or social network)? Or what does the use of a certain source signal - toward potential recruits as well as competing companies? Intervening/Process Variables summarize those factors that may explain the relationship between recruitment activities and outcomes. They imply for instance the attention given to recruitment efforts by potential candidates and their interest triggered, or a recruitment message's credibility (Breaugh \& Starke, 2000). Questions of interest here might be: What do CR recruits value and seek in recruitment messages (e.g. compensation, responsibility, risk, appreciation)? Is it advisable to initially hide the fact that the hiring firm is a competitor? Or to what extent does the hiring firm's work context actually matter to employees in deciding whether to apply for and accept a job or not?

Throughout this dissertation, we assumed that $C R$ is an aggressive personnel acquisition practice that is only limitedly used by hiring firms to recruit a few selected individuals. While having neglected large-scale studies for the sake of in-depth exploration of the $\mathrm{CR}$ phenomenon, we wonder whether the phenomenon is not maybe more widespread than originally expected and even used to fill lower-level vacancies. Possibly, the process of competitor recruitment is also not fully different from a recruitment effort that concerns employee transfers between firms of the same industry - whether competitor or not. Considering our findings that suggest that the processes are at least to some extent distinct and thereby imply different value and cost drivers, further research attention should be given to this issue.

An effective approach towards many suggestions made would be to look at triads of $\mathrm{CR}$ versus non-CR cases by analyzing complete recruitment processes from the identification to the deployment stage from the perspective of each party involved, i.e. the hiring firm, recruit, and the other/rival firm, and potentially the search firm. When comparing the $\mathrm{CR}$ and non-CR cases afterwards - by potentially differentiating non-CR cases into recruits from a firm of the same industry that is however not a rival and recruits from outside the industry -, a holistic picture is obtained that allows for determining the factors that are idiosyncratic to the CR context as well as the core determinants of CR success.

Any future research in the field should attempt to identify causal relationships between the parameters surrounding $C R$ that we exposed here. What are major motives and impediments to $C R$, and how and to what extent do they determine costs and value incurred? Are competitor recruits similar to other recruits in terms of work outcome behaviors? And what is the real value of industry-specific human capital that justifies the investment of time, energy and resources in a highly complex and non-standardized CR process? 


\section{Concluding Implications}

This thesis implies many valuable implications for theory and practice. The academic contribution of this thesis is to have provided a first exploration and empirical assessment of $C R$, i.e. its characteristics, process stages and potential cost and benefit parameters involved, which can serve as a guide to develop an agenda for future research. The added value to practice is that the dissertation delivers an overview of the core factors for CR success that need to be considered when engaging in competitor recruitment. Implications for each audience are outlined below.

\section{Implications for Theory}

This thesis has shown that resource-based, strategic factor market, property rights, human capital and institutional theory thinking can be combined when exploring a strategic human resource management phenomenon. We have provided an example of how these perspectives can be complementary and useful when investigating current labor mobility phenomena. While most researchers apply a strategic firm-level approach to the issue of labor mobility (see Table 2.1), using institutional theory as a lens, though atypical, was shown to have clear additional value too in that it proposes further contingencies that determine the final value captured from competitor recruitment.

Additionally, this dissertation has demonstrated the value of taking a micro approach towards strategic human resource management. It suggests that it is not a firm's human resource management system per se that matters. Instead it seems that there are different pathways towards the creation of an effective HRM system, and that it might be essential to begin with defining a major human resource practice, e.g. recruitment, development or compensation, that determines how to structure the other HRM system elements accordingly. What our research thus emphasizes is that companies that want to use human resource management strategically might need to begin with defining their core value-creating HR practice in alignment with their overall business strategy, and treat other HR practices as supportive elements.

\section{Implications for Practice}

Our findings suggest that hiring firms engaging in competitor recruitment (should) follow motives that differ from those that underlie alternative recruitment practices. It is hence crucial for practitioners to be informed about the conditions under which (not) to poach from competitors due to the risks and likely costs involved. Taking a closer look at the implications of engaging in competitor recruitment, our research makes us conclude that several issues need to be considered when going on the competitor recruitment trail.

Based on our findings of chapter 1 (personnel acquisition becomes more and more aggressive, complex and crucial), chapter 2 (competitor recruits may carry major value creating potential) and chapter 5 (there is no difference in work outcome behavior between recruits of different work context origins), we would generally recommend seeing employees currently employed at rival firms as potential recruits. Based on the findings of 
chapter 3 and 4 of this dissertation, we would specifically recommend recruiting from rivals when (1) valuable, non-public industry insights or product knowledge is sought, (2) the 'premium employee' works at a rival and is not blocked by any non-compete agreement or other contractual clause that cannot be 'worked around', (3) training time wants to be minimized by searching for an employee familiar with certain industry practices who can quickly adjust to the new working context, i.e. can 'plug-and-play', (4) internal employees would welcome the opportunity to work with and learn from colleagues of competitors, or (5) access to a transferable client or customer base or other business networks already held by the recruit is aimed at. Vice versa, companies should avoid recruiting from rivals when (1) 'fresh blood', i.e. creative insights or approaches from other industries, are sought and/or industrial 'inbreeding' is a concern, (2) the expected proceeds of a potential recruit are firm rather than person-bound, in which case they are not likely to transfer along with the recruit, (3) the hiring firm's value system is incompatible with the practice of poaching, and direct colleagues may obstruct the integration of the poached recruit, (4) one does not want to violate unwritten agreements or norms that disapprove of competitor recruitment, (5) serious concerns exist about industrial espionage within the industry, (6) non-compete clauses are easily enforceable, or costly and difficult to overrule or circumvent, or (7) there is a real risk of retaliatory action by a competitor following a poach through, e.g. relational damage or increased competition.

These guidelines for HR professionals and other practitioners that make recruitment decisions outline the ideal conditions under which to recruit form rivals.

Many answers were given in this dissertation and core factors surrounding the competitor recruitment process outlined. Still questions remain. But understanding the factors involved when engaging in $\mathrm{CR}$, and when and why they need to be considered is a first important stride towards the strategic use of competitor recruitment. 


\section{Closing Words}

I started my journey as a researcher with the vision to 'save the world', to have a major impact on society and to work with only visionary people who are kind characters at the same time. My expectations toward the latter were fully confirmed. The social environment I enjoyed during my work and travel as a PhD student was extraordinarily pleasant, inspiring, respectful and friendly. The expectations regarding the former were met to a lesser extent. Though all researchers certainly seek to change the world into something better, with their scientific work, only a few directly and immediately succeed - who are oftentimes from the natural sciences.

So why do research in management? And why do research in human resource management in specific? Both fields are valuable as they seek to show how people's wellbeing can be improved by understanding them well in their role as employees. As management research can help people become better managers it has the potential to increase the well-being of the people being managed. Equally, researching HR topics helps to improve people's lives as employees. But are our findings really world-shaking and implementable in reality - in a reality that we look at through our subjective eyes? This has been a prevailing question for me throughout all four years of writing this dissertation and might be the result of the research approach taken - or even determined it. I came to conclude that most of our findings certainly are not world-shaking - neither do they save the world.

At the same time, I have learnt to appreciate the complexity that I (had to) deal( $t$ ) with throughout this project and accepted the limited direct impact - while recognizing that the steady discourse and intellectual advancement by itself is the moving power! I believe that changes do occur, thanks to research - if so slowly. The field of HR is a good example for this. Within less than 100 years we have completely revolutionized work processes and the way employees are managed. Frederik Taylor introduced the idea of scientific management around the turn of the last century and was thereby one of the first to apply science to management and improve efficiency in manufacturing by standardizing work processes of human behavior. Almost contemporaneously, as one of the most influential contributors to modern concepts of management, Henri Fayol developed his theory of business administration describing core functions of management such as coordinating or planning to be implemented in any organization. The function of a manager was born. A few decades later only, the so-called Hawthorne studies discovered - by chance - that informal organizations and human relations affect the motivation and productivity of employees initiating the discussion on the human side of management. Since then, managers see employees more and more as human beings that are intrinsically eager to contribute to their firms' success without having to be fully controlled by rules, standard operating procedures, or other institutionalized systems.

Though I certainly also have not changed the world into something better with the research conducted (though maybe with the teaching I have delivered, who knows) I am very happy to be able to conclude that I have contributed to a discourse across fields of strategy and human resource management by thoroughly exploring and assessing the phenomenon of competitor recruitment. 

References 
Abrahamson, E. (1996). Management Fashion. Academy of Management Review, 21(1), 254-285.

Abrahamson, E., \& Eisenman, M. (2008). Employee-Management Techniques: Transient Fads or Trending Fashions? Administrative Science Quarterly, 53(4), 719-744.

Acemoglu, D. (1997). Training and Innovation in an Imperfect Labour Market. Review of Economic Studies, 64(3), 445-464.

Ackermann, J., Borghardt, L., \& Mai, J. (2007). Jobmarkt im Höhenflug - Dicke Brieftasche. Retrieved 05/01/2011, from http://www.handelsblatt.com/karriere/ nachrichten/dicke-brieftasche/ 2851772.html.

Adegbesan, J. A. (2009). On the Origins of Competitive Advantage: Strategic Factor Markets and Heterogeneous Resource Complementarity. Academy of Management Review, 34(3), 463-475.

Aime, F., Johnson, S., Ridge, J., \& Hill, A. D. (2010). The Routine May be Stable But the Advantage is Not: Competitive Implications of Key Employee Mobility. Strategic Management Journal, 31(1), 7587.

Allen, D. G. (2006). Do Organizational Socialization Tactics Influence Newcomer Embeddedness and Turnover? Journal of Management, 32(2), 237-256.

Allen, D. G., Bryant, P. C., \& Vardaman, J. M. (2010). Retaining Talent: Replacing Misconceptions With Evidence-Based Strategies. Academy of Management Perspectives, 24(2), 48-64.

All Headhunters. (2009). Headhunter in Deutschland. Retrieved 16/03/2010, from http://www.allheadhunters.com.

Alsleben, C. (2005). The Downside of Knowledge Spillovers: An Explanation for the Dispersion of High-Tech Industries. Journal of Economics, 84(3), 217-284.

Amit, R., \& Schoemaker, P. J. H. (1993). Strategic Assets and Organizational Rent. Strategic Management Journal, 14(1), 33-46.

Argote, L., \& Ingram, P. (2000). Knowledge Transfer: A Basis for Competitive Advantage in Firms. Organizational Behavior and Human Decision Processes, 82(1), 150-169.

Armutat, S., \& Jera, S. (2010). Personalentwicklung nach Bologna. Personal, 3, 42-45.

Arthur, M., Khapova, S., \& Wilderom, C. (2005). Career Success in a Boundaryless Career World. Journal of Organizational Behavior, 26(2), 177-202.

Arthur, M. B., \& Rousseau, D. M. (1996). The Boundaryless Career: A New Employment Principle for a New Organizational Era. New York, NY: Oxford University Press.

AWA. (2007). AWA 2010. Retrieved 12/06/2011, from http://www.faz.net/s/RubED69C69060F5459E8B3 40967F46A923E/Doc $\sim$ E06C7AB1A1BCF4DC882D2DD0E8EA2102B ATpl Ecommon Scontent.ht $\mathrm{ml}$.

Backhaus, K. B. (2004). An Exploration of Corporate Recruitment Descriptions on Monster.com. Journal of Business Communication, 41(2), 115-136.

Badders, B., Cottom-Clark, L., \& Wright, P. M. (2007). Uncertainty and Human Capital Decisions: Traditional Valuation Methods and Real Options Logic. CAHRS Working Paper.

Bailey, E. E., \& Helfat, C. E. (2003). External Management Succession, Human Capital, and Firm Performance: An Integrative Analysis. Managerial and Decision Economics, 24(4), 347-369.

Bamberger, P., \& Meshoulam, I. (2000). Human Resource Strategy: Formulation, Implementation, and Impact. Thousand Oaks, CA: Sage Publications.

Barber, A. E. (1998). Recruiting Employees. Thousand Oaks, CA: Sage Publications.

Barner, R. (2000). Talent Wars in the Executive Suite. Futurist, 34(3), 35-41.

Barney, J. B. (1986). Strategic Factor Market: Expectations, Luck, and Business Strategy. Management Science, 32(10), 1231-1241.

Barney, J. B. (1991). Firm Resources and Sustained Competitive Advantage. Journal of Management, 17(1), 99-120.

Barney, J. B., Ketchen, D. J., \& Wright, M., (2001). The Future of Resource-Based Theory: Revitalization or Decline? Journal of Management, 37(5), 1299-1315.

Barney, J. B., \& Wright, P. M. (1998). On Becoming a Strategic Partner: The Role of Human Resources in Gaining Competitive Advantage. Human Resource Management, 37(1), 31-46.

Barney, J. B., Wright, M., \& Ketchen, D. J. (2001). The Resource-Based View of the Firm: Ten Years after 1991. Journal of Management, 27(6), 625-641.

Baruch, Y., Budhwar, P., \& Khatri, N. (2006). Brain Drain: Inclination to Stay Abroad After Studies. Journal of World Business, 42(1), 99-112.

Barzel, J. B. (1997). Economic Analysis of Property Rights (2nd ed.). Cambridge, UK: Cambridge University Press. 
Battelle, J. (2005). The 70 Percent Solution: Google CEO Eric Schmidt Gives us his Golden Rules for Managing Innovation. Analysis from Business 2.0: The Innovators Retrieved 14/7/2011, from http://money.cnn.com/magazines/business2/ business2_archive/2005/12/01/8364616/ index.htm.

Baugh, S. G., \& Roberts, R. M. (1994). Professional and Organizational Commitment among Engineers: Conflicting or Complementing? Engineering Management, 41(2), 108-114.

BDU. (2008). Studien des Bundesverband Deutscher Unternehmensberater. Retrieved 04/01/2011, from http://www.bdu.de/BDU-Publikationen.html?fuseaction=page.content\&s_kurzname= Studien_BDU.

BDU. (2009). Personalberater in Deutschland 2008/2009. BDU-Studie.

Becker, G. (1962). Investment in Human Capital: A Theoretical Approach. Journal of Political Economy, 70(5), 9-49.

Becker, G. (1964). Human Capital: A Theoretical and Empirical Analysis, with Special Reference to Education (3rd ed.). Chicago, IL: University of Chicago Press.

Becker, T. E., \& Billings, R. S. (1993). Profiles of Commitment: An Empirical Test. Journal of Organizational Behavior, 14(2), 177-190.

Beckman, C. M. (2006). The Influence of Founding Team Company Affiliations on Firm Behavior. Academy of Management Journal, 49(4), 741-758.

Beechler, S., \& Woodward, I. C. (2009). The Global "War for Talent". Journal of International Management, 15(3), 273-285.

Benkhoff, B. (1997). Ignoring Commitment is Costly: New Approaches Establish the Missing Link between Commitment and Performance. Human Relations, 50(6), 701-726.

Bentein, K., Vandenberg, R., Vandenberghe, C., \& Stinglhamber, F. (2005). The Role of Change in the Relationship Between Commitment and Turnover: A Latent Growth Modeling Approach. Journal of Applied Psychology, 90(3), 468-482.

Bhatnagar, J. (2007). Talent Management Strategy of Employee Engagement in Indian ITES Employees: Key to Retention. Employee Relations, 29(6), 640-663.

Bidwell, M., \& Briscoe, F. (2009). Who Contracts? Determinants of the Decision to Work as Independent Contractor among Information Technology Workers. Academy of Management Journal, 52(6), 1148-1168.

Björkman, I., Fey, C. F., \& Park, H. J. (2007). Institutional Theory and MNC Subsidiary HRM Practices: Evidence from a Three-Country Study. Journal of International Business Studies, 38(3), 430-446.

Blau, P. (1964). Exchange and Power in Social Life (1st ed.). New York, NY: John Wiley and Sons.

Blumberg, B., Cooper, D. R., \& Schindler, P. S. (2005). Business Research Methods (1st ed.). New York, NY: McGraw-Hill.

Boeker, H. (2002). Interview mit Dr. Heiner Boeker, Leiter Personalmarketing und Trainee-Programme, Robert Bosch GmbH. Retrieved 12/03/2011, from http://www.karrierefuehrer-automobile.de/ interview/interview_bosch.php.

Boeker, W. (1997). Executive Migration and Strategic Change: The Effect of Top Manager Movement on Product-Market Entry. Administrative Science Quarterly, 42(2), 213-236.

Bologna Declaration. (2011). The Bologna Process: Setting up the European Higher Education Area. Retrieved 10/03/2011, from http://europa.eu/legislation_summaries/education_training_ youth/lifelong_learning/c11088_en.htm.

Boon, C., Paauwe, J., Boselie, P., \& Den Hartog, D. (2009). Institutional Pressures and HRM: Developing Institutional Fit. Personnel Review, 38(5), 492-508.

Boudreau, J. W., \& Ramstad, P. M. (1997). Measuring Intellectual Capital: Learning from Financial History. Human Resource Management, 363(3), 343-356.

Boudreau, J. W., \& Ramstad, P. M. (2005). Talentship and the New Paradigm for Human Resource Management: From Professional Practices to Strategic Talent Decision Science. Human Resource Planning, 28(2), 17-26.

Bowen, D. E., Ledford, G. E., Jr., \& Nathan, B. R. (1991). Hiring for the Organization, Not the Job. Academy of Management Executive, 5(4), 35-51.

Breaugh, J. A. (2008). Employee Recruitment: Current Knowledge and Important Areas for Future Research. Human Resource Management Review 18(3), 103-118.

Breaugh, J. A., \& Starke, M. (2000). Research on Employee Recruitment: So Many Studies, So Many Remaining Questions. Journal of Management, 26(3), 405-434.

Brierley, J. A. (1996). The Measurement of Organizational Commitment and Professional Commitment. Journal of Social Psychology, 136(2), 265-267.

Brück, T. (2002). Die ökonomischen Folgen des neuen globalen Terrorismus. DIW Berlin Wochenbericht, 69(37).

Bryman, A., \& Burgess, R. G. (1994). Analyzing Qualitative Data (1st ed.). New York, NY: Routledge. 
Cable, D. M., \& Parsons, C. K. (2001). Socialization Tactics and Person-Organization Fit. Personnel Psychology, 54(1), 1-23.

Cable, D. M., \& Turban, D. B. (2003). The Value of Organizational Reputation in the Recruitment Context: A Brand-Equity Perspective. Journal of Applied Social Psychology, 33(11), 2244-2266.

Caldwell, R. (2008). HR Business Partner Competency Models: Re-Contextualizing Effectiveness. Human Resource Management Journal, 18(3), 275-294.

Cantrell, S. M., \& Smith, D. (2010). Learning for a Workforce of One. Chief Learning Officer, 9(10), 32-35.

Capgemini Consulting. (2009). HR Barometer 2009. HR Barometer Retrieved 21/06/2011, from http://www.de.capgemini.com/m/de/n/pdf_HR-Barometer_2009.pdf.

Cappelli, P. (2000). A Market-Driven Approach to Retaining Talent. Harvard Business Review, 78(1), 103111.

Cappelli, P. (2003). Will There Really Be a Labor Shortage? Organizational Dynamics, 32(3), 221-233.

Cappelli, P. (2004). Why Do Employers Retrain At-Risk Workers? The Role of Social Capital. Industrial Relations, 43(2), 421-447.

Cappelli, P. (2008). Talent Management for the Twenty-First Century. Harvard Business Review(March), 7481.

Cappelli, P. (2009). A Supply Chain Approach to Workforce Planning. Organizational Dynamics, 38(1), 8-15.

Cascio, W. F. (1998). Managing Human Resources: Productivity, Quality of Work Life, Profits (5th ed.). Boston, MA: McGraw-Hill.

Castanias, R. P., \& Helfat, C. E. (1991). Managerial Resources and Rents. Journal of Management, 17(1), 155-171.

Castanias, R. P., \& Helfat, C. E. (2001). The Managerial Rents Model. Journal of Management, 27, 661-678.

Castrogiovanni, G. J. (2002). Organization Task Environments: Have They Changed Fundamentally over Time? Journal of Management, 28(2), 129-150.

Chamber of Commerce. (2009). Nachvertragliches Wettbewerbsverbot. Retrieved 20/03/2010, from www.darmstadt.ihk24.de/produktmarken/recht_und_fair_play/Arbeitsrecht/Arbeitsrecht/ informationen_zu_besonderen_Arbeitsrechtsthemen/Nachvertragliches_Wettbewerbsverbot. jsp\#2.

Chang, J. Y., \& Choi, J. N. (2007). The Dynamic Relation Between Organizational and Professional Commitment of Highly Educated Research and Development (R\&D) Professionals. Journal of Social Psychology, 147(3), 299-315.

Chatman, J. A. (1989). Improving Interactional Organizational Research: A Model of Person-Organization Fit. Academy of Management Review, 14(3), 333-349.

Cheese, P., Thomas, R. J., \& Craig, E. (2007). The Talent Powered Organisation (1st ed.). London, UK: Kogan Page Limited.

Chen, X. P., Hui, C., \& Sego, D. J. (1998). The Role of Organizational Citizenship Behavior in Turnover: Conceptualization and Preliminary Tests of Key Hypotheses. Journal of Applied Psychology, 83(6), 922-931.

Cheramie, R. A., Sturman, M. C., \& Walsh, K. (2007). Executive Career Management: Switching Organizations and the Boundaryless Career. Journal of Vocational Behavior, 71(3), 359-374.

Coff, R. W. (1997). Human Assets and Management Dilemmas: Coping with Hazards on the Road to Resource-Based Theory. Academy of Management Review, 22(2), 374-402.

Coff, R. W. (2010). The Coevolution of Rent Appropriation and Capability Development. Strategic Management Journal, 31(7), 711-733.

Cohen, A. (2003). Multiple Commitments in the Workplace: An Integrative Approach (1st ed.). Mahwah, NJ: Lawrence Erlbaum Associates.

Cohen, J. (1992). A Power Primer. Psychological Bulletin, 112(1), 155-159.

Cohen, K. J., \& Cyert, R. M. (1973). Strategy: Formulation, Implementation, and Monitoring. Journal of Business and Psychology, 46(3), 349-367.

Collings, D. G., \& Mellahi, K. (2009). Strategic Talent Management: A Review and Research Agenda. Human Resource Management Review, 19(4), 304-313.

Collins, J. (2001). Good to Great: Why Some Companies Make the Leap...And Others Don't (1st ed.). New York, NY: HarperBusiness.

Combs, J. G., \& Skill, M., S. (2003). Managerialist and Human Capital Explanations for Key Executive Pay Premiums: A Contingency Perspective. Academy of Management Journal, 46(1), 63-73.

Conley, C., \& Tosti-Kharas, J. (2010). Crowdsourcing Content Analysis for Behavioral Research: Insights from Mechanical Turk. Paper presented at the Academy of Management Annual Meeting, Montréal, CA.

Connelly, B. L., Certo, S. T., Ireland, R. D., \& Reutzel, C. R. (2011). Signaling Theory: A Review and Assessment. Journal of Management, 37(1), 39-67. 
Consulting Star. (2009). Das Geschäft der deutschen Headhunter kühlt sich merklich ab. Retrieved 18/08/2009, from http://www.consultingstar.com /personalberatung/das-geschaeft-derdeutschen-headhunter-kuehlt-sich-merklich-ab.html.

Daimler AG. (2011). Compliance-Standards of Business Conduct. Retrieved 20/7/2011, from http://www.daimler.com/dccom/0-5-992580-1-998635-1-0-0-1032095-0-0-135-7145-0-0-0-00-0-0.html.

De Saá-Pérez, P., \& García-Falcón, J. M. (2002). A Resource-Based View of Human Resource Management and Organizational Capabilities Development. International Journal of Human Resource Management, 13(1), 123-140.

DeCotiis, T., \& Summers, T. (1987). A Path Analysis of a Model of the Antecedents and Consequences of Organizational Commitment. Human Relations, 40(7), 445-470.

Demsetz, H. (1988). The Theory of the Firm Revisited. Journal of Law, Economics and Organization, 4(1), 141-161.

Destatis. (2006). Germany's Population by 2050 - Results of the 11th Coordinated Population Projection. Retrieved 12/01/2010, from http://www.destatis.de/jetspeed/portal/cms/Sites/destatis/ Internet/EN/Content/Publikationen/SpecializedPublications/Population/GermanyPopulation20 50 , property=file.pdf.

Deutsche Welle (2011). Deutsche Bank's Co-CEO Plan: Clever or Risky? Retrieved 27/07/2011, from http://www.dw-world.de/dw/article/0,,15268718,00.html.

Devanna, M., Fombrun, C., \& Tichy, N. (1981). Human Resources Management: A Strategic Perspective. Organizational Dynamics, 10(3), 51-67.

Dey, I. (1993). Qualitative Data Analysis: A User-Friendly Guide for Social Scientists (1st ed.). New York, NY: Routledge.

Dierickx, I., \& Cool, K. (1989). Asset Stock Accumulation and Sustainability of Competitive Advantage Management Science, 35(12), 1504-1511.

Dignan, L. (2008). The IBM-Apple-Papermaster Triangle: How Far Does a Non-Compete Go? Retrieved 13/02/2010, from http://blogs.zdnet.com/BTL/?p=10748.

Di Lorenzo-Aiss, J., \& Mathisen, R. E. (1996). Marketing Higher Education: Models of Marketing Internship Programs as Tools for the Recruitment and Retention of Undergraduate Majors. Journal of Marketing for Higher Education, 7(1), 71-84.

DiMaggio, P. J., \& Powell, W. W. (1991). The New Institutionalism in Organizational Analysis (1st ed.). Chicago, IL: University of Chicago Press.

Dishon-Berkovits, M., \& Koslowsky, M. (2002). Determinants of Employee Punctuality. Journal of Social Psychology, 142(6), 723-739.

Dobbs, R. L., Sun, J. Y., \& Roberts, P. B. (2008). Human Capital and Screening Theories: Implications for Human Resource Development. Advances in Developing Resources, 10(6), 788-801.

Döhle, P., \& Werres, T. (2008). Olympiade der Konzerne. Retrieved 09/04/2010, from http://www.manager-magazin.de/unternehmen/imageprofile/ 0,2828,530209,00.html.

Ducanes, G., \& Abella., M. (2008). Labour Shortage Responses in Japan, Korea, Singapore, Hong Kong and Malaysia: A Review and Evaluation. Cornell University ILR School.

Eby, L. T., Butts, M., \& Lockwood, A. (2003). Predictors of Success in the Era of the Boundaryless Career. Journal of Organizational Behavior, 24(6), 689-708.

Edmondson, A. C., \& McManus, S. E. (2007). Methodological Fit in Management Field Research. Academy of Management Review, 32(4), 1155-1179.

Edwards, J. R. (1991). Person-Job fit: A Conceptual Integration, Literature Review, and Methodological Critique. In C. L. Cooper \& I. T. Robertson (Eds.), International Review of Industrial and Organizational Psychology (Vol. 6, pp. 283-357). New York, NY: John Wiley and Sons.

e-fellows. (2011). Unsere Angebote. Retrieved 20/7/2010, from http://www.e-fellows.net/show/detail. php/1658.

Ehrentraut, O., \& Fetzer, S. (2007). Die Bedeutung älterer Arbeitnehmer im Zuge der demografischen Entwicklung. In P. Da-Cruz \& M. Holz (Eds.), Demografische Entwicklung in der Betriebspraxis (pp. 23-35). Frankfurt: Gabler.

Ellemers, N., De Gilder, D., \& Van den Heuvel, H. (1998). Career-Oriented versus Team-Oriented Commitment and Behavior at Work. Journal of Applied Psychology, 83, 717-730.

Elmer-DeWitt, P. (2008). The Papermaster Chronicles: An Apple vs. IBM Timeline. Retrieved 12/02/2010, from http://tech.fortune.cnn.com/2008/11/08/the-papermaster-chronicles-an-apple-vs-ibmtimeline/. 
Elmer-DeWitt, P. (2010a). Mark Papermaster Should Be Happier at Cisco than he Was at Apple. Retrieved 20/06/2011, from http://tech.fortune.cnn.com/2010/11/13/mark-papermaster-should-behappier-at-cisco-than-he-was-at-apple/.

Elmer-DeWitt, P. (2010b). The Man Who Made the iPhone 4 is Out. Retrieved 20/06/2011, from http://tech.fortune.cnn.com/2010/08/07/the-man-who-made-the-iphone-4-is-out/.

EUROSTAT. (2008). Total Fertility Rates. Retrieved 18/12/2010, from http://epp.eurostat.ec.europa.eu/ statistics_explained/images/a/a5/Total_fertility_rate\%28mean_number_of_children_per_wom an\%29.PNG.

Farndale, E., \& Paauwe, J. (2007). Uncovering Competitive and Institutional Drivers of HRM Practices in Multinational Corporations. Human Resource Management Journal, 17(4), 355-375.

Fay, C. H., \& Thompson, M. A. (2001). Contextual Determinants of Reward Systems' Success: An Exploratory Study. Human Resource Management, 40(3), 213-226.

FAZ. (2005). Das „Unwort des Jahres“: „Humankapital“. Retrieved 30/06/2010, from http://www.faz.net/s/RubCC21B04EE95145B3AC877C874FB1B611/Doc E6612EBCE2DCF4D69 AC6CBB0296B09833 ATpl Ecommon Scontent.html.

FAZ. (2010). Rente mit 67 kommt trotz heftiger Proteste. Retrieved 17/11/2010, from http://www.faz.net/s/Rub594835B672714A1DB1A121534F010EE1/Doc E91F6844C7A614E01B 02245807C4E8F56 ATpl Ecommon Scontent.html.

Fernandez-Aráoz, C. (2007). Making People Decisions in the New Global Environment. MITSloan Management Review, 49(1), 17-20.

Fernández-Aráoz, C., Groysberg, B., \& Nohria, N. (2009). The Definitive Guide to Recruiting in Good Times and Bad. Harvard Business Review, 87(5), 74-84.

Fernandez-Mateo, I. (2007). Who Pays the Price of Brokerage? Transferring Constraint through Price Setting in the Staffing Sector. American Sociological Review, 72(2), 291-317.

Field, A. (2009). Discovering Statistics Using SPSS (3rd ed.). Thousand Oaks, CA: Sage Publications.

Flanagan, J. C. (1954). The Critical Incident Technique. Revue de Psychologie Appliquee, 51(4), 267-295.

Foss, K., \& Foss, N. (2005). Resources and Transaction Costs: How Property Rights Economics Furthers the Resource-Based View. Strategic Management Journal, 26(6), 541-555.

Foss, K., \& Foss, N. J. (2008). Understanding Opportunity Discovery and Sustainable Advantage: The Role of Transaction Costs and Property Rights. Unpublished Working Paper. Center for Strategic Management and Globalization, Copenhagen Business School.

Foss, N. J. (2008). Human Capital and Transaction Cost Economics. Unpublished Working Paper. Center for Strategic Management and Globalization, Copenhagen Business School.

Fuchs, J., Söhnlein, D., \& Weber, B. (2008). Demographic Effects on the German Labour Supply - A Decomposition Analysis. Institut für Arbeitsmarkt- und Berufsforschung.

Gandossy, R., \& Kao, T. (2004). Talent Wars: Out of Mind, Out of Practice. Human Resource Planning, 27(4), 15-19.

Gardner, T. M. (2002). In the Trenches at the Talent Wars: Competitive Interaction for Scarce Human Resources. Human Resource Management, 41(2), 225-237.

Gardner, T. M. (2005). Interfirm Competition for Human Resources: Evidence from the Software Industry. Academy of Management Journal, 48(2), 237-256.

Gardner, T. M., Stansbury, J., \& Hart, D. (2010). The Ethics of Lateral Hiring. Business Ethics Quarterly, 20(3), 341-369.

Gehrig, T., \& Stenbacka, R. (2007). Information Sharing and Lending Market Competition with Switching Costs and Poaching. European Economic Review, 51(1), 77-99.

Gerstein, M., \& Reisman, H. (1983). Strategic Selection: Matching Executives to Business Conditions. Sloan Management Review, 24(2), 1-18.

Giancola, F. L. (2009). Is Total Rewards a Passing Fad? Compensation Benefits Review, 41(4), 29-35.

Goldstone, J. (2010). The New Population Bomb. Foreign Affairs, 89(1), 31-43

Gostomzyk, T. (2006). Was jungen Juristen beim Berufsstart droht. Retrieved 21/09/2010, from www.spiegel.de/unispiegel/jobundberuf/0,1518,412423,00.html.

Gouldner, A. W. (1957). Cosmopolitans and Locals: Toward an Analysis of Latent Social Roles. Administrative Science Quarterly, 2(3), 281-306.

Gramke, K., Gischer, D., Schlesinger, M., \& Schüssler, R. (2009). Arbeitslandschaft 2030 - Auswirkungen der Wirtschafts- und Finanzkrise. Retrieved 30/06/2010, from http://www.vbw-bayern.de/ agv/downloads/41822@agv/091217_Arbeitslandschaft2030_Wirtschaftskrise_Kurz_end.pdf. 
Green, J., Willis, K., Hughes, E., Small, R., Welch, N., Gibbs, L., \& Daly, J. (2007). Generating Best Evidence from Qualitative Research: The Role of Data Analysis. Australian and New Zealand Journal of Public Health, 31(6), 545-550.

Greenberg, J., \& Baron, A. B. (2003). Behavior in Organizations (8th ed.). Upper Saddle River, NJ: Sage Publications.

Griffeth, R. W., Hom, P. W., \& Gaertner, S. (2000). A Meta-Analysis of Antecedents and Correlates of Employee Turnover: Update, Moderator Tests, and Research Implications for the Next Millennium. Journal of Management, 26(3), 463-488.

Gross, S., Bundy, K., \& Johnson, R. (2011). The Ongoing Integration of Total Rewards. Employment Relations Today, 37(4), 11-17.

Groysberg, B., \& Abrahams, R. (2006). Lift Outs: How to Acquire a High-Functioning Team. Harvard Business Review, 84(12), 133-140.

Groysberg, B., \& Lee, L.-E. (2008). The Effect of Colleague Quality on Top Performance: the Case of Security Analysts. Journal of Organizational Behavior, 29(8), 1123-1144.

Groysberg, B., \& Lee, L.-E. (2009). Hiring Stars and Their Colleagues: Exploration and Exploitation in Professional Service Firms. Organization Science, 20(4), 740-758.

Groysberg, B., Lee, L.-E., \& Nanda, A. (2008). Can They Take It With Them? The Portability of Star Knowledge Workers' Performance. Management Science, 54(7), 1213-1230.

Groysberg, B., McLean, A. N., \& Nohria, N. (2006). Are Leaders Portable? Harvard Business Review, 84(5), 92-100.

Gunz, H. P., \& Gunz, S. P. (1994). Professional/Organizational Commitment and Job Satisfaction for Employed Lawyers. Human Relations, 47(7), 801-828.

Gupta, A., \& Govindarajan, V. (2002). Cultivating a Global Mindset. Academy of Management Executive, 16(1), 116-126.

Hall, P. A., \& Taylor, R. C. R. (1996). Political Science and the Three New Institutionalisms. Political Studies, 44(5), 936-957.

Hamori, K. (2010). Who Gets Headhunted - and Who Gets Ahead? The Impact of Search Firms on Executive Careers. Academy of Management Perspectives, 24(4), 46-59.

Hamori, M., \& Kakarika, M. (2009). External Labor Market Strategy and Career Success: CEO Careers in Europe and the United States. Human Resource Management, 48(3), 355-378.

Handfield-Jones, H., Michaels, E., \& Axelrod, B. (2001). Talent Management: A Critical Part of Every Leader's Job. Ivey Business Journal, 66(2), 53-58.

Harcourt, M., Lam, H., \& Harcourt, S. (2005). Discriminatory Practices in Hiring: Institutional and Rational Economic Perspectives. International Journal of Human Resource Management, 16(11), 21132132.

Harris, A. (2008). Motorola Claims Executive Now With Apple Took Secrets (Update2) Retrieved 12/06/2011, from http://www.bloomberg.com/apps/news?pid=newsarchive\&sid= addkX1GCw6zw.

Harris, D., \& Helfat, C. (1997). Specificity of CEO Human Capital and Compensation. Strategic Management Journal, 18, 895-920.

Hart, D. W., \& Thompson, J. A. (2007). Untangling Employee Loyalty: A Psychological Contract Perspective. Business Ethics Quarterly, 17, 297-323.

Hatch, N. W., \& Dyer, J. H. (2004). Human Capital and Learning as a Source of Sustainable Competitive Advantage. Strategic Management Journal, 25(12), 1155-1178.

Hatfield, D. M., Liebeskind, J. P., \& Opler, T. C. (1996). The Effects of Corporate Restructuring on Aggregate Industry Specialization. Strategic Management Journal, 17, 55-73.

Helfat, C. E., \& Peteraf, M. A. (2003). The Dynamic Resource-Based View: Capability Lifecycles. Strategic Management Journal, 24(10), 997-1010.

Helft, M. (2010). Executive Leaves After iPhone Antenna Troubles. Retrieved 12/06/2011, from http://forum.tipb.com/iphone-4-forum/196201-executive-mark-papermaster-leaves-afteriphone-antenna-troubles.html.

Herscovitch, L., \& Meyer, J. P. (2002). Commitment to Organizational Change: Extension of a ThreeComponent Model. Journal of Applied Psychology, 87(3), 474-487.

Herz, C., \& Schneider, M. C. (2010). Volkswagen wildert erneut bei Konkurrenz. Retrieved 12/06/2011, from http://www.handelsblatt.com/unternehmen/management/ koepfe/volkswagen-wilderterneut-bei-konkurrenz/3523652.html?p3523652=all.

Heslin, P. A. (2005). Conceptualizing and Evaluating Career Success. Journal of Organizational Behavior, 26, 113-136. 
Hirsh, M. (1996). GM vs. VW. Retrieved 12/06/2011, from http://www.newsweek.com/ 1996/12/08/gmvs-vw.html.

Hitt, M. A., Bierman, L., Shimizu, K., \& Kochhar, R. (2001). Direct and Moderating Effects of Human Capital on Strategy and Performance in Professional Service Firms: A Resource-Based Perspective. Academy of Management Journal, 44(1), 13-28.

Hitt, M. A., \& Ireland, R. D. (1985). Strategy, Contextual Factors, and Performance. Human Relations, 38(8), 793-812.

Hofstede, G. (1991). Cultures and Organizations: Software of the Mind. London, UK: McGraw-Hill.

Hohmann, G. (2010). "Mister Opel" wechselt zu VW. Retrieved 12/06/2011, from http://www.tagesschau.de/wirtschaft/demant106.html.

Höhn, C., Mai, R., \& Micheel, F. (2007). Demographic Change in Germany. In I. Hamm, H. Seitz \& M. Werding (Eds.), Demographic Change in Germany: The Economic and Fiscal Consequences (pp. 9-32). Berlin, D: Springer.

Holsti, O. R. (1969). Content Analysis for the Social Sciences and Humanities. Reading, MA: AddisonWesley.

Homans, C. G. (1961). Social Behavior: Its Elementary Forms. New York, NY: Harcourt, Brace \& World.

Hoopes, D. G., Hadsen, T. L., \& Walker, G. (2003). Guest Editors' Introduction to the Special Issue: Why is There a Resource-Based View? Toward a Theory of Competitive Heterogeneity. Strategic Management Journal, 24(10), 889-902.

Hrebiniak, L. G., \& Alutto, J. A. (1972). Personal and Role-Related Factors in the Development of Organizational Commitment. Administrative Science Quarterly, 17(4), 555-573.

Huselid, M. A., Beatty, R. W., \& Becker, B. E. (2005). A Players or A Positions? Harvard Business Review, 83(12), 110-117.

Hutterer, M. (2010). Mit 63 Jahren ist meistens Schluss. Retrieved 27/08/2010, from http://www.focus.de/finanzen/altersvorsorge/rente/tid-19469/rentendebatte-mit-63-jahrenist-meistens-schluss_aid 540285.html.

IfM. (2002). KMU-Definition des IfM Bonn. Bonn: Institut für Mittelstandsforschung.

IfM. (2005). Bedeutung des Mittelstands in Deutschland. Universität Mannheim: Institut für Mittelstandsforschung.

IfM. (2009). Schlüsselzahlen des Mittelstands in Deutschland 2006/2007. Bonn: Institut für Mittelstandsforschung.

Igbaria, M., \& Greenhaus, J. H. (1992). Determinants of MIS Employees' Turnover Intentions: A Structural Equation Model. Communication of the ACM, 35(2), 35-49.

Igbaria, M., \& Guimaraes, J. H. (1999). Exploring Differences in Employee Turnover Intentions and its Determinants Among Telecommuters and Nontelecommuters. Journal of Management Information Systems, 16(1), 147-164.

Irving, P. G., Coleman, D. F., \& Cooper, C. L. (1997). Further Assessments of a Three-Component Model of Occupational Commitment: Generalizability and Differences Across Occupations. Journal of Applied Psychology, 82(3), 444-452.

Iverson, R. D., \& Buttigieg, D. (1999). Affective, Normative, and Continuance Commitment: Can the Right Kind of Commitment be Managed? Journal of Management Studies, 36(3), 307-333.

Jaros, S., Jermier, J., Koehler, J., \& Sincich, T. (1993). Effects of Continuance, Affective and Moral Commitment on the Withdrawal Process: An Evaluation of Eight Structural Equation Models. Academy of Management Journal, 36(5), 951-995.

Jauch, L. R., Osborn, R. N., \& Martin, T. N. (1980). Structured Content Analysis of Cases: A Complementary Method for Organizational Research. Academy of Management Review, 5(4), 517-525.

Jetuah, D. (2007). KPMG Poaches Economics Guru from PwC. Retrieved 10/06/2011, from http://www.accountancyage.com/aa/news/1779706/kpmg-poaches-economics-guru-pwc.

Johnson, H. (2011). Secrets To Stealing Employees From Competitors. 21/06/2011, from http://www.businessinsider.com/how-to-poach-an-employee-from-a-competitor-2011-3.

Johnston, W. B. (1992). The Coming Labor Shortage. Journal of Labor Research, 13(1), 5-10.

Judge, T. A., Boudreau, J. W., \& Bretz, R. D. (1994). Job and Life Attitudes of Male Executives. Journal of Applied Psychology, 79, 767-782.

Judge, T. A., Cable, D. M., Boudreau, J. W., \& Bretz, R. D. (1995). An Empirical Investigation of the Predictors of Executive Career Success. Personnel Psychology, 48, 485-519.

Judge, T. A., Shaw, J. C., Jackson, C. L., Scott, B. A., \& Rich, B. L. (2007). Self-Efficacy and Work-Related Performance: The Integral Role of Individual Differences. Journal of Applied Psychology, 92(1), 107-127. 
Kane, Y. I., \& Sherr, I. (2010). IPhone Executive Is Out At Apple Retrieved 12/06/2011, from http://online.wsj.com/article/SB1000142405274870426800 4575417572159585144.html.

Kang, C. (2009). Federal Antitrust Probe Targets Tech Giants, Sources Say. Retrieved 23/02/2011, from http://www.washingtonpost.com/wpdyn/content/ article/2009/06/02/AR2009060203412. html.

Kaplan, R. S., \& Norton, D. P. (1992). The Balanced Scorecard - Measures that Drive Performance. Harvard Business Review(Jan.-Feb.), 71-80.

Kato, J. (1996). Institutions and Rationality in Politics - Three Varieties of Neo-Institutionalists. British Journal of Political Science, 26, 553-582.

Keating, G. (2008). Motorola Sues Former Executive over iPhone Job. Retrieved 12/06/2011, from http://in.reuters.com/article/2008/07/19/motorola-fenger-idINN1846432620080719.

Kim, J., \& Mahoney, J. T. (2002). Resource-Based and Property Rights Perspectives on Value Creation: The Case of Oil Field Unitization. Managerial and Decision Economics, 23(4/5), 225-245.

Kim, J., \& Mahoney, J. T. (2006). How Property Rights Economics Furthers the Resource-Based View: Resources, Transaction Costs and Entrepreneurial Discovery. International Journal of Strategic Change Management, 1(1/2), 40-52.

Koppel, . (2010). Ingenieurarbeitsmarkt 2009/10 - Berufs- und Branchenflexibilität, demografischer Ersatzbedarf und Fachkräftelücke. Retrieved 26/06/2010, from http://www.vdi.de/uploads/media/Ingenieurstudie_VDI-IW.pdf.

Kor, Y. Y., \& Leblebici, H. (2005). How Do Interdependencies Among Human-Capital Deployment, Development, and Diversification Strategies Affect Firms' Financial Performance? Strategic Management Journal, 26(10), 967-985.

Koster, F.de Grip, A., \& Fouarge, D. (2011). Does Perceived Support to Employee Development Affect Personnel Turnover? International Journal of Human Resoruce Management, 22(11), 24032418.

Kran, D. (2009). Mehr Soft Skills bitte. Personalwirtschaft, 7, 39-41.

Krippendorff, K. (2004). Content Analysis - An Introduction to Its Methodology (2nd ed.). Thousand Oaks, CA: Sage Publications.

Kristof-Brown, A. L., Zimmerman, R. D., \& Johnson, E., C. (2005). Consequences of Individuals` Fit at Work: A Meta-Analysis of Person-Job, Person-Organization, Person-Group, and Person-Supervisor Fit. Personnel Psychology, 58(2), 281-342.

Kvale, S. (1996). Interviews: An Introduction to Qualitative Research Interviewing. Thousand Oaks, CA: Sage Publications.

Larwood, L., \& Gutek, B. (1987). Working Towards a Theory of Women's Career Development. In B. Gutek \& L. Larwood (Eds.), Women's Career Development. Beverly Hills, CA: Sage Publications.

Lazear, E. P. (1983). Raids and Imitation. NBER Working Paper.

Lazear, E. P., \& Moore, R. L. (1984). Incentives, Productivity, and Labor Contracts. Quarterly Journal of Economics, 99(2), 275-296.

Lazear, E. P., \& Shaw, K. L. (2007). Personnel Economics: The Economist's View of Human Resources. Journal of Economic Perspectives, 21(4), 91-114.

Lee, T. H., Gerhart, B., Weller, I., \& Trevor, C. O. (2008). Understanding Voluntary Turnover: Path-Specific Job Satisfaction Effects and the Importance of Unsolicited Job Offers. Academy of Management Journal, 51(4), 651-671.

Leisy, B., \& Pyron, D. (2009). Talent Management Takes On New Urgency. Compensation Benefits Review, 41(4), 58-63.

Lepak, D. P., \& Snell, S. A. (1999). The Human Resource Architecture: Toward a Theory of Human Capital Allocation and Development. Academy of Management Review, 24(1), 31-48.

Leung, R., \& Law, R. (2010). A Review of Personality Research in the Tourism and Hospitality Context. Journal of Travel and Tourism Management, 27(5), 439-459.

Levinson, D. (1978). The Seasons of a Man's Life. New York, NY: Knopf.

Lippman, S. A., \& Rumelt, R. P. (2003). A Bargaining Perspective on Resource Advantage Strategic Management Journal, 24(11), 1069-1086.

Litecky, C. R., Arnett, K. P., \& Prabhakar, B. (2004). The Paradox of Soft Skills versus Technical Skills in IS Hiring. Journal of Computer Information Systems, 45(1), 69-76.

Mahoney, J. T., \& Pandian, J. R. (1992). The Resource-Based View within the Conversation of Strategic Management. Strategic Management Journal, 13(5), 363-380. 
Maisto, M. (2009). Apple's Jobs Wanted a Gentleman's Agreement with Palm, Report Says. Retrieved 12/02/2010, from www.eweek.com/c/a/Mobile-and-Wireless/Apples-Jobs-Wanted-aGentlemans-Agreement-with-Palm-Report-Says-607440/.

Makadok, R. (2001). Toward a Synthesis of the Resource-Based and Dynamic-Capability Views of Rent Creation. Strategic Management Journal, 22(5), 387-401.

Makadok, R., \& Barney, J. B. (2001). Strategic Factor Market Intelligence: An Application of Information Economics to Strategy Formulation and Competitor Intelligence. Management Science, 47(12), 1621-1638.

March, J. G., \& Olsen, J. P. (1984). The New Institutionalism: Organizational Factors in Political Life. American Political Science Review, 78(3), 734-749.

March, J. G., \& Olsen, J. P. (1989). Rediscovering Institutions: The Organizational Basis of Politics. New York, NY: Free Press/Macmillan.

Markman, G. D., Gianiodis, P. T., \& Buchholtz, A. K. (2009). Factor-Market Rivalry. Academy of Management Review, 34(3), 423-441.

Marshall, K. (2007). Corporate Masters. AFR Boss, 8, 78-81.

Marx, M., Strumsky, D., \& Fleming, L. (2009). Mobility, Skills, and the Michigan Non-Compete Experiment. Management Science, 55(6), 875-889.

Mathieu, J., \& Zajac, D. (1990). A Review and Meta-analysis of the Antecedents, Correlates and Consequences of Organizational Commitment. Psychological Bulletin, 108, 171-194.

Mattioli, D. (2010). Firms Poach Top-Talent from Recession-Weary Rivals. Retrieved 07/03/2010, from http://online.wsj.com/article/NA_WSJ_PUB:SB10001424052748703894304575047160151 066820.html.

Mayring, P. A. E. (2002). Einführung in die qualitative Sozialforschung. Eine Anleitung zu qualitativem Denken (5 ed.). Weinheim, D: Psychologie Verlags Union.

McClelland, P. L., Liang, X., \& Barker, V. L. (2009). CEO Commitment to the Status Quo: Replication and Extension Using Content Analysis. Journal of Management, 36(5), 1215-1277.

McDonnell, A. (2011). Still Fighting the "War for Talent"? Bridging the Science Versus Practice Gap. Journal of Business and Psychology, 26(2), 169-173.

McEvoy, G. M., \& Cascio, W. F. (1987). Do Good or Poor Performers Leave? A Meta-Analysis of the Relationship between Performance and Turnover. Academy of Management Journal, 30(4), 744-762.

McLean. (2008). Apple Recruits Top Chip Designer, IBM Responds with Suit. Retrieved 18/08/2009, from http://www.appleinsider.com/articles/08/10/30/ apple_recruits_top_chip_designer_ibm_ responds_with_suit.html.

Mehrmann, E. (2004). Der Weg in die Personalberatung-Erfolgsprogramme für Berufseinstieg und Weiterbildung. Wiesbaden, D: Gabler.

Mellahi, K., \& Collings, D. G. (2009). The Barriers to Effective Global Talent Management: The Example of Corporate Elites in MNEs. Journal of World Business, 45(2), 143-149.

Meyer, J. P., \& Allen, N. J. (1984). Testing the 'Side-Bet Theory' of Organizational Commitment: Some Methodological Considerations. Journal of Applied Psychology, 69, 372-378.

Meyer, J. P., \& Allen, N. J. (1988). Links Between Work Experience and Organizational Comitment During the First Year of Employment: A Longitudinal Analysis. Journal of Occupational Psychology, 61(3), 195-209.

Meyer, J. P., \& Allen, N. J. (1991). A Three-Component Conceptualization of Organizational Commitment. Human Resource Management Review, 1(1), 61-89.

Meyer, J. P., \& Allen, N. J. (1997). Commitment in the Workplace: Theory, Research, and Application. Thousand Oaks, CA: Sage Publications.

Meyer, J. P., Allen, N. J., \& Smith, C. A. (1993). Commitment to Organizations and Occupations: Extension and Test of a Three-Component Conceptualization. Journal of Applied Psychology, 78(4), 538551.

Meyer, J. W., \& Rowan, B. (1977). Institutional Organizations: Formal Structure as Myth and Ceremony. American Journal of Sociology, 83(2), 340-363.

Meyer, J. P., \& Smith, C. A. (2000). HRM Practices and Organizational Committment: Test of a Mediation Model. Canadian Journal of Administrative Science, 17(4), 319-331.

Meyer, J. P., Stanley, D. J., Herscovitch, L., \& Topolnytsky, L. (2002). Affective, Continuance and Normative Commitment to the Organization: A Meta-Analysis of Antecedens, Correlates, and Consequences. Journal of Vocational Behavior, 61(1), 20-52.

Michaels, E., Handfield-Jones, H., \& Axelrod, B. (2001). The War for Talent. Boston, MA: Harvard Business School Press.

Miles, M. B., \& Huberman, A. M. (1994). Qualitative Data Analysis (2nd ed.). Thousand Oaks, CA: Sage Publications. 
Monster Worldwide Deutschland GmbH. (2011). Über uns. Retrieved 20/7/2011, from http://unternehmen.monster.de/monsterde.aspx.

Morrow, P. C., \& Wirth, R. E. (1989). Work Commitment among Salaried Professionals. Journal of Vocational Behavior, 34(1), 40-56.

Mowday, R. T., Porter, L. W., \& Steers, R. M. (1982). Employee-Organization Linkages. In P. Warr (Ed.), Organizational and Occupational Psychology (pp. 219-229). New York: Academic Press.

Mowday, R. T., Steers, R. M., \& Porter, L. W. (1979). The Measurement of Organizational Commitment. Journal of Vocational Behavior, 14(2), 224-247.

Murmann, J. (1999). Personalberatung in Deutschland 1999. Bonn: Bundesverband Deutscher Unternehmensberater (BDU).

Murmann, J. (2009). Personalberatung in Deutschland 2008/2009. Bonn: Bundesverband Deutscher Unternehmensberater (BDU).

Murphy, P., \& Poist, R. F. (2007). Skill Requirements of Senior-Level Logisticians: A Longitudinal Assessment. Supply Chain Management, 12(6), 423-431.

Muzio, E., \& Fisher, D. (2009). Soft Skill Quantification (SSQ): Human Performance vs. Metric. Cost Engineering, 51(3), 26-31.

Nash, T. (1989). Up for Grabs: Is Poaching Staff Wrong? Director(April), 90-95.

Nohria, N., Groysberg, B., \& Lee, L.-E. (2008). Employee Motivation: A Powerful New Model. Harvard Business Review, 86(7/8), 78-84.

North, D. C. (1971). Institutional Change and Economic History. Journal of Economic History, 31(1), 118125.

Norton, C. (2010). Are You Risking Your Staff Being Poached If You Let Them Use Social Media? Retrieved 21/06/2011, from http://www.deaddinosaur.co.uk/social-media/are-you-risking-your-staffbeing-poached-if-you-let-them-use-social-media/.

Offstein, E. H., Gnyawali, D. R., \& Cobb, A. T. (2005). A Strategic Human Resource Perspective of Firm Competitive Behavior. Human Resource Management Review, 15(4), 305-318.

Okhuysen, G., \& Bonardi, J.-P. (2011). Editors' Comment: The Challenges of Building Theory by Combining Lenses. Academy of Management Review, 36(1), 6-11.

O'Leary, B. S., Lindholm, M. L., Whitford, R. A., \& Freeman, S. E. (2002). Selecting the Best and the Brightest: Leveraging Human Capital. Human Resource Management, 41(3), 325-340.

Olian, J. D., \& Rynes, S. L. (1984). Organizational Staffing: Integrating Practice with Strategy. Industrial Relations, 23(2), 170-183.

Oliver, C. (1997). Sustainable Competitive Advantage: Combining Institutional and Resource-Based Views. Strategic Management Journal, 18(9), 697-713.

Orr, R. J. 2004). Coping with Cognitive-Cultural, Normative and Regulative Institutional Asymmetry on Global Projects: A Learning Perspective. Stanford University.

Paauwe, J. (2004). HRM and Performance: Achieving Long-term Viability. Oxford, UK: Oxford University Press.

Paauwe, J., \& Boselie, P. (2003). Challenging 'Strategic HRM' and the Relevance of the Institutional Setting. Human Resource Management Journal, 13(3), 56-70.

Palrecha, R., Spangler, W., \& Yammarino, F. (2010). Computerized Content Analysis: An Iterative Process to Code Qualitative Data Accurately. Paper presented at the Academy of Management Annual Meeting, Montréal, CA.

Patton, M. Q. (2001). Qualitative Research \& Evaluation Methods (3rd ed.). Thousand Oaks, CA: Sage Publications.

Penrose, E. T. (1959). The Theory of the Growth of the Firm (1st ed.). New York, NY: John Wiley and Sons.

Peteraf, M. A. (1993). The Cornerstones of Competitive Advantage: A Resource-Based View. Strategic Management Journal, 14(3), 179-191.

Peters, B. G. (1999). Institutional Theory: The "New Institutionalism" in Political Science (1st ed.). London, UK: Cassells.

Pfeffer, J. (1994). Competitive Advantage Through People. California Management Review, 36(Winter), 928.

Pfeffer, J. (2001). Fighting the War for Talent is Hazardous to Your Organization's Health. Organizational Dynamics, 29(4), 248-259.

Pfeffer, J., \& Sutton, R. I. (2006). Hard Facts, Dangerous Half-Truths \& Total Nonsense: Profiting from Evidence-Based Management (Vol. 1). Boston, MA: Harvard Business School Press. 
Phillips, D. J. (2002). A Genealogical Approach to Organizational Life Chances: The Parent-Progeny Transfer among Silicon Valley Law Firms, 1946-1996. Administrative Science Quarterly, 47(3), 474-506.

Ployhart, R. E., Weekley, J. A., \& Ramsey, J. (2009). The Consequences of Human Resource Stocks and Flows: A Longitudinal Examination of Unit Service Orientation and Unit Effectiveness. Academy of Management Journal, 52(5), 996-1015.

Porter, M. E. (1980). Industry Structure and Competitive Strategy: Keys to Profitability. Financial Analysts Journal, 36(4), 30-41.

Porter, M. E. (1985). Competitive Advantage: Creating and Sustaining Superior Performance (1st ed.). New York, NY: Free Press.

Potter, E. (2005). Part 1: Changing Workforce Demographics and Management Challenges. Retrieved 10/03/2011, from http://mcgraw-hill.co.uk/tpr/chapters/ 1591395216.pdf.

Pötzsch, O. (2007). Geburten in Deutschland. Wiesbaden: Statistisches Bundesamt.

Powell, W. (1998). Institutional Theory. In C. L. Cooper \& C. Argyris (Eds.), Encyclopedia of Management. Oxford, UK: Blackwell Business.

Pratt, M. G. (2009). From the Editors: For the Lack of a Boilerplate: Tips on Writing Up (and Reviewing) Qualitative Research. Academy of Management Review, 52(5), 856-862.

Preston, M. (2008). How to Poach your Competitors' Best Staff. Retrieved 17/09/2008, from http://www.smartcompany.com.au/Premium-Articles/Top-Story/20080910-How-to-poachyour-competitors-best-staff.html.

Priem, R. L., \& Butler, J. E. (2001). Is the Resource-Based "View" a Useful Perspective for Strategic for Strategic Management Research? Academy of Management Review, 26(1), 22-40.

Purcell, J., Kinnie, N., Hutchinson, S., Rayton, B., \& Swart, J. (2003). Understanding the People and Performance Link: Unlocking the Black Box. London, UK: Chartered Institute of Personnel and Development.

Quiñones, M. A., Ford, J. K., \& Teachout, M. S. (1995). The Relationship between Work Experience, and Job Performance: A Conceptual and Meta-Analytic Review. Personnel Psychology, 48, 887-910.

Randall, D. M. (1990). The Consequences of Organizational Commitment: Methodological Investigation. Journal of Organizational Behavior, 11(5), 361-378.

Rao, H., \& Drazin, R. (2002). Overcoming Resource Constraints on Product Innovation by Recruiting Talent from Rivals: a Study of the Mutual Fund Industry, 1986-94. Academy of Management Journal, 45(3), 491-507.

Rapley, T. J. (2001). The Art(fulness) of Open-Ended Interviewing: Some Considerations on Analysing Interviews. Qualitative Research, 1(3), 303-323.

Rappaport, A., Bancroft, E., \& Okum, L. (2003). The Aging Workforce Raises New Talent Management Issues for Employers. Journal of Organizational Excellence, 23(1), 55-66.

Ready, D. A., \& Conger, J. A. (2007). Make Your Company a Talent Factory. Harvard Business Review, 85(6), 68-77.

Reuters. (2008). Update 1-Apple Hires IBM Exec to Head iPods; IBM Objects. Retrieved 12/02/2010, from http://uk.reuters.com/article/idUKN0436992720081104.

Richardson, L. (2003). A Method of Inquiry. In N. K. Denzin \& Y. S. Lincoln (Eds.), Collecting and Interpreting Qualitative Materials (pp. 499-541). Thousand Oaks, CA: Sage Publications.

Ritter, D. B., \& Rosenberg, S. (2007). The Ins and Outs of Non-Competes. Compensation and Benefits Review, 39(6), 40-46.

Rosen, B. \& Mericle, M. F. (1979). Influence of Strong Versus Weak Fair Employment Practices and Applicant's Sex on Selection Decisions and Salary Recommendations in a Management Simulation. Journal of Applied Psychology, 64(4), 435-439.

Rosenkopf, L., \& Almeida, P. (2003). Overcoming Local Search Through Alliances and Mobility. Management Science, 49(6), 751-766.

Rousseau, D. R. (1995). Psychological Contracts in Organizations. Thousand Oaks, CA: Sage Publications.

Rule, E. G., \& Irwin, D. W. (1988). Fostering Intrapreneurship: The New Competitive Edge. Journal of Business Strategy, 9(3), 43-47.

Rynes, S. L., \& Barber, A. E. (1990). Applicant Attraction Strategies: An Organizational Perspective. Academy of Management Review, 15, 286-310.

Rynes, S.L., Bretz, R. D., \& Gerhart, B. (1991). The Importance of Recruitment in Job Choice: A Different Way of Looking. Personnel Psychology, 44, 487-521.

Rynes, S. L., Brown, K. G., \& Colbert, A. E. (2002). Seven Common Misconceptions About Human Resource Practices: Research Findings Versus Practitioner Beliefs. Academy of Management Executive, 16(3), 92-103. 
Schmidt, F. L., Hunter, J. E., \& Outerbridge, A. N. (1986). Impact of Job Experience and Ability on Job Knowledge, Work Sample Performance, and Supervisory Ratings of Job Performance. Journal of Applied Psychology, 71(3), 432-439.

Schneider, H., \& Stein, D. (2006). Personalpolitische Strategien Deutscher Unternehmen zur Bewältigung demografisch bedingter Rekrutierungsengpässe bei Führungskräften (No. 6). Bonn, D: Institut zur Zukunft der Arbeit (IZA).

Schuler, R., \& Jackson, S. (2010, June). Global Talent Management Initiatives for Global Talent Challenges. Paper presented at the International Human Resource Management Conference, Aston University, Birmingham.

Schwab, D. P. (1982). Recruiting and Organizational Participation. In K. Rowland and G. Ferris Eds.), Personnel Management. Boston: Allyn \& Bacon, 103-128.

Schwab, S. J., \& Thomas, R. S. (2006). An Empirical Analysis of CEO Employment Contracts: What Do Top Executives Bargain For? Washington and Lee Law Review, 63, 231-270.

Schweiger, D. M., \& Goulet, P. K. (2005). Facilitating Acquisition Integration Through Deep-Level Cultural Learning Interventions: A Longitudinal Field Experiment. Organization Studies, 26(10), 14771499.

Scott, W. R. (1987). The Adolescence of Institutional Theory. Administrative Science Quaterly, 32(4), 493511.

Scott, W. R. (2001). Institutions and Organizations. Thousand Oaks, CA: Sage Publications.

Scott, W. R. (2004). Institutional Theory: Contributing to a Theoretical Research Program. In K. G. Smith \& M. A. Hitt (Eds.), Great Minds in Management: The Process of Theory Development. Oxford, UK: Oxford University Press.

Seibert, S. E., Kraimer, M. L., \& Liden, R. C. (2001). A Social Capital Theory of Career Success. Academy of Management Journal, 44(2), 219-237.

Sherer, P. D. (2008). The Changed World of Large Law Firms and Their Lawyers: An Opportune Context for Organizational Researchers. In P. Cappelli (Ed.), Understanding Employment in the 21st Century (pp. 179-222). Cambridge, UK: Cambridge University Press.

Simpson, R.,\& Altman, Y. (2000). The Time Bounded Glass Ceiling and Young Women Managers: Career Progress and Career Success - Evidence from the UK. Journal of European Industrial Training, 24(2/3/4), 190-198.

Solinger, O. N., Van Olffen, W., \& Roe, R. A. (2008). Beyond the Three-Component Model of Organizational Commitment. Journal of Applied Psychology, 93(1), 70-83.

Somaya, D., Williamson, I. O., \& Lorinkova, N. (2008). Gone But not Lost: The Different Performance Impacts of Employee Mobility Between Cooperators Versus Competitors. Academy of Management Journal, 51(5), 936-953.

Somech, A., \& Bogler, R. (2002). Antecedents and Consequences of Teacher Organizational and Professional Commitment. Educational Administration Quarterly, 38(4), 555-577.

Song, J., Almeida, P., \& Wu, G. (2003). Learning-by-Hiring: When Is Mobility More Likely to Facilitate Interfirm Knowledge Transfer? Management Science, 49(4), 351-365.

Spear, Z. (2009). IBM to Keep Tabs on Papermaster's New Position at Apple. Retrieved 18/08/2009, from http://www.appleinsider.com/articles/09/01/28/ibm_to_keep_tabs_on_papermasters_new_ position_at_apple.html.

Stafford, P. (2010). How to Poach a Competitor's Best Staff. Retrieved 21/06/2011, from http://www.dailymercury.com.au/story/2010/02/17/how-poach-competitors-best-staff/.

Staudinger, U. M. (2008). Personalmanagement und demografischer Wandel: Eine interdisziplinäre Perspektive. In J. Deller, S. Kern, E. Hausmann \& Y. Diederichs (Eds.), Personalmanagement im demografischen Wandel: Ein Handbuch für den Veränderungsprozess. Heidelberg, D: Springer.

Steers, R. M. (1977). Antecedents and Outcomes of Organizational Commitment. Administrative Science Quarterly, 22(1), 46-56.

StepStone GmbH. (2011). Über StepStone. Retrieved 20/7/2011, from http://www.stepstone.de/ UeberStepStone/.

Stinglhamber, F., Bentein, K., \& Vandenberghe, C. (2002). Extension of the Three-Component Model of Commitment to Five Foci: Development of Measures and Substantive Test. European Journal of Psychological Assessment, 18, 123-138.

Stone, K. V. W. (2002). Knowledge at Work: Disputes over the Ownership of Human Capital in the Changing Workplace. Connecticut Law Review, 34(3), 721-763.

Stone, K. V. W. (2004). From Widgets to Digits: Employment Regulation for the Changing Workplace. New York, NY: Cambridge University Press.

Strack, R., Baier, J., \& Fahlander, A. (2008). Managing Demographic Risk. Harvard Business Review, 86(2), 119-128. 
Strauss, A., \& Corbin, J. (1998). Review of Basics of Qualitative Research Techniques and Procedures for Developing Grounded Theory (2nd ed.). London, UK: Sage Publications.

Streb, C. K., Voelpel, S. C., \& Leibold, M. (2008). Managing the Aging Workforce: Status Quo and Implications for the Advancement of Theory and Practice. European Management Journal, 26(1), 1-10.

Sturges, J., \& Guest, D. (2001). Don't Leave Me This Way!: An Exploration of the Influences Likely to Affect Graduates' Decisions to Stay with or Quit their Employer in the Early Years of their Career. British Journal of Guidance and Counselling, 29(4), 447-462.

Sturman, M. C., Trevor, C. O., Boudreau, J. W., \& Gerhart, B. (2003). Is it Worth it to Win the Talent War? Evaluating the Utility of Performance-Based Pay. Personnel Psychology, 56(4), 997-1035.

Sturman, M. C., Walsh, K., \& Cheramie, R. A. (2008). The Value of Human Capital Specificity Versus Transferability. Journal of Management, 34(2), 290-316.

Sullivan, J. (2008). Poaching the Best Talent Worldwide. Retrieved 20/10/2008, from http://www.drjohnsullivan.com/content/view/83/29/.

Sullivan, S. E. (1999). The Changing Nature of Careers: A Review and Research Agenda. Journal of Management, 25(3), 457-484.

Sullivan, S. E., \& Arthur, M. B. (2006). The Evolution of the Boundaryless Career Concept: Examining Physical and Psychological Mobility. Journal of Vocational Behavior, 69(1), 19-29.

Taft, F. P., \& Powell, C. (2005). The European Pensions and Benefits Environment: A Complex Ecology. Compensation and Benefits Review, 37(1), 37.

Tang, K., \& Tseng, Y. (2004). Industry-Specific Human Capital, Knowledge Labour, and Industry Wage Structure in Taiwan. Applied Economics(36), 155-164.

The Economist. (2011). Schumpeter | The Catalan Kings - The Management Secrets of Barcelona Football Club. The Economist, May 21-27.

Thomas, D. R. (2006). A General Inductive Approach for Analyzing Qualitative Evaluation Data. American Journal of Evaluation, 27(2), 237-246.

Thompson, J. A., \& Van de Ven, A.-H. (2002). Commitment Shift during Organizational Upheaval: Physicians' Transitions from Private Practitioner to Employee. Journal of Vocational Behavior, 60(3), 382-404.

Thornhill, A., \& Saunders, M. N. K. (1998). What if Line Managers Don't Realize They're Responsible for HR? Personnel Review, 27(6), 460-476.

Todd, P. A., McKeen, J. D., \& Gallupe, R. B. (1995). The Evolution of IS Job Skills: A Content Analysis of IS Job Advertisements from 1970 to 1990. MIS Quarterly, 19(1), 1-27.

Tucker, E., Kao, T., \& Verma, N. (2005). Next-Generation Talent Management: Insights On How Workforce Trends Are Changing The Face Of Talent Management. Business Credit, 106(7), 20-27.

Tuma, N. B., \& Grimes, A. J. (1981). A Comparison of Models of Role Orientations of Professionals in a Research-Oriented University. Administrative Science Quarterly, 26(2), 187-206.

Tung, R. L., \& Lazarova, M. (2006). Brain Drain versus Brain Gain: An Exploratory Study of Ex-Host Country Nationals in Central and East Europe. International Journal of Human Resource Management, 17(11), 1853-1872.

Ulrich, D. (1997). Human Resource Champions: The Next Agenda for Adding Value and Delivering Results (1st ed.). Boston, MA: Harvard Business School Press.

Ulrich, D., \& Brockbank, W. (2009). The HR Business-Partner Model: Past Learnings and Future Challenges. People \& Strategy, 32(2), 5-7.

United Nations. (2011). Detailed Structure and Explanatory Notes ISIC Rev.4. Retrieved 12/06/2011, from http://unstats.un.org/unsd/cr/registry/regcst.asp?Cl=27.

United States District Court/Southern District of NewYork. (2008a). Non-Compete Agreement Papermaster/IBM. Retrieved 12/06/2010, from http://images.appleinsider.com/ibm_ papermaster_non_compete_081030.pdf.

United States District Court/Southern District of NewYork. (2008b). IBM's complaint. Retrieved 12/02/2010, from http://images.appleinsider.com/ibm_papermaster_suit_081030.pdf.

United States District Court/Southern District of NewYork. (2008c). International Business Machines Corporation v. Papermaster Filing 12. Retrieved 12/02/2010, from http://docs.justia.com/cases/federal/district-courts/newyork/nysdce/7:2008cv09078/334178/ 12/. 
Van Maanen, J. (1975). Police Socialization: A Longitudinal Examination of Job Attitudes in an Urban Police Department. Administrative Science Quarterly, 20(2), 207-228.

Van Maanen, J., \& Schein, E. H. (1979). Toward a Theory of Organizational Socialization. In B. Staw (Ed.), Research in Organizational Behavior (Vol. 1, pp. 209-264). Grennwich, CT: JAI Press.

Waldman, J. D., Kelly, F., Arora, S., \& Smith, H. (2004). The Shocking Cost of Turnover in Health Care. Health Care Management Review, 29(1), 2-7.

Wallace, J. E. (1995). Organizational and Professional Commitment in Professional and Nonprofessional Organizations. Administrative Science Quarterly, 40(2), 228-255.

Wang, X., \& Armstrong, A. (2004). An Empirical Study of PM Professionals' Commitment to their Profession and Employing Organizations. International Journal of Project Management, 22(5), 377-386.

Wang, H. C., \& Barney, J. B. (2006). Employee Incentives to Make Firm-Specific Investments: Implications for Resource-Based Theories of Corporate Diversification. Academy of Management Review, 31(2), 466-476.

Weber, K. (2010). Research Designs Using Content Analysis. Paper presented at the Academy of Management Annual Meeting.

Weber, R. (1990). Basic Content Analysis (2nd ed.). Newbury Park, CA: Sage Publications.

Wengraf, T. (2001). Qualitative Research Interviewing: Biogarphic, Narrative, and Semistructured Methods. Thousand Oaks, CA: Sage Publications.

Werbel, J. D., \& Johnson, D. J. (2001). The Use of Person-Group Fit for Employment Selection: A Missing Link in Person-Environment Fit. Human Resource Management, 40(3), 227-240.

Wernerfelt, B. (1984). A Resource-Based View of the Firm. Strategic Management Journal, 5(2), 171-180.

Wezel, F. C., Cattani, G., \& Pennings, J. M. (2006). Competitive Implications of Interfirm Mobility. Organization Science, 17(6), 691-709.

Wiener, Y. (1982). Commitment in Organizations: A Normative View. Academy of Management Review, 7(3), 418-428.

Wilk, S. L., \& Cappelli, P. (2003). Understanding the Determinants of Employer Use of Selection Methods. Personnel Psychology, 56(1), 103-124.

Williamson, O. E. (1975). Market and Hierarchies: Analysis and Antitrust Implications. New York, NY: Free Press.

Williamson, O. E. (1991). Strategizing, Economizing, and Economic Organization. Strategic Management Journal, 12(Special Issue: Fundamental Research Issues in Strategy and Economics), 75-94.

Wright, P. M., \& McMahan, G. C. (1992). Theoretical Perspectives for Strategic Human Resource Management. Journal of Management, 18(2), 295-320.

Wucherer, K. (2005). VDE-Positionen zur Ingenieurausbildung. Retrieved 10/03/2011, from http://www.vde.com/de/Ausschuesse/Ingenieurausbildung/Bologna-Prozess/2005Oeffentlich/Seiten/position-ingenieurausbildung.aspx.

Yin, R. K. (2003). Case Study Research, Design and Methods (3rd ed.). Newbury Park, CA: Sage Publications.

Zajac, E. J., \& Kraatz, M. S. (1993). A Diametric Forces Model of Strategic Change: Assessing the Antecedents and Consequences of Restructuring in the Higher Education Industry. Strategic Management Journal, 14(Special Issue: Corporate Restructuring), 83-102.

Zingheim, P. K., \& Schuster, J. R. (2008). Developing Total Pay Offers for High Performers. Compensation and Benefits Review, 40(4), 55-59.

Zottoli, M.A., \& Wanous, J.P. (2000). Recruitment Source Research: Current Status and Future Directions. Human Resource Management Review, 10(4), 353-382. 



\section{Appendices}

1.Coding Scheme for Job Postings Analysis (Chapter 1) 2.Interview Protocols (Chapter 3 and 4) 3.Survey Questions (Chapter 5) 


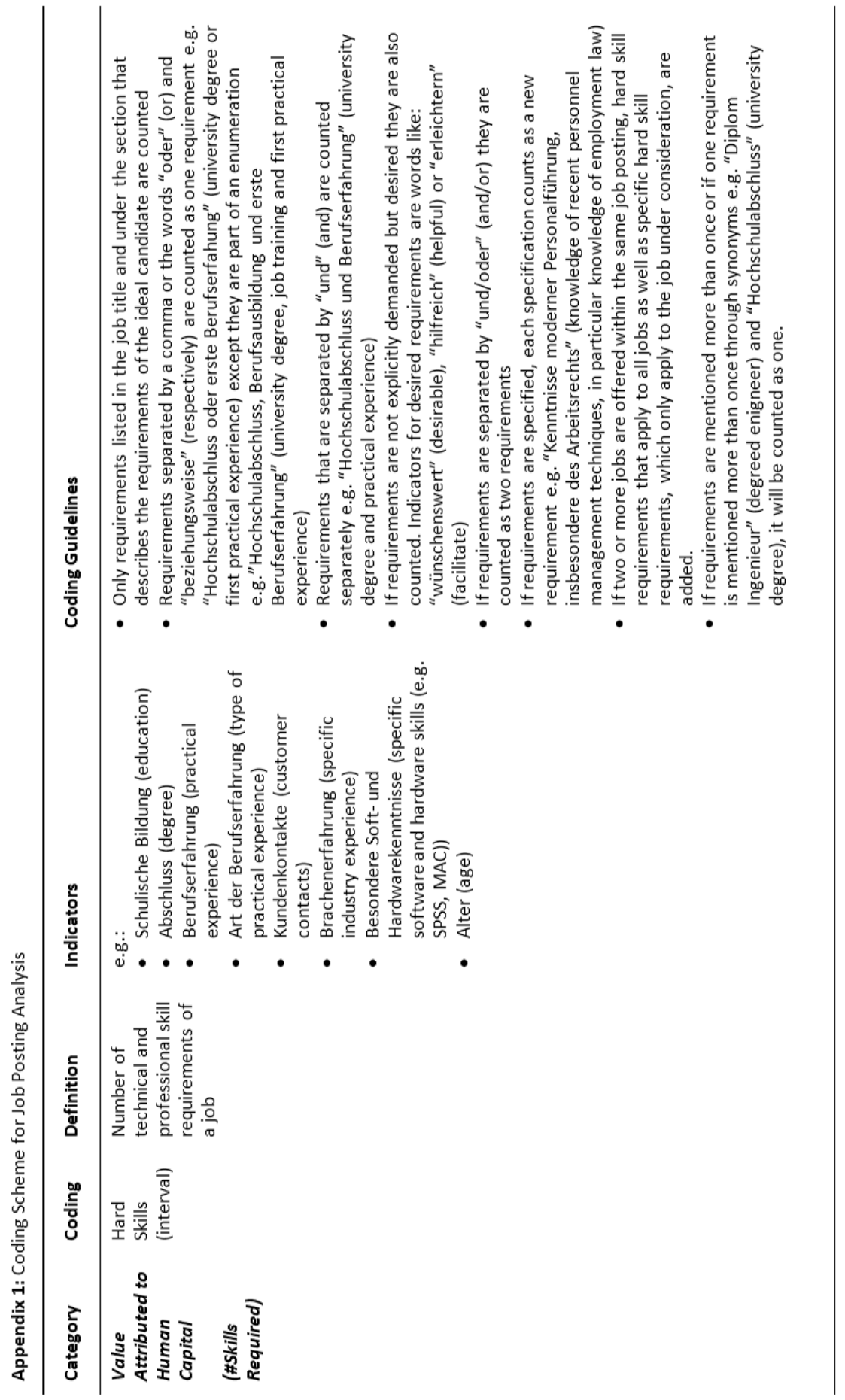




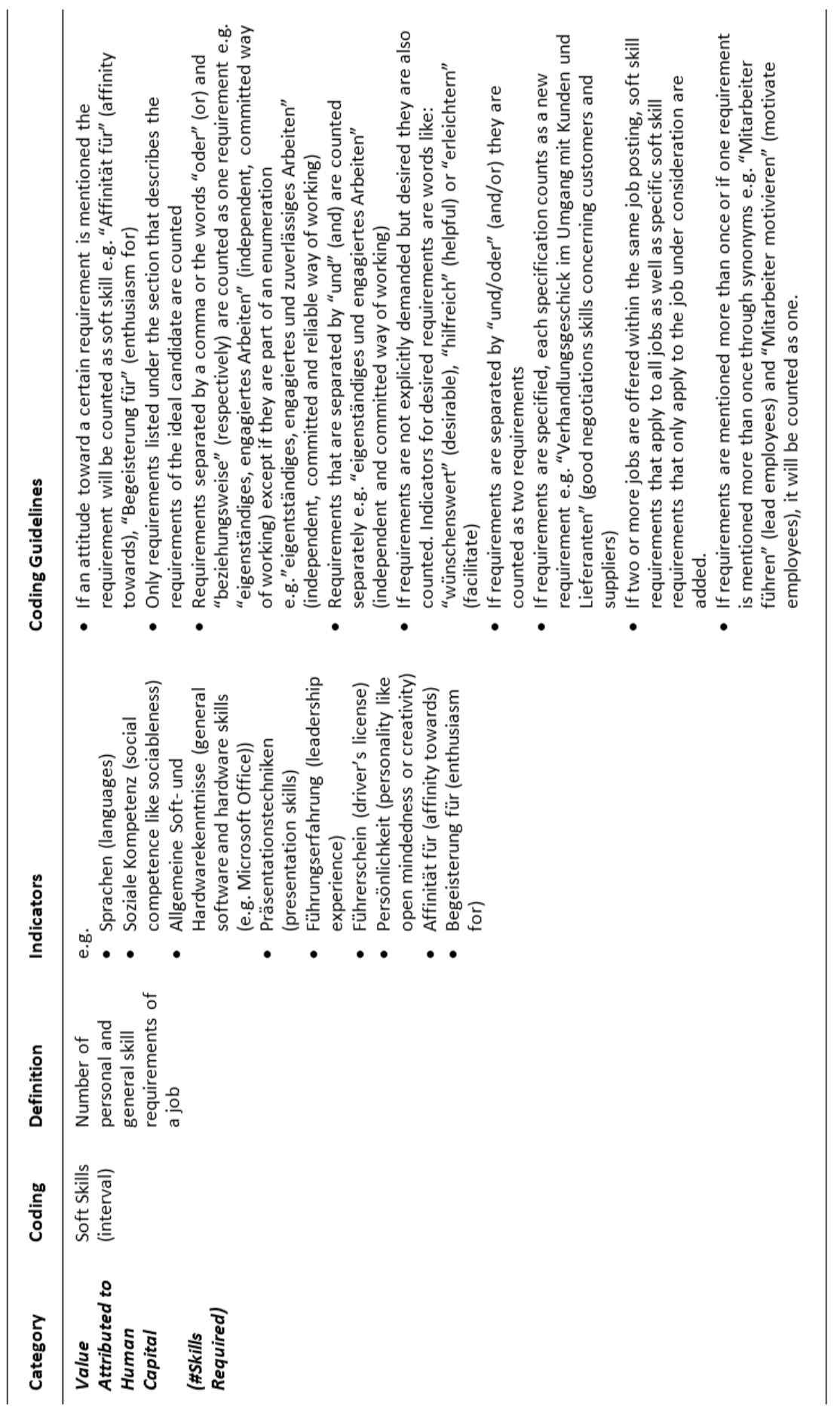



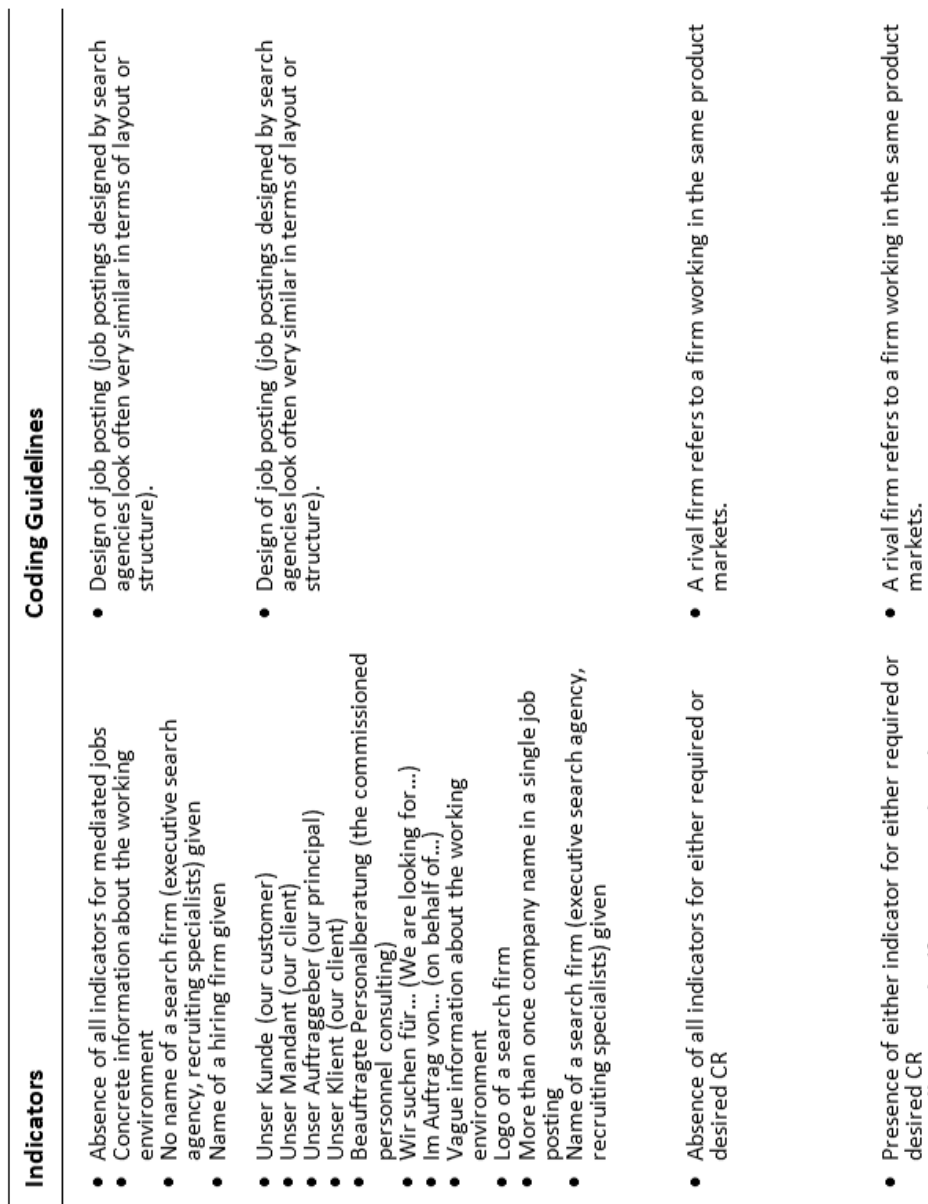

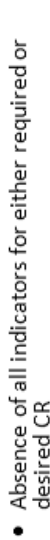

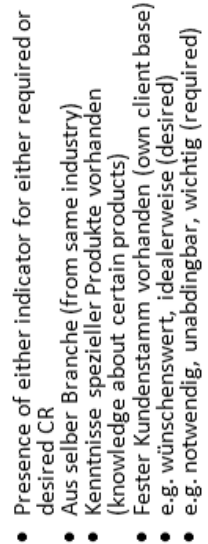

站
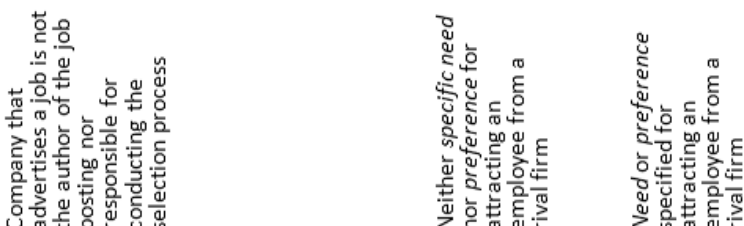

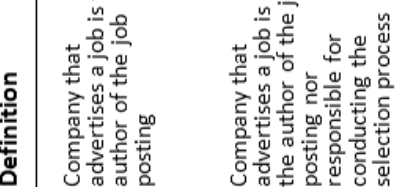

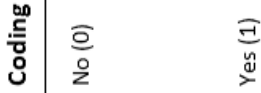

$\frac{\overline{0}}{2}$

$\underset{\frac{\Xi}{y}}{x}$

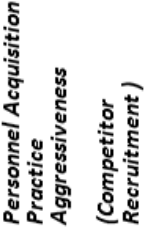




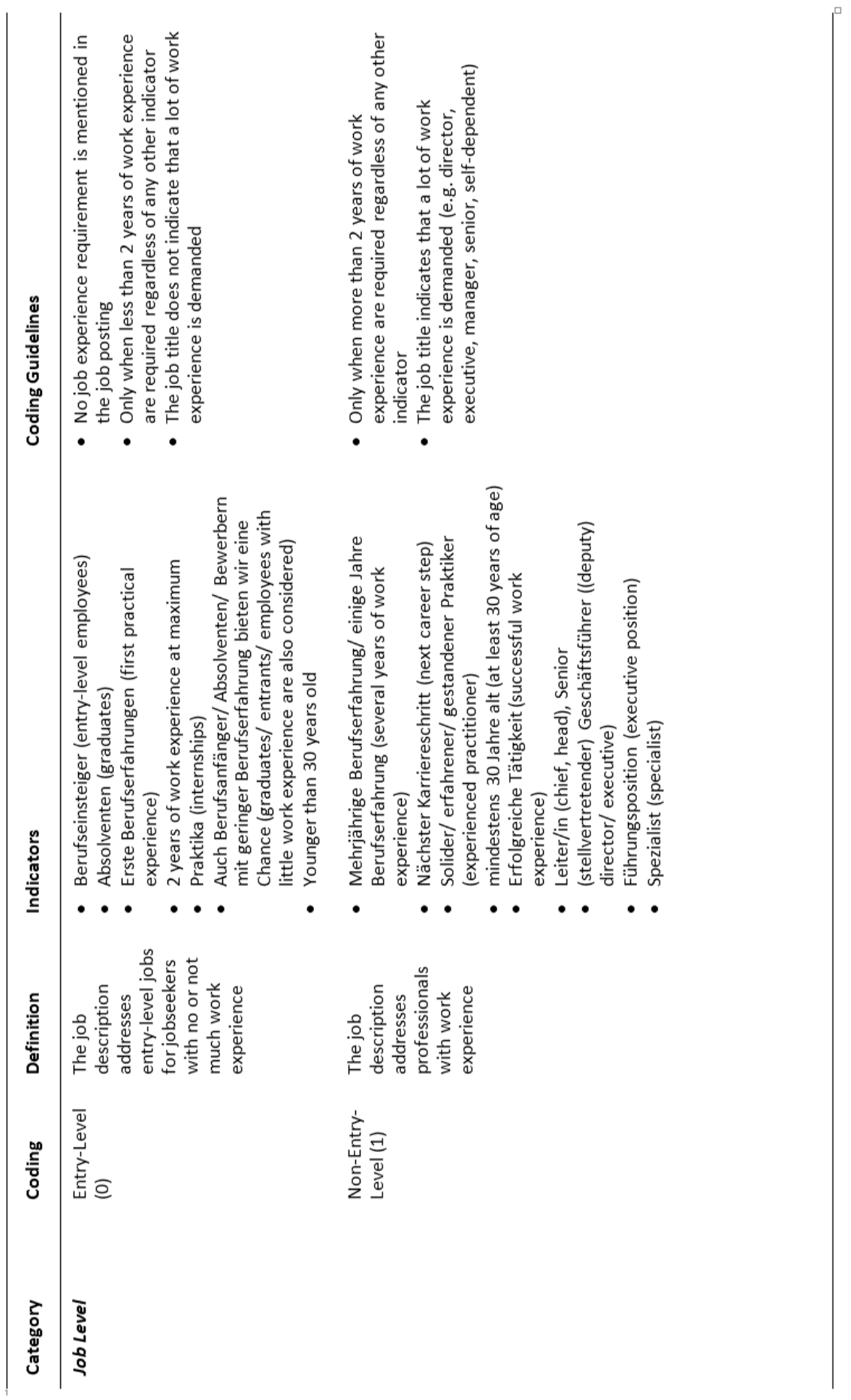




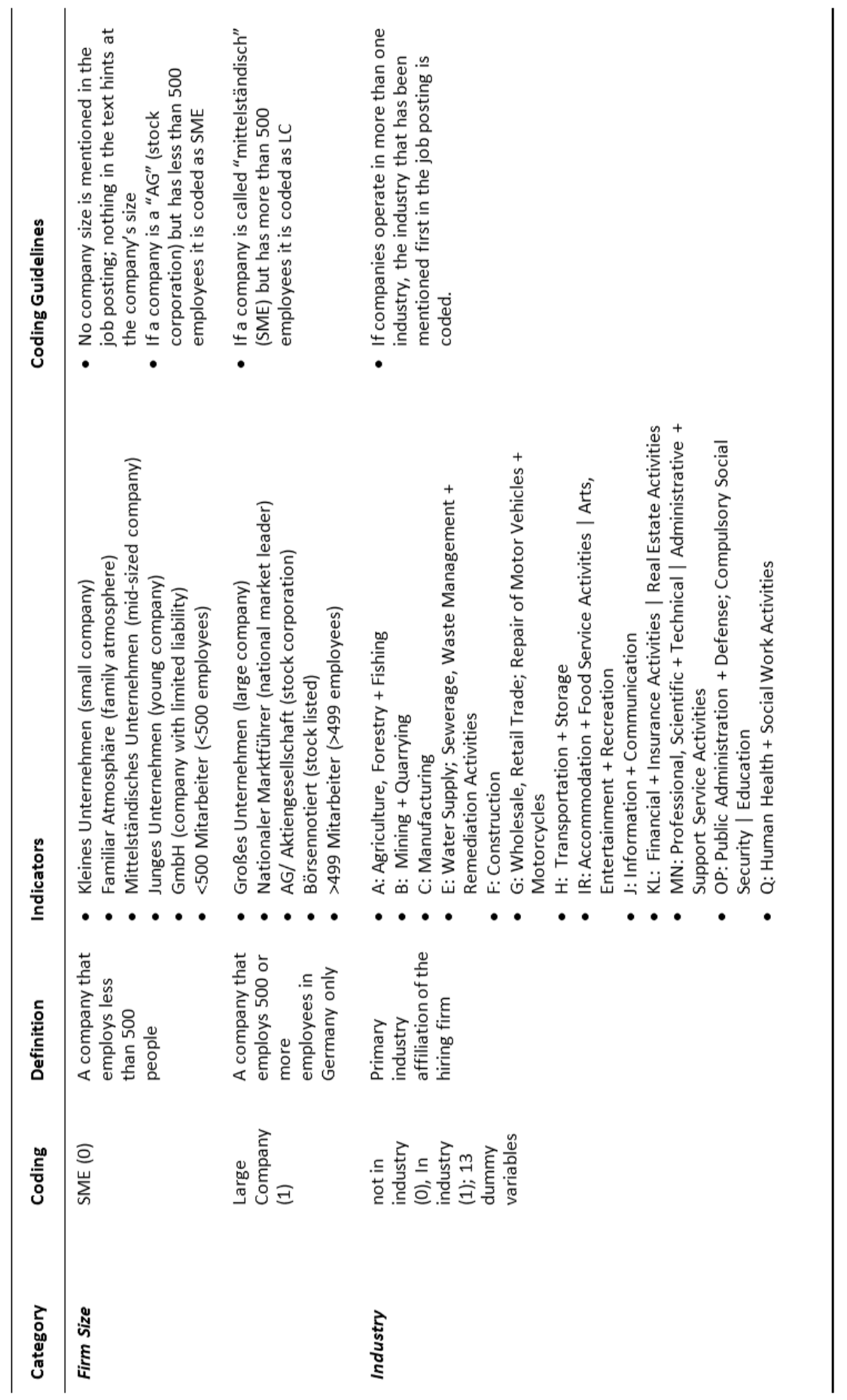




\section{Appendix 2: Interview Protocol}

Introduction by Interviewer

Outline goal of research

Present general structure of interview

Vaguely define $C R$ as a transfer of employee(s) between of the same industry

\section{Collect/Check Respondent Characteristics}

Age

Current job position

Tenure at current employer

Tenure in (executive) search industry

Project/industry experience

\section{Appendix 2a: Consultants}

\section{Main Questions}

1. What kind of recruiting trends (qualitative + quantitative) do you observe?

2. Have you ever witnessed $C R$ as a recruitment practice?

3. What types of firms use $C R$ as a recruitment practice?

4. For which positions is it used?

5. Why do firms engage in $\mathrm{CR} /$ what do firms expect from $\mathrm{CR}$ ?

6. How (often) is it used in order to obtain a competitive advantage?

7. What are the success factors of engaging in $\mathrm{CR}$ according to your experience?

8. How does the integration process of a CR recruit work (out)?

9. Under which conditions would you recommend/refrain from a CR attack?

10. Do you have any additional remarks concerning the phenomenon that you would like to share?

\section{Appendix 2b: HR Professionals}

\section{Main Questions}

1. Have you made any experiences/ contact with Competitor Recruitment (CR) so far?

2. Can you think of potential factors that prevent $C R$ to occur?

3. Can you think of any formal or informal standing orders that constrain CR?

4. How is the frequency of CR in your specific industry?

5. Do you have a code of ethics/ conduct and is CR in line with that?

6. How is the general attitude towards $C R$ in your company like?

7. Can you think of any German values or characteristics that constrain CR to occur?

8. How is your personal attitude towards CR? 


\section{Appendix 3: Questionnaire Elements}

\section{Recruit Work Context Origin and Human Capital:}

Please indicate your career path since entering your working life as a full-time employee.

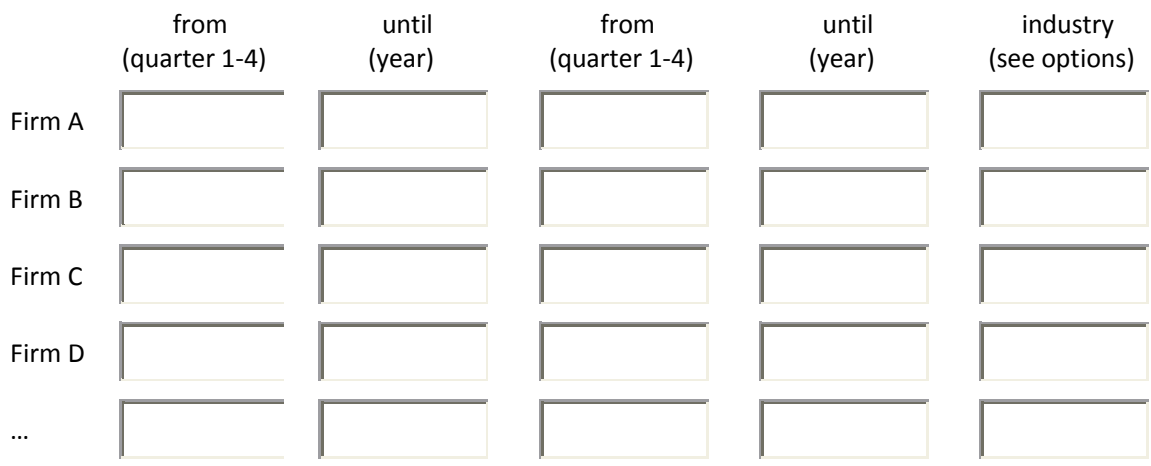

Industry Options:

Agriculture, Forestry and Hunting

Fishing

Mining and Quarrying

Manufacturing Water Supply; Sewerage, Waste Management and Remediation Activities

Construction Wholesale, Retail Trade; Repair of Motor Vehicles and Motorcycles

Accommodation and Food Service Activities

Transportation and Storage

Financial, Insurance

Real Estate Activities

Public Administration and Defense; Compulsory Social Security

Education

Human Health and Social Work Activities

Arts, Entertainment and Relaxation

Information and Communication

Professional and Scientific and Technical Activities 


\section{Commitment}

Listed below are the series of statements that were presented in the respective questionnaire. Each statement had to be rated in terms of degree of agreement ranging from 1 (= I totally disagree) to 7 (I totally agree).

\section{Organization Commitment:}

1. I am willing to put in a great deal of effort beyond that normally expected in order to help this organization be successful.

2. I talk up this firm to my friends as a great organization to work for.

3. I would accept almost any type of job assignment in order to keep working for this company.

4. I find that my values and my employer's values are very similar.

5. I am proud to tell others that I am part of this organization.

6. This organization really inspires the very best in me in the way of job performance.

7. I am extremely glad that I chose this firm to work for over others I was considering at the time I joined.

8. I really care about the fate of this organization.

9. For me this is the best of all possible organizations for which to work.

\section{Industry Commitment:}

1. I am willing to put in a great deal of effort beyond that normally expected in order to help the industry I work in advance.

2. I talk up the industry I work in to my friends as a great industry to work in.

3. I would accept almost any type of job assignment in order to keep working in this industry.

4. I find that my values and the values of the industry I work in are very similar. I am proud to tell others that I am part of this industry.

5. This industry really inspires the very best in me in the way of job performance.

6. I am extremely glad that I chose to work in this industry over others I was considering at the time I joined.

7. I really care about the fate of the industry I work in.

8. For me this is the best of all possible industries in which to work.

\section{Willingness to Switch}

How willing would you be today to switch...

(1= definitely not willing, 3= probably not willing, 5=maybe willing, 7= highly willing)

o ...to a different job within your current organization

o ...to a competing firm 



\section{Summary}

Demographic changes are expected to lead to future talent shortages - despite any economic downturns. As a result, a four-year PhD project was initiated at Maastricht University mid-2007 with the aim of gaining first insights into the possible sourcing solution of 'Competitor Recruitment' (CR). The inquiry into the topic was conducted through 'theory and practice-based explorations'. 
The value of employees in general, and human capital in specific, has gained in recognition over the past decades. At the same time, demographic changes and impending labor shortages are expected to pose severe challenges to firms in staffing key functions with valuable employees in the future. Though not a solution, a skilled engagement in Competitor Recruitment $(C R)$, i.e. the recruitment of highly qualified employees from industry competitors, might constitute a worthwhile tool to fight and win the consequential talent crunch.

As a result, I decided to focus my dissertation on this issue and to provide a theoretical exploration and empirical assessment of CR theory and practice. In specific, I aimed to outline factors that underlie endeavors (not) to engage in competitor recruitment as well as preconditions for a successful CR process. To this end, I let field practitioners reflect on - and determine - what competitor recruitment is, how it is experienced, when appreciated or condemned, and in how far competitor recruits differ from other (external and internal) recruits. I approached the phenomenon from a variety of primarily qualitative methodological angles and sketched the core parameters involved, leading to a comprehensive model of CR.

In particular, I conducted five studies that are presented in five individual chapters. Chapter 1 takes a historical perspective on recruitment practices investigating the rise of human capital and aggressive recruitment practices over the past 20 years. In this chapter I report results of a) a content analysis of a cross-section of 5982 job postings published between 1990 and 2010 in one of the most influential German newspapers, the Frankfurter Allgemeine Zeitung (FAZ), and b) a keyword search in the largest German social sciences publication database, the Datenbank für Wirtschaft und Soziales (WISO). I had three particular issues of interest: whether (1) human capital is increasingly considered a firm value creator, (2) perceived labor market complexity has increased and (3) recruitment practices have become more aggressive. Findings suggest that the value attributed to human capital rose significantly and the competition for labor became slightly more complex and aggressive over the period of investigation. These results support the need for further research in the field of strategic recruitment practices such as competitor recruitment.

Chapter 2 then presents theoretical reasons for an engagement in competitor recruitment. I argue that the final value gained from an employee hired through CR is determined by the perceived recruit's human capital benefit and complementarities created once internalized minus any hidden and explicit costs of appropriating the employee's human capital during the stages of identification, transfer and deployment. I identify conditions that determine the final value to be captured by a hiring firm using resourcebased, strategic factor market and property rights theory and conclude with a conceptual model illustrating how human capital value can be captured through CR. This chapter shows that looking at a new phenomenon like CR from different (resource-based) theories can be highly insightful.

Chapter 3 subsequently empirically investigates whether competitor recruitment is a common recruitment practice and under which conditions it occurs. I studied interview data from 19 consultants working for top executive search firms in Germany. Results indicate that $\mathrm{CR}$ oftentimes concerns individuals or teams of middle or higher managers and specialists with a strong industry-specific knowledge component. It may pay off when motives for $\mathrm{CR}$, such as the need for market knowledge, client contacts or a fast onboarding process, and impediments to CR, such as gentlemen's agreements or the need for 'fresh blood', are carefully weighed.

In chapter 4, I offer an empirical exploration of the cost and value drivers outlined in chapter 2. Data are collected through interviews with the same consultants as in chapter 3 
and 9 additional HR managers from different companies. I again found that competitor recruits can be highly beneficial to a hiring firm since they carry valuable industry-specific human capital. Whether the hiring firm can appropriate this human capital, however, depends on certain costly deployment practices employed by the hiring firm, such as investments in training, compensation or incentive schemes. It generally seems to apply that the higher the fit between the recruit and the organizational environment, the fewer investments are needed, and hence the higher the overall value captured. It is thus not sufficient to look at the potential value acquired through competitor recruits' human capital, but to also consider prevailing institutional barriers (e.g. non-compete agreements) and likely consequential investments needed that limit the actual benefit gained in the end.

Finally, chapter 5 proposes a new theoretical link between recruits' work context origin, their dominant type of human capital carried and work behavior outcomes. Specifically, it explores the extent to which the type of human capital varies between recruits with different work context origins, i.e. whether originating from a competitor or non-competitor, how this is related to their commitment focus, i.e. whether committed to the industry or the organization, and this in turn to their willingness to switch to another job within the current organization or to a competing firm. The analysis of survey data of 63 recruits demonstrates that competitor recruits indeed carry relatively more industry-specific human capital than non-competitor recruits. Surprisingly, I did not find any significant differences in terms of level or focus of commitment and its association with willingness to switch work contexts. For organizations this implies that the supposed risk of hiring a competitor recruit - due to lower commitment and a higher willingness to leave the organization - is not corroborated by my data.

Overall, I hence found that (1) the value attributed to human capital rose significantly and the competition for labor became slightly more complex and aggressive over the past 20 years, (2) CR often concerns individuals or teams of middle or higher managers and specialists and is done both directly and indirectly with the help of a personnel search firm. The prime aim is to strengthen the firm's own resources, which may pay off when driven by specific motives, such as the need for industry-specific human capital or a fast integration process, (3) whether the hiring firm can appropriate the expected human capital depends to a large extent on the fit between the recruit and the organizational environment and certain costly deployment practices employed by the hiring firm, and (4) competitor recruits indeed carry relatively more industry-specific human capital than non-competitor recruits, but differences in terms of level or focus of commitment and willingness to switch work contexts between CR recruits and other external or internal recruits could not be uncovered.

This article-based dissertation has made a first promising stride towards understanding the phenomenon of competitor recruitment through both a theoretical exploration and empirical assessment of CR theory and practice. The academic contribution of this thesis is having developed a first comprehensive model of CR outlining its characteristics, process stages and potential cost and benefit parameters involved. Scholars in the field can retrieve from my findings an agenda for further research. The contribution to practice is an overview of the core factors for CR success that need to be considered when engaging in competitor recruitment. Despite the valuable contribution to theory and practice however, questions remain. But having developed an understanding of the factors that are involved when engaging in $\mathrm{CR}$, and a comprehension of when and why they need to be considered is a an important first stride towards the strategic use of competitor recruitment. 



\section{Samenvatting}

Ondanks de recente economische teruggang zullen demografische veranderingen naar verwachting leiden tot een toekomstig tekort aan talent. Organisaties worden hierdoor gedwongen hun werving en selectie strategieën kritisch onder de loep te nemen. Dit promotieonderzoek, dat tussen 2007 en 2011 plaatsvond aan de Universiteit Maastricht, is gericht op het onderzoeken van een specifieke vorm van strategische personeelsacquisitie, namelijk 'Competitor Recruitment' (CR). Middels 'theorieen praktijkgericht exploraties' wordt het fenomeen vanuit verschillende invalshoeken nader geanalyseerd. 
Het belang van menselijk kapitaal in organisaties heeft in de afgelopen decennia steeds bredere erkenning gekregen. Door demografische ontwikkelingen en dreigende tekorten op de arbeidsmarkt zullen in de nabije toekomst ernstige problemen ontstaan bij het invullen van belangrijke functies, niet alleen in Duitsland, maar in alle ontwikkelde landen. Competitor Recruitment $(C R)$ - het werven van personeel bij een directe concurrent - kan een waardevol instrument zijn om de aanstaande talent crunch te overwinnen. Vanwege het actuele belang van dit thema heeft de auteur dit fenomeen als studie onderwerp voor deze dissertatie gekozen. Het proefschrift is gericht op het schetsen en exploreren van belangrijkste parameters van succesvol werven bij concurrenten. Zo probeert het een solide basis te bouwen voor toekomstig onderzoek op het gebied van strategische personeelsacquisitie in het algemeen en $\mathrm{CR}$ in het bijzonder.

Het onderzoek bestaat uit vijf studies in vijf hoofdstukken. Op basis van uitgewerkte case voorbeelden worden de belangrijkste vragen rond het onderwerp vanuit verschillende theoretische en methodologische invalshoeken benaderd. Hierbij is CR vanuit het perspectief van verschillende partijen beschouwd en zijn de mogelijkheden voor toekomstig onderzoek besproken. Het proefschrift sluit af met enkele praktische overwegingen.

In hoofdstuk 1 wordt vanuit historisch perspectief gekeken naar wervingspraktijken van menselijk kapitaal en de opkomst van meer agressieve vormen hiervan in de afgelopen 20 jaar. Het rapporteert de resultaten van een inhoudsanalyse van 5982 vacatures uit de Frankfurter Allgemeine Zeitung (FAZ) tussen 1990 en 2010 en een trefwoordanalyse in de grootste Duitse sociaal wetenschappelijke database, de Datenbank für Wirtschaft und Soziales (WISO). Onderzocht werd of er inderdaad een opwaartse trend bestaat in (1) de waarde die wordt toegekend aan menselijk kapitaal, (2) de gepercipieerde arbeidsmarkt complexiteit en (3) de agressiviteit van de wervingspraktijken. De bevindingen ondersteunen het bestaan van deze trends in het onderzochte tijdvak en de noodzaak tot verder onderzoek op het gebied van strategische rekruteringspraktijken zoals CR.

Hoofdstuk 2 geeft een theoretische onderbouwing van de keuze voor CR. Het beargumenteert dat de uiteindelijke waarde van een via $C R$ gerekruteerde medewerker wordt bepaald door $z^{\prime} n$ bestaande kennis en vaardigheden en de mate waarin het rekruterende bedrijf in staat is deze (beter) te benutten, minus alle (verborgen) kosten die verbonden zijn aan het proces van identificatie, transfer en inzet van de nieuwe medewerker. De factoren die de waarde van een CR medewerker bepalen worden beschreven aan de hand van de resource based theorie, strategische factor markt theorie en eigendomsrechten theorie. Het hoofdstuk sluit af met een conceptueel model dat illustreert hoe door middel van CR meer waarde uit menselijk kapitaal kan worden gecreëerd.

Hoofdstuk 3 onderzoekt onder welke omstandigheden zich CR voordoet. Zorgvuldige analyse van interviews met 19 consultants van Duitse top executive search bedrijven laat zien dat CR zich veelal richt op individuen of teams van midden- of hoger management niveas én op specialisten met sterke industrie-specifieke kennis. Bij de beslissing om van een concurrent te werven worden voordelen -zoals snelle on-boarding- en belemmeringen -zoals industrienormen- in de praktijk scherp tegen elkaar afgewogen. Niettemin blijkt CR in het algemeen als een waardevolle wervingstactiek te worden beschouwd.

Hoofdstuk 4 biedt een empirische exploratie van de kosten- en opbrengstenfactoren uit hoofdstuk 2. De interviewpartners uit hoofdstuk 3 zijn hiertoe aangevuld met 9 HR managers van verschillende bedrijven. De resultaten bevestigen de conclusie uit hoofdstuk 2 dat concurrentie rekruten zeer waardevol kunnen zijn vanwege hun bedrijfstak- 
specifieke menselijk kapitaal. Of en in hoeverre het inhurende bedrijf zich dit kapitaal daadwerkelijk kan toe-eigenen blijkt echter afhankelijk van gerichte, kostbare implementatie-investeringen zoals extra training, compensatie of prikkels. In het algemeen geldt dat dergelijke investeringen lager - en de netto opbrengsten bijgevolg groter - zijn naarmate de fit tussen de rekruut en de nieuwe werkomgeving groter is. Het is daarom niet voldoende alleen te kijken naar wat de rekruut aan waarde inbrengt, maar ook naar de kosten die verbonden zijn aan het overwinnen van (institutionele) barrières (bijvoorbeeld concurrentiebedingen) en andere additionele kosten die echte waardecreatie van de overstap in de weg staan.

Hoofdstuk 5, tenslotte, introduceert een nieuw theoretisch verband tussen de herkomst van de rekruut, zijn dominant soort menselijk kapitaal en de werkuitkomsten. Concreet wordt hier onderzocht of rekruten van concurrenten in vergelijking met 'normale' rekruten relatief meer industrie-specifiek kapitaal bezitten en daardoor een sterkere binding ervaren aan de bedrijfstak als geheel dan aan een specifieke organisatie. Een analyse van survey data onder 63 rekruten laat zien dat concurrentie rekruten inderdaad relatief meer industrie-specifiek kapitaal bezitten, maar dat hun bindingsfocus daardoor niet wordt beïnvloed. Voor organisaties betekent dit, dat het theoretische risico van zwak organisatiegebonden concurrentie rekruten niet door de data wordt ondersteund.

Samenvattend kunnen wij concluderen dat: (1) in de afgelopen 20 jaar, de waarde die wordt toegekend aan menselijk kapitaal sterk is toegenomen en dat de concurrentie om talent zowel complexer als agressiever is geworden; (2) CR zich veelal richt op individuen of teams in midden- of hoger management én op specialisten; (3) CR voornamelijk is gericht op de versterking van de eigen concurrentiepositie en dat dit succesvol is wanneer, bijvoorbeeld, industrie-specifieke kennis of snelle proces-integratie is vereist; (5) de potentiële waarde van CR afhangt van de fit tussen kandidaat en de organisatie omgeving als ook van investeringen die door het ontvangende bedrijf in het creëren van die fit zijn gedaan; (6) we geen verschillen hebben ontdekt tussen CR-kandidaten en andere kandidaten met betrekking tot hun mate en focus van commitment of hun neiging snel tussen werkgevers te switchen.

Deze dissertatie heeft een eerste, veelbelovende stap gezet naar een beter begrip van het opkomende CR fenomeen middels een theoretische en empirische exploratie. Het belang van dit werk is gelegen in het bieden van een eerste alomvattend model van CR dat de kenmerken, stadia en de potentiële kosten- en opbrengsten parameters in kaart brengt. Van hieruit ontstaat een heldere agenda voor toekomstig onderzoek. Het belang voor de praktijk is gelegen in de identificatie van de kernfactoren voor het succesvol ondernemen van $\mathrm{CR}$. 



\section{Zusammenfassung}

Der demografische Wandel wird in Zukunft zu Engpässen bei der Beschaffung gut ausgebildeter Fach- und Führungskräfte führen - selbst bei wirtschaftlichen Abschwüngen.

Vor diesem Hintergrund wurde Mitte 2007 an der Universität Maastricht ein auf vier Jahre angesetztes Forschungsprojekt mit dem Ziel gestartet, eine bestimmte personalpolitische Strategie, nämlich die des,Competitor Recruitment' (CR), näher zu beleuchten: Es folgten ,theorie- und praxisbasierte Untersuchungen'. 
Der ökonomische Wert von Mitarbeitern, das sogenannte Humankapital, hat in den vergangenen Jahrzehnten zunehmend an Bedeutung gewonnen. Gleichzeitig driftet die Schere zwischen Angebot und Nachfrage von hochqualifizierten Fach- und Führungskräften bedingt durch den demografischen Wandel immer weiter auseinander. Die gezielte, systematische Beschaffung externer Kandidaten von direkten Wettbewerbern als mögliche Konsequenz dieser Entwicklung ist ein bisher noch kaum erforschtes Gebiet des strategischen Personalmanagements. Deshalb wurde dieses Forschungsthema, das im angelsächsischen Raum als Competitor Recruitment (CR) bezeichnet wird, als Dissertationsgegenstand gewählt.

Das primäre Ziel dieser Arbeit war die Bestimmung jener Faktoren, die Competitor Recruitment rechtfertigen und zugleich die Voraussetzungen für einen erfolgreichen CRProzess bilden. Zu diesem Zweck wurden unter anderem anerkannte Fachleute zu dieser Thematik befragt: wie erleben sie $C R$, in welchen Fällen wird CR befürwortet und wann abgelehnt, und wie unterscheiden sich Wettbewerbskandidaten von anderen externen und internen Kandidaten? Fallbeispiele wurden untersucht und die wichtigsten Fragen zum Thema Competitor Recruitment theoretisch wie empirisch mit Hilfe von überwiegend qualitativen Untersuchungsmethoden beleuchtet. Die Ergebnisse bilden schließlich die Grundlage für die Entwicklung eines umfangreichen CR-Modells.

Zunächst wirft Kapitel 1 einen Blick auf die klassischen Personalbeschaffungsmaßnahmen sowie die Bedeutung von Humankapital in den vergangenen 20 Jahren. Die Daten wurden a) im Rahmen einer Inhaltsanalyse von 5982 in der Frankfurter Allgemeinen Zeitung (FAZ) zwischen 1990 und 2010 veröffentlichten Stellenangeboten und b) einer Stichwortsuche in der Datenbank für Wirtschaft und Soziales (WISO), der umfangreichsten deutschen Datenbank für sozialwissenschaftliche Publikationen, zusammengetragen und analysiert. Drei Fragestellungen waren dabei von Interesse: (1) Wird Humankapital zunehmend als ein Wertschöpfungsfaktor angesehen? (2) Wie hat sich die Arbeitsmarktkomplexität verändert? (3) Sind Personalbeschaffungsmaßnahmen aggressiver geworden? Die Ergebnisse deuten darauf hin, dass innerhalb des untersuchten Zeitraums die Bedeutung des Humankapitals signifikant angestiegen und der Wettbewerb um Arbeitskräfte sowohl komplexer als auch aggressiver geworden ist. Die Ergebnisse unterstreichen die Notwendigkeit weiterer Forschungen auf dem Gebiet der strategischen Personalbeschaffung.

Kapitel 2 widmet sich einer theoretischen Annäherung an Competitor Recruitment als eine Form der strategischen Personalbeschaffung. Diese basiert auf der Hypothese, dass sich der letztendlich gewonnene Wert der durch CR akquirierten Mitarbeiter aus deren branchenspezifischem Know-how und Fähigkeiten, den zusätzlich ausgeschöpften Potenzialen dieser Mitarbeiter sowie den synergetischen Effekten innerhalb des Unternehmens zusammensetzt, abzüglich aller impliziten und expliziten Kosten, die einem Arbeitgeber im Rahmen des Beschaffungsprozesses und der Beschäftigung des Mitarbeiters entstehen. Günstige Bedingungen für einen wertschöpfenden Rekrutierungsprozess werden mit Hilfe von ressourcenbasierten Theorien konzeptionell erläutert.

Kapitel 3 untersucht dann empirisch, unter welchen Bedingungen Competitor Recruitment zur Anwendung kommt. Hierzu wurden Interviewdaten von 19 Beratern, die für Top Executive Search Unternehmen in Deutschland tätig sind, analysiert. Die Ergebnisse zeigen, dass heute durch CR Einzelpersonen oder komplette Teams bestehend aus mittleren oder höheren Fach- und Führungskräften mit starken branchenspezifischen Kenntnissen angesprochen werden. Dabei müssen Motive wie schnelle Integrierbarkeit und ,InsiderWissen' gegenüber Hindernissen wie Konkurrenzklauseln oder Gentlemen Agreements 
sorgfältig abgewogen werden, damit letztlich der Nutzen die Risiken und Kosten der CR Maßnahme übersteigt.

Anschließend präsentiert Kapitel 4 eine empirische Untersuchung der in Kapitel 2 konzeptionell vorgestellten Kosten- und Werttreiber von Competitor Recruitment und spezifiziert somit die in Kapitel 3 aus der Praxis abgeleiteten Argumente für und gegen CR. Ergänzend zu den Daten aus Kapitel 3 wurden 9 personalverantwortliche Manager verschiedener Unternehmen befragt. In Übereinstimmung mit den Ergebnissen aus dem vorherigen Kapitel kann geschlussfolgert werden, dass CR-Kandidaten aufgrund ihres hohen branchenspezifischen Humankapitalanteils sowie ihrer komplementären ,soft skills' bevorzugt werden. Ob eine Beschaffungsmaßnahme allerdings letztendlich als Erfolg zu bewerten ist, hängt neben den skizzierten Wertsteigerungspotenzialen auch vom Grad möglicher Widerstände ab. Generell gilt aber: Je besser der Kandidat in das neue Arbeitsumfeld passt und umso weniger CR-typische (institutionelle) Barrieren wie Konkurrenzklauseln bestehen, desto geringer sind die Kosten und umso höher der Wert der Investition.

Kapitel 5 schließlich untersucht den Zusammenhang zwischen der Herkunft eines Mitarbeiters, seinem Humankapital und seinem Arbeitsverhalten während seiner neuen Anstellung. Die Studie vergleicht das Humankapital zwischen den von Wettbewerbern abgeworbenen und anderen extern beschafften Mitarbeitern. Sie betrachtet außerdem die Bindung zum neuen Unternehmen und die Bereitschaft eines Mitarbeiters, an einen anderen Arbeitsplatz oder zu einem anderen Unternehmen zu wechseln. Das Ergebnis der Umfrage bestätigt, dass Wettbewerbskandidaten gegenüber anderen externen Kandidaten keine signifikanten Unterschiede in Bezug auf das Ausmaß ihrer Bindung an das neue Unternehmen oder die Bereitschaft, erneut den Arbeitgeber zu wechseln oder in einem anderen Umfeld tätig zu werden, aufweisen. Diese Studie bestätigt demnach kein überdurchschnittliches Verlustrisiko von Wettbewerbskandidaten.

Zusammengefasst lässt sich feststellen: (1) Der Wert, der Humankapital beigemessen wird, ist in den vergangenen 20 Jahren signifikant gestiegen. Der Wettbewerb um Talente ist komplexer und aggressiver geworden; (2) CR betrifft vorrangig Einzelkandidaten oder komplette Teams des mittleren oder höheren Managements oder Spezialisten. CR findet direkt oder indirekt durch Personalvermittlungen statt und verfolgt als primäres Ziel die Stärkung des eigenen Ressourcenportfolios. CR zahlt sich in bestimmten Situationen aus, wie zum Beispiel bei Bedarf nach branchenspezifischem Wissen oder schneller Prozessintegration; (3) Das Wertschöpfungspotenzial durch CR bemisst sich zum großen Teil am Fit zwischen Kandidaten und dem Umfeld des beschaffenden Unternehmens sowie den daraus folgenden Personalinvestitionen; (4) Unterschiede zwischen CR-Kandidaten und anderen Bewerbern in Bezug auf Mitarbeiterbindung bzw. einer Neigung zu schnelleren Jobwechseln existieren nicht.

Insgesamt trägt diese artikelbasierte Dissertation durch ihren theoretischen und explorativen Ansatz sowie die empirische Bewertung der CR Praxis zu einem besseren Verständnis von $C R$ bei und liefert einen ersten vielversprechenden wissenschaftlichen Schritt in Richtung der Erforschung dieser Thematik. Sie bietet erste umfassende Einblicke in die vielfältigen Facetten des $C R$, die relevanten Prozessschritte, die Kostenstruktur und den Nutzen dieser Personalbeschaffungsmaßnahme. Sie stellt damit eine Grundlage für zukünftige Forschungsprojekte in diesem Bereich dar. Unternehmen finden in dieser Arbeit ein praxisnahes, instrumentelles Kompendium für erfolgreiche CR-Initiativen. 


\section{About the Author}

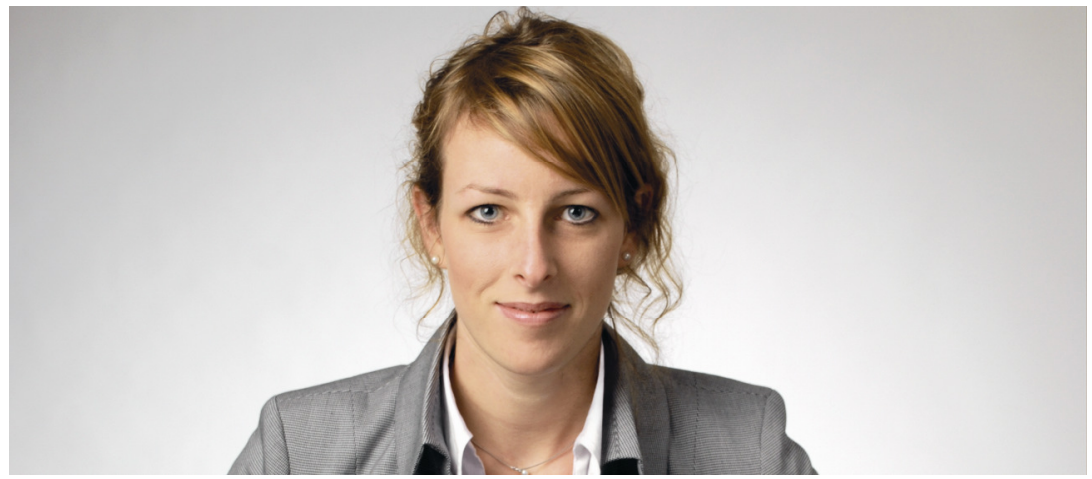

Sarah Horn was born on Boxing Day just making it to the ' 83 vintage. She grew up in the German cities of Dusseldorf and Mettmann. At the age of 17, she left Germany and the Konrad-Heresbach Gymnasium of Mettmann to spend a few months in a boarding school in France, in the area of Villères-Cottêrets. Once back, she switched schools to attend the French/German bilingual School Gymansium Vohwinkel in Wuppertal.

Having received her German Abitur in 2003, Sarah started her academic career at the liberal arts University College Maastricht in The Netherlands from which she graduated with a Bachelors of Arts in Social Sciences degree (cum laude) in June 2006. Before she moved on to study Management at Bradford University School of Management in England (with distinction) from mid-2006 to mid-2007, she worked as an intern in Cologne at access KellyOCG, an international Personnel Sourcing Agency and HR Consultancy. During her four years of study, she spent academic semesters at Waikato University Management School (Hamilton, New Zealand), Audencia Ecole de Management (Nantes, France) and EADA Escuela de Alta Dirección y Administración (Barcelona, Spain).

Sarah began her four-year appointment as a PhD candidate at the Department of Organization and Strategy of the School of Business and Economics in August 2007, funded by Maastricht Research School of Economics of Technology and Organizations (METEOR). Within the realm of her research, she presented her work at various conferences, namely EGOS in Barcelona, the People and Organizations Conference 2010 at Wharton School in Philadelphia (right when Michael Jackson died...), the Academy of Management Annual Meeting 2010 in Montréal (Organization Management Theory \& Human Resource Management Division) and the Strategic Management Society Conference 2010 in Rome (Strategic Human Capital Division). She has served as a reviewer for both divisions of the AOM

Next to her research, she has taught courses on Bachelor and Master level in the area of Strategic Human Resource Management, Marketing and Management or Organizational Change and Consultancy, participated in PhD courses at Tilburg University, Rotterdam School of Management or Copenhagen Business School, supported the faculty during promotion events or EQUIS reaccreditations, acted as a programme manager for a 6-months international in-company executive education course provided to 25 future executives of Vodafone, and worked on a full-time 3-months consultancy project in the area of HR demand and capacity planning at Medtronic. 

